Illinois State University

ISU ReD: Research and eData

Theses and Dissertations

$10-20-2017$

\title{
The Biochemical Assessment Of Two Secreted Acid Phosphatases From Leishmania Tarentolae, Their Response To Electric Fields, Glycosidase Incubation, And/or Vanadium
}

Benjamin M. Dorsey

Illinois State University, bmdors2@gmail.com

Follow this and additional works at: https://ir.library.illinoisstate.edu/etd

Part of the Biochemistry Commons, Chemistry Commons, and the Parasitology Commons

\section{Recommended Citation}

Dorsey, Benjamin M., "The Biochemical Assessment Of Two Secreted Acid Phosphatases From Leishmania Tarentolae, Their Response To Electric Fields, Glycosidase Incubation, And/or Vanadium" (2017). Theses and Dissertations. 804.

https://ir.library.illinoisstate.edu/etd/804

This Thesis is brought to you for free and open access by ISU ReD: Research and eData. It has been accepted for inclusion in Theses and Dissertations by an authorized administrator of ISU ReD: Research and eData. For more information, please contact ISUReD@ilstu.edu. 
THE BIOCHEMICAL ASSESSMENT OF TWO SECRETED ACID PHOSPHATASES FROM LEISHMANIA TARENTOLAE, THEIR RESPONSE TO ELECTRIC FIELDS, GLYCOSIDASE INCUBATION, AND/OR VANADIUM

\section{Benjamin M. Dorsey}

\section{Pages}

Leishmaniasis, as defined by the Center for Disease Control and Prevention, is a neglected tropical disease with 1.6 million new cases reported each year. However, there is yet to be safe, effective, and affordable treatments provided to those affected by this disease (Leishmaniasis, 2016). Still underappreciated as potential pharmaceutical targets, especially for cutaneous leishmaniasis infections, are the two isozymes of secreted acid phosphatase (SAP), secreted acid phosphatase 1 (SAP1) and secreted acid phosphatase 2 (SAP2). These enzymes are involved in the survival of the parasite in the sand fly vector, and the prevention of host macrophages from forming parasitophorous vacuole and hydrogen peroxide (Fernandez Soares, Saraiva, Meyer-Fernandez, Souto-Padron, 2013;M. Baghaei and M. BAGHAEI, 2003). Thus, the kinetic behavior of these SAPs is of interest. Vanadium $\left(\mathrm{V}^{5+}\right)$, specifically the monomeric oxyanion orthovanadate $\left(\mathrm{VO}_{4}{ }^{3-}\right)$, is reported to be a competitive inhibitor of phosphatases (VanEtten, Waymack, Rehkop, 1974; Abbott, Jones, Weinman, Backhoff, McLafferty, Knowles,1979; Knowles, 1980; Gressor, Tracey, Stankiewwicz, 1987; Gordon, 1991; Li, Ding, Baruah, Crans, Wang, 2008). Orthovanadate serves as a known competitive inhibitor for the enzyme inhibition experiments done in the research presented here. The application of electric or electromagnetic fields as a medicinal therapeutic is not new (Holden, 2017). The utility of 
applying electric fields for the treatment of leishmaniasis is under studied (Hejazi, Eslami, Dalimi, 1972), and the application of electric fields to Leishmania secreted acid phosphatases has not yet been reported. The results of such studies using $L$. tarentolae as a model system, with and without the addition of orthovanadate, are reported here. Furthermore, the effect specific electric fields have on the kinetic parameters of $L$. tarentolae SAPs are also reported.

KEYWORDS: Leishmania, Leishmaniasis, Secreted Acid Phosphatase, Electric Field, Glycosidase, Orthovanadate, Potential Treatment 
THE BIOCHEMICAL ASSESSMENT OF TWO SECRETED ACID PHOSPHATASES FROM LEISHMANIA TARENTOLAE, THEIR RESPONSE TO ELECTRIC FIELDS, GLYCOSIDASE INCUBATION, AND/OR VANADIUM

BENJAMIN M. DORSEY

A Thesis Submitted in Partial Fulfillment of the Requirements for the Degree of

MASTER OF SCIENCE

Department of Chemistry

ILLINOIS STATE UNIVERSITY 
C 2017 Benjamin M. Dorsey 


\section{THE BIOCHEMICAL ASSESSMENT OF TWO SECRETED ACID PHOSPHATASES FROM LEISHMANIA TARENTOLAE, THEIR RESPONSE TO ELECTRIC FIELDS, GLYCOSIDASE INCUBATION, AND/OR VANADIUM}

\section{BENJAMIN M. DORSEY}

COMMITTEE MEMBERS:

Marjorie A. Jones, Chair

Jon A. Friesen

Craig C. McLauchlan 


\section{ACKNOWLEDGMENTS}

I would first like to thank my research advisor, Dr. Jones, for her immense support and guidance during my time at Illinois State University. I would like to thank Dr. Friesen and Dr. McLauchlan for their input on this work.

I would like to acknowledge the faculty, staff, my fellow students, and my lab peers at Illinois State University for providing a supportive, accepting, and challenging environment in which I was able to grow and learn.

I would like to thank the Kurz Fellowship and The Millennium Pain Center for summer support. Their support allowed me to focus my summer efforts on completing research required for this thesis work.

Finally, I thank my family and friends that offered support to me while I completed my degree. Without you all, completing this work would not have been possible.

B. M. D. 


\section{CONTENTS}

Page

ACKNOWLEDGMENTS

CONTENTS

TABLES

FIGURES

CHAPTER

I. INTRODUCTION 1

Leishmania, Leishmaniasis, and Current Treatment Options 1

Phosphatases $\quad 2$

L. tarentolae Secreted Acid Phosphatase Enzymes $\quad 3$

Electric Fields Applied as a Therapeutic, in General $\quad 4$

Electric Fields for the Purpose of Affecting L. tarentolae Motility, Clumping, Cell Viability, and Secreted Acid Phosphatase Activity 7

Vanadium Background, Vanadium Human Exposure, Vanadium Chemistry and $\begin{array}{ll}\text { Speciation } & 7\end{array}$

Vanadium is a Potential Medicinal Agent as a Phosphatase Inhibitor 9

II. MATERIALS AND METHODOLOGY 13

Cell Culture of L. tarentolae and Assessment of Cell Viability by the MTT Viability Assay

Microscopy of L. tarentolae

Preparation of the L. tarentolae Acid or Alkaline Phosphatase Enzyme Source 14

Secreted Acid or Alkaline Phosphatase Enzyme Assay 14

Kinetic Enzyme Assay $\quad 15$

Designing Waveforms for the Production of Electric Fields 15

Electrode Tested $\quad 18$

Parameters of Tested Waveforms 19

Testing the Acute Effects of Electric Fields on L. tarentolae Growth Curves and Microscopy

Testing the Effects of Electric Fields on L. tarentolae Acid Phosphatase Activity in Supernatant or Pellet (Cells), Method 1 20

Testing the Effects of Electric Fields on L. tarentolae Acid Phosphatase Activity in Supernatant or Pellet (Cells), Method 2

Secreted Acid Phosphatase Enzyme Inhibition Assay (Following the Method of Baumhardt et al., 2015)

Secreted Acid Phosphatase Enzyme Inhibition Assays with Pretreatment With Electric 
Fields Followed by Incubation with and without Orthovanadate $(25 \mu \mathrm{M})$

Secreted Acid Phosphatase Kinetics Assay with and without the Preincubation with a

Glycosidase, Followed by Pretreatment with and without Electric Fields

III. RESULTS AND DISCUSSION

Cell Culture of L. tarentolae and Assessment of Cell Viability by the MTT Viability Assay

Microscopy of L. tarentolae

Secreted Acid or Alkaline Phosphatase Enzyme Assay

Kinetic Enzyme Assay

Testing the Acute Effects of Electric Fields on L. tarentolae Growth Curves and Microscopy

Testing the Effects of Electric Fields on L. tarentolae Acid Phosphatase Activity in Supernatant or Pellet (Cells), Method 1

Testing the Effects of Electric Fields on L. tarentolae Acid Phosphatase Activity in Supernatant or Pellet (Cells), Method 2

Secreted Acid Phosphatase Enzyme Inhibition Assay (Following the Method of Baumhardt et al., 2015)

Secreted Acid Phosphatase Enzyme Inhibition Assays with Pretreatment with Electric Fields Followed by Incubation with and without Orthovanadate $(25 \mu \mathrm{M}$ or $\log [\mathrm{S}] /[\mathrm{I}]=1.19$ )

Secreted Acid Phosphatase Kinetics Assay with and without the Preincubation with a Glycosidase, Followed by Pretreatment with and without Electric Fields

Cell Culture and Microscopy of L. tarentolae and Assessment of Cell Viability by the MTT Assay

Secreted Acid or Alkaline Phosphatase Enzyme Assay

Kinetic Enzyme Assay

Testing The Acute Effects of Electric Fields on L. tarentolae Growth Curves and Microscopy

Testing the Effects of Electric Fields on L. tarentolae Acid Phosphatase Activity in Supernatant or Pellet (Cells), Method 1

Testing the Effects of Electric Fields on L. tarentolae Acid Phosphatase Activity in Supernatant or Pellet (Cells), Method 2

Comparing the Effectiveness of Method 1 to Method 2

Secreted Acid Phosphatase Enzyme Inhibition Assay (Following the Method of Baumhardt et al., 2015)

Secreted Acid Phosphatase Enzyme Inhibition Assays with Pretreatment with Electric Fields Followed by Incubation with and without Orthovanadate $(25 \mu \mathrm{M})$

Secreted Acid Phosphatase Kinetic Assay with and without the Preincubation with a Glycosidase, Followed by Pretreatment with and without Electric Fields 
APPENDIX A: THE INDIVIDUAL LINEWEAVER-BURK PLOTS AND DATA POINTS CORRESPONDING TO THE TEXT (TABLE 2, FIGURE 18, TABLE 3, AND FIGURE 19) 


\section{TABLES}

Table

Page

1. The Concentrations Of Vanadium Used As Either Total Vanadium, Or Orthovanadate, Or Decavanadate In Each Sample

2. The Calculated $\mathrm{k}_{\mathrm{M}}$ And $\mathrm{V}_{\mathrm{MAX}}$ Values For Enzyme 1 From L. tarentolae As A Function Of Day In Culture

3. The Calculated $\mathrm{k}_{\mathrm{M}}$ Or $\mathrm{V}_{\mathrm{MAX}}$ Values For Enzyme 2 From L. tarentolae As A Function Of Day In Culture

4. Enzyme 1 Kinetic Parameters $\mathrm{k}_{\mathrm{M}}$ And $\mathrm{V}_{\mathrm{MAX}}$ Under Different Conditions Compared To Control

5. Enzyme 2 Kinetic Parameters $\mathrm{k}_{\mathrm{M}}$ And $\mathrm{V}_{\mathrm{MAX}}$ Under Different Conditions Compared To Control 


\section{FIGURES}

Figure

Page

1. Vanadium (V) Speciation As A Mole Fraction Of Total Vanadium Present At A Given pH, Over The Typical pH Scale (0-14) (Baes, Mesmer, 1976)

2. Multiple Sequence Alignment Of Three Acid Phosphatases

3. A Plot Of Time $(\mu \mathrm{s})$ vs. Voltage $(\mathrm{mV})$ Is Shown For A Symmetric Biphasic Waveform

4. Model Of The General Shape Of The Electric Field That Is Applied To Either L. tarentolae Whole Cells Or Cell Supernatant Is Shown

5. Simplified Experimental Model Of Setup To Apply Electric Fields To

L. tarentolae Whole Cells Or Cell Supernatant

6. Flow Diagram Of Method 1

7. Flow Diagram Of Method 2

8. A Typical Growth Curve For L. tarentolae With The Corrected MTT Response Plotted On The Y-Axis And The Day In Culture Plotted On The X-Axis

9. The Above Image Depicts L. tarentolae By Microscopy (400X) During The Lag Phase Of Their Growth Curve

10. The Above Image Depicts L. tarentolae By Microscopy (400X) During The Log Phase Of Their Growth Curve

11. The Above Image Depicts L. tarentolae By Microscopy (400X) During The Stationary Phase Of Their Growth Curve

12. The Above Image Depicts L. tarentolae By Microscopy (400X) During The Senescence Phase Of Their Growth Curve

13. Secreted Acid (Red Curve) Or Secreted Alkaline (Lime Green Curve) Phosphatase Activity Detected As A Function Of Day In Culture

14. A Typical V Versus S Curve Utilizing L. tarentolae Log Phase Supernatant As The Enzyme Source

15. A Typical Lineweaver-Burk Linear Transformation Using L. tarentolae Log Phase Supernatant As The Enzyme Source 
16. A Typical Lineweaver-Burk Linear Transformation Using L. tarentolae Log Phase Supernatant As The Enzyme Source

17. A Typical Lineweaver-Burk Linear Transformation Using L. tarentolae Log Phase Supernatant As The Enzyme Source

18. A Plot Of Calculated VMAX Value (Y-Axis) For Enzyme 1 As A Function Of Day In Culture (X-Axis)

19. The Calculated $V_{\text {MAX }}$ (Y-axis) Value For Enzyme 2 As A Function Of L. tarentolae Day In Culture (X-Axis)

20. L. tarentolae Lag Phase Control Cells Viewed At 400X Magnification

21. L. tarentolae Lag Phase Cells Exposed To An Electric Field $(50 \mathrm{~Hz}, 500 \mu \mathrm{A}, 30$ Min, Symmetric Biphasic) Viewed At 400X Magnification

22. L. tarentolae Lag Phase Cells Exposed To An Electric Field (10,000 Hz, $500 \mu \mathrm{A}$, 30 Min, Symmetric Biphasic) Viewed At 400X Magnification

23. L. tarentolae Lag Phase Cells Exposed To An Electric Field (50 Hz, $100 \mu \mathrm{A}, 30$ Min, Symmetric Biphasic) Viewed At 400X Magnification

24. L. tarentolae Lag Phase Cells Exposed To An Electric Field $(50 \mathrm{~Hz}, 100 \mu \mathrm{A}, 30 \mathrm{Min}$, Cathodic) Viewed At 400X Magnification

25. L. tarentolae Lag Phase Cells Exposed To An Electric Field $(50 \mathrm{~Hz}, 100 \mu \mathrm{A}$, Anodic) Viewed At 400X Magnification

26. The Effects Of A $50 \mathrm{~Hz}$, Cathodic Electric Field At Various Current Exposures On L. tarentolae Secreted Acid Phosphatase Are Plotted As Percent Different From Same Time Control

27. The Effects Of A $50 \mathrm{~Hz}$, Cathodic Electric Field At Various Current Exposures On L. tarentolae Cell Pellet Acid Phosphatase Are Plotted As Percent Different From Same Time Control

28. The Effects Of A $50 \mathrm{~Hz}$, Symmetric Biphasic Electric Field At Various Current Exposures On L. tarentolae Secreted Acid Phosphatase Are Plotted As Percent Different From Same Time Control

29. The Effects Of A $50 \mathrm{~Hz}$, Symmetric Biphasic Electric Field At Various Current Exposures On L. tarentolae Cell Pellet Acid Phosphatase Are Plotted As Percent Different From Same Time Control

30. The Effects Of A $50 \mathrm{~Hz}$, Anodic Electric Field At Various Current Exposures On 
L. tarentolae Secreted Acid Phosphatase Are Plotted As Percent Different From Same Time Control

31. The Effects Of A $50 \mathrm{~Hz}$, Anodic Electric Field At Various Current Exposures On L. tarentolae Cell Pellet Acid Phosphatase Are Plotted As Percent Different From Same Time Control

32. The Effects Of A $10,000 \mathrm{~Hz}$, Cathodic Electric Field At Various Current Exposures On L. tarentolae Secreted Acid Phosphatase Are Plotted As Percent Different From Same Time Control

33. The Effects Of A 10,000 Hz, Cathodic Electric Field At Various Current Exposures On L. tarentolae Cell Pellet Acid Phosphatase Are Plotted As Percent Different From Same Time Control

34. The Effects Of A 10,000 Hz, Symmetric Biphasic Electric Field At Various Current Exposures On L. tarentolae Secreted Acid Phosphatase Are Plotted As Percent Different From Same Time Control

35. The Effects Of A 10,000 Hz, Symmetric Biphasic Electric Field At Various Current Exposures On L. tarentolae Cell Pellet Acid Phosphatase Are Plotted As Percent Different From Same Time Control

36. The Effects Of A 10,000 Hz, Anodic Electric Field At Various Current Exposures On L. tarentolae Secreted Acid Phosphatase Are Plotted As Percent Different From Same Time Control

37. The Effects Of A 10,000 Hz, Anodic Electric Field At Various Current Exposures On L. tarentolae Cell Pellet Acid Phosphatase Are Plotted As Percent Different From Same Time Control

38. The Effects Of A $50 \mathrm{~Hz}$, Cathodic Electric Field At Various Current Exposures On L. tarentolae Secreted Acid Phosphatase Are Plotted As Percent Different From Same Time Control

39. The Effects Of A $50 \mathrm{~Hz}$, Cathodic Electric Field At Various Current Exposures On L. tarentolae Cell Pellet Acid Phosphatase Are Plotted As Percent Different From Same Time Control

40. The Effects Of A $50 \mathrm{~Hz}$, Symmetric Biphasic Electric Field At Various Current Exposures On L. tarentolae Cell Pellet Acid Phosphatase Are Plotted As Percent Different From Same Time Control

41. The Effects Of A $50 \mathrm{~Hz}$, Anodic Electric Field At Various Current Exposures On L. tarentolae Secreted Acid Phosphatase Are Plotted As Percent Different From Same Time Control 
42. The Effects Of A $50 \mathrm{~Hz}$, Anodic Electric Field At Various Current Exposures On L. tarentolae Cell Pellet Acid Phosphatase Are Plotted As Percent Different From Same Time Control

43. The Effects Of A 10,000 Hz, Cathodic Electric Field At Various Current Exposures On L. tarentolae Secreted Acid Phosphatase Are Plotted As Percent Different From Same Time Control

44. The Effects Of A 10,000 Hz, Cathodic Electric Field At Various Current Exposures On L. tarentolae Cell Pellet Acid Phosphatase Are Plotted As Percent Different From Same Time Control

45. The Effects Of A 10,000 Hz, Symmetric Biphasic Electric Field At Various Current Exposures On L. tarentolae Secreted Acid Phosphatase Are Plotted As Percent Different From Same Time Control

46. The Effects Of A 10,000 Hz, Symmetric Biphasic Electric Field At Various Current Exposures On L. tarentolae Cell Pellet Acid Phosphatase Are Plotted As Percent Different From Same Time Control

47. The Effects Of A 10,000 Hz, Anodic Electric Field At Various Current Exposures On L. tarentolae Secreted Acid Phosphatase Are Plotted As Percent Different From Same Time Control

48. The Effects Of A 10,000 Hz, Anodic Electric Field At Various Current Exposures On L. tarentolae Cell Pellet Acid Phosphatase Are Plotted As Percent Different From Same Time Control

49. L. tarentolae Secreted Acid Phosphatase Enzyme Activity (Y-Axis) When Incubated With Decavanadate (Red Curve) Or Orthovanadate (Blue Curve) Plotted As A Function Of Log [S]/[I] (X-Axis)

50. L. tarentolae Secreted Acid Phosphatase Enzyme Activity (Y-Axis) When Incubated With Decavanadate (Red Curve) Or Orthovanadate (Blue Curve) Plotted As A Function Of Log [S]/[I] (X-Axis)

51. The Effects, Plotted As Percent Different From Control, Of Pretreating The Log Phase L. tarentolae Secreted Acid Phosphatase Enzyme Pool With $50 \mathrm{~Hz}$, Cathodic Electric Field At Various Current Exposures Followed By Orthovanadate $(25 \mu \mathrm{M})$ Incubation Compared To Same Time Control $(25 \mu \mathrm{M}$ Orthovanadate Exposure Only) Are Shown

52. The Effects, Plotted As Percent Different From Control, Of Pretreating The Log Phase L. tarentolae Secreted Acid Phosphatase Enzyme Pool With $50 \mathrm{~Hz}$, Symmetric Biphasic Electric Field At Various Current Exposures Followed By Orthovanadate $(25 \mu \mathrm{M})$ Incubation Compared To Same Time Control $(25 \mu \mathrm{M}$ 
53. The Effects, Plotted As Percent Different From Control, Of Pretreating The Log Phase L. tarentolae Secreted Acid Phosphatase Enzyme Pool With 50 Hz, Anodic Electric Field At Various Current Exposures Followed By Orthovanadate $(25 \mu \mathrm{M})$ Incubation Compared To Same Time Control $(25 \mu \mathrm{M}$ Orthovanadate Exposure Only) Are Shown

54. The Effects, Plotted As Percent Different From Control, Of Pretreating The Log Phase L. tarentolae Secreted Acid Phosphatase Enzyme Pool With 10,000 Hz, Cathodic Electric Field At Various Current Exposures Followed By Orthovanadate $(25 \mu \mathrm{M})$ Incubation Compared To Same Time Control $(25 \mu \mathrm{M}$ Orthovanadate Exposure Only) Are Shown

55. The Effects, Plotted As Percent Different From Control, Of Pretreating The Log Phase L. tarentolae Secreted Acid Phosphatase Enzyme Pool With 10,000 Hz, Symmetric Biphasic Electric Field At Various Current Exposures Followed By Orthovanadate $(25 \mu \mathrm{M})$ Incubation Compared To Same Time Control $(25 \mu \mathrm{M}$ Orthovanadate Exposure Only) Are Shown

56. The Effects, Plotted As Percent Different From Control, Of Pretreating The Log Phase L. tarentolae Secreted Acid Phosphatase Enzyme Pool With 10,000 Hz, Anodic Electric Field At Various Current Exposures Followed By Orthovanadate $(25 \mu \mathrm{M})$ Incubation Compared To Same Time Control $(25 \mu \mathrm{M}$ Orthovanadate Exposure Only) Are Shown

57. A Summary Of The Results From Method $1 \quad 81$

58. A Summary Of The Results From Method 2 


\section{CHAPTER I}

\section{INTRODUCTION}

\section{Leishmania, Leishmaniasis, and Current Treatment Options}

Leishmaniasis is defined by the Center for Disease Control and Prevention as a neglected tropical disease carried by the sand fly vector. It affects populations in Asia, India, the Middle East, Africa (particularly in the tropical region and North Africa, with some cases elsewhere), Central and South America and southern Europe (Leishmaniasis, 2016). No cases of leishmaniasis have been reported in Australia or the Pacific islands. This disease is caused by any of 20 species of the parasitic protozoan Leishmania (Leishmaniasis, 2016). Leishmaniasis presents clinically in three forms: visceral, cutaneous, and mucocutaneous (Leishmaniasis, 2016). Over 1.6 million new cases of leishmaniasis are reported yearly (Leishmaniasis, 2016), and current treatment options include: pentavalent antimony salts, amphotericin B, liposomal amphotericin B, ketoconazole, itraconazole, and fluconazole (Leishmaniasis Professionals, 2016). Treatments can cost from $\$ 20-\$ 252$ USD per day, and treatments can last from 20 days to 4 months or longer depending on how long it takes for the lesion to heal (World Health Organization Leishmaniasis Treatment Cost, 2017). Leishmania diseases are becoming more wide spread, and there are few good drug therapies, thus new directions of treatments should be explored. As a consequence of sequencing Leishmania major and Leishmania infantum genomes, a large number of potential new drugs targets have been identified (Chawla, Madhubala, 2010). These potential drug targets include: the sterol biosynthetic pathway, the glycolytic pathway, the purine salvage pathway, nucleotide transporters, purine salvage enzymes, the glycosylphosphatidylinositol (GPI) pathway, protein kinases, mitogen-activated protein kinases (MAP kinases), proteinases, folate biosynthesis, the glyoxalase system, the trypanothione 
pathway, topoisomerases, and the hypusine pathway (Chawla, Madhubala, 2010). However, nondrug treatments affecting these or other potential targets may also be of value in treating leishmaniasis.

\section{Phosphatases}

Phosphatases are hydrolytic enzymes (EC 3.1) that are responsible for the hydrolysis of phosphoesters from substrate producing a phosphate and an alcohol (ExPASy, 2016). There are three general types of phosphatases; acid phosphatases, neutral phosphatases, and alkaline phosphatases (Vincent, Crowder, Averill, 1992; Gani, Wilkie, 1997). These enzymes are categorized based upon their $\mathrm{pH}$ optimum. Most relevant to this thesis work are acid phosphatases. Acid phosphatases are located, in humans, in the cellular components of bone, spleen, kidney, liver, intestine, and are also found in the blood (Henneberry, Engel, Grayhack, 1979). The pathogenesis of Leishmania changes during the life cycle from the amastigote form to the promastigote form of the parasite. (Mojtahedi, Clos, Kamali-Sarvestani, 2008). In vitro parasites in the stationary phase of their growth curve are more infective to macrophages than are parasites in the logarithmic phase (Mojtahedi et al., 2008). It has also been reported that the kinetic parameters of secreted acid phosphatases isolated from the in vitro stationary phase of Leishmania major change, such that the enzymes have a larger $\mathrm{V}_{\max }$ and a smaller $\mathrm{K}_{\mathrm{m}}$ compared to the logarithmic phase enzyme (Navabi, Soleimanifard, 2015). Leishmania secreted acid phosphatases are established to play several roles during the life cycle of the parasite, including: aiding in the survival of the parasite in the sand fly alternative host (Fernandes, Soares, Saraiva, Meyer-Fernandez, Souto-Padron, 2013), and formation of the parasitophorous vacuole, thus preventing macrophages from forming hydrogen peroxide (M. Baghaei, M. BAGHAEI, 2003). 
Thus, Leishmania secreted acid phosphatases are of interest as potential pharmaceutical targets for the treatment of leishmaniasis.

\section{L. tarentolae Secreted Acid Phosphatase Enzymes}

Secreted acid phosphatase enzymes are defined as proteins with phosphatase activity that are released from cells into the medium. In general, they are large molecular weight glycoproteins that in some Leishmania species are reported to be up to $70 \%(\mathrm{w} / \mathrm{w})$ carbohydrate (Ilg, Stierhof, Etges, Adrian, Harbecke, 1991). These proteins have both N- and O- linked sugars. The O-linked carbohydrate polymers are reported to be up to 32 repeat units in length (Lippert, Dwyer, Li, Olafson, 1999). There are at least two genes reported for Leishmania (Shakariana, Ellisa, Mallinsonac, Olafsonb, Dwyera, 1997). Furthermore, it is reported that these enzymes promote parasite survival in the sand fly, and promote the formation and evolution of the parasitophorous vacuole, in host macrophages, by dephosphorylating macrophage membrane proteins, thus preventing macrophage hydrogen peroxide production (M. Baghaei, M. BAGHAEI, 2003). Furthermore, the flagellar pocket of Leishmania is specialized, and is the location for the discharge of the two different secreted acid phosphatases, the most regularly secreted protein for Leishmania major, the human parasite (Isnard, Shio, Oliver, 2012; Fernandes et al., 2013). L. tarentolae, which infect reptiles but not humans, have also been shown to secrete acid phosphatases (Mendez, Dorsey, McLauchlan, Beio, Turner, Nguyen, Su, Beynon, Friesen, Jones, 2014).

L. tarentolae serves as a good model system for the investigation of the two Leishmania secreted acid phosphatases for several reasons. First, L. tarentolae are easy to grow, and their growth in culture is easily assessed. L. tarentolae do not infect humans, thus are less risky to work with. L. tarentolae have utility in the macrophage model system used to assess infectivity. Finally, L. tarentolae are sensitive to current treatment options, thus therapeutics that are effective in this 
model system may also work on the L. major species (Taylor, Munoz, Cedeno, Velez, Jones, Robledo, 2010). Furthermore, to test the role of N-linked carbohydrate found on L. tarentolae secreted acid phosphatases, cell supernatants containing these enzymes can be incubated with PNGase F, a glycosidase. PNGase F is a glycoaminidase, thus cleaving the N-C bond between asparagine and N-acetylglucosamines (PNGase F, 2017). These incubations will allow the investigation of the role of $\mathrm{N}$-linked carbohydrate in secreted acid phosphatase enzyme activity.

\section{Electric Fields Applied as a Therapeutic, in General}

Electromagnetic fields are composed of an electric component, and a perpendicular magnetic component. When applying an electric field to a biological sample, two types of processes may occur: Faradaic or non-Faradaic processes. Faradaic processes are electron transfer reactions, where as non-Faradaic process involve reorientation of solvent molecules and charges at the electrode surface (Merrill, Bikson, Jefferys, 2005). Electrons move from potentials that are more negative to potentials that are more positive. When applying cathodic current (negative voltage) to a biological sample, thus making the sample's potential more positive than the electrode, electrons move from the electrode to the sample. Cathodic current (Cat.) is thus reductive to the sample. Furthermore, while making the medium of the biological sample more negative, the cell potential becomes more positive. The cell potential is relative and is based on the charge outside of the cell versus the charge on the inside of the cell. As the exterior of the cell becomes more negative, the interior of the cell becomes relatively more positive, thus potentially causing depolarization for voltage-gated processes (Biophysics of Membrane Potential, 2017). When applying anodic current (positive voltage), the biological sample becomes more negative, thus electrons are transferred from the sample to the electrode (Merrill et al., 2005). Anodic current (And.) is thus oxidative to the biological sample. Furthermore, 
while making the medium of the biological sample more positive, the cell potential becomes more negative. As the exterior of the cell become more positive, the interior of the cell becomes relatively more negative, thus potentially causing hyperpolarization for voltage-gated processes (Biophysics of Membrane Potential, 2017). The Food and Drug Administration has approved the application of electromagnetic fields, with differential properties, for the following indications: electric bone growth stimulators, for the treatment of non-union fractures, failed joint fusion following arthrodesis, failed spinal fusion, congenital pseudoarthritis, palliative treatment of post-operative edema and pain, and major depressive disorder (Holden, 2017). Many of the mentioned potential drug targets for the treatment of leishmaniasis have some component that is voltage regulated. Some examples include the following. The movement of acetyl-CoA from within the mitochondria to the cytoplasm that requires transport of pyruvate across the inner and outer mitochondrial membranes. The outer mitochondrial membrane pyruvate transporter is a voltage regulated membrane protein (King, 2017). MAP kinases have been reported to be regulated by a calcium/calmodulin-dependent protein kinase cascade that is itself regulated by secondary messenger $\mathrm{Ca}^{2+}$ (Enslen, Tokumitsu, Stork, Davis, Soderling, 1996). If calcium concentrations in cells are affected by the movement of calcium inward through voltage gated calcium transporters, these processes will be impacted. The importance of these processes in normal cellular metabolism warrant the investigation of their response to the application of an electric field for therapeutic treatment of leishmaniasis.

As a therapeutic, electricity has been applied to L. major in culture, and has been applied to two different types of mouse models, Naval Medical Research Institute (NMRI) strain or Bagg Albino (BALB/c) strain, for the treatment of pre-existing L. major lesions (Hejazi, Eslami, Dalimi, 1972). These authors tested the following conditions: 3, 6, 9, or 12 Volts with current 
ranging from $0.19-10.65 \mathrm{~mA}$ (Direct current). Their in vivo experiments showed that when the electrodes were placed $2 \mathrm{~cm}$ apart, direct voltages of 3,6, 9, and 12 volts at various currents killed all L. major promastigotes. Furthermore, when the electrodes were $2 \mathrm{~cm}$ apart, the application of 3 volts for 10 minutes caused the $\mathrm{pH}$ to drop from 7 to 4 . This drop in $\mathrm{pH}$ has several physical and chemical implications. First, the drop in $\mathrm{pH}$ occurred due to the oxidation of water (see equation 1).

$2 \mathrm{H}_{2} \mathrm{O}(l) \rightarrow 4 \mathrm{H}^{+}(a q)+4 \mathrm{e}^{-}+\mathrm{O}_{2}(g)$ Equation 1.

Because electrons were removed from water to produce protons (hence the drop to more acidic $\mathrm{pH}$ ), we infer that the driving force for this reaction was the applied voltage. To cause the oxidation of water, this applied potential must have been anodic, or positive voltage, in character. Thus, these authors investigated the effects of anodic waveforms on L. major.

Hejazi et al. (1972) treated L. major infected mice with electricity that was applied twice a week for three weeks after the inoculation of 4-6 week old mice (NMRI or BALB/c) with L. major ( $10^{6}$ stationary phase parasites). The diameter of skin lesions was measured as a metric to determine the effectiveness of the electrical therapies. The NMRI mice with infection, but with no treatment, reached a maximum lesion diameter of $\sim 4 \mathrm{~mm}$ and spontaneously healed completely by week 10. The NMRI mice with infection and electrical therapeutic $(3 \mathrm{~V}, 0.05 \mathrm{~mA}$ for $10 \mathrm{~min})$ reached a maximum lesion diameter of $2.5 \mathrm{~mm}$, and were healed completely at 6 weeks. Thus, in the NMRI mice, electricity was therapeutic, and lead to remission of lesions with no reoccurrence up to 23 weeks (the duration of the study). It should be noted that the control mice were also in complete remission at 23 weeks, but their remission took longer to initiate (10 weeks). The $\mathrm{BALB} / \mathrm{c}$ mice with infection, but with no treatment, reached a maximum lesion diameter of $\sim 16$ $\mathrm{mm}$ and were all dead by week 20 . The BALB/c mice with infection and electrical therapies $(3 \mathrm{~V}$, 
$0.05 \mathrm{~mA}$ for $10 \mathrm{~min}$ ) reached a maximum lesion diameter of $\sim 17 \mathrm{~mm}$, and were still alive at 23 weeks. The electricity treated mice had lesions the same size as the control from weeks 1-3. At week 3 electricity treatment occurred, and the control lesions continued to grow while the treated lesions reached a minimum of $\sim 0 \mathrm{~mm}$ at week 8 . On week 9 the treated lesions began to grow linearly, and reached a maximum diameter of $\sim 17 \mathrm{~mm}$ at week 23 , at which point the study ended (Hejazi et al., 1972). These data indicate that electricity applied as a therapeutic does have an effect on lesion size, but depending on the species of mouse, the lasting effect is different, and thus different therapeutic durations may be required. The authors did not speculate on the therapeutic mechanism.

Electric Fields for the Purpose of Affecting L. tarentolae Motility, Clumping, Cell Viability, and Secreted Acid Phosphatase Activity

With this in mind, we propose evaluating the effects of applying electric fields to $L$. tarentolae. We wanted to test the ability of L. tarentolae to secrete acid phosphatases, the catalytic activity of secreted acid phosphatases, as well as cell motility (as evaluated by microscopy), and cell viability (MTT assay). We are especially interested in the potential effect of the application of an electric field to induce or inhibit the release of secreted acid phosphatase from Leishmania since it had reported that Leishmania secreted acid phosphatase (SAP) has an important role in the infectivity by Leishmania (Vannier-Santos, Martiny, de Souza, 2002). Thus, these data have implications for clinical treatments of cutaneous Leishmania infections.

\section{Vanadium Background, Vanadium Human Exposure, Vanadium Chemistry and Speciation}

Vanadium, element number 23, is found in the soil, water and air, and can enter the human body through the lungs or digestive tract (Agency for Toxic Substances and Disease 
Registry, 2016; Rehder, 2013). Atmospheric vanadium is found in dust, marine aerosol, and volcanic emissions. Air is typically not a large source of vanadium exposure for humans. Cigarette smokers are exposed to approximately $4 \mu \mathrm{g}$ of vanadium per cigarette smoked (Agency for Toxic Substances and Disease Registry, 2016). Water and soil are likely the greatest sources of vanadium, other than food supplements, that humans are exposed to. Water and soil can typically contain $0.04-220 \mu \mathrm{g} / \mathrm{L}$ vanadium (Agency for Toxic Substances and Disease Registry, 2016). The typical total amount of vanadium in humans is $1 \mathrm{mg}$ (Rehder, 2013). Vanadium is a very versatile element and has 5 common oxidation states available, with the vanadium (V) oxidation state being the overwhelmingly dominant species in aqueous solution. Vanadium forms covalent adducts with oxygen, which produce numerous different species of vanadium in its (V) oxidation state as a function of $\mathrm{pH}$ (Figure 1, Baes, Mesmer, 1976). Speciation of vanadium, specifically decavanadate speciation in acidic media, has been investigated (Figure 1, Baes, Mesmer, 1976). It is clear that under acidic conditions, protonation status changes either by deprotonation or cation exchange with the medium, and vanadium speciation is a function of vanadium concentration, solution $\mathrm{pH}$, and ionic strength of the solution (F. Rossotti, H. Rossitti, 1956; Corigliano, Pasquale, 1975). Because of this, vanadium speciation, degree of protonation, and degree of proton displacement by cations in solution are likely different for solutions of different composition. Therefore, when using decavanadate or orthovanadate as inhibitors of phosphatases, it is not always clear what species are present, or what species are responsible for inhibition of the enzyme being assayed. 


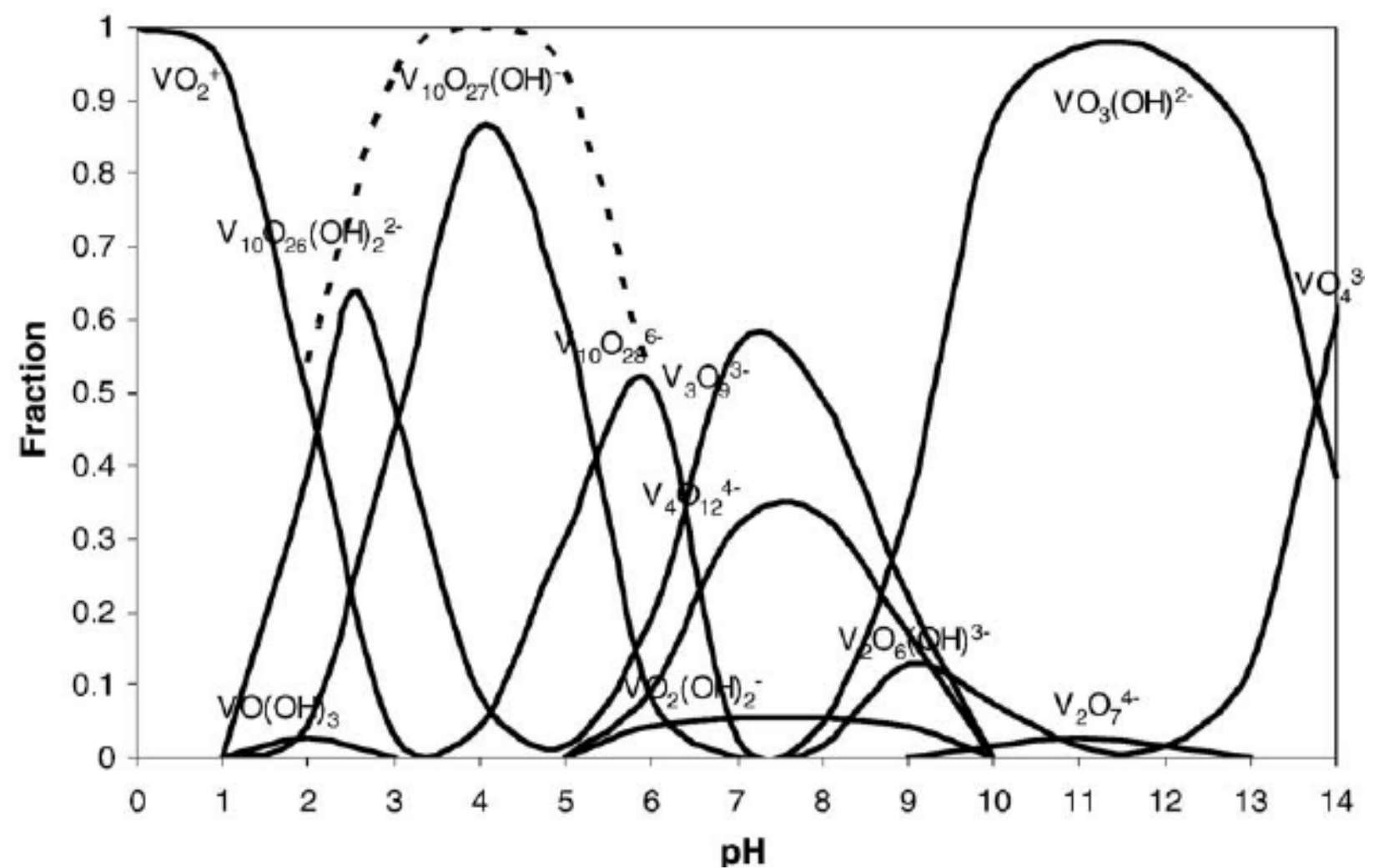

Figure 1. Vanadium (V) speciation as a mole fraction of total vanadium present at a given $\mathrm{pH}$, over the typical $\mathrm{pH}$ scale (0-14) (Baes, Mesmer, 1976). This speciation diagram is for a $0.1 \mathrm{~m}$ vanadium solution

\section{Vanadium is a Potential Medicinal Agent as a Phosphatase Inhibitor}

It is well known that oxovanadium species act as phosphatase inhibitors (VanEtten et al., 1974; Abbott, Jones, Weinman, Bockhoff, McLafferty, Knowles, 1979; Knowles, 1980; Gressor, Tracey, Stankiewwicsz, 1987; Gordon, 1991; Li, Baruah, Crans, Wang, 2008;). How vanadium acts as a phosphatase inhibitor is thought to be through the action of a vanadium (V) monomeric oxyanion, vanadate, mimicking a 5 coordinate high energy intermediate of the transition state phosphate, therefore behaving as a competitive inhibitor (Abbott et al., 1979; Knowles, 1980; Rehder, 2013). There are numerous crystal structures of phosphatases, with nitrogen-containing, oxygen containing, or sulfur-containing active site amino acids, deposited in the Protein Data Bank, that have been recently reviewed (McLauchlan, Peters, Willsky, Crans, 2015). These 
phosphatases function to hydrolyze esters, phosphoesters, and phosphoanhydrides. These crystal structures had been soaked with vanadium complexes, the majority of experiments using orthovanadate, at $\mathrm{pH}$ values ranging from 5.40-8.00. The overwhelming majority of these phosphatases, regardless of the type of active site amino acid residues ( $\mathrm{O}, \mathrm{N}$, or $\mathrm{S}$ containing), have a monomeric form of vanadium $\left(\mathrm{VO}_{3}{ }^{2-}\right.$ or $\left.\mathrm{VO}_{4}{ }^{3-}\right)$ present in the phosphatase active site upon solving the crystal structure. It should be noted at the used concentrations of vanadium and in this $\mathrm{pH}$ range, that di-, tri-, and tetrameric vanadium species are predicted to be the major forms of vanadium present, and not the monomeric forms $\left(\mathrm{VO}_{3}{ }^{2-}\right.$ or $\left.\mathrm{VO}_{4}{ }^{3-}\right)$ that are reported in the enzyme's active site. Thus, there is a discrepancy between what one might hypothesize about the species responsible for inhibition (the major species present is responsible for the inhibition), and what one actually finds (a minor species present is responsible for the inhibition).

Regardless, it is thought that these monomeric species are likely responsible for phosphatase inhibition. There is, however, a likely discrepancy between solid state speciation of vanadium that occurs under soaking conditions, and aqueous speciation of vanadium that occurs in enzymatic assays because crystal dynamic conditions are likely to be different than those of the more flexible protein under enzymatic assay conditions in terms of $\mathrm{pH}$, ionic strength, and vanadium concentration. Therefore, the species of vanadium present in enzymatic assays cannot necessarily be assumed to be the same as the species present after crystal soaking experiments. To further stress the importance of speciation, crystallographic soaking studies that used metavanadate $(50 \mathrm{mM})$ starting material, under acidic conditions ( $\mathrm{pH} 5.0)$ produced protein crystals of $B$. stearothermophilus phosphatase with trivanadate, $\mathrm{V}_{3} \mathrm{O}_{8}{ }^{2-}$, located in the putative active site, when in fact, the authors had expected to find orthovanadate, $\mathrm{VO}_{4}{ }^{3-}$ (PDB ID $1 \mathrm{~h} 2 \mathrm{f}$., Rigden, Littlejohn, Henderson, Jedrzejas, 2003). 
Using acid phosphatase amino acid sequence alignment from rat (APR. norvegicus EC3.1.3.2, PDB 1rpt) as a comparative model to Leishmania secreted acid phosphatases, it can be seen that there is in fact overlap between the reported vanadate binding residues in the $A P R$. norvegicus and the L. mexicana acid phosphatases (SAP1L.mex gene accession number Z46969.1 and SAP2L.mex gene accession number Z46970.1). The gray and black highlights are the amino acids reported to be in the active site. Gray highlights indicate different amino acids between species. Black highlights indicate identical amino acids between species. Using the amino acid numbering from $A P R$. norvegicus, the following residues are responsible for coordinating vanadate, Arg11, His12, Arg15, Arg79, and His257, and are highlighted in red in Figure 2.

SAP1L.mex
SAP2L.mex
APR.norvegicus
SAP1L.mex
SAP2L.mex
APR.norvegicus
SAP1L.mex
SAP2L.mex
APR.norvegicus

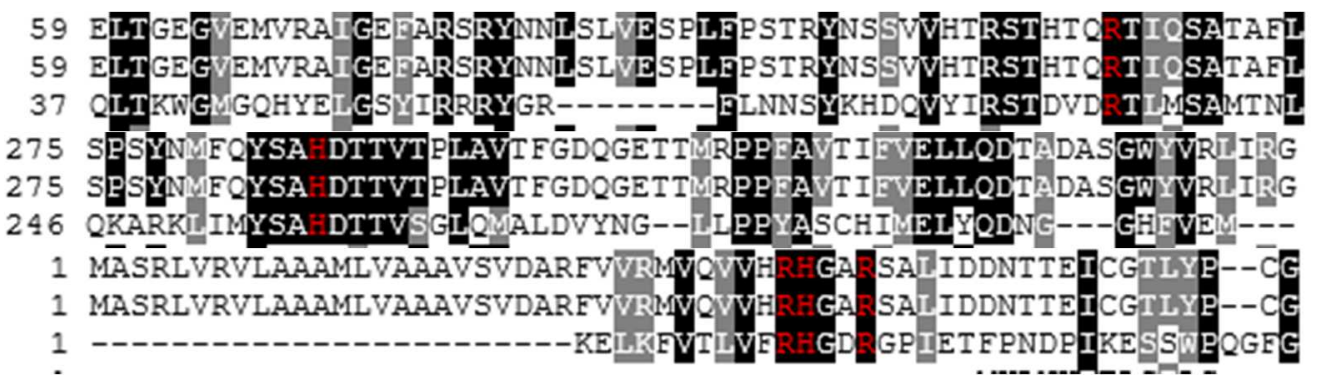

Figure 2. Multiple Sequence Alignment of three acid phosphatases. This sequence alignment was completed using Kalign and the BoxShade Server (Kalign, 2016; BoxShade Server, 2017)

To further investigate the ambiguities of vanadium speciation and phosphatase inhibition, we use a previously published model (Baumhardt, Dorsey, McLauchlan, Jones, 2015) for comparing competitive enzyme inhibitors to compare decavanadate and orthovanadate as inhibitors of $L$. tarentolae secreted acid phosphatases. These studies can give insight into the clinical use of these and other vanadate complexes as anti-Leishmania therapies. 
Because leishmaniasis is an endemic disease with costly treatment options, and multiple cellular targets, including acid phosphatases, here we investigated the effects that electric fields, with or without the presence of vanadium complexes, or glycosidase preincubation have on $L$. tarentolae in vitro for the purpose of discovering new, cheap therapeutics for the treatment of leishmaniasis. 


\section{CHAPTER II}

\section{MATERIALS AND METHODOLOGY}

\section{Cell Culture of $L$. tarentolae and Assessment of Cell Viability by the MTT Viability Assay}

L. tarentolae (ATCC 30143) promastigote cells were sterilely grown in brain heart infusion (BHI; $37.0 \mathrm{~g} / \mathrm{L})$ supplemented with hemin $(10 \mu \mathrm{M})$, penicillin $(10,000$ units/ $\mathrm{mL})$ and streptomycin $(10 \mathrm{mg} / \mathrm{mL})$ following a published method (Morgenthaler, Peters, Cedeno, Constantino, Edwards, Kamowski, Jones, 2008). L. tarentolae cell viability was assessed by the 3-(4,5-dimethylthiazol-2-yl)-2,5-diphenyltetrazolium bromide (MTT) viability assay (Mosmann, 1983). The MTT assay serves as a quantitative measure (A595 nm) of cell mitochondrial activity, and therefore indirectly monitors cell viability. Sample absorbance at A595 nm was determined with an iMark microplate reader (BioRad Laboratories, Hercules, CA). The BHI growth medium alone was considered as a blank value subtracted from the sample absorbance (BHI and cells). Results are reported as corrected absorbance (A595 nm/Hr incubation with MTT reagent, or A595 $\mathrm{nm} / \mathrm{Hr}$ incubation with medium only) mean \pm standard deviation (SD) for $\mathrm{n}=4$ replicates. In all cases where error bars less than $5 \%$ were not shown. In this work, the parasites were grown at room temperature in $25 \mathrm{~cm}^{2}$ canted flasks (Corning, Inc.; Product number 430372). Samples for assessment by MTT assay were collected daily using sterile technique.

\section{Microscopy of $L$. tarentolae}

Microscopic analysis of $L$. tarentolae for motility, shape, and clumping was undertaken. The parasites were observed microscopically to monitor the effect of each treatment on the parasite. A Jenco International, Inc. (Portland,OR) inverted compound microscope Model CP2A1 was used. This microscope can be adjusted to focus on cells at the bottom, middle, or upper focal planes of the culture flask which will allows observations of the parasite throughout the 
culture medium. Images of cells (at 400x magnification) were taken using the camera on the Google Pixel cellular phone. Microscopy was performed on all L. tarentolae cell cultures daily.

Preparation of the L. tarentolae Acid or Alkaline Phosphatase Enzyme Source

A sample of L. tarentolae from each stage of the growth curve (lag, log, stationary, and senescence) was collected and centrifuged (2000xg, $10^{\circ} \mathrm{C}, 10$ minutes). The supernatant was collected and stored on ice until it was used for acid or alkaline phosphatase enzyme assays. The pellet was immediately resuspended in a volume of BHI equal to the volume of supernatant collected from that same sample. The pellets were then stored on ice until they were used in acid or alkaline phosphatase enzyme assays.

\section{Secreted Acid or Alkaline Phosphatase Enzyme Assay}

Secreted acid or alkaline phosphatase (SAP) activity was evaluated using paranitrophenyl phosphate ( $p$ NPP) as substrate following the method of Mendez et al. (2014). This assay at room temperature was performed in $1.5 \mathrm{~mL}$ polypropylene tubes in a total reaction volume of $0.9 \mathrm{~mL}$. Sodium acetate buffer $(500 \mu \mathrm{L}, 0.5 \mathrm{M}, \mathrm{pH} 4.5)$ was used for acid phosphatase assays. Tris-Base (500 $\mu \mathrm{L}, 0.5 \mathrm{M}, \mathrm{pH} 8.3)$ was used for alkaline phosphatase assays. The enzyme source was L. tarentolae cell supernatant or pellet from each phase of the growth curve $(300 \mu \mathrm{L})$. The substrate ( $5 \mathrm{mg} p \mathrm{NPP} / 1 \mathrm{~mL}$ buffer), made in sodium acetate buffer $(0.5 \mathrm{M}, \mathrm{pH} 4.5)$ for acid phosphatase assays, or Tris-Base (0.5 M, pH 8.3) for alkaline phosphatase assays was added (100 $\mu \mathrm{L})$ to start the reaction $(500 \mu \mathrm{M}$ final concentration). After room temperature incubation for 23 hours, the reaction was stopped with addition of $100 \mu \mathrm{L}$ of $10 \mathrm{M}$ sodium hydroxide, and samples were vortexed. Product formation was measured by spectroscopy at A405 nm. BHI was used to replace enzyme source for spectrophotometric blanks. Data are reported as absorbance (A405 
$\mathrm{nm}$ ) per day in culture. Product (para-nitrophenolate) was calculated from corrected A405 nm/23 $\mathrm{Hr}$ divided by molar absorptivity $\left(18,000 \mathrm{~cm}^{-1 *} \mathrm{M}^{-1}\right)$ and reported as $\mu \mathrm{M} / 23 \mathrm{Hr}$.

\section{Kinetic Enzyme Assay}

The order of addition of material to the kinetic enzyme assay was as follows. Sodium acetate buffer $(500 \mu \mathrm{L}, 0.5 \mathrm{M}, \mathrm{pH} 4.5)$ was used for acid phosphatase assays. The artificial substrate, para-nitrophenylphosphate ( $p$ NPP), was freshly prepared in buffer, then it was added to the assay to give final substrate concentrations of 2.0, 2.6, 3.0, 3.4, 3.7, 4.1, 4.5, 6.0, 8.8, 12.0, $14.0,18.0,150.0,200.0,250.0,300.0,350.0,400.0,450.0,500.0,550.0,1000.0,2000.0$, or $4000.0 \mu \mathrm{M}$. Lastly, log phase L. tarentolae cell supernatant as enzyme source $(300 \mu \mathrm{L})$ was added to the $1.5 \mathrm{~mL}$ polypropylene tubes to start the reaction. The final assay volume was 0.9 $\mathrm{mL}(\mathrm{n}=3)$. Assays were incubated at room temperature for 23 hours, previously determined to be under apparent first order conditions (Mendez et al., 2014), in the dark. To stop the reaction, sodium hydroxide $(100 \mu \mathrm{L}, 10 \mathrm{M})$ was added and the samples were vortexed. Product was then evaluated by spectroscopy (A405 nm). Spectrophotometric blanks were prepared using the same volumes of assay buffer and substrate as experimental samples, but the enzyme source was replaced with brain heart infusion medium, the same medium as the supernatant fraction, but not exposed to cells.

\section{Designing Waveforms for the Production of Electric Fields}

Using a comma-separated values (CSV) excel file, the waveforms to be applied to $L$. tarentolae whole cells or cell supernatant were generated. The number of data points $(\mathrm{N})$ is used to determine the time resolution (S) of the signal. The resolution of the signal is the time between current applications. The larger the number of data points $(\mathrm{N})$, the smaller the resolution $(\mathrm{S})$ is. 
For these experiments, $\mathrm{N}=40,000$. The frequency $(\mathrm{F})$, defined as a cycle per second, was then used to calculate the period $(\mathrm{T})$ of the waveform.

$\mathrm{T}=1 / \mathrm{F}$

Equation 2

The period and number of data points were used to calculate the resolution of the signal (S).

$\mathrm{S}=\mathrm{T} / \mathrm{N}$

Equation 3

The excel file contained two columns, one column for time, and the other for the voltage that is entered into the waveform generator. Time zero will have a value of 0S. Time 1 will have a value of $1 \mathrm{~S}$. Time two will have a value of $2 \mathrm{~S}$, and so on to fill the 40,000 data points. The value of the voltage in the other column was either be zero or four. When the value is equal to zero, then zero voltage will be applied. When the value is equal to four, then an input of four was sent to the waveform generator (Singlet Function/Arbitrary Waveform Generator) and voltage was then generated from the electrode. To determine when the values of voltage are zero or four, the period of the waveform $(\mathrm{T})$ was divided by three to generate three equal time points; the pulse width (PW), the interphase delay (IPD) and the space between cycles (CS). These three values add up to equal the period (T).

$\mathrm{T}=2 \mathrm{PW}+\mathrm{IPD}+\mathrm{CS}$

Equation 4

When the period is divisible by three, producing an integer value, the value of CS is equal to zero. When the period is not divisible by three, producing a non-integer value, the value of CS is the smallest value that will produce a period divisible by three. The following equations are also true:

$\mathrm{PW}=\mathrm{IPD}$

Equation 5

$\mathrm{PW}=(\mathrm{T}-\mathrm{CS}) / 3$ Equation 6

$\mathrm{PW}=\mathrm{T} / 3$ if $\mathrm{CS}=0$ Equation 7 
To generate Figure 3, a data file containing forty thousand data points, $N=40,000$, was used. For a frequency of $5000 \mathrm{~Hz}, \mathrm{~F}=5000 \mathrm{~s}^{-1}$, thus $\mathrm{T}=1 / \mathrm{F}, \mathrm{T}=1 / 5000, \mathrm{~T}=2 * 10^{-4}$ seconds. The resolution was calculated as $\mathrm{S}=\mathrm{T} / \mathrm{N}, \mathrm{S}=\left(2 * 10^{-4}\right.$ seconds $) / 40,000, \mathrm{~S}=5^{*} 10^{-9}$ seconds. The time points in the excel file started at zero and grew in increments of $5^{*} 10^{-9} \mathrm{~s}$ at each iteration. To determine the time of PW, and thus IPD, the period $(\mathrm{T}=200 \mu \mathrm{s})$ must be divided into three equal parts. To do this, CS will have a value of $2 \mu$ s. Using equation 5, PW will be determined. $\mathrm{PW}=(\mathrm{T}-\mathrm{CS}) / 3, \mathrm{PW}=(200 \mu \mathrm{s}-2 \mu \mathrm{s}) / 3, \mathrm{PW}=66 \mu \mathrm{s}$

PW, as calculated for a symmetric waveform, means the cathodic segment will be $66 \mu \mathrm{s}$ and the anodic segment will be $66 \mu \mathrm{s}$. Using equation 4, IPD will be determined. $\mathrm{IPD}=\mathrm{PW}, \mathrm{IPD}=66 \mu \mathrm{s}$

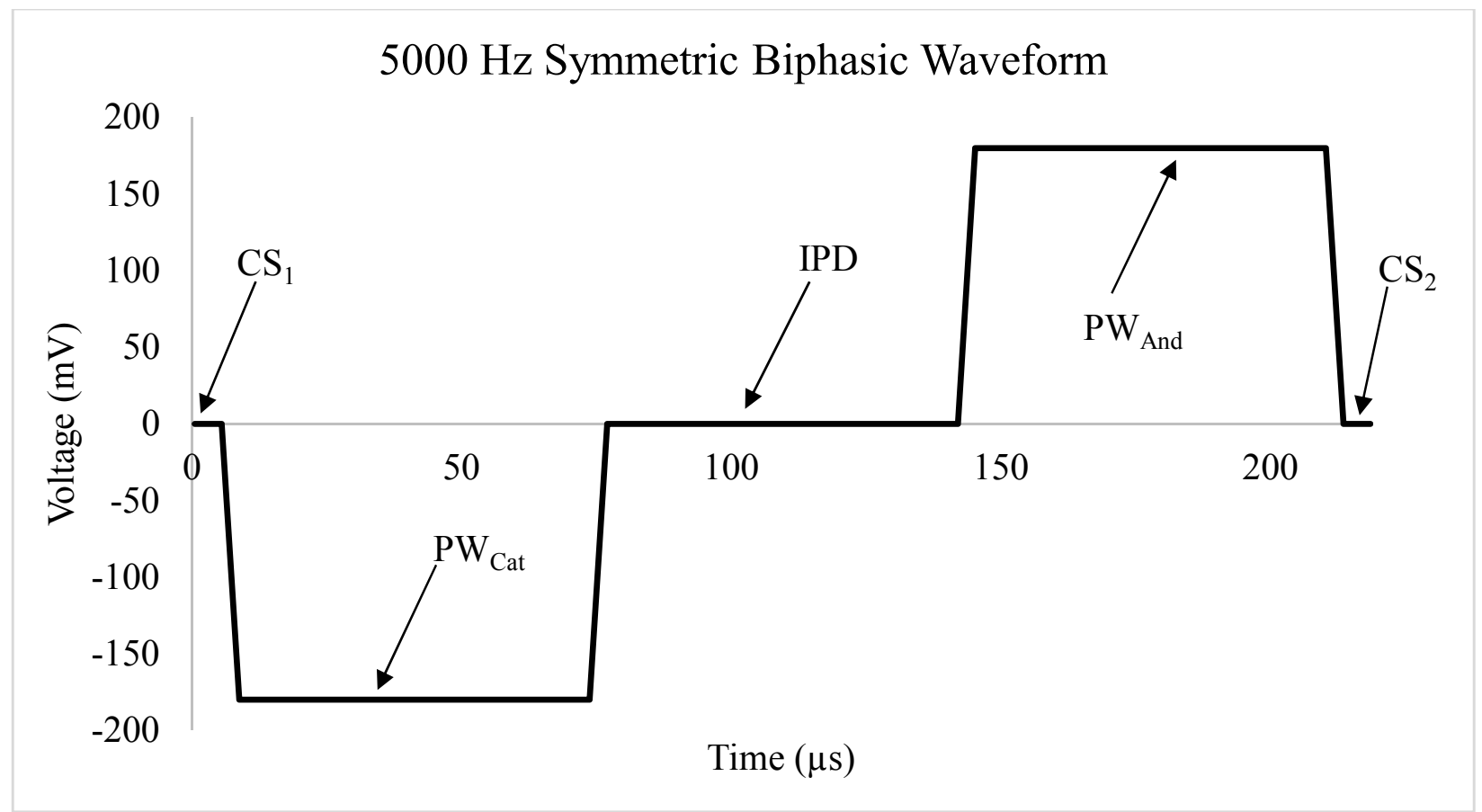

Figure 3. A plot of time $(\mu \mathrm{s})$ vs. voltage $(\mathrm{mV})$ is shown for a symmetric biphasic waveform 
In an excel file, the following spread sheet was written to generate the waveform in Figure 3. From 0-2 $\mu$ s (The CS), in increments of $0.005 \mu$ s (Resolution, S), the voltage input was assigned to 0 , thus producing $0 \mathrm{mV}\left(\mathrm{CS}_{1}\right)$. This occupies 400 data points. From 2-68 $\mu$ s, the voltage was assigned to 4 , thus producing $-180 \mathrm{mV}$ ( $\mathrm{PW}_{\text {Cat }}$ ). This occupies 13,200 data points. From $68-134 \mu \mathrm{s}$, the voltage of 0 was assigned, thus producing $0 \mathrm{mV}$ (IPD). This occupies 13,200 data points. From 134-200 $\mu$ s, the voltage of 4 was assigned, thus producing $180 \mathrm{mV}$ ( $\left.\mathrm{PW}_{\text {And }}\right)$. This occupies 13,200 data points. All 40,000 data points are thus be accounted for. $\mathrm{CS}_{2}$ immediately follows $\mathrm{PW}_{\mathrm{And}}$, and will have identical parameters of $\mathrm{CS}_{1} . \mathrm{CS}_{2}$ is the space between cycle one and cycle two.

\section{Electrode Tested}

The electrode used was a concentric bipolar electrode from FHC Neuro Micro Targeting ${ }^{\mathrm{TM}}$ Worldwide. Figure 4 is a model of the general shape of the electric fields that are applied to L. tarentolae whole cells or $L$. tarentolae cell supernatant.

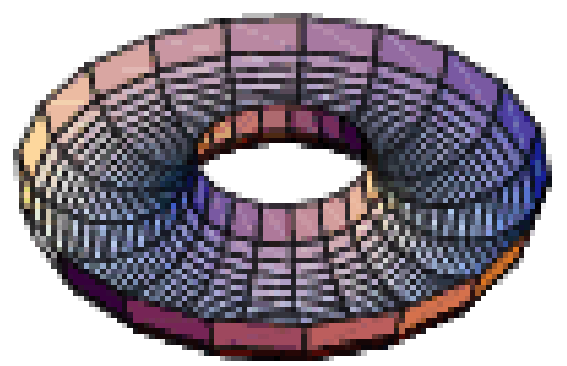

Figure 4. Model of the general shape of the electric field that is applied to either L. tarentolae whole cells or cell supernatant is shown 


\section{Parameters of Tested Waveforms}

The waveforms were loaded on to a singlet arbitrary waveform generator. The following parameters of the waveform that produces the electric filed were modified using an isolator (World Precision Instruments stimulus isolator): frequency (50-10,000 Hz), current (0.1-1.0 $\mathrm{mA}$ ), polarity of the waveform (symmetric biphasic, cathodic, or anodic), and exposure time (2.5 min-12 hours ) to the electric field. A simplified model of the experimental setup is shown in Figure 5 .

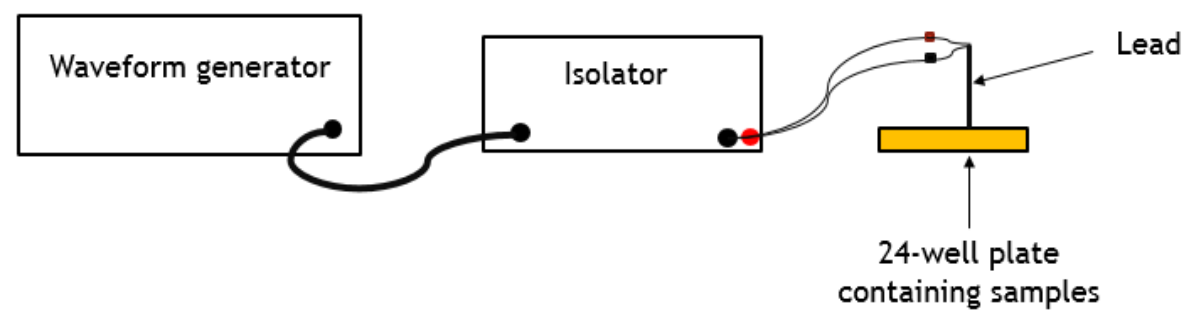

Figure 5. Simplified experimental model of setup to apply electric fields to L. tarentolae whole cells or cell supernatant

\section{Testing the Acute Effects of Electric Fields on L. tarentolae Growth Curves and Microscopy}

L. tarentolae were transferred from $25 \mathrm{~cm}^{2}$ canted flasks into 24 well plates (Falcon; 0.5 $\mathrm{mL}$ per well), taking care to deliver a consistent number of cells to each well. Using a singlet arbitrary waveform generator coupled to a stimulus isolator, an electrode was applied to these cells to expose them to a characterized electric field for a specific amount of time. After exposure to the electric field, L. tarentolae were assessed for cell viability by the MTT assay. Immediately following the application of an electric field, these cells were monitored by microscopy. Results were compared to cells not exposed to the electric field. 


\section{Testing the Effects of Electric Fields on L. tarentolae Acid Phosphatase Activity in Supernatant or Pellet (Cells), Method 1}

L. tarentolae were collected from the log phase of their growth curve, centrifuged (2000xg, $10 \mathrm{~min}, 10^{\circ} \mathrm{C}$ ), and the supernatant was collected. The cell pellet was resuspended in a volume of BHI growth medium equal to the volume of supernatant collected. The supernatant or pellets were transferred into a 24-well plate (Falcon, $0.5-2.0 \mathrm{~mL}$ per well). Using a singlet arbitrary waveform generator coupled to a stimulus isolator, a concentric bipolar electrode was applied to these samples to expose them to an electric field, or not (control). The samples exposed to the same type of electric fields, or not (control), were pooled and rested on ice until they were assessed by the acid phosphatase enzyme assay. The process is outlined in the flow diagram below in Figure 6. Data are plotted as percent different from same time control for $n=3$. Data were first evaluated by ANOVA, and those that were significantly different were further analyzed. When reporting percent different relative to the same time control, only those data that were statistically different in a paired, two-tailed t-test at the 0.05 level were reported. 


\section{L. tarentolae cell culture}

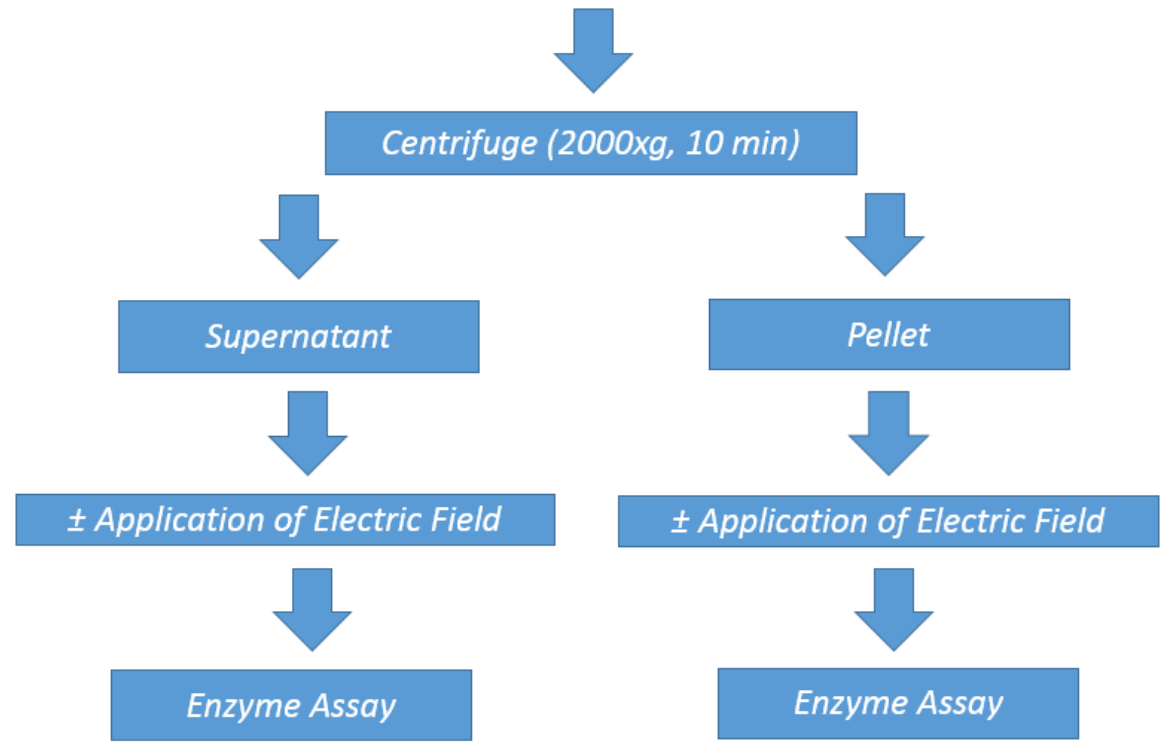

Figure 6. Flow diagram of Method 1. Thus, method 1 allows testing of direct effects of electric field on the previously secreted enzyme

\section{Testing the Effects of Electric Fields on L. tarentolae Acid Phosphatase Activity in}

\section{Supernatant or Pellet (Cells), Method 2}

L. tarentolae were collected from the log phase of their growth curve, and were then transferred from culture flasks to $24-$ well plates (Falcon, $0.5-2.0 \mathrm{~mL}$ per well), taking care to deliver a consistent number of cells to each well. Using a single arbitrary waveform generator coupled to a stimulus isolator (World Precision Instruments), a concentric bipolar electrode was applied to these samples to expose the cells an electric field, or not (control). The cells were collected. Cells that were exposed to the same type of electric fields or control cells were pooled. These pools were centrifuged $\left(2000 \mathrm{xg}, 10 \mathrm{~min}, 10^{\circ} \mathrm{C}\right)$, and the supernatant was collected. The cell pellets were resuspended in a volume of BHI equal to the volume of the supernatant collected. The samples were rested on ice until they were used in the acid phosphatase enzyme 
assays. The process is outlined in Figure 7. Data are plotted as percent different from same time control for $n=3$. Data were first evaluated by ANOVA, and those that were significantly different were further analyzed. When reporting percent different relative to the same time control, only those data that were statistically different in a paired, two-tailed t-test at the 0.05 level were reported.

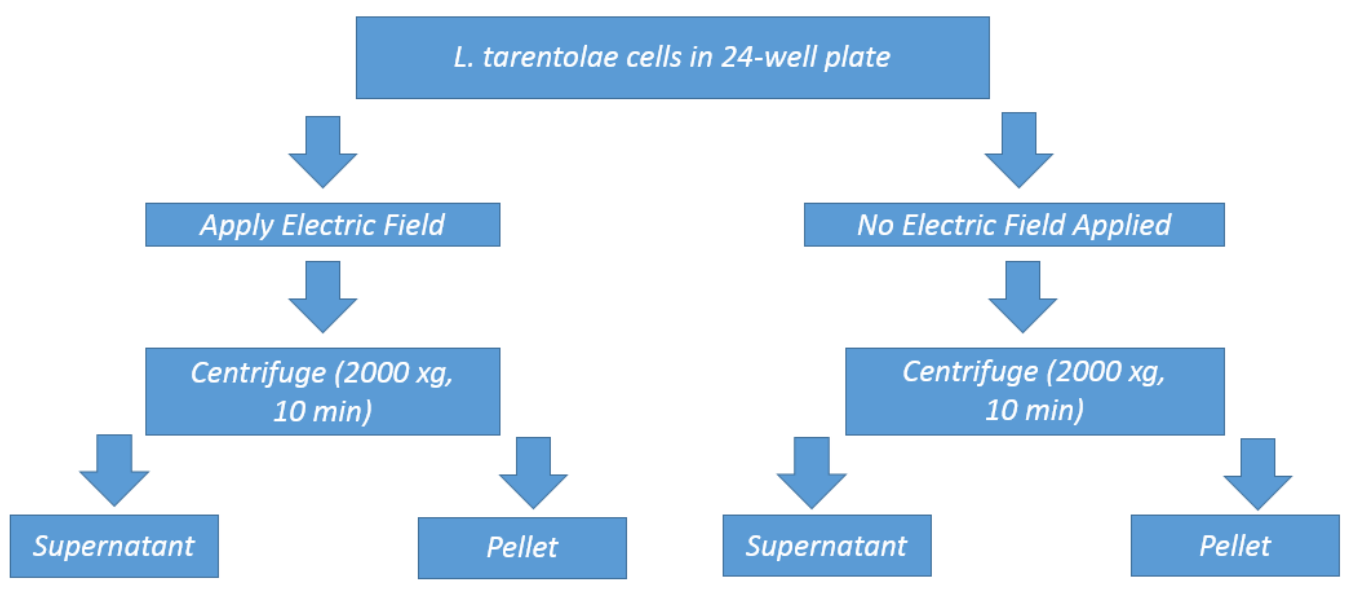

Figure 7. Flow diagram of Method 2. Thus, method 2 allows assessment of the effect of electric field on secretion of acid phosphatase from cells

\section{Secreted Acid Phosphatase Enzyme Inhibition Assay (Following the Method of Baumhardt et al., 2015)}

To determine which form of vanadium is most useful in L. tarentolae secreted acid phosphatase enzyme assays, decavanadate or orthovanadate, the method of Baumhardt et al. (2015) was used. Using the previously determined $\mathrm{k}_{\mathrm{M}}$ substrate concentration of $391 \mu \mathrm{M}$, the $\log$ ratio of substrate to total vanadium concentration in the assay was calculated for either orthovanadate or decavanadate (as shown in Table 1). This amount of substrate was used as a 
first approximation of $\mathrm{k}_{\mathrm{M}}$ from previous work (Mendez et al., 2014) with the same enzyme source.

\begin{tabular}{|c|c|c|c|c|}
\hline Sample & $\log [\mathrm{S}] /[\mathrm{I}]$ & {$[$ Total Vanadium $] \mathrm{mM}$} & [Decavanadate] $\mathrm{mM}$ & [Orthovanadate] $\mathrm{mM}$ \\
\hline 1 & -2.0 & $3.91 \mathrm{E}+01$ & $3.91 \mathrm{E}+00$ & $3.91 \mathrm{E}+01$ \\
\hline 2 & -1.5 & $1.24 \mathrm{E}+01$ & $1.24 \mathrm{E}+00$ & $1.24 \mathrm{E}+01$ \\
\hline 3 & -1.0 & $3.91 \mathrm{E}+00$ & $3.91 \mathrm{E}-01$ & $3.91 \mathrm{E}+00$ \\
\hline 4 & -0.5 & $1.24 \mathrm{E}+00$ & $1.24 \mathrm{E}-01$ & $1.24 \mathrm{E}+00$ \\
\hline 5 & 0.0 & $3.91 \mathrm{E}-01$ & $3.91 \mathrm{E}-02$ & $3.91 \mathrm{E}-01$ \\
\hline 6 & 0.5 & $1.24 \mathrm{E}-01$ & $1.24 \mathrm{E}-02$ & $1.24 \mathrm{E}-01$ \\
\hline 7 & 1.0 & $3.91 \mathrm{E}-02$ & $3.91 \mathrm{E}-03$ & $3.91 \mathrm{E}-02$ \\
\hline 8 & 1.5 & $1.24 \mathrm{E}-02$ & $1.24 \mathrm{E}-03$ & $1.24 \mathrm{E}-02$ \\
\hline 9 & 2.0 & $3.91 \mathrm{E}-03$ & $3.91 \mathrm{E}-04$ & $3.91 \mathrm{E}-03$ \\
\hline
\end{tabular}

Table 1. The concentrations of vanadium used as either total vanadium, or orthovanadate, or decavanadate in each sample.

Table 1 indicates the relationship between the log of substrate to inhibitor ratio to the total moles of vanadium, or the total moles of decavanadate, or the total moles of orthovanadate in the assay. It should be noted that for every mole of orthovanadate, there is one mole of vanadium. For every mole of decavanadate, there are ten moles of vanadium. Thus, orthovanadate was used at ten times the molar concentration of decavanadate, but the total moles of vanadium from either compound, in the assay, was the same as listed in Table 1. In all cases the concentration of the artificial substrate, para-nitrophenylphosphate ( $p$ NPP), is $391 \mu \mathrm{M}$.

The order of addition of material to the assay was as follows. Sodium acetate buffer $(0.5$ $\mathrm{M}, \mathrm{pH} 4.5$ ), vanadium as either orthovanadate or decavanadate freshly prepared in assay buffer, and enzyme source ( $300 \mu \mathrm{L}$ of $\log$ phase $L$. tarentolae cell supernatant) were added to the assay and allowed to preincubate at room temperature for 10 minutes. The artificial substrate, paranitrophenylphosphate ( $p$ NPP) was added to the assay to give final concentrations of $391 \mu \mathrm{M}$ 
$p$ NPP. The final assay volume was $0.9 \mathrm{~mL}$. Assays were incubated at room temperature for 23 hours. To stop the reaction sodium hydroxide $(100 \mu \mathrm{L}, 10 \mathrm{M})$ was added and the samples were vortexed. Product was evaluated by spectroscopy at A405 nm. Spectrophotometric blanks were prepared using the same volumes of assay buffer, vanadium as either orthovanadate or decavanadate, and substrate as experimental samples. The enzyme source was replaced with brain heart infusion, the same medium the enzyme was in for kinetic and inhibition assays. Data are reported as mean \pm standard deviation for $\mathrm{n}=4$ replicates.

\section{Secreted Acid Phosphatase Enzyme Inhibition Assays with Pretreatment with Eelectric Fields Followed by Incubation with and without Orthovanadate (25 $\mu \mathrm{M})$}

To test the effect of pretreating $L$. tarentolae log phase cell supernatant with electric fields followed by incubation with orthovanadate $(25 \mu \mathrm{M})$, supernatant was collected $(50 \mathrm{~mL})$ from the stationary phase of the growth curve, exposed to electric fields, and then used as the enzyme source for end point acid phosphatase assays. This concentration of orthovanadate was selected based on the experiments done using the model reported by Baumhardt et al., 2015. This concentration of orthovanadate inhibits L. tarentolae secreted acid phosphatase activity, but does not completely shut down the enzyme. Thus, if a synergistic effect occurs between orthovanadate and electric field application, and is large enough, it can be measured. The order of addition of material to the assay was as follows. Sodium acetate buffer $(0.5 \mathrm{M}, \mathrm{pH} 4.5)$, orthovanadate freshly prepared in assay buffer, and enzyme source $(300 \mu \mathrm{L})$ were added to $1.5 \mathrm{~mL}$ polypropylene tubes for the assay and allowed to preincubate at room temperature for 10 minutes. The artificial substrate, para-nitrophenylphosphate ( $p N P P)$ was added to the assay to give a final concentration of $391 \mu \mathrm{M} p \mathrm{NPP}$. The final assay volume was $0.9 \mathrm{~mL}$. Assays were incubated at room temperature for 23 hours. To stop the reaction sodium hydroxide $(100 \mu \mathrm{L}$, 
$10 \mathrm{M}$ ) was added and the samples were vortexed, and product was evaluated by spectroscopy A405 nm.

\section{Secreted Acid Phosphatase Kinetics Assay with and without the Preincubation with a Glycosidase, Followed by Pretreatment with and without Electric Fields}

The L. tarentolae log phase cell supernatant was collected via centrifugation (2000xg, 10 min, $\left.10^{\circ} \mathrm{C}\right)$, incubated with the glycosidase PNGase $\mathrm{F}(10 \mu \mathrm{L}$ of PNGase F with activity of 10 $\mathrm{U} / \mu \mathrm{L}$ per $25 \mathrm{~mL}$ enzyme pool; Promega Madison, WI) enzyme source for 24 hours at room temperature, and then this enzyme pool was used in kinetic assays. The order of addition of material to the assay was as follows. Sodium acetate buffer (500 $\mu \mathrm{L}, 0.5 \mathrm{M}, \mathrm{pH} 4.5)$ was added to $1.5 \mathrm{~mL}$ polypropylene tubes. The artificial substrate, para-nitrophenylphosphate ( $p \mathrm{NPP}$ ), was freshly prepared in buffer, then it was added to the assay to give final substrate concentrations of: 2.0, 2.6, 3.0, 3.4, 3.7, 4.1, 4.5, 6.0, 8.8, 12.0, 14.0, 18.0, 150.0, 200.0, 250.0, 300.0, 350.0, 400.0, $450.0,500.0,550.0,1000.0,2000.0$, or $4000.0 \mu \mathrm{M}$. Lastly, L. tarentolae cell supernatant as enzyme source $(300 \mu \mathrm{L})$ was added to the $1.5 \mathrm{~mL}$ polypropylene tubes. The final assay volume was $0.9 \mathrm{~mL}(\mathrm{n}=3)$. Assays were incubated at room temperature for 23 hours (previously determined to be under apparent first order conditions (Mendez et al., 2014), in the dark. To stop the reaction, sodium hydroxide $(100 \mu \mathrm{L}, 10 \mathrm{M})$ was added and the samples were vortexed. Product was evaluated by spectroscopy (A405 nm). Spectrophotometric blanks were prepared using the same volumes of assay buffer and substrate as experimental samples, but the enzyme source was replaced with brain heart infusion medium, the same medium as the supernatant fraction, but not exposed to cells. 


\section{CHAPTER III}

\section{RESULTS AND DISCUSSION}

\section{Cell Culture of L. tarentolae and Assessment of Cell Viability by the MTT Viability Assay}

During their growth curve, L. tarentolae respond in a predictable manner to the MTT

reagent. This predictable and repeatable response is useful as a metric because it gives a context

for normal L. tarentolae behavior, and serves a reference point from which enzyme pools, whole cells or cell supernatant, are collected. Furthermore, knowing what phase of the growth curve cells are in is useful because it allows more accurate interpretation of an effective potential treatment. Figure 8 shows a typical growth curve with the four characteristic phases of in vitro cell growth exhibited by L. tarentolae.

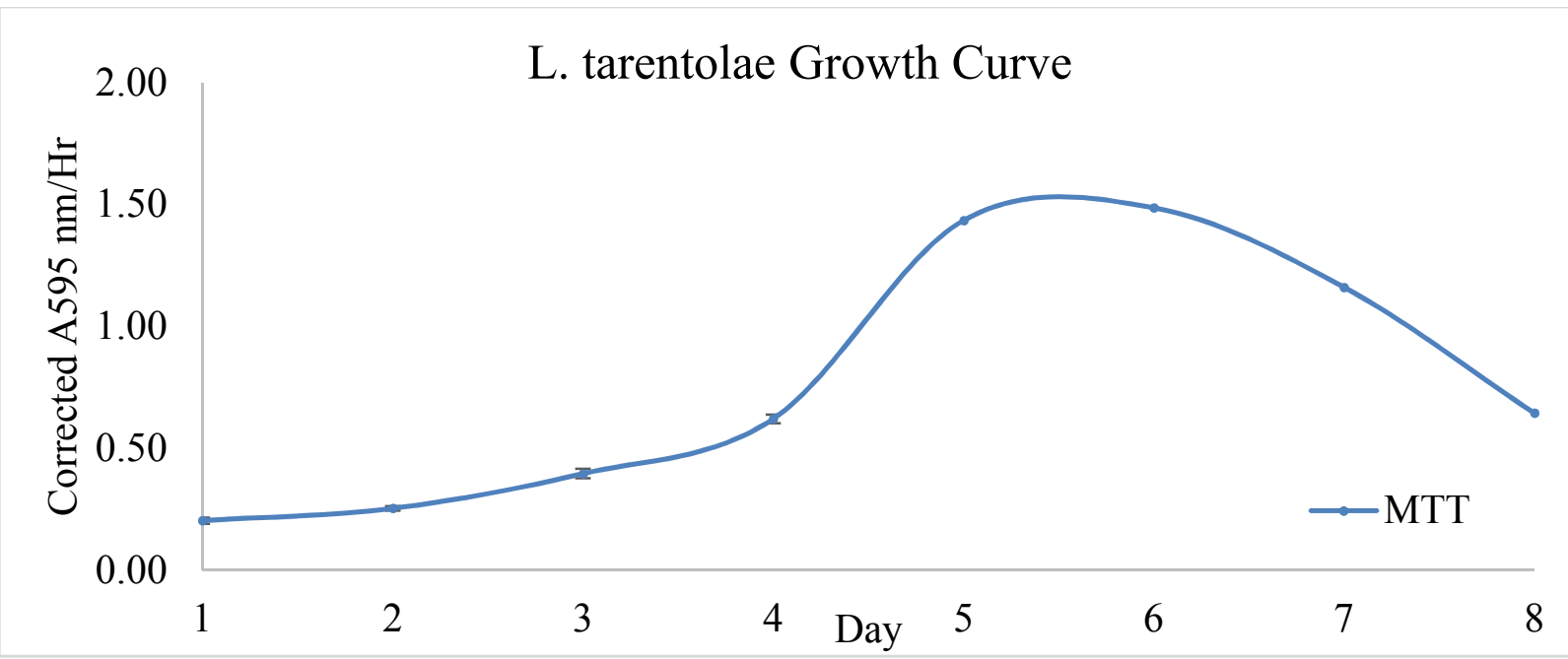

Figure 8. A typical growth curve for L. tarentolae with the corrected MTT response plotted on the $\mathrm{Y}$-axis and the day in culture plotted on the $\mathrm{X}$-axis. The lag phase occurs on days 1-3. The $\log$ phase occurs on days 4-5. The stationary phase occurs between days 5-6. The senescence phase occurs on days 6-8. Each point is the mean \pm standard deviation of $n=4$ replicates 


\section{Microscopy of L. tarentolae}

During their growth curve, L. tarentolae exhibit typical behavior that is observable by light microscopy. During the lag phase (days 1-3), the cells have a distinct, elongated shape, and do not clump. The cells exhibit moderate motility, and the cell population does not appear to be over crowded (Figure 9). During the log phase (days 4-5), the cells have a distinct, elongated shape, and do not clump. The cells exhibit increased motility, and the cell population appears significantly more crowded. Cells exhibit no clumping during this phase (Figure 10). During the stationary phase (between days 5-6), the shapes of most cells are still distinct and elongated. Some cells begin to appear rounded, and the cell population exhibits variable motility. Some cells are moving rapidly, while other cells are not moving at all. The cell population still appears crowded during the stationary phase. Cells exhibit clumping during the stationary phase. Each cell clump contains between 3 and 10 cells (Figure 11). During the senescence phase (days 6-8), the shape of cells becomes increasingly more rounded as the culture ages. The cells that appear more rounded in shape, also appear to not be moving. The cells that are more elongated are still moving, but with decreasingly less rigor. The cell population appears crowded, but the majority of cells are rounded and not moving. Little or no clumping is observed during this phase of the growth curve (Figure 12). 


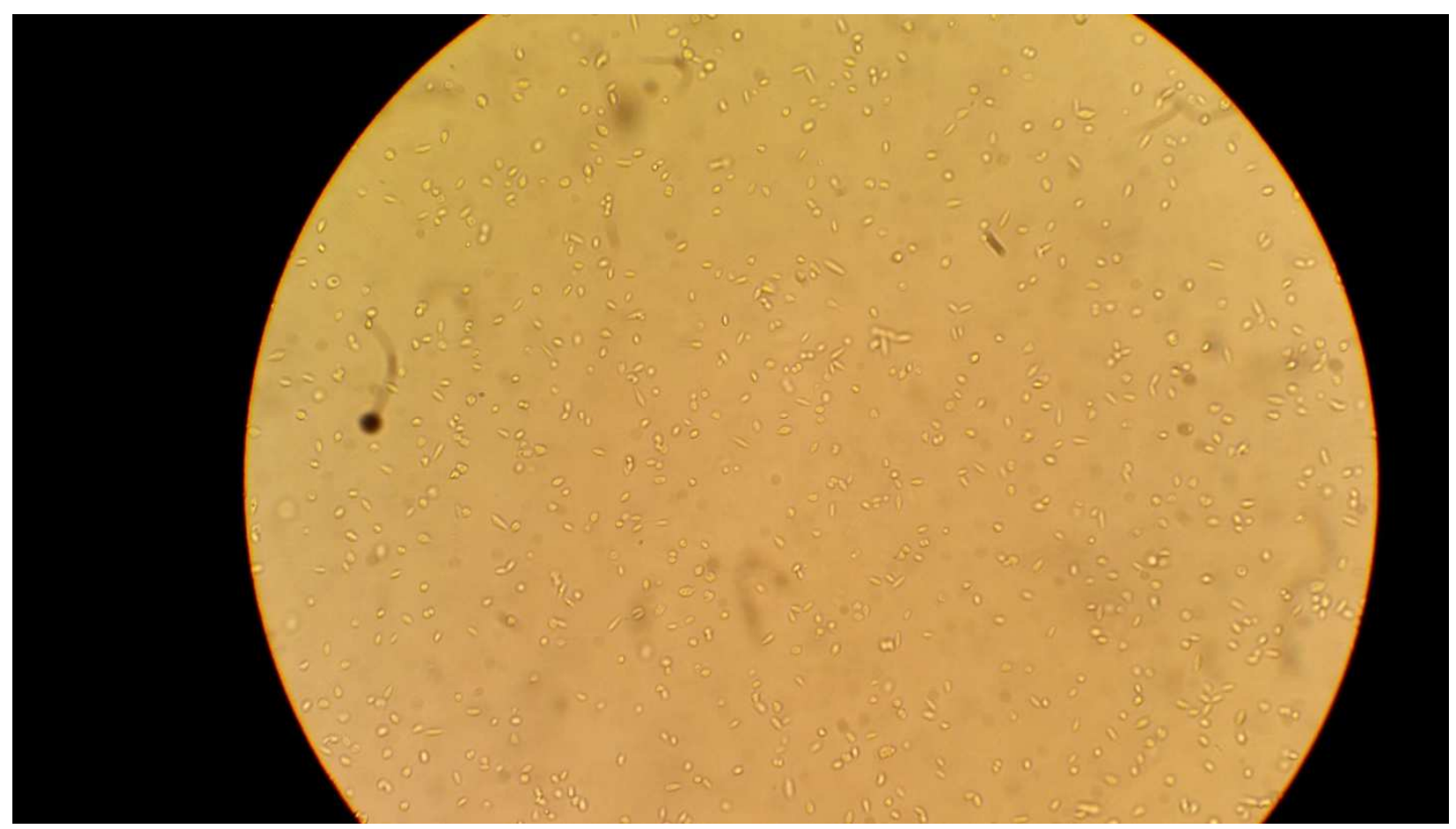

Figure 9. The above image depicts L. tarentolae by microscopy (400X) during the lag phase of their growth curve

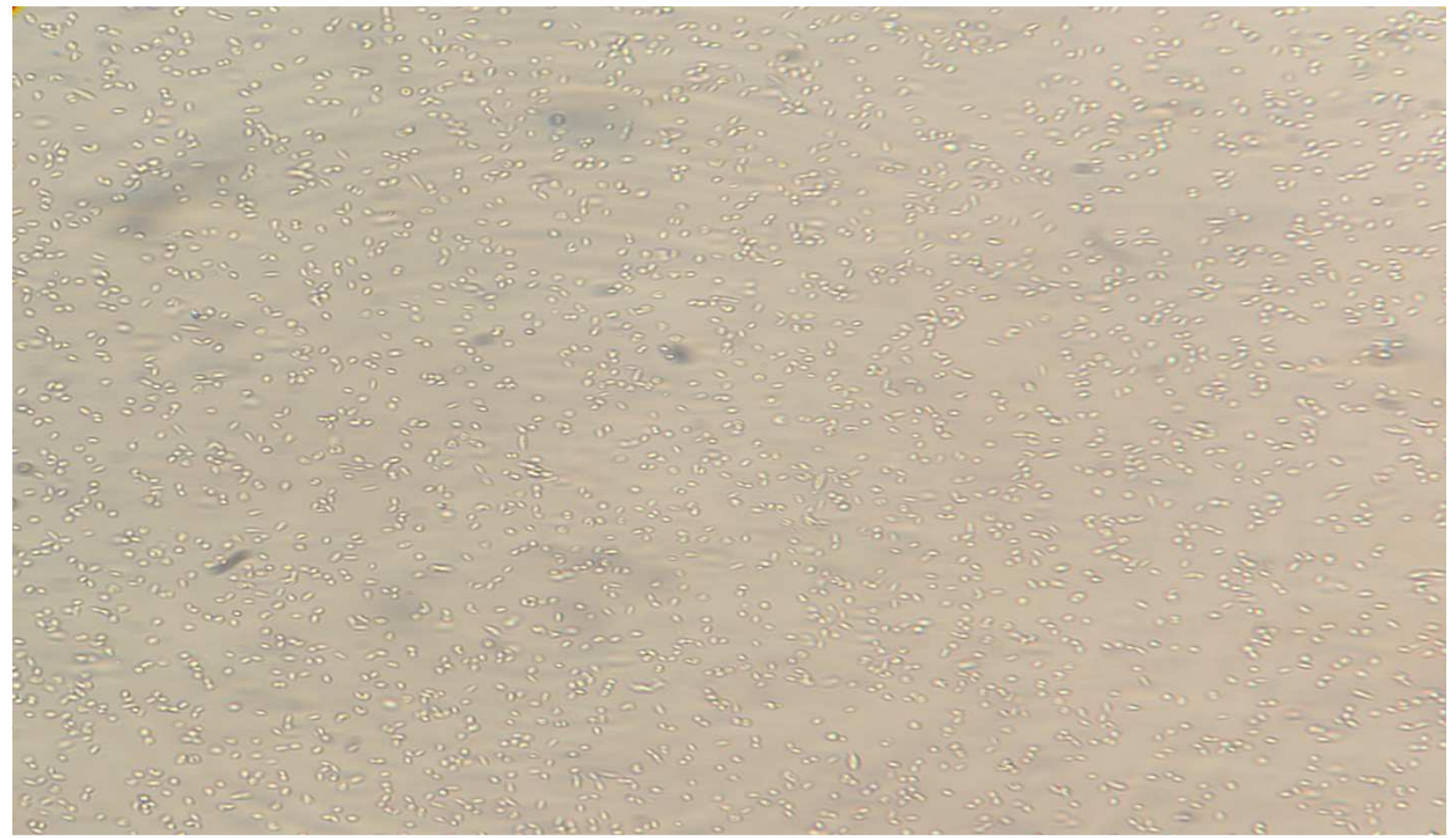

Figure 10. The above image depicts L. tarentolae by microscopy (400X) during the log phase of their growth curve 


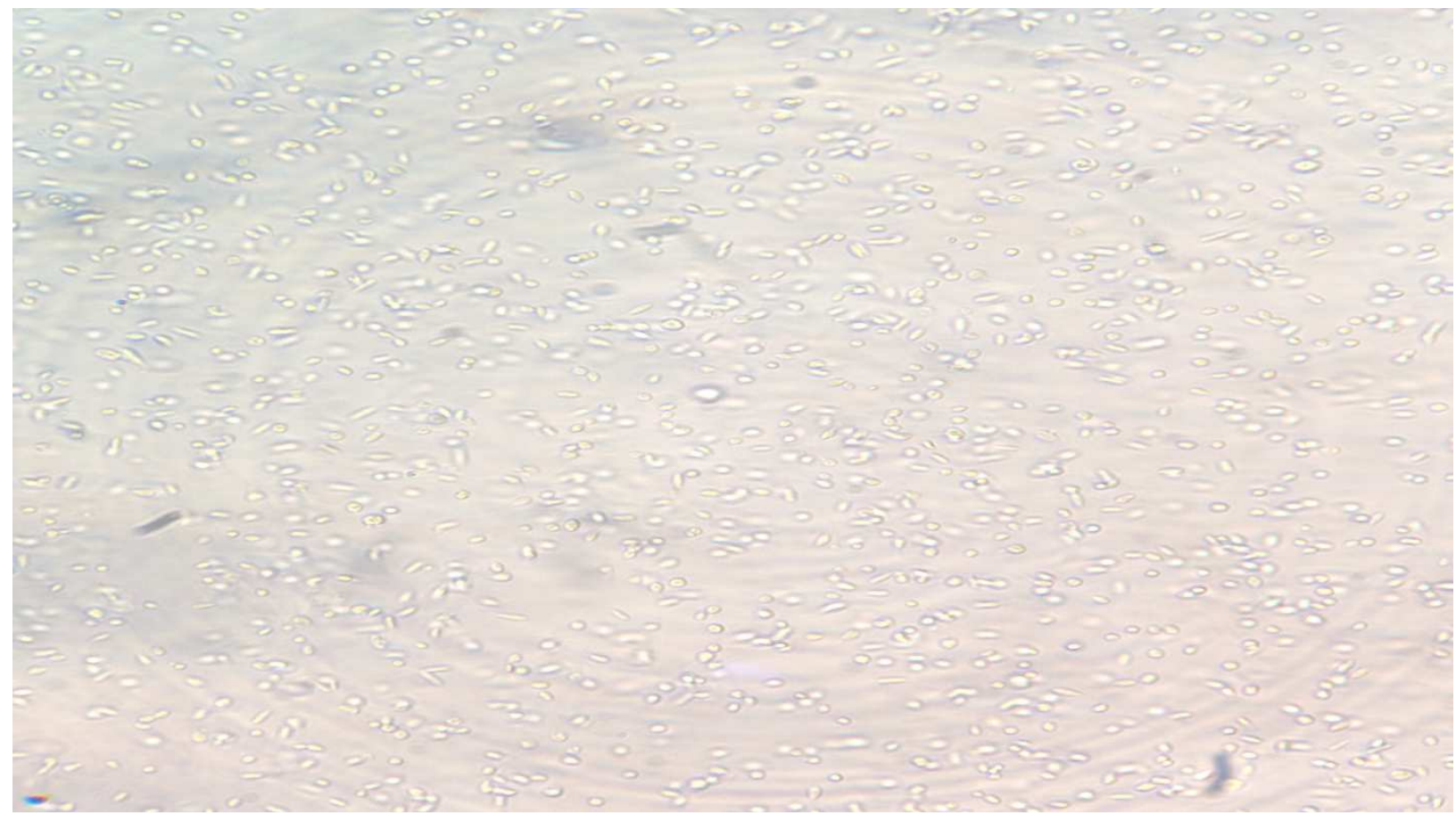

Figure 11. The above image depicts L. tarentolae by microscopy (400X) during the stationary phase of their growth curve

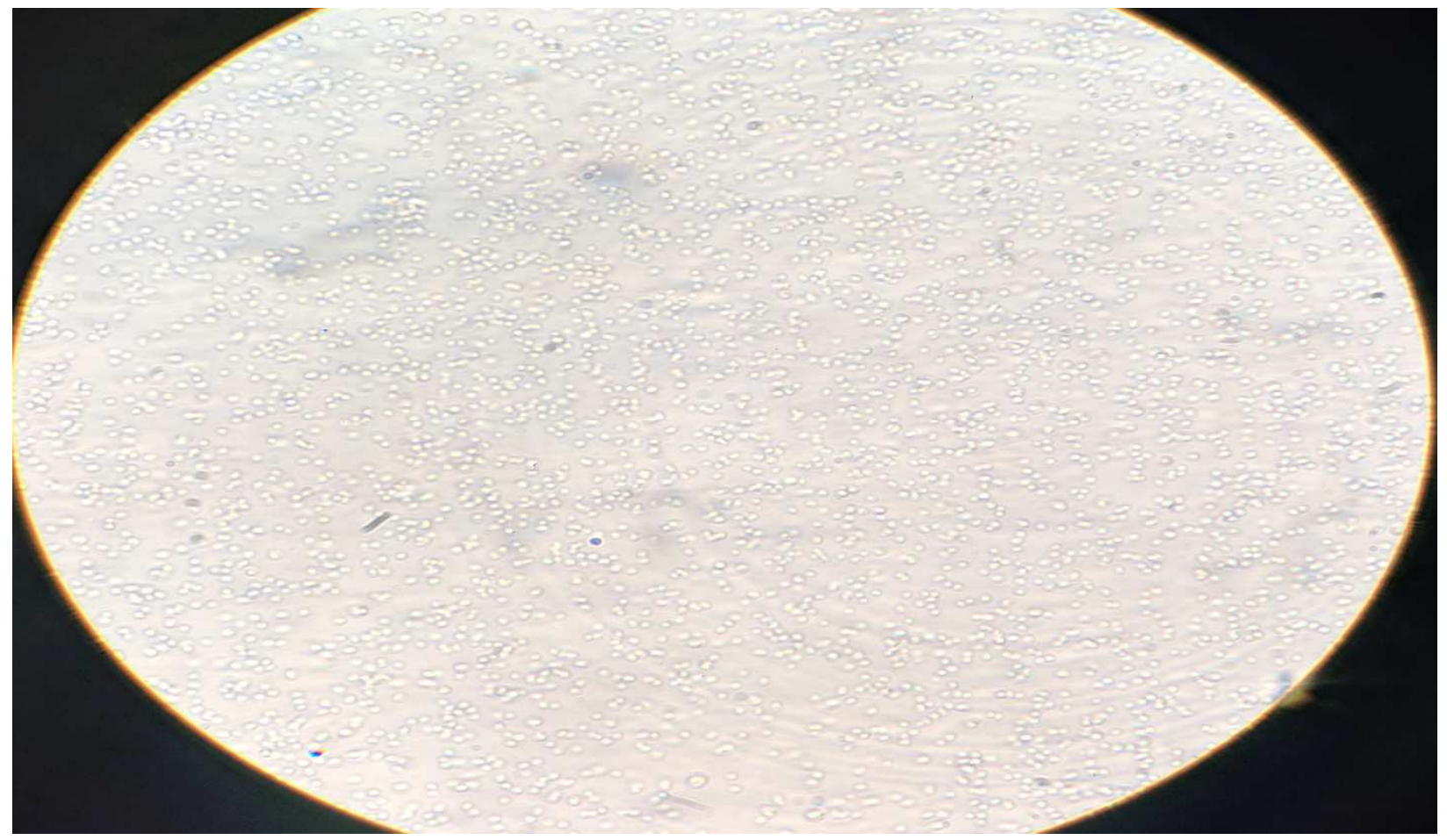

Figure 12. The above image depicts L. tarentolae by microscopy (400X) during the senescence phase of their growth curve 


\section{Secreted Acid or Alkaline Phosphatase Enzyme Assay}

Using the growth curve as a reference point, detectable secreted acid phosphatase activity tracks with the MTT response up to day 6, as shown in Figure 13. When the cells' response to the MTT reagent decreases, the detectable secreted acid phosphatase activity plateaus (days 6-8). Alkaline phosphatase activity in the supernatant was not detectable during any point of the 8 day growth curve, as shown in Figure 13.

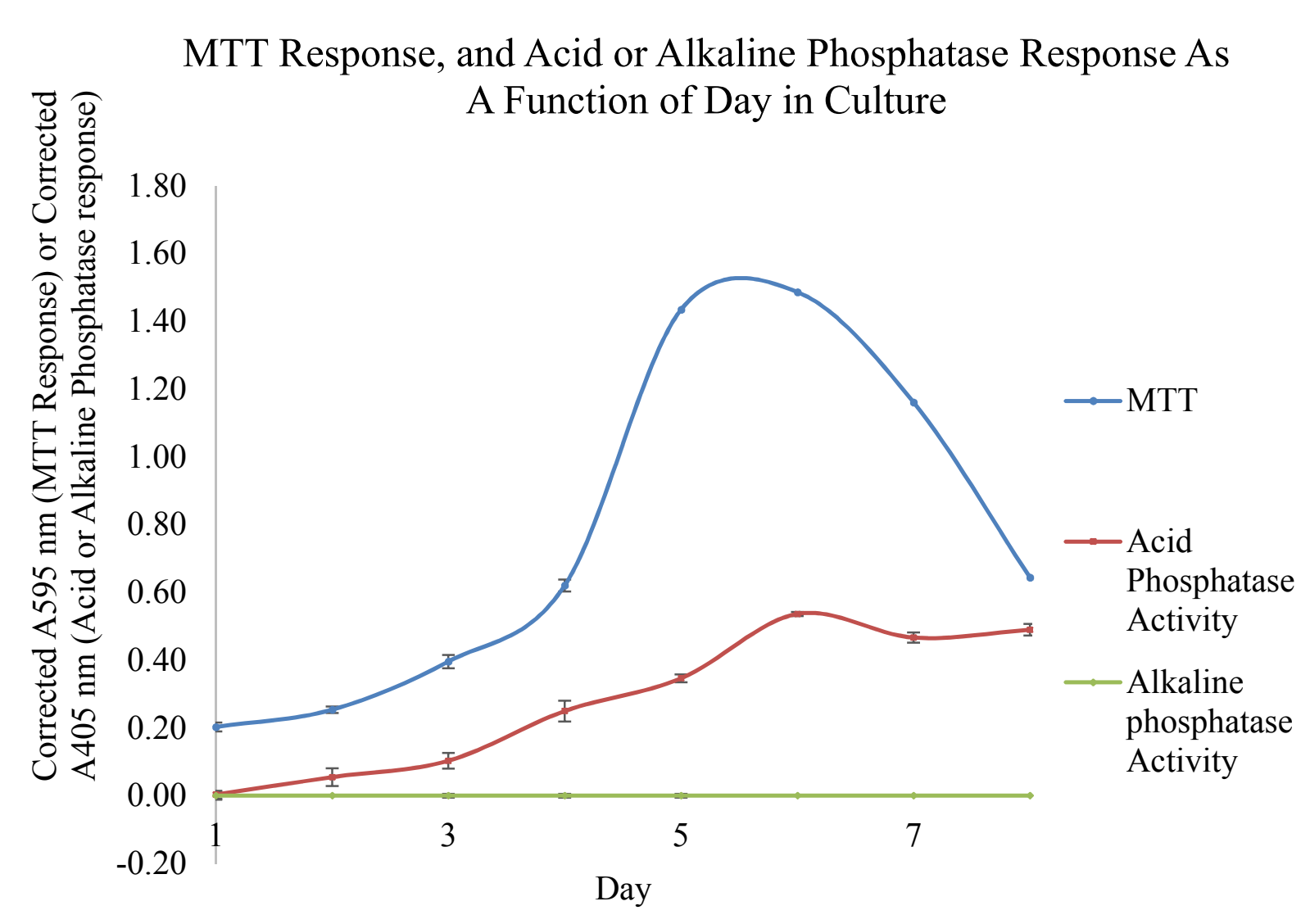

Figure 13. Secreted acid (red curve) or secreted alkaline (lime green curve) phosphatase activity detected as a function of day in culture. The blue curve is the typical L. tarentolae growth curve evaluated by MTT response. Each point is the mean \pm standard deviation of $n=3$ replicates 


\section{Kinetic Enzyme Assay}

The L. tarentolae log phase supernatant appeared to exhibit Michaelis-Menten type enzyme behavior as a response to increasing substrate concentrations (Figure 14). The response depicts an apparent first order portion with a large response to increases in substrate concentration. This apparent first order response is followed by a decreased response to increasing substrate concentration, thus indicating that $\mathrm{V}_{\mathrm{MAX}}$ is being approached by the enzyme pool. A noticeable derivation from the apparent first order trend occurs at $350 \mu \mathrm{M} p \mathrm{NPP}$ (indicated by arrow) was, however, suggestive of non-Michaelis-Menten behavior. It should be noted that in this work, $\mathrm{V}_{\text {MAX }}$ data are not corrected for total amount of enzyme present.

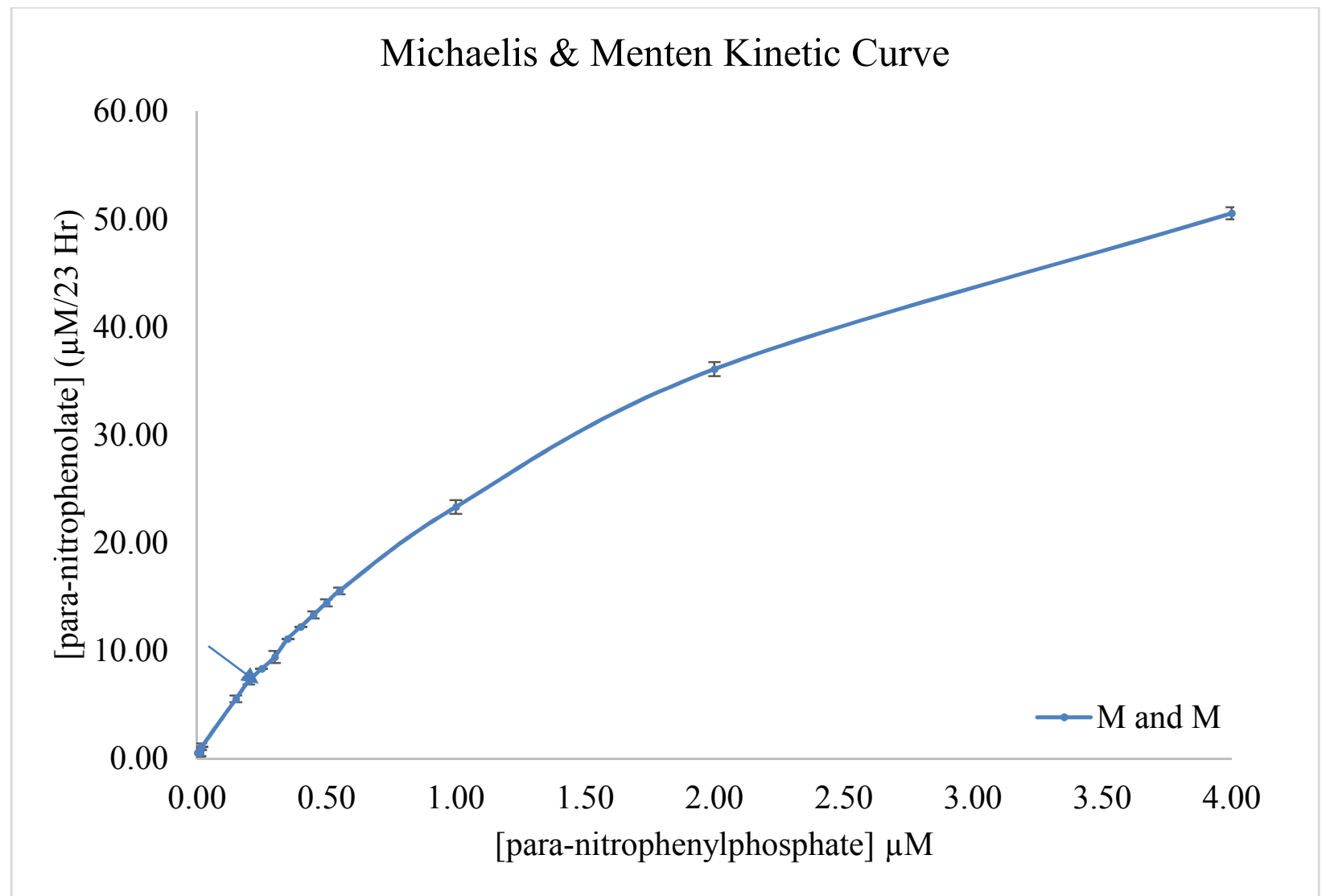

Figure 14. A typical V versus $\mathrm{S}$ curve utilizing L. tarentolae log phase supernatant as the enzyme source. Each point is the mean \pm standard deviation of $n=3$ replicates 
The Lineweaver-Burk linear transformation of the Michaelis-Menten curve, that typically produces a single line for a single enzyme source, produced two different lines for the $L$. tarentolae log phase supernatant (Figures 15, 16, and 17).

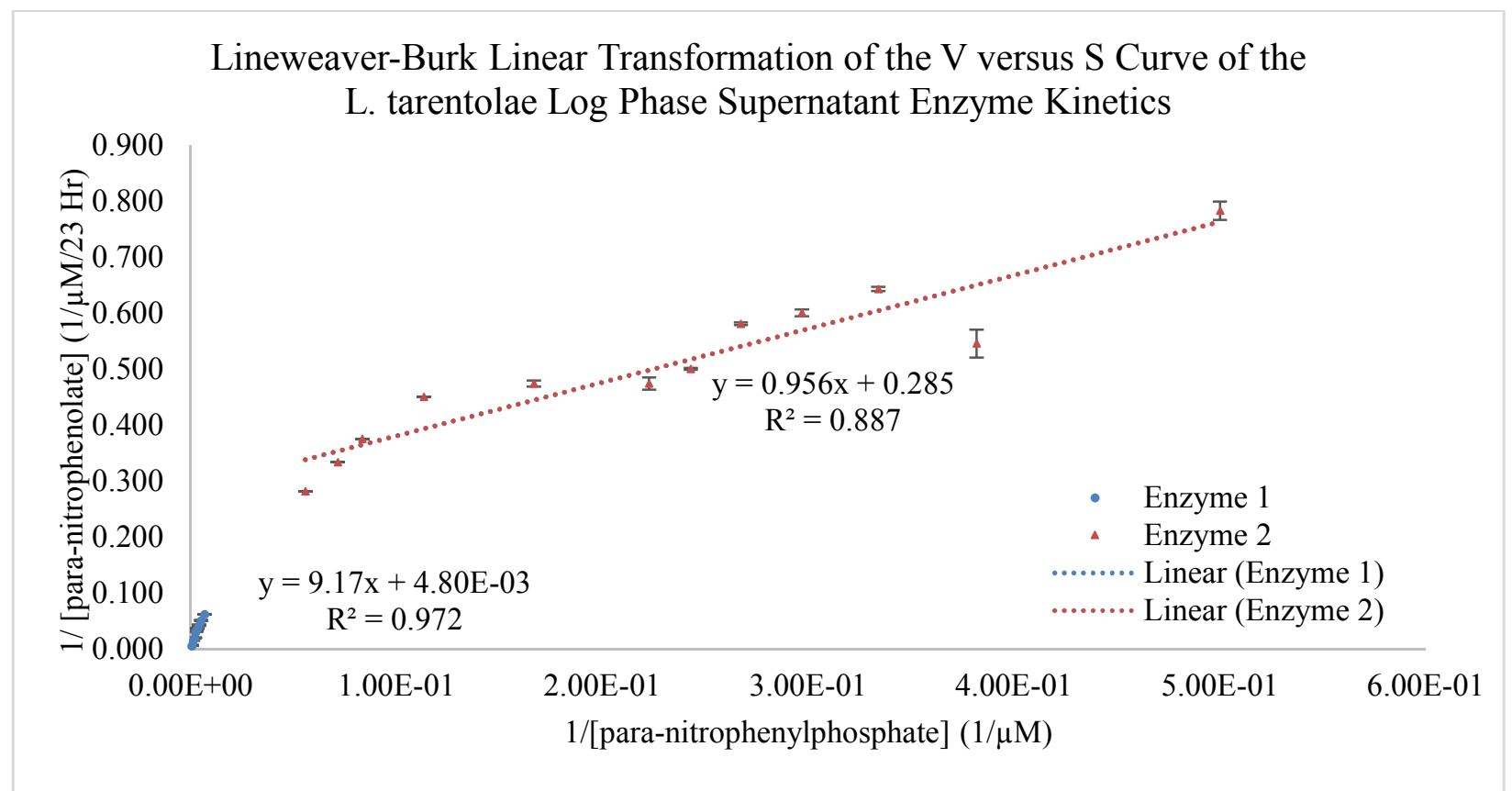

Figure 15. A typical Lineweaver-Burk linear transformation using L. tarentolae log phase supernatant as the enzyme source. Enzyme 1 is shown in blue circles. Enzyme 2 is shown in red triangles. Each point is the mean \pm standard deviation of $n=3$ replicates 


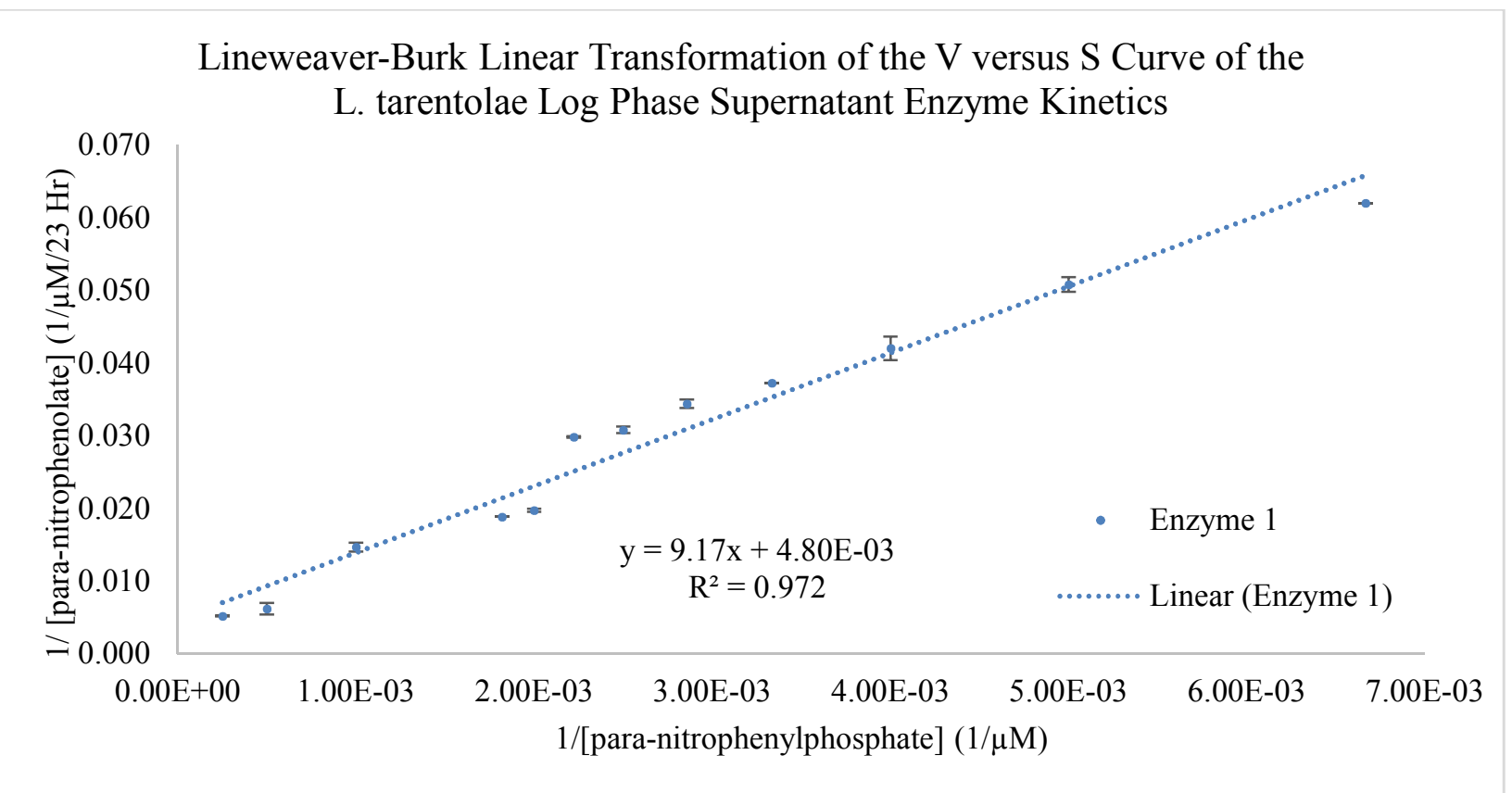

Figure 16. A typical Lineweaver-Burk linear transformation using L. tarentolae log phase supernatant as the enzyme source. This graph only depicts the response of Enzyme 1 with $n=12$ points. Each point is the mean \pm standard deviation of $n=3$ replicates

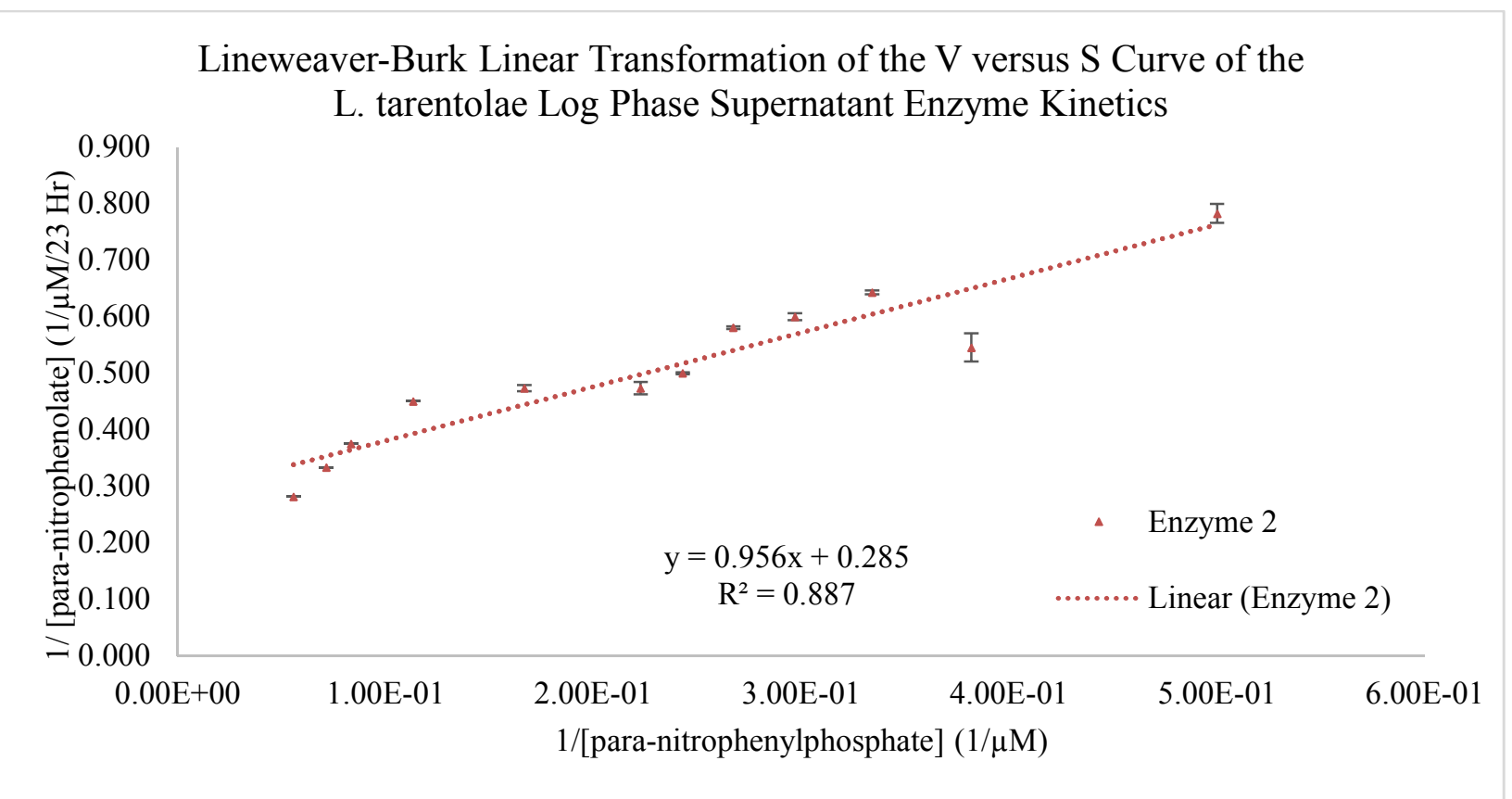

Figure 17. A typical Lineweaver-Burk linear transformation using L. tarentolae log phase supernatant as the enzyme source. This graph only depicts the response of Enzyme 2 with $n=12$ points. Each point is the mean \pm standard deviation of $n=3$ replicates 
Enzyme 1 is present and detectable during the course of the entire eight day growth curve (Figure 18). The $\mathrm{k}_{\mathrm{M}}$ value for enzyme 1 changes subtly as a function of day in culture. The $\mathrm{V}_{\mathrm{MAX}}$ value of enzyme 1 changes with culture age (Table 2 and Figure 18). This change, up to day five of the L. tarentolae growth curve, is likely due to increasing cell number, and thus increasing amount of total secreted enzyme. The apparent disconnect between the number of viable cells and calculated $\mathrm{V}_{\mathrm{Max}}$ value of enzyme 1 that occurs on day 6-8 of the $L$. tarentolae growth curve may be explained in two ways. It could be that enzyme 1 is resistant to being denatured and remains active once secreted into the culture medium. It could also be the case that enzyme 1 is stored in L. tarentolae whole cells, and is released upon their death, thus leading to a plateau in the calculated $V_{\text {MAX }}$ value of enzyme 1, due to an approximately constant amount of enzyme 1 being present in the culture medium. Incubation of day 8 supernatant with the glycosidase, that has recognition for $\mathrm{N}$-linked carbohydrates, noticeably changed experimental $\mathrm{k}_{\mathrm{M}}$ and $\mathrm{V}_{\mathrm{MAX}}$ values of enzyme 1 relative to the non-glycosidase treated supernatant. The $\mathrm{k}_{\mathrm{M}}$ decreased by 24.4 $\%$, and the $\mathrm{V}_{\text {MAX }}$ increased by $13.5 \%$ (Table 2). 


\begin{tabular}{|c|c|c|}
\hline Day in culture & $\mathrm{K}_{\mathrm{M}}(\mu \mathrm{M})$ & $\begin{array}{c}\mathrm{V} \\
(\mu \mathrm{M} / 23 \mathrm{Hr})\end{array}$ \\
\hline 1 & $1.36 \mathrm{E} 03 \pm 1.3 \mathrm{E} 02$ & $54.9 \pm 1.1 \mathrm{E}-01$ \\
\hline 2 & $1.27 \mathrm{E} 03 \pm 1.0 \mathrm{E} 02$ & $57.1 \pm 1.0 \mathrm{E}-01$ \\
\hline 3 & $1.11 \mathrm{E} 03 \pm 9.1 \mathrm{E} 01$ & $63.3 \pm 9.0 \mathrm{E}-01$ \\
\hline 4 & $1.27 \mathrm{E} 03 \pm 9.0 \mathrm{E} 01$ & $69.4 \pm 6.1 \mathrm{E}-01$ \\
\hline 5 & $1.91 \mathrm{E} 03 \pm 1.3 \mathrm{E} 02$ & $208 \pm 1.0 \mathrm{E} 01$ \\
\hline 6 & $1.56 \mathrm{E} 03 \pm 6.0 \mathrm{E} 01$ & $159 \pm 7.0$ \\
\hline 7 & $1.10 \mathrm{E} 03 \pm 3.0 \mathrm{E} 01$ & $200 \pm 8.0$ \\
\hline 8 & $1.28 \mathrm{E} 03 \pm 5.0 \mathrm{E} 01$ & $227 \pm 50$ \\
\hline $8+$ Glycosidase & $968 \pm 1.3 \mathrm{E} 02$ & 29.0 \\
\hline
\end{tabular}

Table 2. The calculated $\mathrm{k}_{\mathrm{M}}$ and $\mathrm{V}_{\mathrm{MAX}}$ values for enzyme 1 from L. tarentolae as a function of day in culture

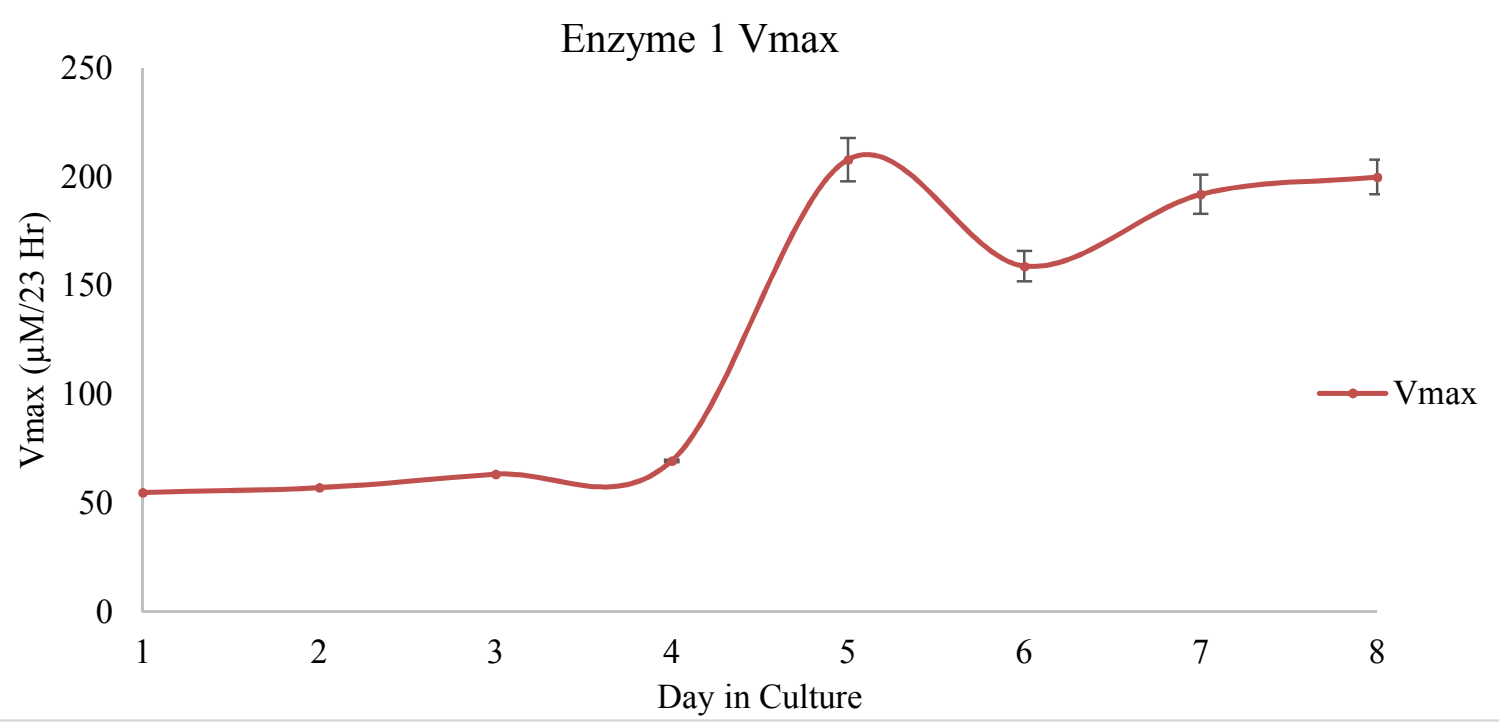

Figure 18. A plot of calculated $\mathrm{V}_{\mathrm{MAX}}$ value (Y-axis) for enzyme 1 as a function of day in culture (X-axis). This value is not a simple function of culture age. Each point is the mean \pm standard deviation of $n=3$ replicates 
Enzyme 2 is not detectable during the first two days of the L. tarentolae growth curve, but becomes detectable on day 3 and remains detectable through day 8 . The $\mathrm{k}_{\mathrm{M}}$ value for enzyme 2 remains in the same order of magnitude from days 3-5 of culture. The $\mathrm{k}_{\mathrm{M}}$ values from days 6-8 indicating that enzyme becomes less efficient at binding substrate as the culture ages. The $\mathrm{V}_{\mathrm{MAX}}$ value of enzyme 2 remain consistent with culture age until senescence phase (Figure 19). There is a large increase in the $\mathrm{V}_{\mathrm{MAX}}$ value of enzyme 2 on day 7 of culture (Table 3). This change as shown in Figure 19 occurs during the senescence phase of the L. tarentolae growth curve, and may indicate that the total amount of enzyme 2 in the culture medium increases as cells die. This suggests that the majority of enzyme 2 is stored and is secreted upon external stimulus. Incubation with a glycosidase drastically increased experimental $\mathrm{k}_{\mathrm{M}}$ and $\mathrm{V}_{\mathrm{MAX}}$ values of enzyme 2. The $\mathrm{k}_{\mathrm{M}}$ increased by $92.5 \%$, and the $\mathrm{V}_{\mathrm{MAX}}$ increased by $93.4 \%$ compared to non-glycosidase incubated control. 


\begin{tabular}{|c|c|c|}
\hline $\begin{array}{c}\text { Day in } \\
\text { Culture }\end{array}$ & $\mathrm{K}_{\mathrm{M}}(\mu \mathrm{M})$ & $\begin{array}{c}\mathrm{V}_{\mathrm{MAX}} \\
(\mu \mathrm{M} / 24 \mathrm{Hr})\end{array}$ \\
\hline 1 & Not Detectable & Not Detectable \\
\hline 2 & Not Detectable & Not Detectable \\
\hline 3 & $2.26 \pm 7.20 \mathrm{E}-02$ & $3.40 \pm 2.00 \mathrm{E}-01$ \\
\hline 4 & $6.93 \pm 0.42$ & $3.51 \pm 2.9 \mathrm{E}-01$ \\
\hline 5 & $3.35 \pm 7.7 \mathrm{E}-02$ & $2.82 \pm 1.9 \mathrm{E}-01$ \\
\hline 6 & $10.3 \pm 8.1 \mathrm{E} 01$ & $16.2 \pm 7.0 \mathrm{E}-01$ \\
\hline 7 & $36.6 \pm 1.8$ & $7.63 \pm 8.4 \mathrm{E}-01$ \\
\hline 8 & $24.8 \pm 2.3$ & $115 \pm 17$ \\
\hline Glycosidase & $331 \pm 14$ & \\
\hline
\end{tabular}

Table 3. The calculated $\mathrm{k}_{\mathrm{M}}$ or $\mathrm{V}_{\mathrm{MAX}}$ values for enzyme 2 from L. tarentolae as a function of day in culture 


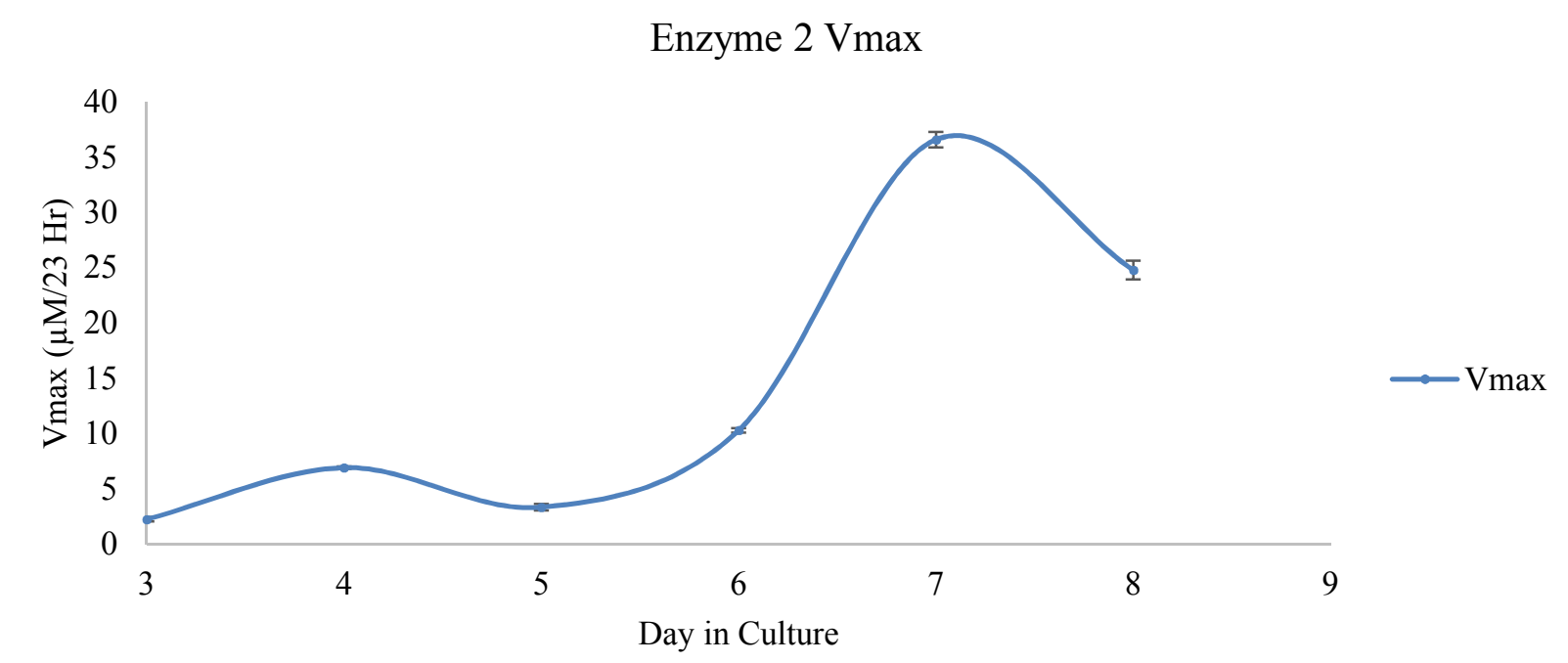

Figure 19. The calculated $\mathrm{V}_{\operatorname{MAX}}$ (Y-axis) value for enzyme 2 as a function of $L$. tarentolae day in culture (X-axis). Each point is the mean \pm standard deviation of $n=3$ replicates

\section{Testing the Acute Effects of Electric Fields on L. tarentolae Growth Curves and Microscopy}

The application of electric fields $(50 \mathrm{~Hz}$ or $10,000 \mathrm{~Hz}, 100-500 \mu \mathrm{A}, 30 \mathrm{~min}$, cathodic, or symmetric biphasic, or anodic waveforms) to L. tarentolae whole cells followed by the MTT viability assay led to no statistically significant results $(\mathrm{p}<, 0.05$ for paired, two tailed t-test; data not shown). The application of electric fields did lead to changes in cell clumping (Figures 2025). The effect of frequency is observed by comparing Figure 20 to Figures 21 and 22 . As the frequency increases from $50 \mathrm{~Hz}$ to $10,000 \mathrm{~Hz}$, the amount of cell aggregation (clumping) drastically increases. The effect of current is observed when comparing Figure 20 to Figures 21 and 23. There are no large differences between $100 \mu \mathrm{A}$ and $500 \mu \mathrm{A}$, but there is an increase in cell aggregation when comparing $50 \mathrm{~Hz}$ symmetric biphasic at $100 \mu \mathrm{A}$ (Figure 23) or $500 \mu \mathrm{A}$ (Figure 21) to control cells (Figure 20). The effect of waveform polarity is observed when comparing Figures 20 to Figures 23, 24, and 25. The application of any type of electric field causes an increase in cell aggregation. The largest effect on cell clumping caused by polarity 
differences is caused by a $50 \mathrm{~Hz}, 100 \mu \mathrm{A}$, anodic electric field (Figure 25). The application of this electric field not only caused aggregation of cells, but also caused them to clump. We interpret cell clumping as an indication that the cells are stressed.

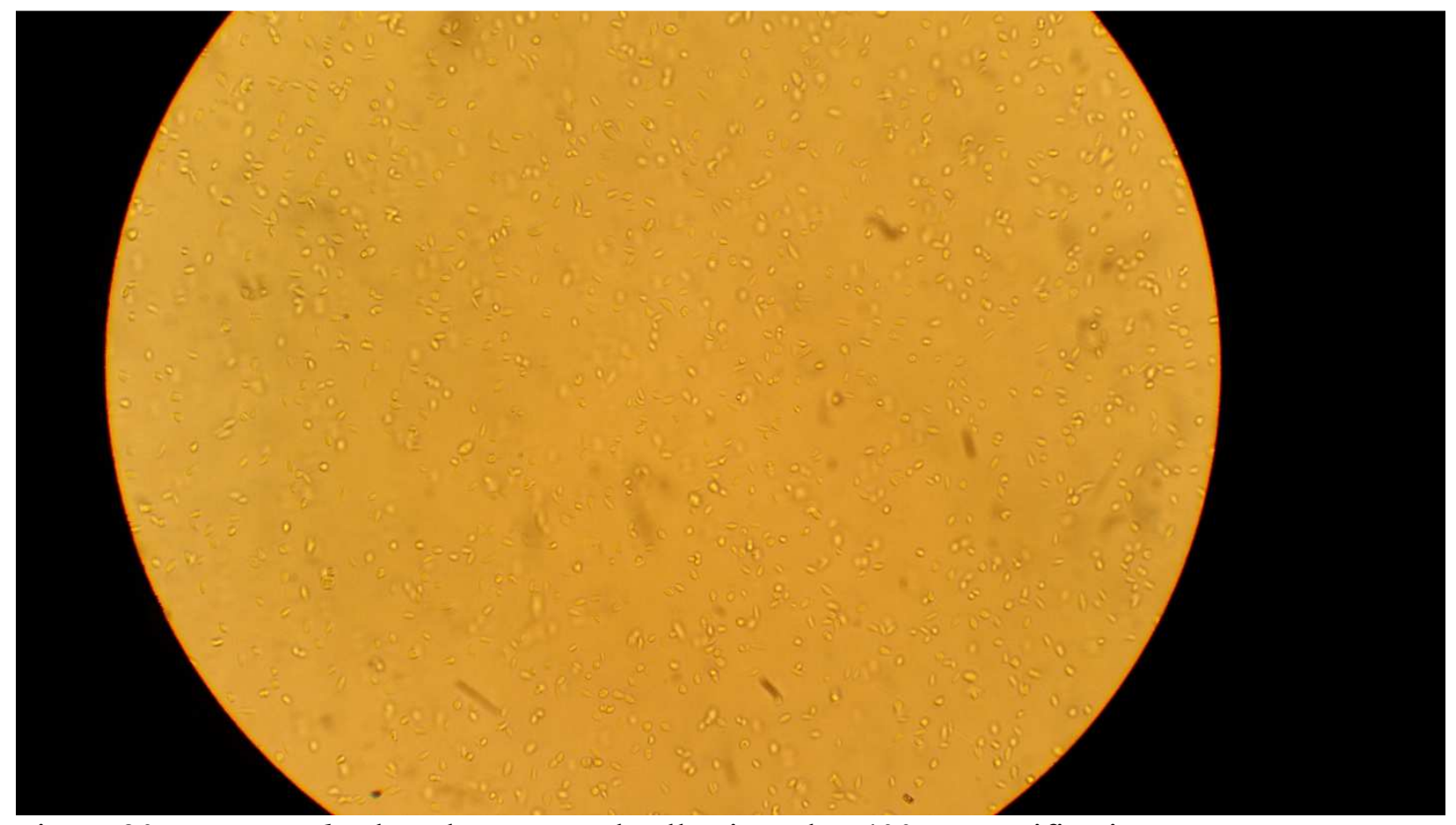

Figure 20. L. tarentolae lag phase control cells viewed at 400X magnification 


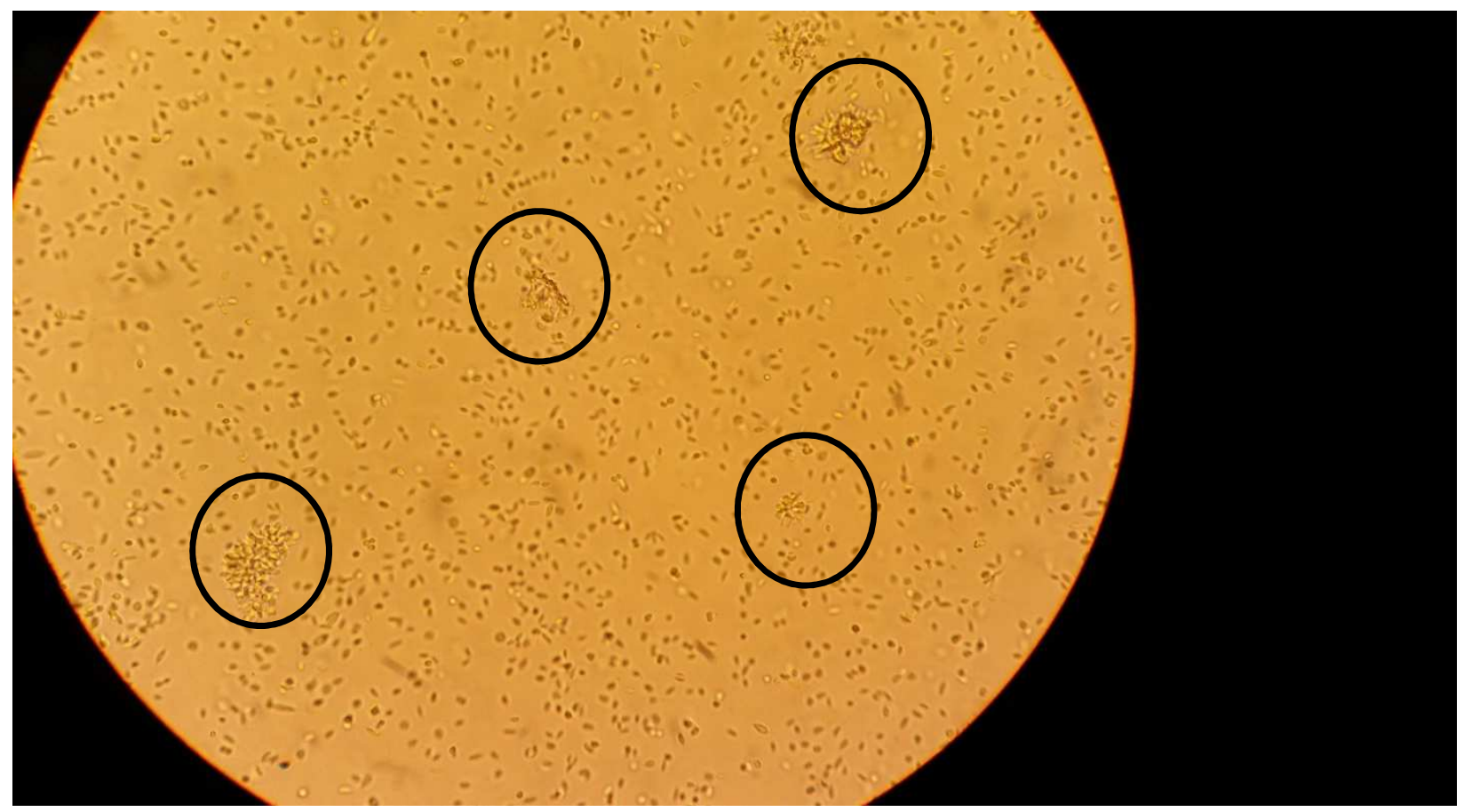

Figure 21. L. tarentolae lag phase cells exposed to an electric field $(50 \mathrm{~Hz}, 500 \mu \mathrm{A}, 30 \mathrm{~min}$, symmetric biphasic) viewed at $400 \mathrm{X}$ magnification. These cells exhibit several large clumps (circled areas)

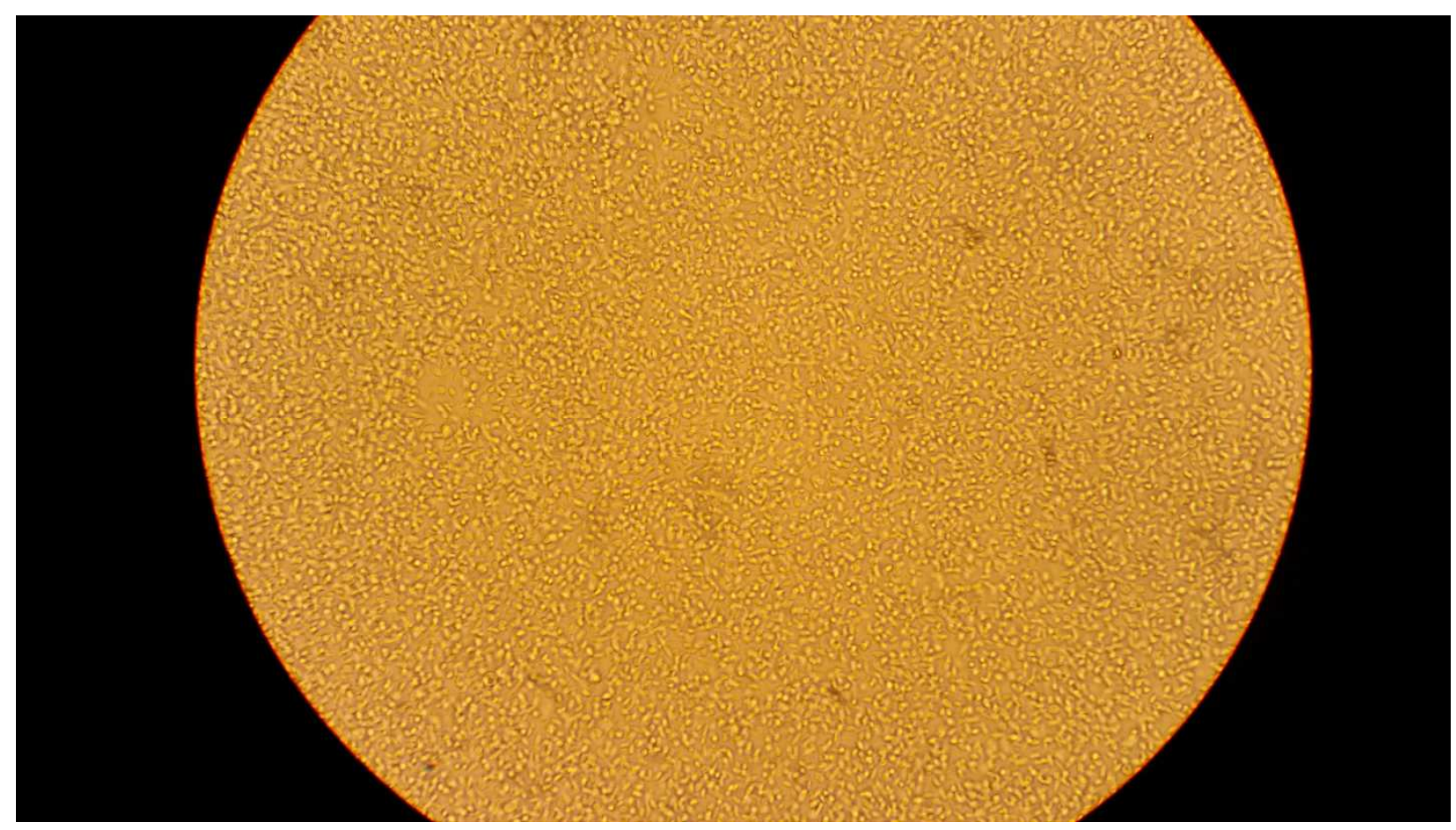

Figure 22. L. tarentolae lag phase cells exposed to an electric field $(10,000 \mathrm{~Hz}, 500 \mu \mathrm{A}, 30 \mathrm{~min}$, symmetric biphasic) viewed at $400 \mathrm{X}$ magnification. These cells are completely packed into a single area 
Figure 23. L. tarentolae lag phase cells exposed to an electric field $(50 \mathrm{~Hz}, 100 \mu \mathrm{A}, 30 \mathrm{~min}$, symmetric biphasic) viewed at $400 \mathrm{X}$ magnification. These cells are more concentrated than typical L. tarentolae lag phase cells

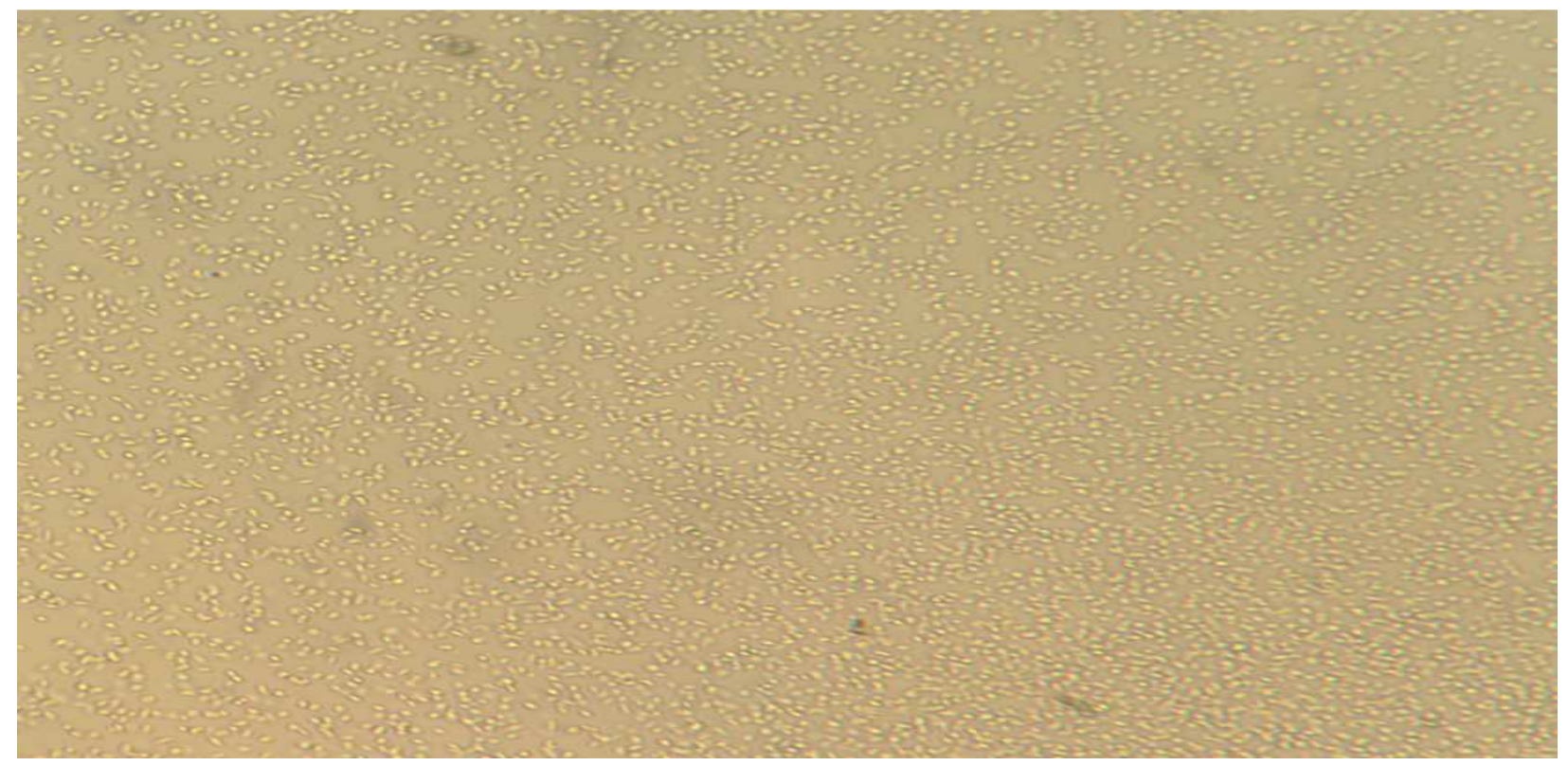

Figure 24. L. tarentolae lag phase cells exposed to an electric field $(50 \mathrm{~Hz}, 100 \mu \mathrm{A}, 30 \mathrm{~min}$, cathodic) viewed at $400 \mathrm{X}$ magnification. These cells are more concentrated than typical $L$. tarentolae lag phase cells 


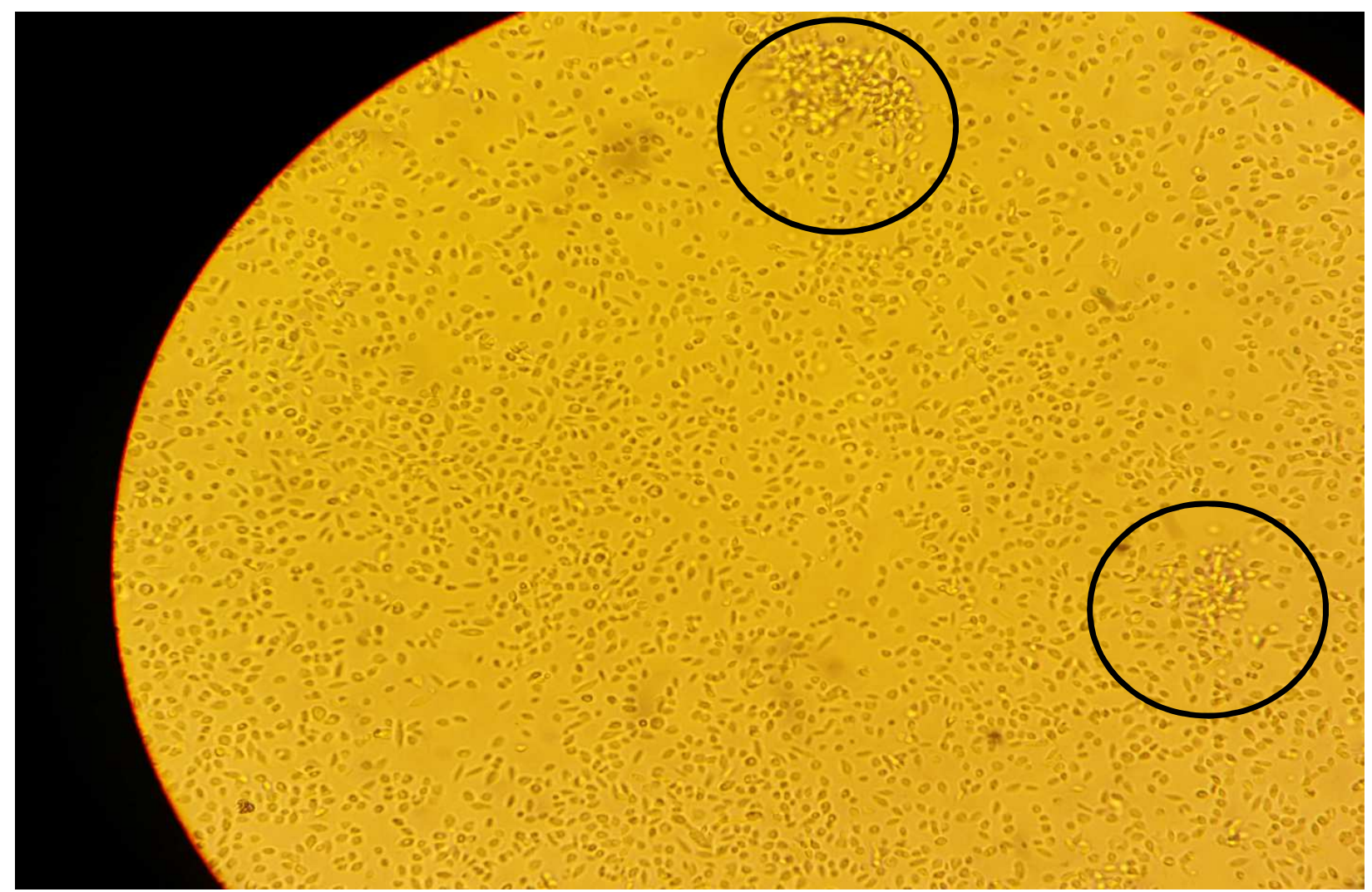

Figure 25. L. tarentolae lag phase cells exposed to an electric field (50 Hz, $100 \mu \mathrm{A}$, anodic) viewed at $400 \mathrm{X}$ magnification. The microscopic observations imply that the cells are moving toward the electrode during the electrode stimulation

\section{Testing the Effects of Electric Fields on L. tarentolae Acid Phosphatase Activity in}

\section{Supernatant or Pellet (Cells), Method 1}

In method 1, the L. tarentolae log phase cells are separated, then electric fields (7 different current conditions, 3 different wave forms, and 2 different frequencies) were applied to small volumes $(0.5-2.0 \mathrm{~mL})$ of resuspended cell pellets or harvested cell supernatants. The samples were then assayed for acid phosphatase activity. For data to be shown, the experimental condition must be statistically different from the non-treated control $(\mathrm{p}<0.05)$ in a paired, two tailed t-test. The data are plotted as percent different from same time control (Equation 8). A positive number means the treatment caused an increase in acid phosphatase activity compared 
to control. A negative number means the treatment caused a decrease in acid phosphatase activity compared to control.

Equation 8.

Percent Different $=($ Experimental Activity - Control Activity $) /($ Control Activity $) * 100 \%$

The application of a $50 \mathrm{~Hz}$, cathodic electric field (7 different current conditions) to $L$.

tarentolae supernatant or pellet followed by the assessment of acid phosphatase activity resulted in measurable effects in both the supernatant and pellet activity that were significantly different from their controls. Six out of seven conditions had an effect on supernatant acid phosphatase activity, but no consistent trend between current and supernatant activity was observed (Figure 26). Six out of seven conditions had an effect on pellet acid phosphatase activity, but no consistent trend between current and pellet activity was observed (Figure 27). The current conditions that affected both the supernatant and pellet acid phosphatase activity were 100, 150, 200,250 , or $400 \mu \mathrm{A}$. The 100,250 , or $400 \mu \mathrm{A}$ currents caused an increase in supernatant activity, and a decrease in pellet activity. The 150 or $200 \mu \mathrm{A}$ conditions caused an increase in both supernatant and pellet activity. All effects on either supernatant or pellet acid phosphatase activity were small ( $<6 \%$ different than control). 


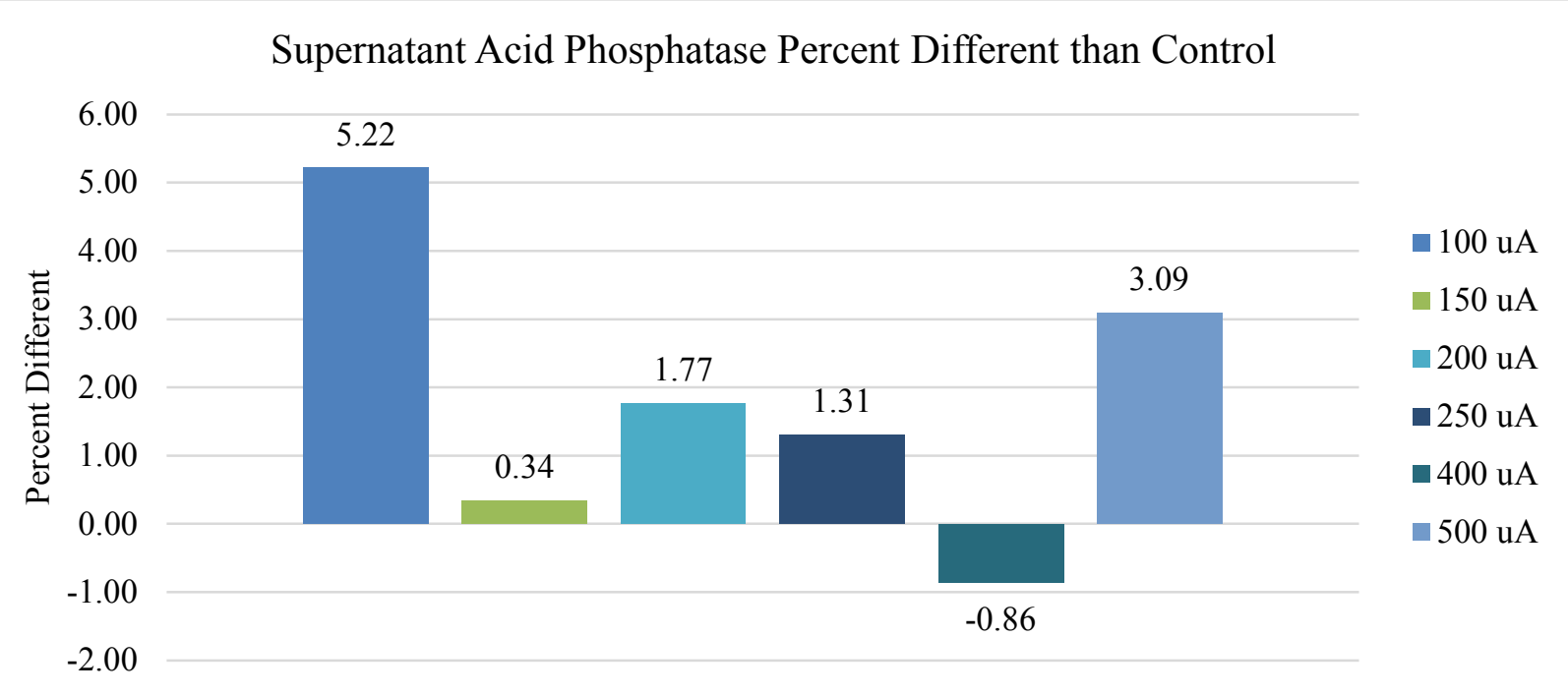

Figure 26. The effects of a $50 \mathrm{~Hz}$, cathodic electric field at various current exposures on $L$. tarentolae secreted acid phosphatase are plotted as percent different from same time control

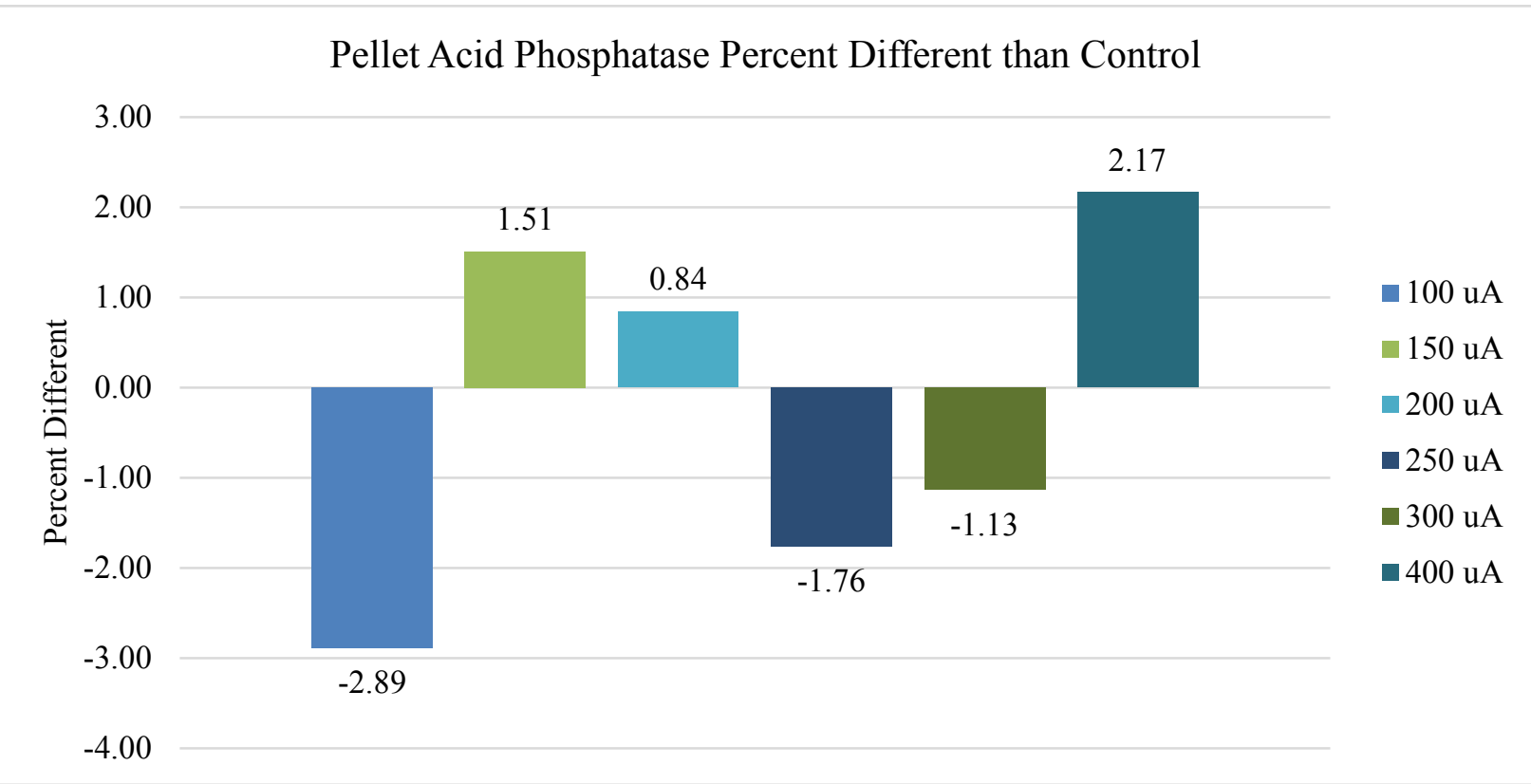

Figure 27. The effects of a $50 \mathrm{~Hz}$, cathodic electric field at various current exposures on $L$. tarentolae cell pellet acid phosphatase are plotted as percent different from same time control

The application of a $50 \mathrm{~Hz}$, symmetric biphasic electric field (7 different current conditions) to L. tarentolae supernatant or pellet followed by the assessment of acid phosphatase 
activity resulted in measurable effects in both the supernatant and pellet activity that were significantly different from their controls. Six out of seven conditions had an effect on supernatant acid phosphatase activity, but no consistent trend between current and supernatant activity was observed (Figure 28). Five out of seven conditions had an effect on pellet acid phosphatase activity, but no consistent trend between current and pellet activity was observed (Figure 29). The current conditions that affected both the supernatant and pellet acid phosphatase activity were $100,150,200$, or $400 \mu \mathrm{A}$. The 100 or $400 \mu \mathrm{A}$ currents caused an increase in supernatant activity, and a decrease in pellet activity. The $150 \mu \mathrm{A}$ condition caused an increase in both supernatant and pellet activity. The $200 \mu \mathrm{A}$ condition caused a decrease in both supernatant and pellet activity. All effects on either supernatant or pellet acid phosphatase activity were small ( $<7 \%$ different than control).

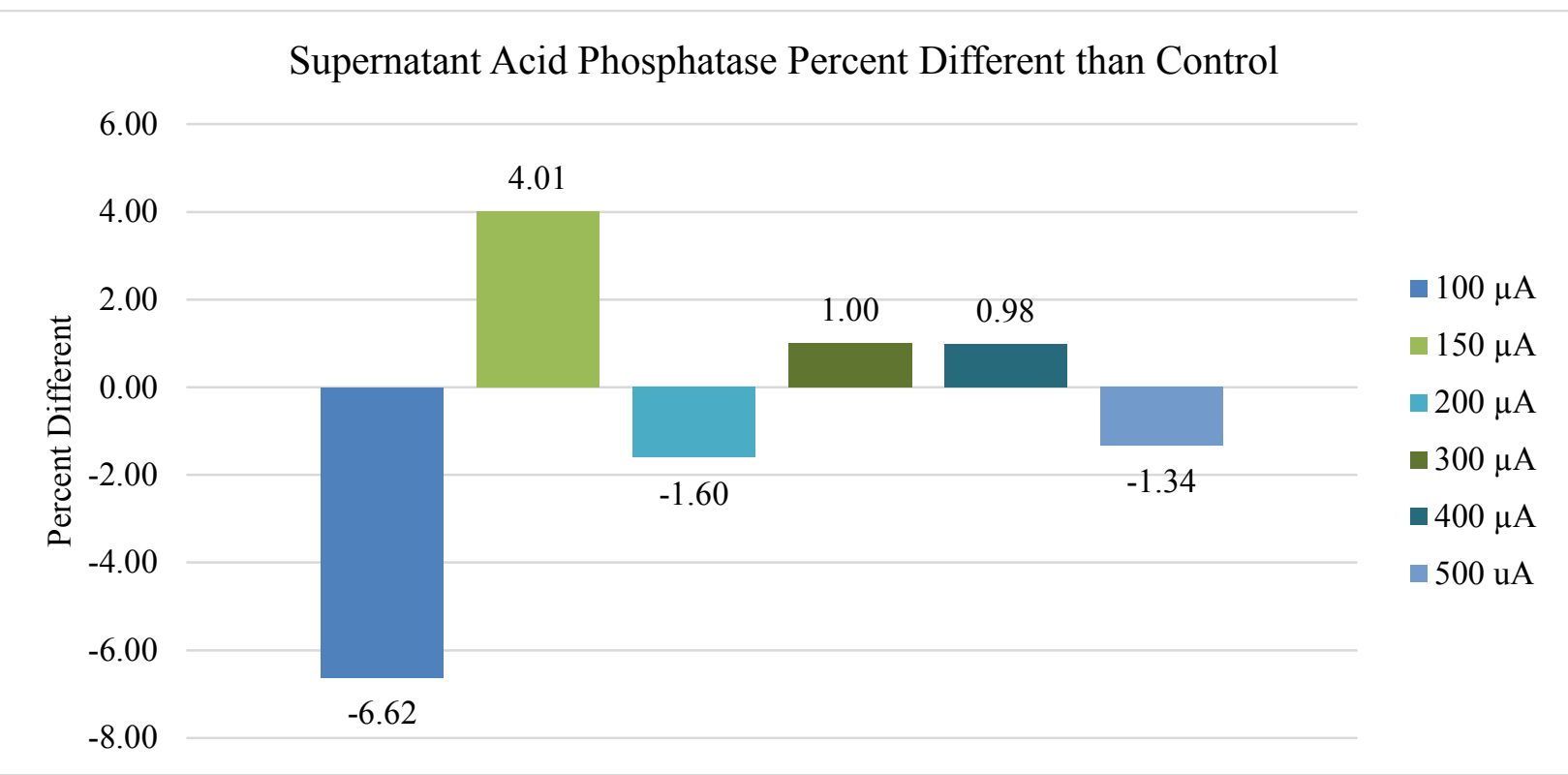

Figure 28. The effects of a $50 \mathrm{~Hz}$, symmetric biphasic electric field at various current exposures on L. tarentolae secreted acid phosphatase are plotted as percent different from same time control 


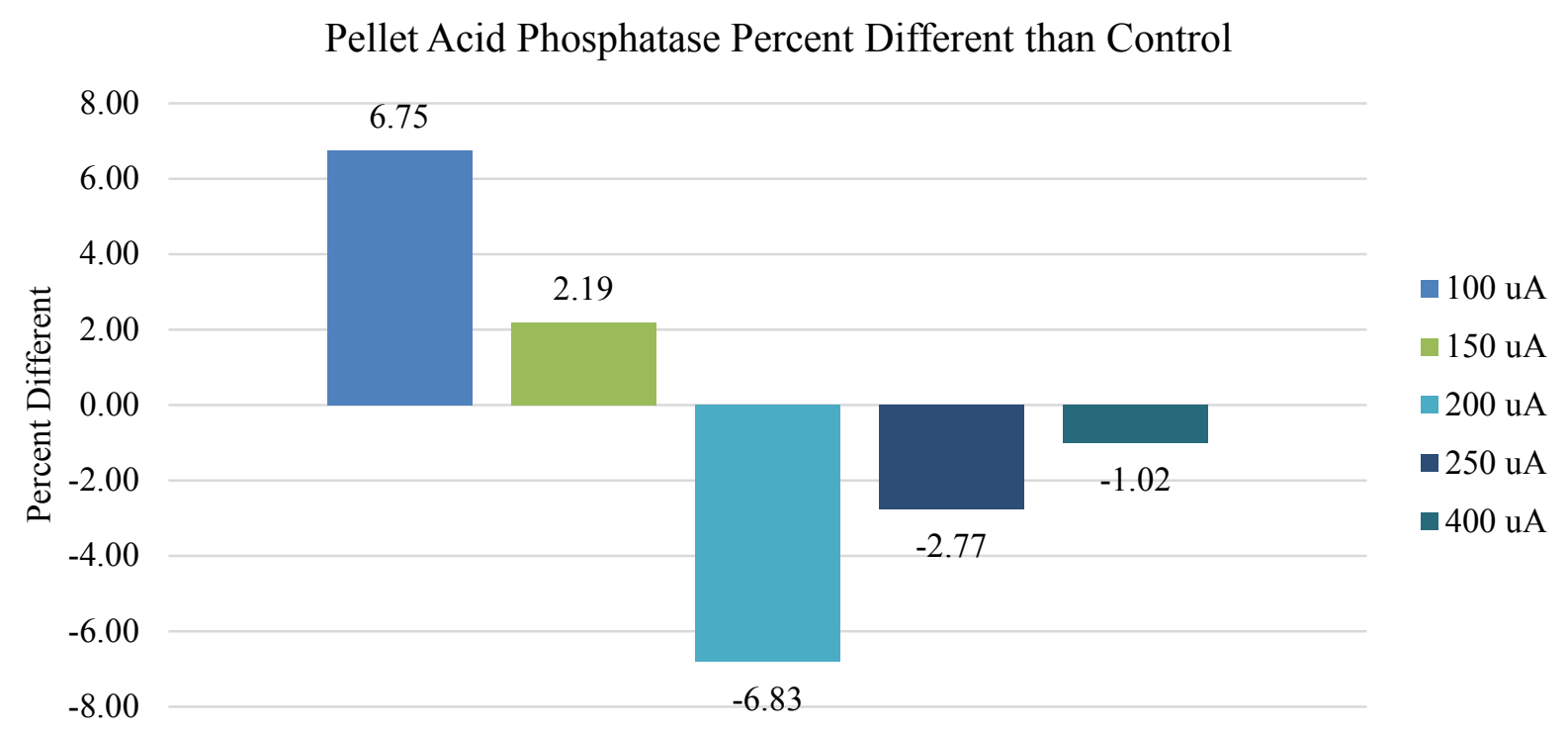

Figure 29. The effects of a $50 \mathrm{~Hz}$, symmetric biphasic electric field at various current exposures on L. tarentolae cell pellet acid phosphatase are plotted as percent different from same time control

The application of a $50 \mathrm{~Hz}$, anodic electric field (7 different current conditions) to $L$. tarentolae supernatant or pellet followed by the assessment of acid phosphatase activity resulted in measurable effects in both the supernatant and pellet activity that were different from their controls. Six out of seven conditions had an effect on supernatant acid phosphatase activity, but no consistent trend between current and supernatant activity was observed (Figure 30). Five out of seven conditions had an effect on pellet acid phosphatase activity, but no consistent trend between current and pellet activity was observed (Figure 31). The current conditions that affected both the supernatant and pellet acid phosphatase activity were 150, 200, 250, or $400 \mu \mathrm{A}$. The $150 \mu \mathrm{A}$ condition caused an increase in supernatant and pellet activity. The $200 \mu \mathrm{A}$ condition caused an increase in supernatant activity and a decrease in pellet activity. The $250 \mu \mathrm{A}$ condition caused a decrease in both supernatant and pellet activity. The $400 \mu \mathrm{A}$ condition caused 
a decrease in supernatant activity, but an increase in pellet activity. All effects on either supernatant or pellet acid phosphatase activity were small ( $<6 \%$ different than control).

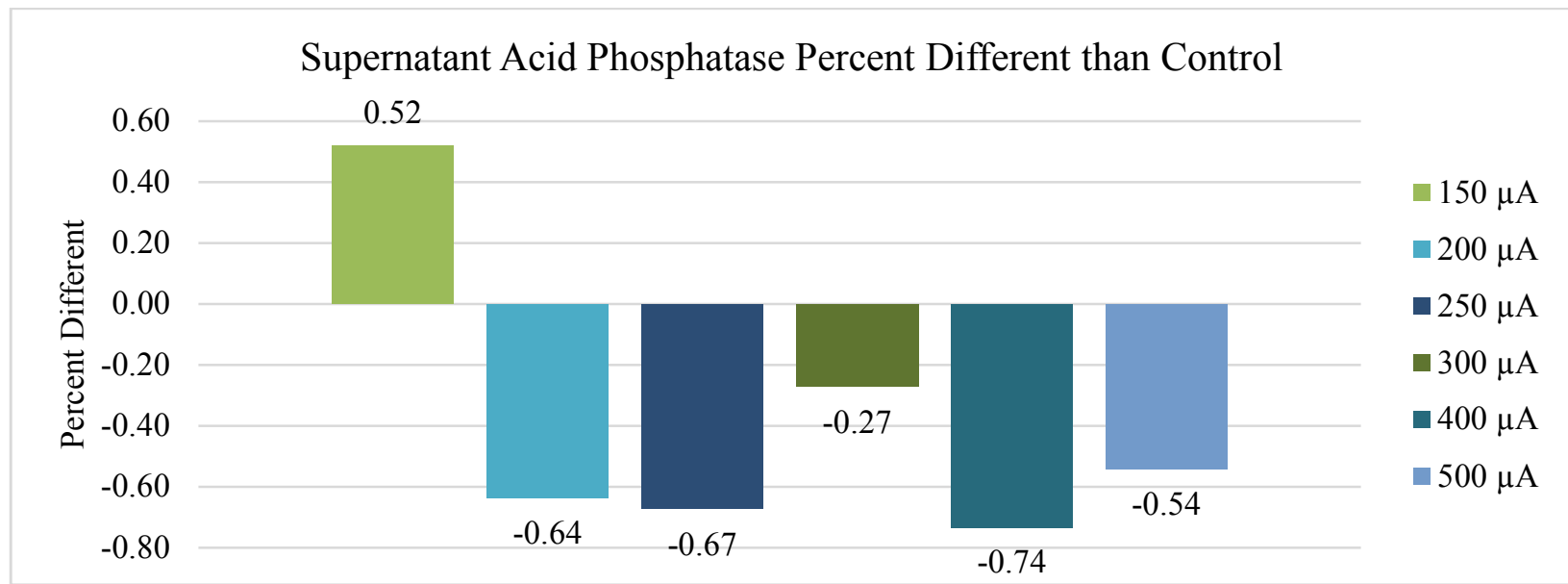

Figure 30. The effects of a $50 \mathrm{~Hz}$, anodic electric field at various current exposures on $L$. tarentolae secreted acid phosphatase are plotted as percent different from same time control

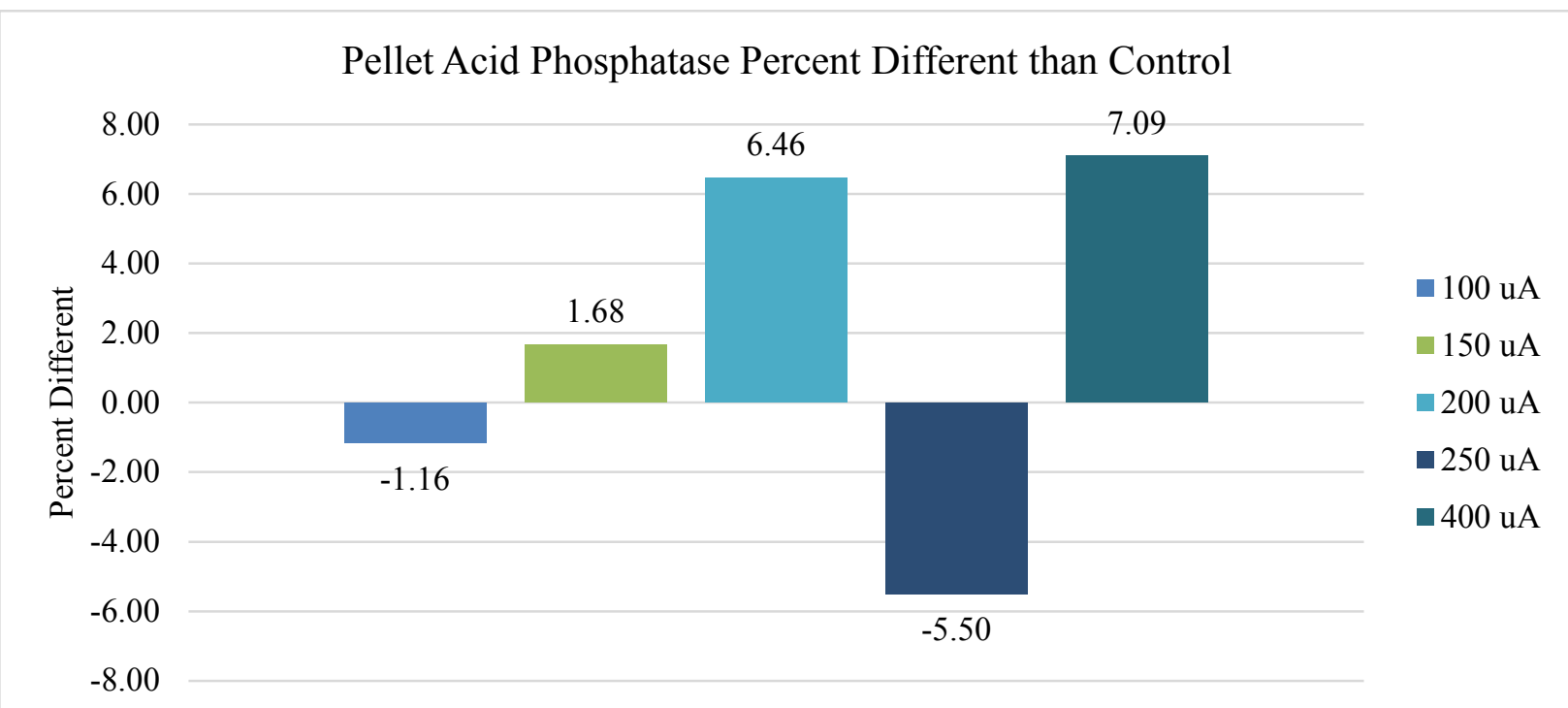

Figure 31 . The effects of a $50 \mathrm{~Hz}$, anodic electric field at various current exposures on $L$. tarentolae cell pellet acid phosphatase are plotted as percent different from same time control

The application of a 10,000 Hz, cathodic electric field ( 7 different current conditions) to L. tarentolae supernatant or pellet followed by the assessment of acid phosphatase activity 
resulted in measurable effects in both the supernatant and pellet activity that were significantly different from their controls. Six out of seven conditions had an effect on supernatant acid phosphatase activity (Figure 32). An upward trend was observed between 100-300 $\mu$ A. Under these conditions, more current application resulted in more acid phosphatase activity. Five out of seven conditions had a negative effect on pellet activity (Figure 33), suggesting a reciprocal trend between current and pellet activity was observed. The 250 or $500 \mu \mathrm{A}$ conditions led to the largest decreases in pellet activity. The current conditions that affected both the supernatant and pellet acid phosphatase activity were $100,150,250$, or $400 \mu \mathrm{A}$. All of these conditions caused an increase in supernatant activity, and a decrease in pellet activity. In general the effects of a $10,000 \mathrm{~Hz}$ cathodic electric field were substantially larger than the effects of a $50 \mathrm{~Hz}$ cathodic electric field.

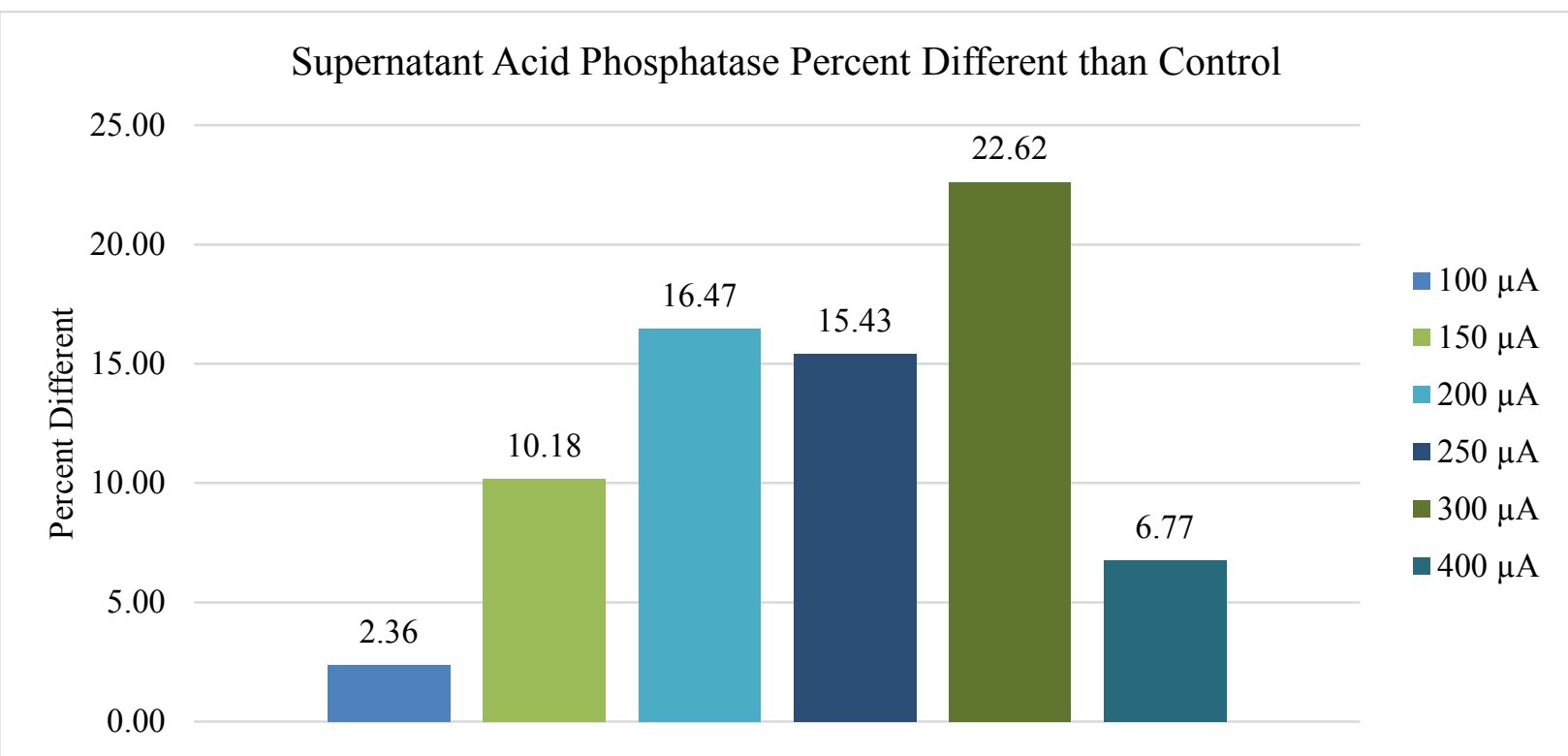

Figure 32. The effects of a 10,000 Hz, cathodic electric field at various current exposures on $L$. tarentolae secreted acid phosphatase are plotted as percent different from same time control 


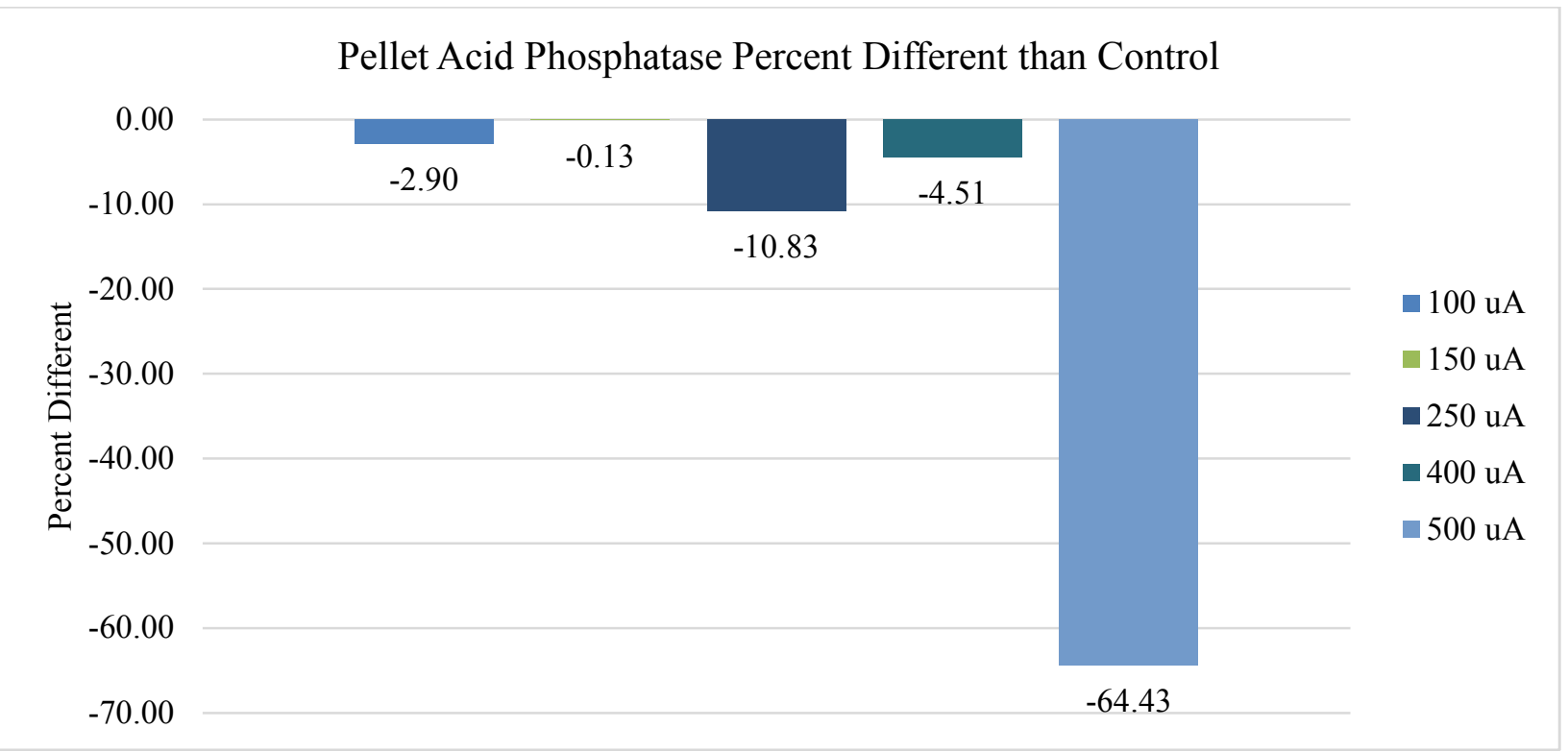

Figure 33. The effects of a 10,000 Hz, cathodic electric field at various current exposures on $L$. tarentolae cell pellet acid phosphatase are plotted as percent different from same time control

The application of a 10,000 Hz, symmetric biphasic electric field (7 different current conditions) to L. tarentolae supernatant or pellet followed by the assessment of acid phosphatase activity resulted in measurable effects in both the supernatant and pellet activity that were significantly different from their controls. Seven out of seven conditions had an effect on supernatant acid phosphatase activity (Figure 34). The application of 100, 150, or $200 \mu \mathrm{A}$ resulted in greater enzyme activation than did the application of $250,300,400$, or $500 \mu \mathrm{A}$. There is an apparent threshold between 200 and $250 \mu \mathrm{A}$ current application, where by applying less current resulted in greater acid phosphatase activity. Seven out of seven conditions had an effect on pellet acid phosphatase activity (Figure 35), but no consistent trend between current and pellet activity was observed. The current conditions that affected both the supernatant and pellet acid phosphatase activity were $100,150,200,250,300,400$ or $500 \mu \mathrm{A}$. The $100,150,200,250,300$, or $500 \mu \mathrm{A}$ currents caused an increase in supernatant activity, and a decrease in pellet activity. The $400 \mu \mathrm{A}$ condition caused a decrease in both supernatant and pellet activity. 


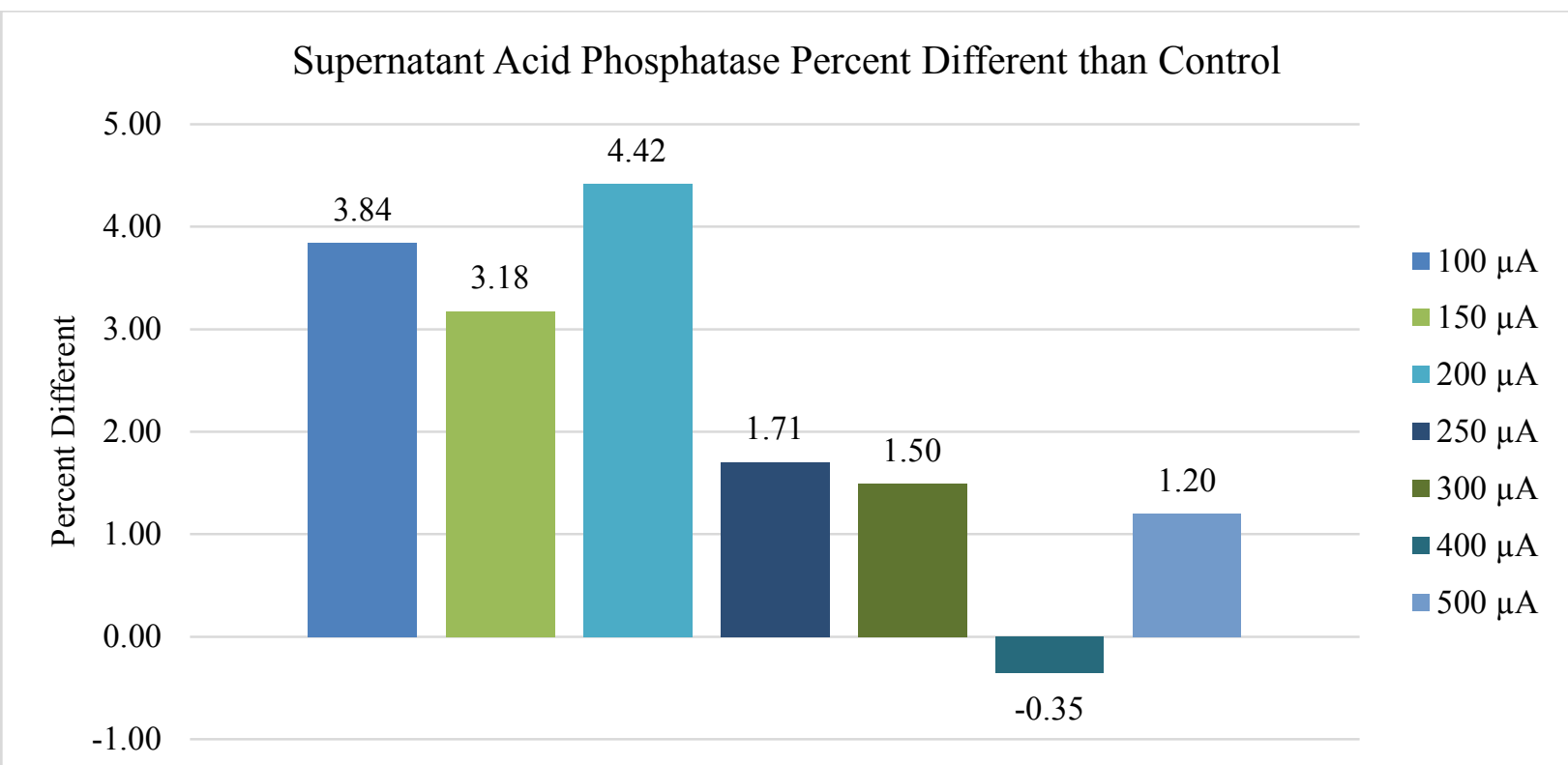

Figure 34. The effects of a 10,000 Hz, symmetric biphasic electric field at various current exposures on L. tarentolae secreted acid phosphatase are plotted as percent different from same time control

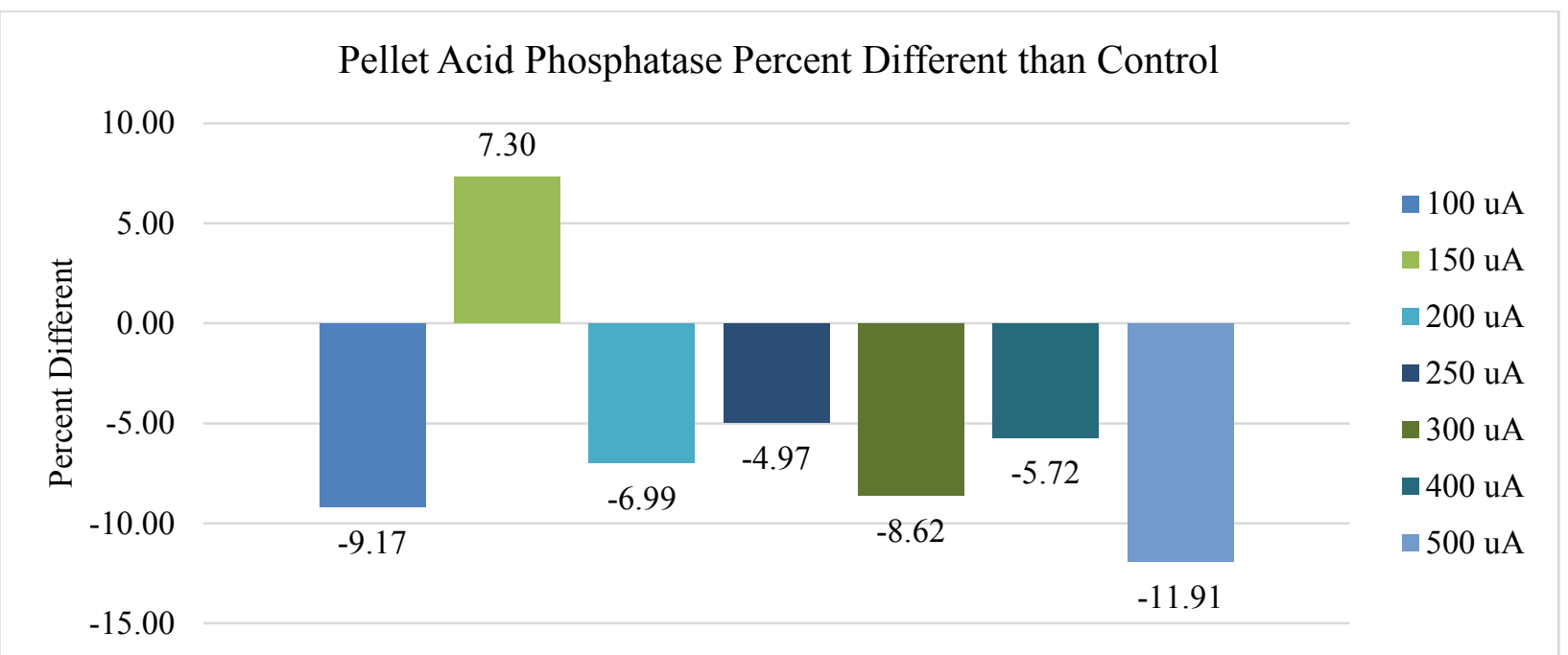

Figure 35 . The effects of a 10,000 Hz, symmetric biphasic electric field at various current exposures on L. tarentolae cell pellet acid phosphatase are plotted as percent different from same time control

The application of a 10,000 Hz, anodic electric field (7 different current conditions) to $L$. tarentolae supernatant or pellet followed by the assessment of acid phosphatase activity resulted 
in measurable effects in both the supernatant and pellet activity that were significantly different from their controls. Seven out of seven conditions had an effect on supernatant acid phosphatase activity (Figure 36). Lower current applications resulted in less detectable SAP activity. Higher current applications resulted in more detectable SAP activity. There is an apparent threshold between 200 and $250 \mu \mathrm{A}$, where by more current results in more SAP activity. Six out of seven conditions had an effect on pellet acid phosphatase activity (Figure 37). There is an apparent trend between $150-400 \mu \mathrm{A}$ where by applying less current leads to greater deactivation of the enzyme activity. The current conditions that affected both the supernatant and pellet acid phosphatase activity were $100,150,200,300,400$ or $500 \mu \mathrm{A}$. The application of currents between 100-400 $\mu \mathrm{A}$ caused an increase in supernatant and a decrease in pellet activity. The 500 $\mu \mathrm{A}$ condition caused an increase in both supernatant activity and in pellet activity.

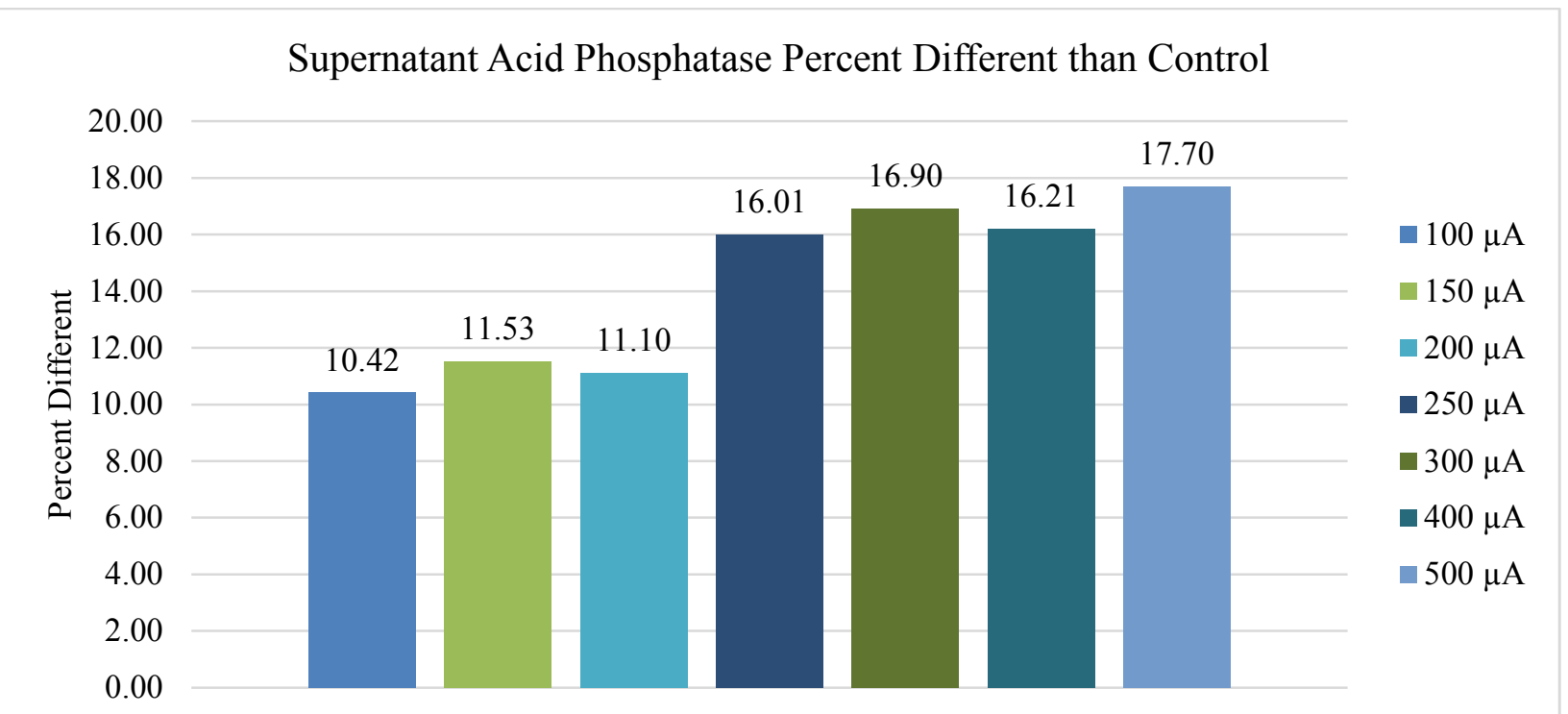

Figure 36. The effects of a 10,000 Hz, anodic electric field at various current exposures on $L$. tarentolae secreted acid phosphatase are plotted as percent different from same time control 


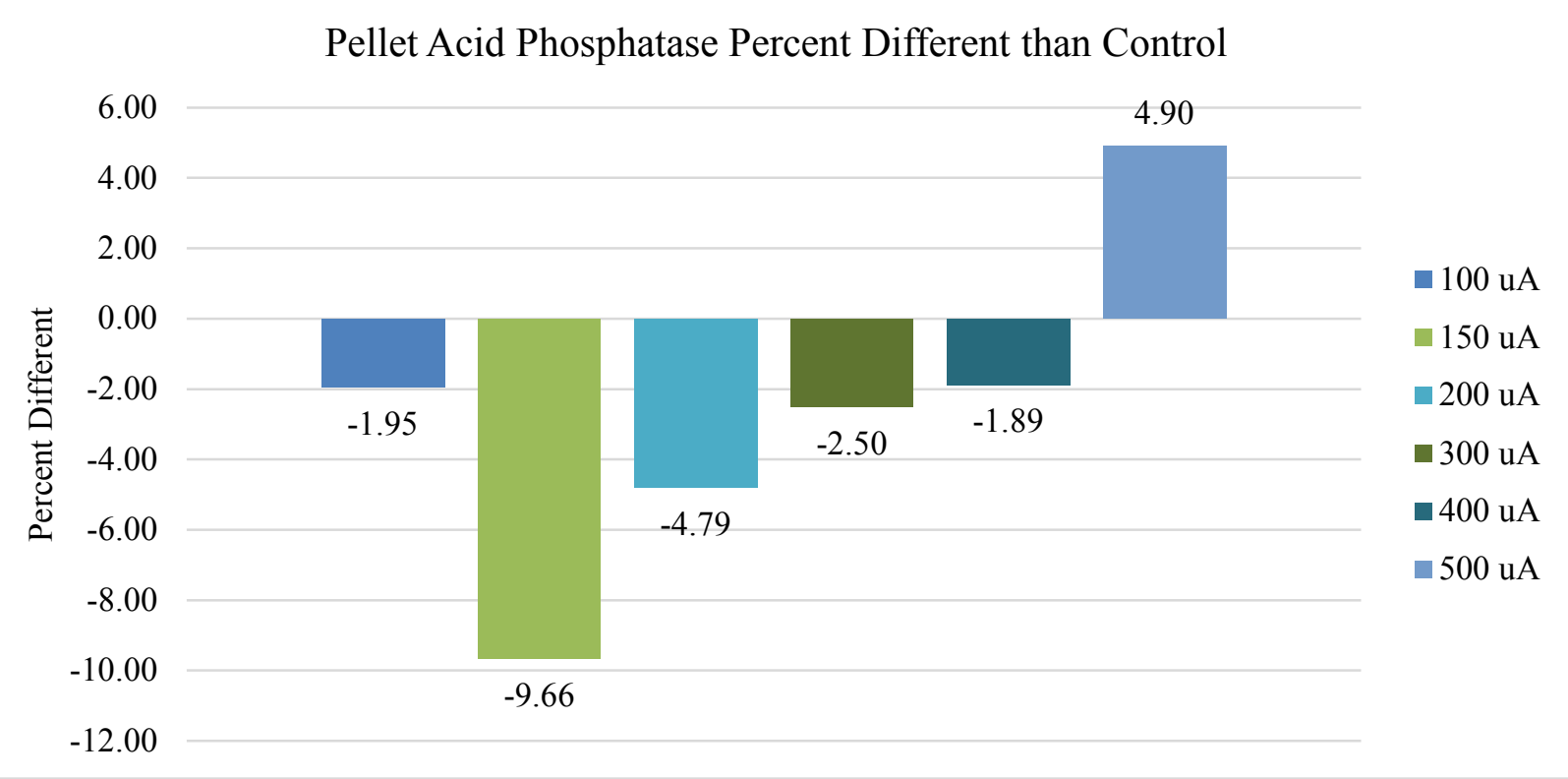

Figure 37. The effects of a 10,000 Hz, anodic electric field at various current exposures on $L$. tarentolae cell pellet acid phosphatase are plotted as percent different from same time control

\section{Testing the Effects of Electric Fields on L. tarentolae Acid Phosphatase Activity in Supernatant or Pelet (Cells), Method 2}

In method 2, small volumes $(0.5-2.0 \mathrm{~mL})$ of L. tarentolae log phase cells are exposed to electric fields, followed by separation, suspension of pellets, and assaying of acid phosphatase activity. For data to be shown, the experimental condition must be significantly different from the non-treated control $(\mathrm{p}<0.05)$ in a paired, two tailed t-test. The data are plotted as percent different from same time control (Equation 8).

The application of a $50 \mathrm{~Hz}$, cathodic electric field (7 different current conditions) to $L$. tarentolae whole cells followed by the separation and assessment of acid phosphatase activity resulted in measurable effects in both the supernatant and pellet activity that were significantly different from their controls. Five out of seven conditions had an effect on supernatant acid phosphatase activity (Figure 38), but there was no consistent trend between the current applied and the effect on enzyme activity. Six out of seven conditions had an effect on pellet acid 
phosphatase activity (Figure 39), but there was no consistent trend between the current applied and the effect on enzyme activity. The current conditions that affected both the supernatant and pellet acid phosphatase activity were $100,300,400$ or $500 \mu \mathrm{A}$. The application of $100 \mu \mathrm{A}$ caused an increase in supernatant and a decrease in pellet activity. The application of 300 or $500 \mu \mathrm{A}$ caused a decrease in supernatant activity and an increase in pellet activity. The application of 400 $\mu \mathrm{A}$ caused an increase in both supernatant and pellet activity.

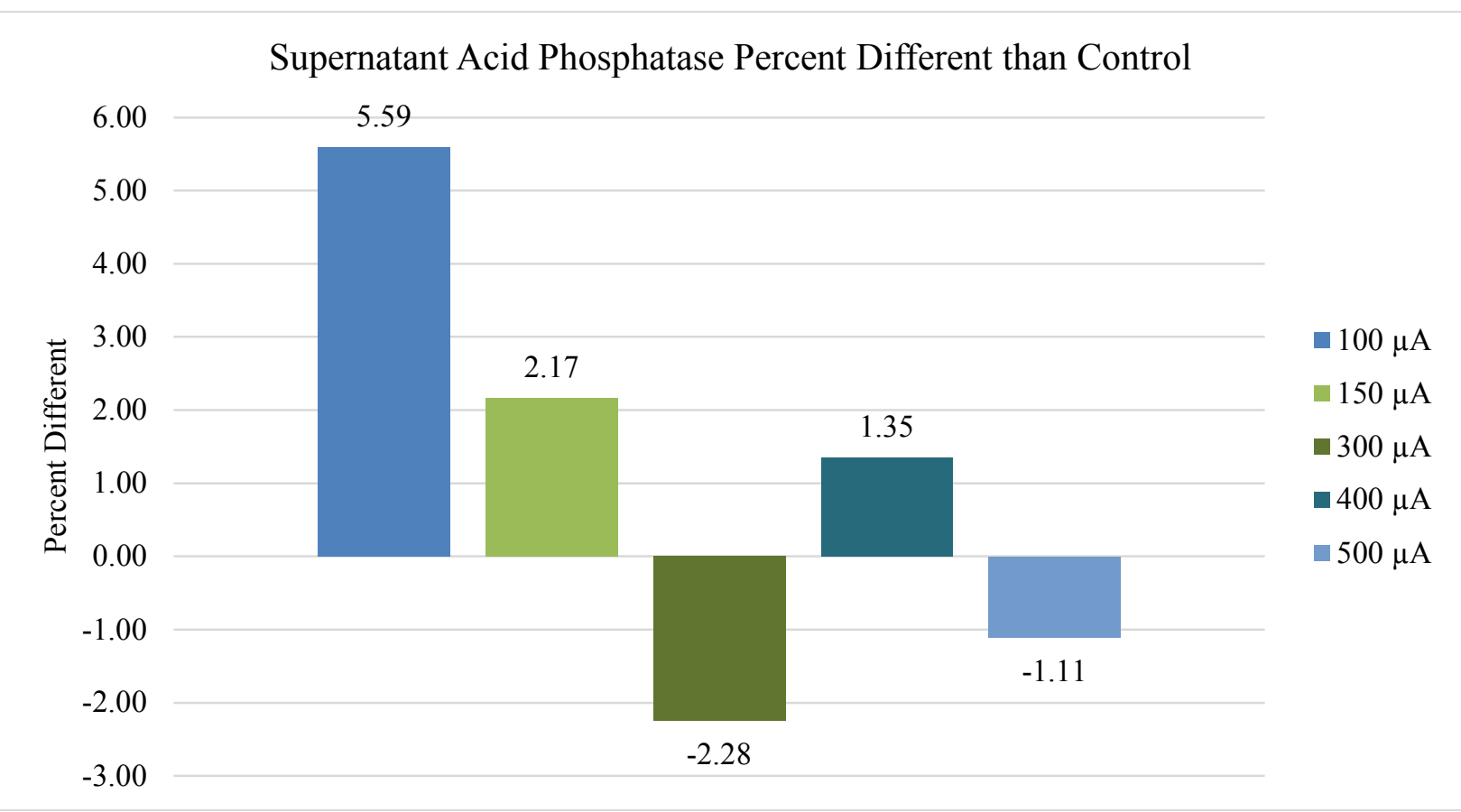

Figure 38. The effects of a $50 \mathrm{~Hz}$, cathodic electric field at various current exposures on $L$. tarentolae secreted acid phosphatase are plotted as percent different from same time control 


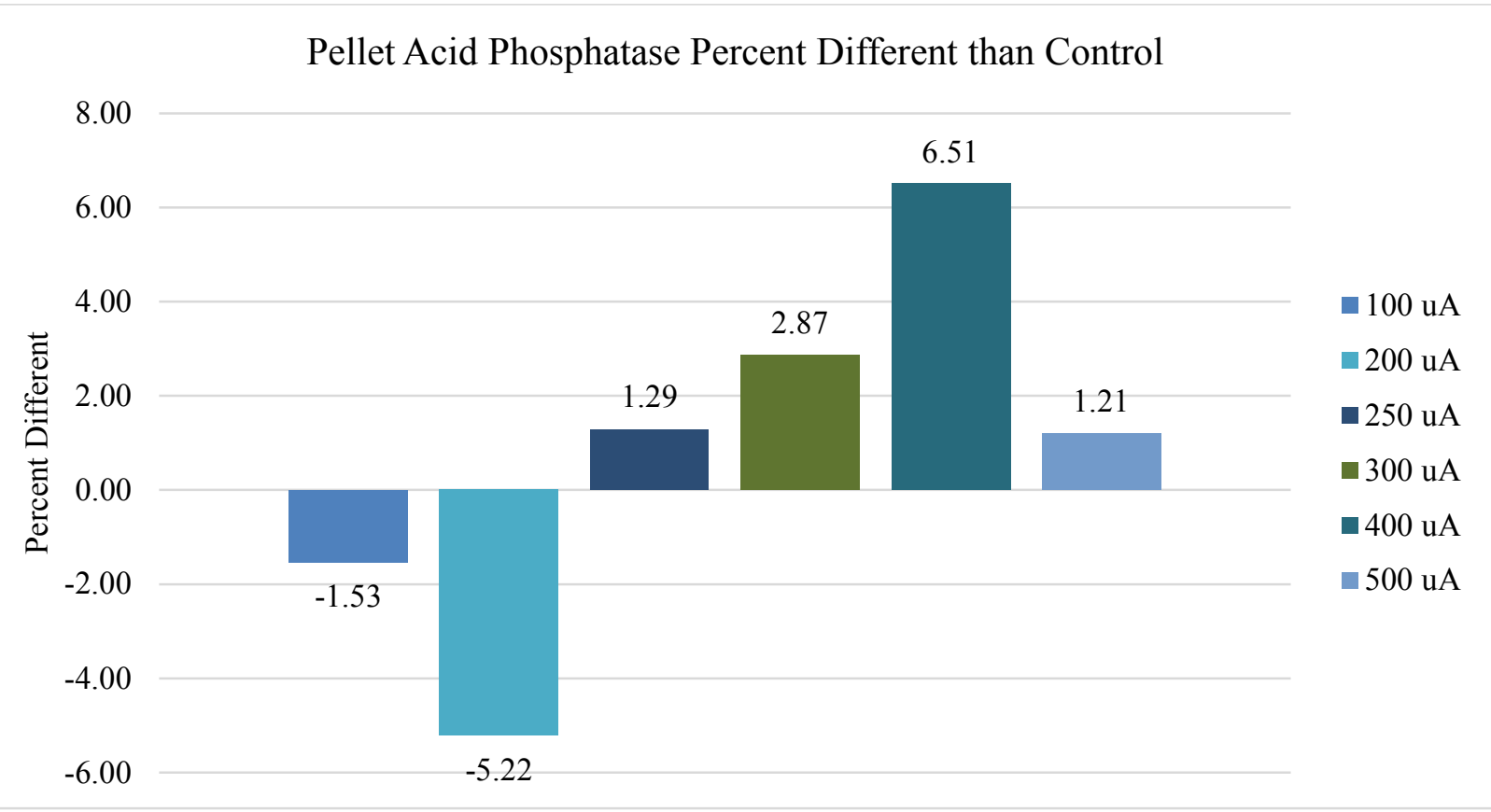

Figure 39. The effects of a $50 \mathrm{~Hz}$, cathodic electric field at various current exposures on $L$. tarentolae cell pellet acid phosphatase are plotted as percent different from same time control

The application of a $50 \mathrm{~Hz}$, symmetric biphasic electric fields (7 different current conditions) to L. tarentolae whole cells followed by the separation and assessment of acid phosphatase activity resulted in measurable effects on only the pellet activity that were significantly different from their non-treated controls. Zero out of seven conditions had an effect on supernatant acid phosphatase activity (data not shown). Two out of seven conditions had an effect on pellet acid phosphatase activity (Figure 40), but there was no obvious trend between the current applied and the effect on enzyme activity. There were no current conditions that affected both the supernatant and pellet acid phosphatase activity. 


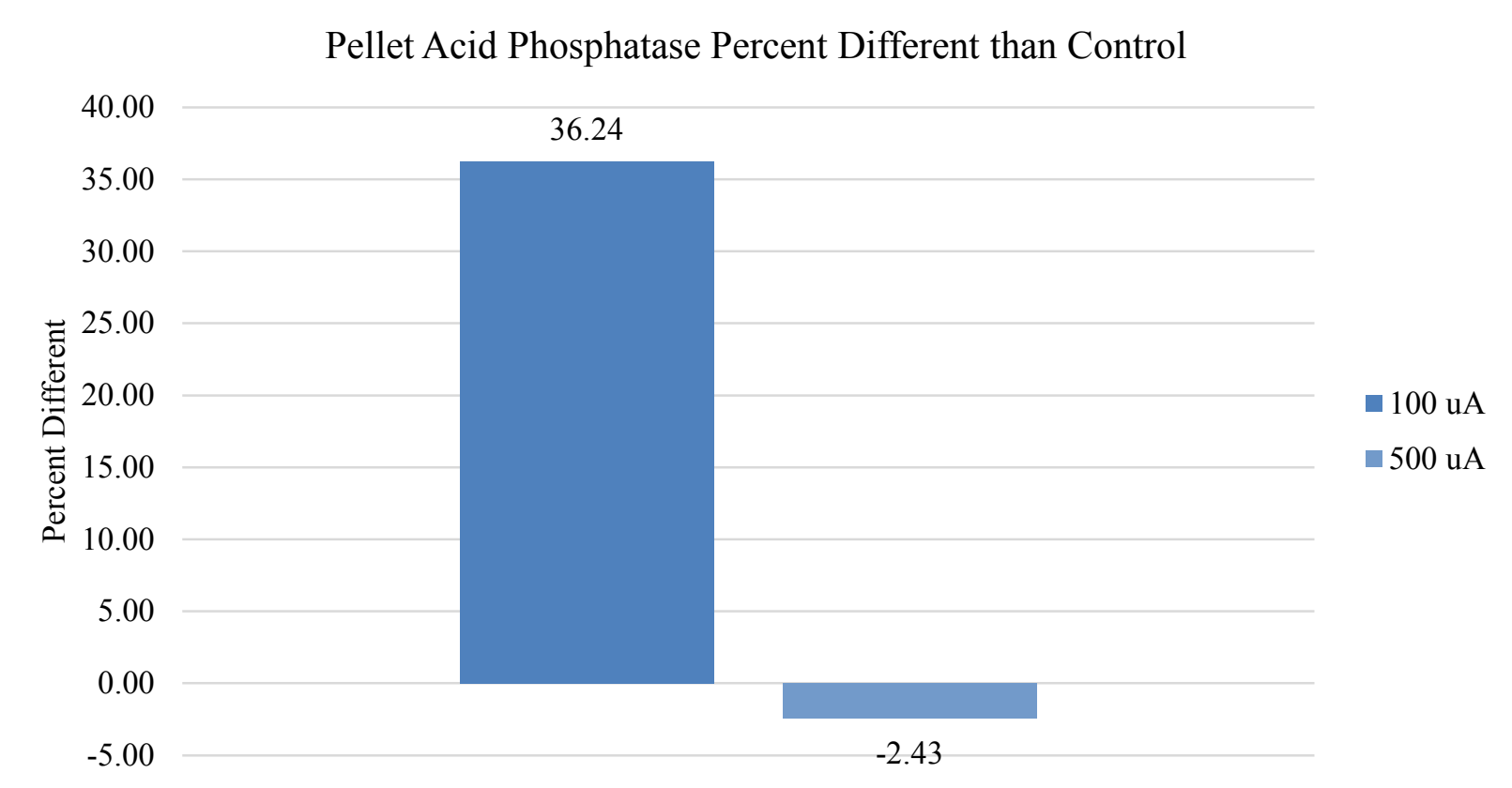

Figure 40. The effects of a $50 \mathrm{~Hz}$, symmetric biphasic electric field at various current exposures on $L$. tarentolae cell pellet acid phosphatase are plotted as percent different from same time control

The application of a $50 \mathrm{~Hz}$, anodic electric field (7 different current conditions) to $L$. tarentolae whole cells followed by the separation and assessment of acid phosphatase activity resulted in measurable effects in both the supernatant and pellet activity that was different from their non-treated controls. Two out of seven conditions had an effect on supernatant acid phosphatase activity (Figure 41), but there was no consistent trend between the current applied and the effect on enzyme activity. Five out of seven conditions had an effect on pellet acid phosphatase activity (Figure 42), but there was no consistent trend between the current applied and the effect on enzyme activity. The current condition that affected both the supernatant and pellet acid phosphatase activity was $400 \mu \mathrm{A}$, and this condition caused an increase in both the supernatant and pellet activity. 


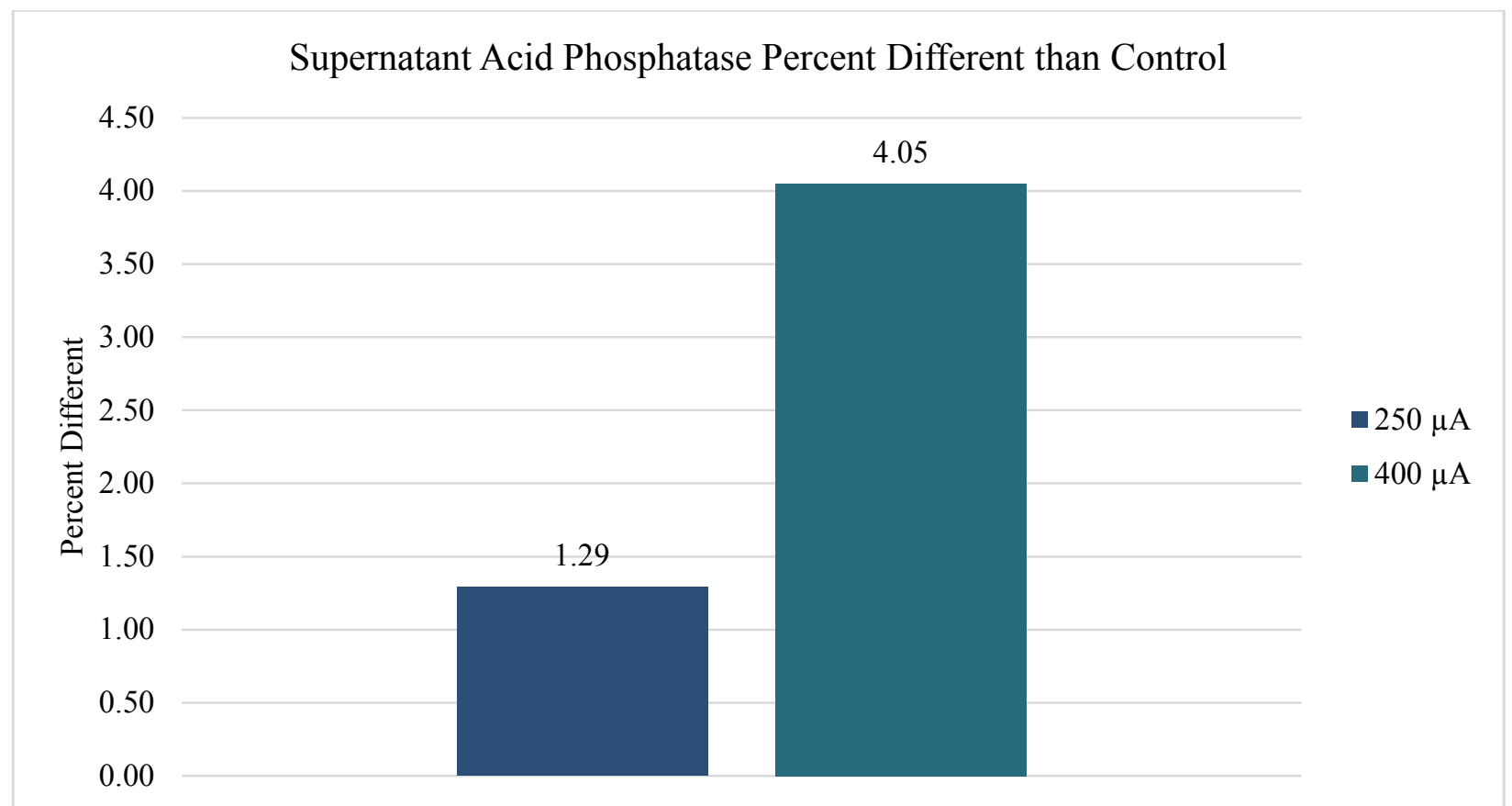

Figure 41. The effects of a $50 \mathrm{~Hz}$, anodic electric field at various current exposures on $L$. tarentolae secreted acid phosphatase are plotted as percent different from same time control

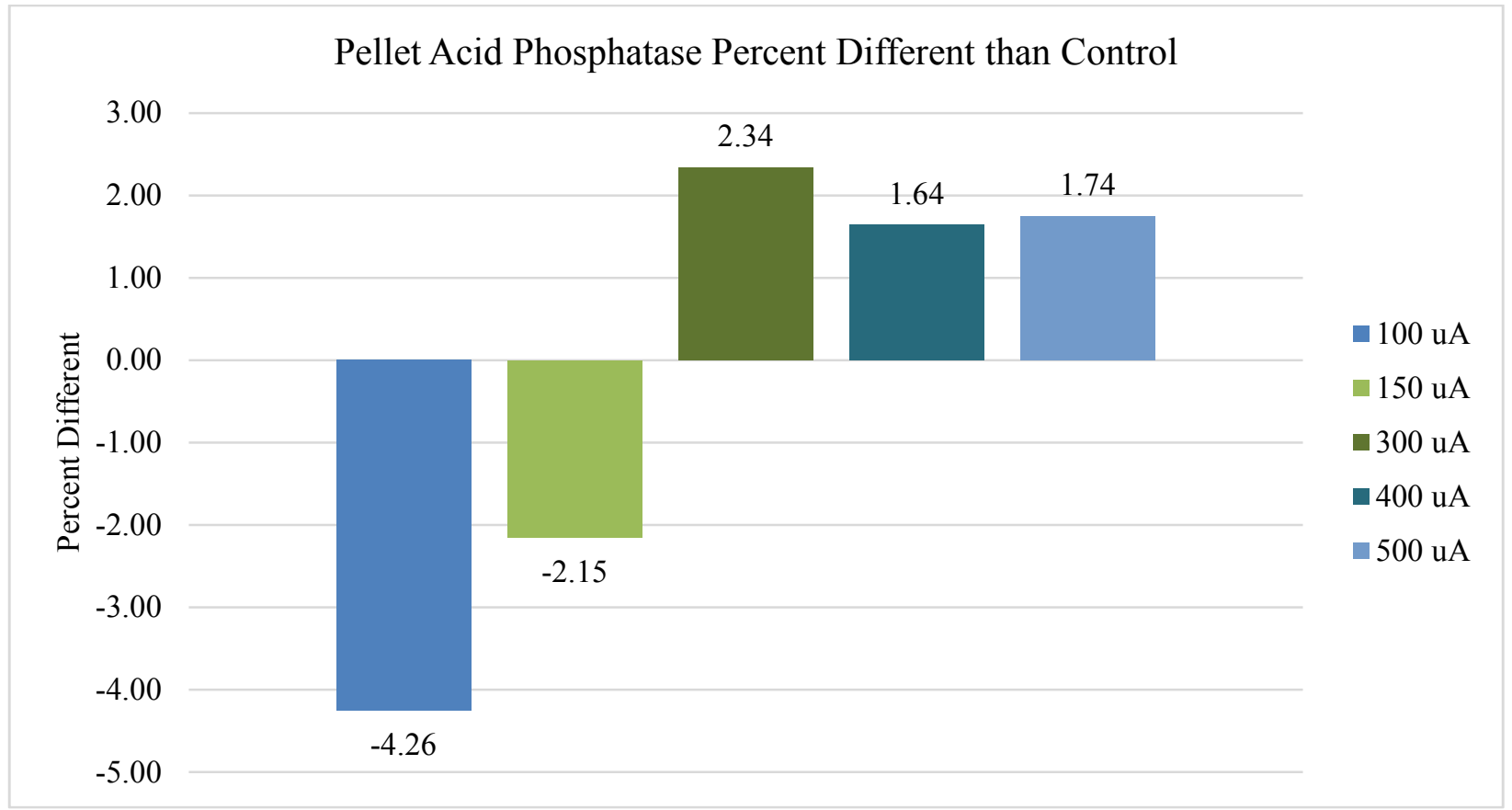

Figure 42. The effects of a $50 \mathrm{~Hz}$, anodic electric field at various current exposures on $L$. tarentolae cell pellet acid phosphatase are plotted as percent different from same time control 
The application of a $10,000 \mathrm{~Hz}$, cathodic electric field (7 different current conditions) to L. tarentolae whole cells followed by the separation and assessment of acid phosphatase activity resulted in measurable effects in both the supernatant and pellet activity that were significantly different from their non-treated controls. Five out of seven conditions had an effect on supernatant acid phosphatase activity (Figure 43). An apparent trend exists between 300-500 $\mu \mathrm{A}$ where by more current leads to less enzyme activation. Five out of seven conditions had an effect on pellet acid phosphatase activity (Figure 44), but there was no consistent trend between the current applied and the effect on enzyme activity. The current conditions that affected both the supernatant and pellet acid phosphatase activity were 150,300 , or $400 \mu \mathrm{A}$. The application of $150 \mu \mathrm{A}$ resulted in decreased activity in both the supernatant and pellet. The $300 \mu \mathrm{A}$ condition caused an increase in supernatant activity and in pellet activity. The $400 \mu \mathrm{A}$ condition caused an increase in supernatant activity, but a decrease in pellet activity.

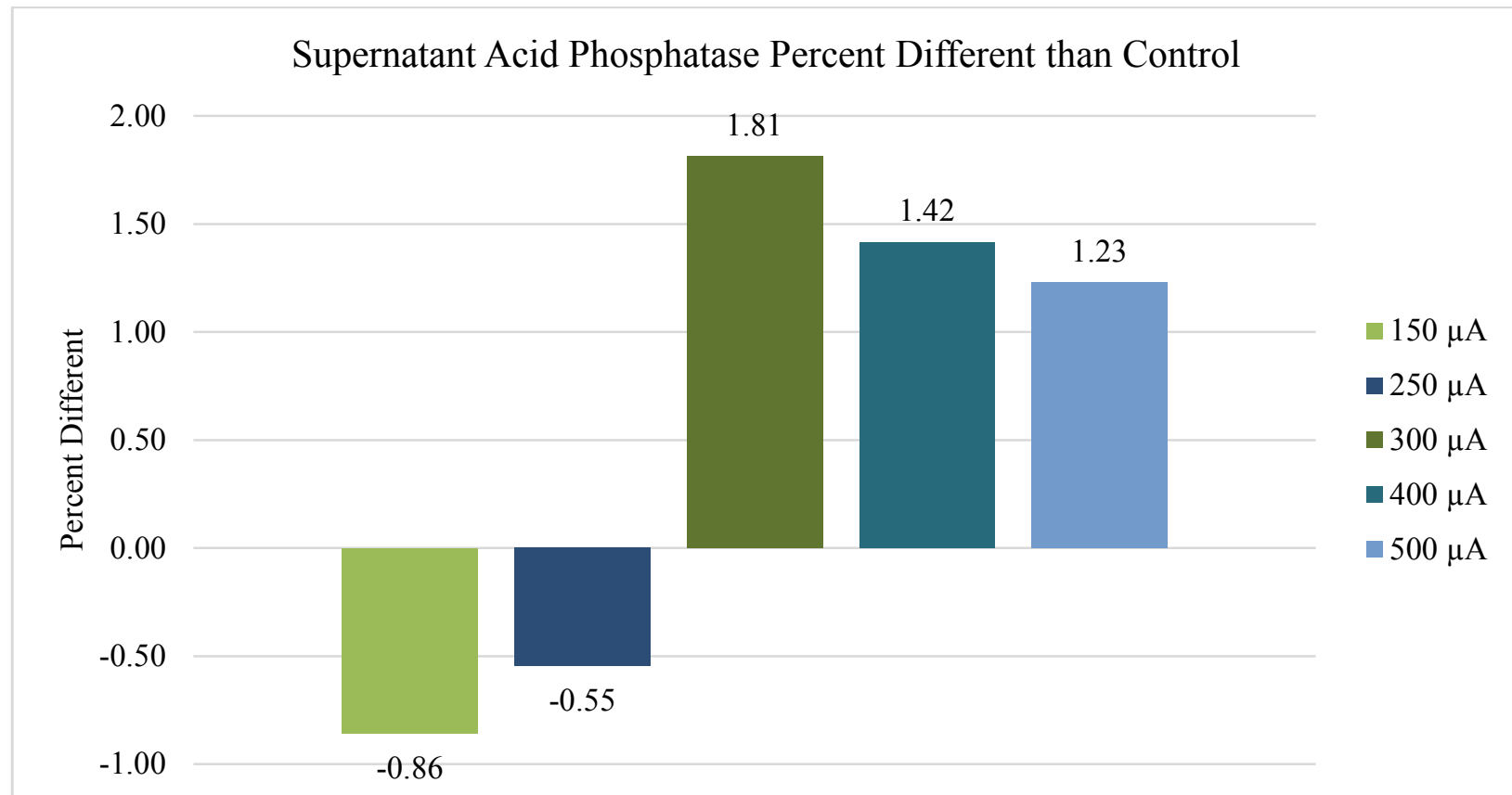

Figure 43. The effects of a $10,000 \mathrm{~Hz}$, cathodic electric field at various current exposures on $L$. tarentolae secreted acid phosphatase are plotted as percent different from same time control 


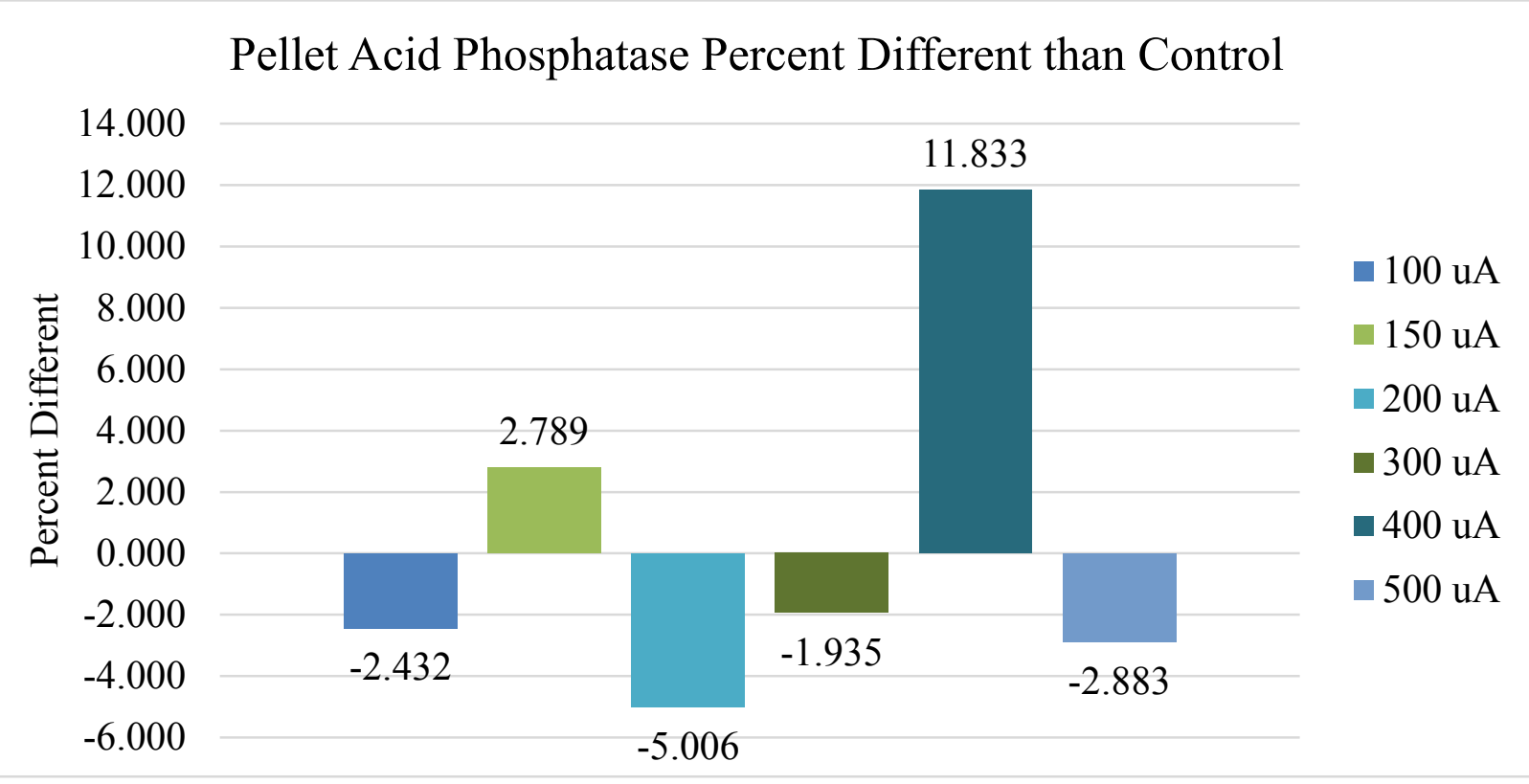

Figure 44. The effects of a 10,000 Hz, cathodic electric field at various current exposures on $L$. tarentolae cell pellet acid phosphatase are plotted as percent different from same time control

The application of a 10,000 Hz, symmetric biphasic electric field (7 different current conditions) to L. tarentolae whole cells followed by the separation and assessment of acid phosphatase activity resulted in measurable effects in both the supernatant and pellet activity that were different from their non-treated controls. Three out of seven conditions had an effect on supernatant acid phosphatase activity (Figure 45), but there was no consistent trend between the current applied and the effect on enzyme activity. Three out of seven conditions had an effect on pellet acid phosphatase activity (Figure 46), but there was no consistent trend between the current applied and the effect on enzyme activity. The current conditions that affected both the supernatant and pellet acid phosphatase activity were 300 or $500 \mu \mathrm{A}$. The application of $300 \mu \mathrm{A}$ caused an increase in both the supernatant or pellet activity. The application of $500 \mu \mathrm{A}$ caused a decrease in both the supernatant or pellet activity. 


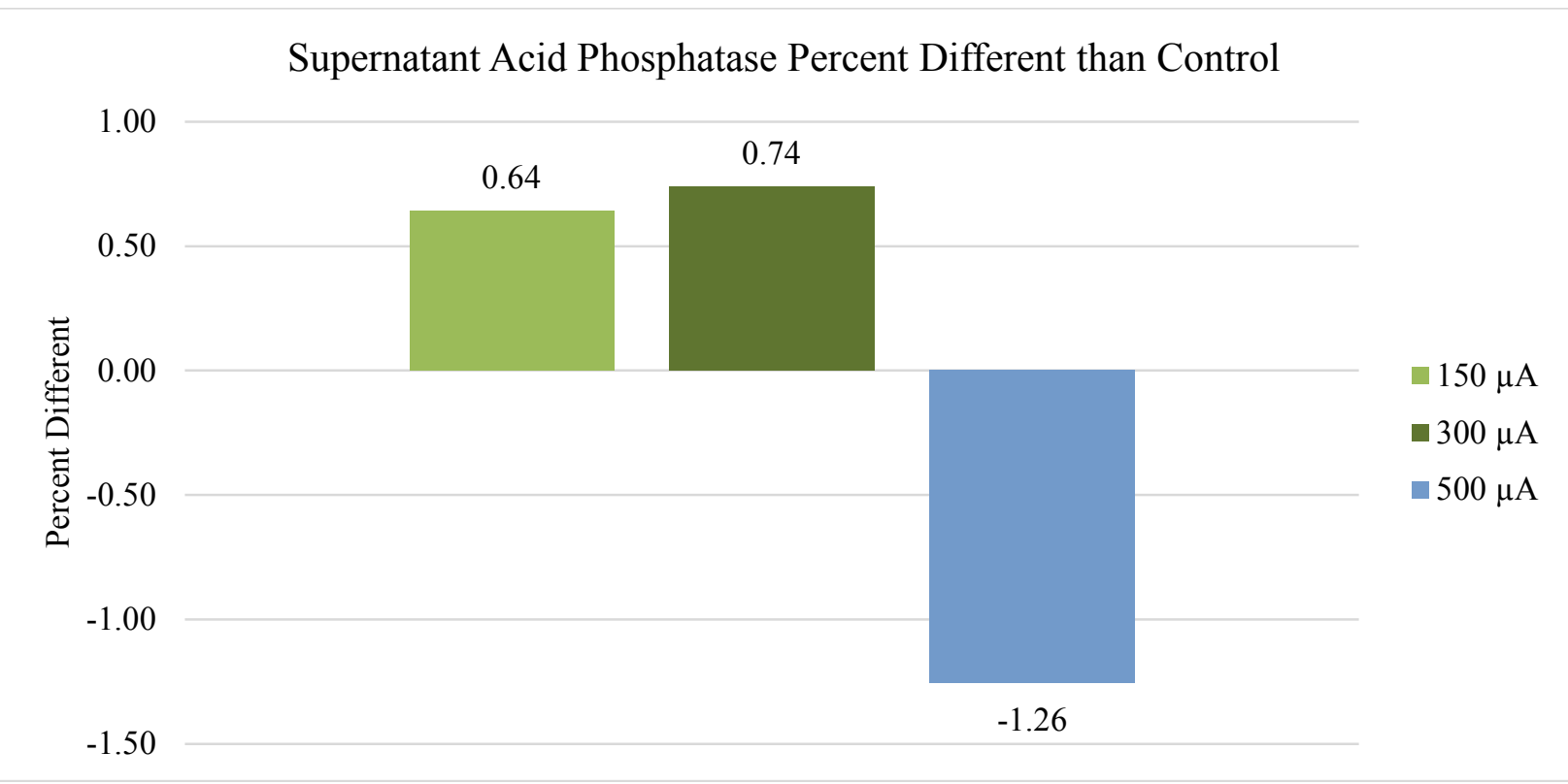

Figure 45. The effects of a $10,000 \mathrm{~Hz}$, symmetric biphasic electric field at various current exposures on $L$. tarentolae secreted acid phosphatase are plotted as percent different from same time control

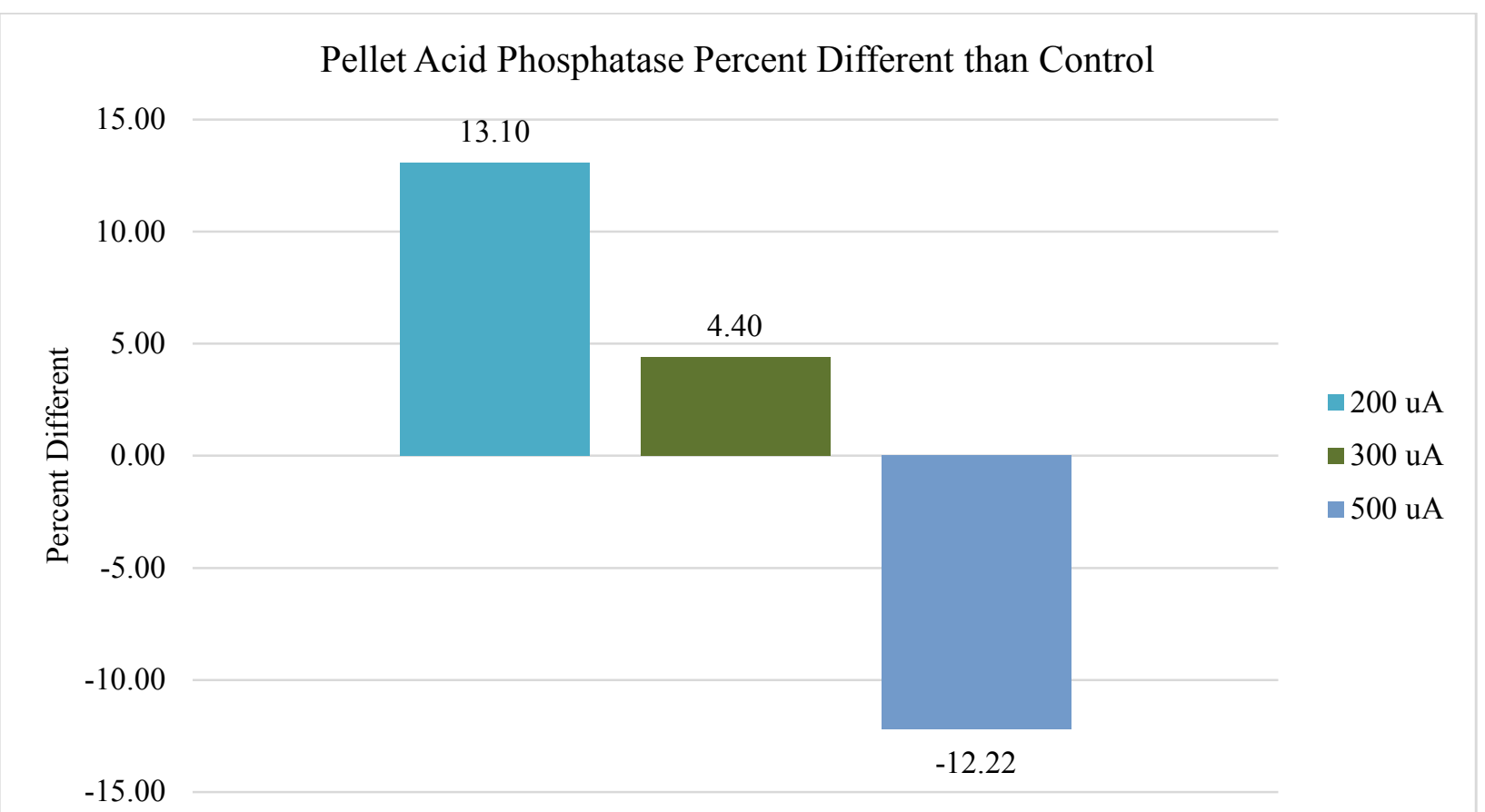

Figure 46. The effects of a $10,000 \mathrm{~Hz}$, symmetric biphasic electric field at various current exposures on L. tarentolae cell pellet acid phosphatase are plotted as percent different from same time control 
The application of a $10,000 \mathrm{~Hz}$, anodic electric field (7 different current conditions) to $L$. tarentolae whole cells followed by the separation and assessment of acid phosphatase activity resulted in measurable effects in both the supernatant and pellet activity that was different from their non-treated controls. Four out of seven conditions had an effect on supernatant acid phosphatase activity (Figure 47), but there was no consistent trend between the current applied and the effect on enzyme activity. Five out of seven conditions had an effect on pellet acid phosphatase activity (Figure 48), but there was no consistent trend between the current applied and the effect on enzyme activity. The current conditions that affected both the supernatant and pellet acid phosphatase activity were $200,250,300$ or $400 \mu \mathrm{A}$. The application of $200 \mu \mathrm{A}$ caused a decrease in supernatant and an increase in pellet activity. The 250 or $400 \mu \mathrm{A}$ conditions caused an increase in both the supernatant activity or pellet activity. The application of $300 \mu \mathrm{A}$ resulted in decreased in both the supernatant or pellet activity.

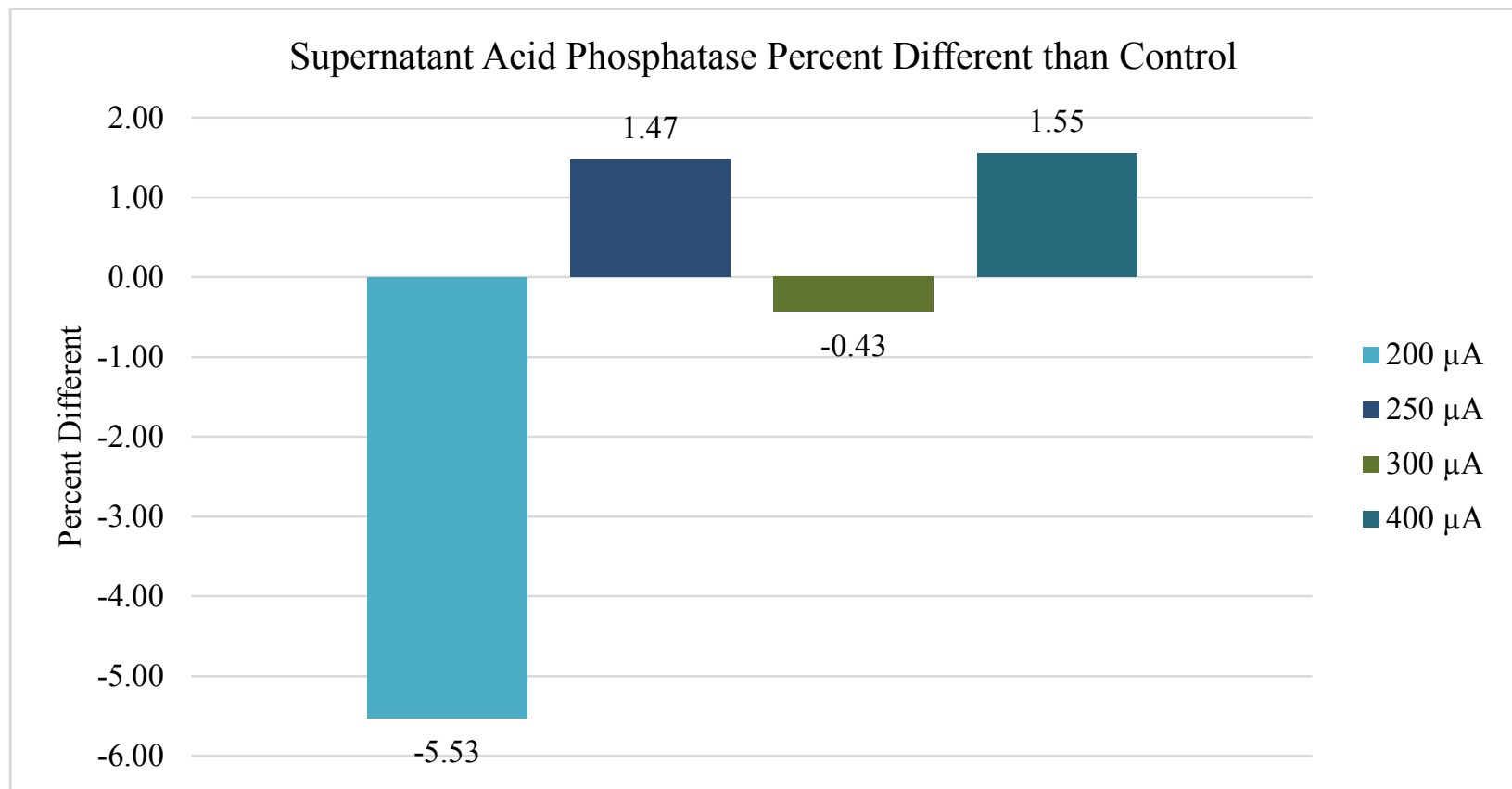

Figure 47. The effects of a 10,000 Hz, anodic electric field at various current exposures on $L$. tarentolae secreted acid phosphatase are plotted as percent different from same time control 


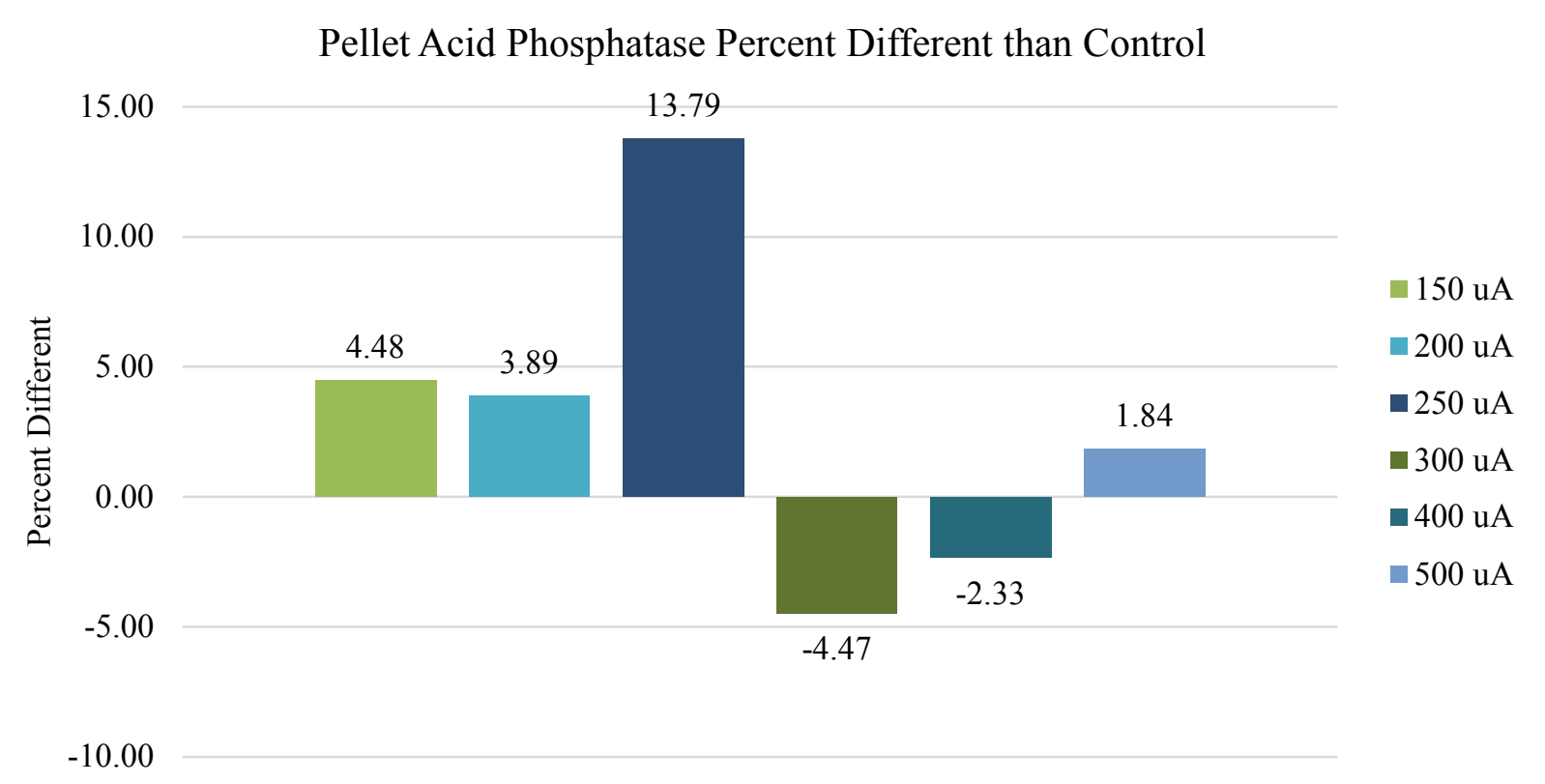

Figure 48. The effects of a 10,000 Hz, anodic electric field at various current exposures on $L$. tarentolae cell pellet acid phosphatase are plotted as percent different from same time control

\section{Secreted Acid Phosphatase Enzyme Inhibition Assay (Following the Method of Baumhardt et al., 2015)}

Due to the complexity of the enzyme pool, the relative amounts of mono-, di-, tri-, tetra-, octa-, or deca-nuclear vanadium present in assay are not known. Standard speciation diagrams would indicate that under secreted acid phosphatase assay conditions, the main form of vanadium present is decavanadate (Figure 1, Baes, mesmer, 1976). When plotting (Figure 49) $L$. tarentolae secreted acid phosphatase enzyme activity (y-axis) incubated with $\mathrm{V}_{10}$ (red curve) or $\mathrm{VO}_{4}{ }^{3-}$ (blue curve) as a function of $\log [\mathrm{S}] /[\mathrm{I}]$ ( $\mathrm{x}$-axis), where $[\mathrm{I}]$ is either total moles of $\mathrm{V}_{10}$ or $\mathrm{VO}_{4}{ }^{3-}$, there are three conditions where decavanadate or orthovanadate resulted in different effects from control and each other. These conditions are statistically significant $(\mathrm{p}<0.05$ in a paired, two-tailed t-test). These conditions occur when the $\log [\mathrm{S}] /[\mathrm{I}]$ ratio is equal to $-0.5,1.5$, or 2.0. Orthovanadate is a better inhibitor in two of these conditions $(\log [\mathrm{S}] /[\mathrm{I}]=-0.5$ or 2.0$)$, and 
decavanadate is a better inhibitor in one condition $(\log [\mathrm{S}] /[\mathrm{I}]=1.5)$. Plotting the data in this manner assumes that no vanadium speciation occurs. When plotting (Figure 50) L. tarentolae secreted acid phosphatase enzyme activity (y-axis) incubated with $\mathrm{V}_{10}$ (red curve) or $\mathrm{VO}_{4}{ }^{3-}$ (blue curve) as a function of $\log [\mathrm{S}] /[\mathrm{I}](\mathrm{X}$-axis), where $[\mathrm{I}]$ is total moles of vanadium, there are six conditions where decavanadate or orthovanadate resulted in different effects from control and each other. These conditions are statistically significant $(\mathrm{p}<0.05$ in a paired, two-tailed t-test). These conditions occur when the $\log [\mathrm{S}] /[\mathrm{I}]$ ratio is equal to $-1.5,-1.0,-0.5,0.0,0.5$, or 1.0 . Orthovanadate is a better inhibitor in all six of these conditions. Plotting the data in this manner attempts to compensate for the uncertainty associated with vanadium speciation and takes into account only the total moles of vanadium present. Under this assumption, orthovanadate is consistently better at inhibiting secreted acid phosphatase activity, on a mole of vanadium basis compared to decavanadate for an enzyme pool collected from L. tarentolae log phase cells. 


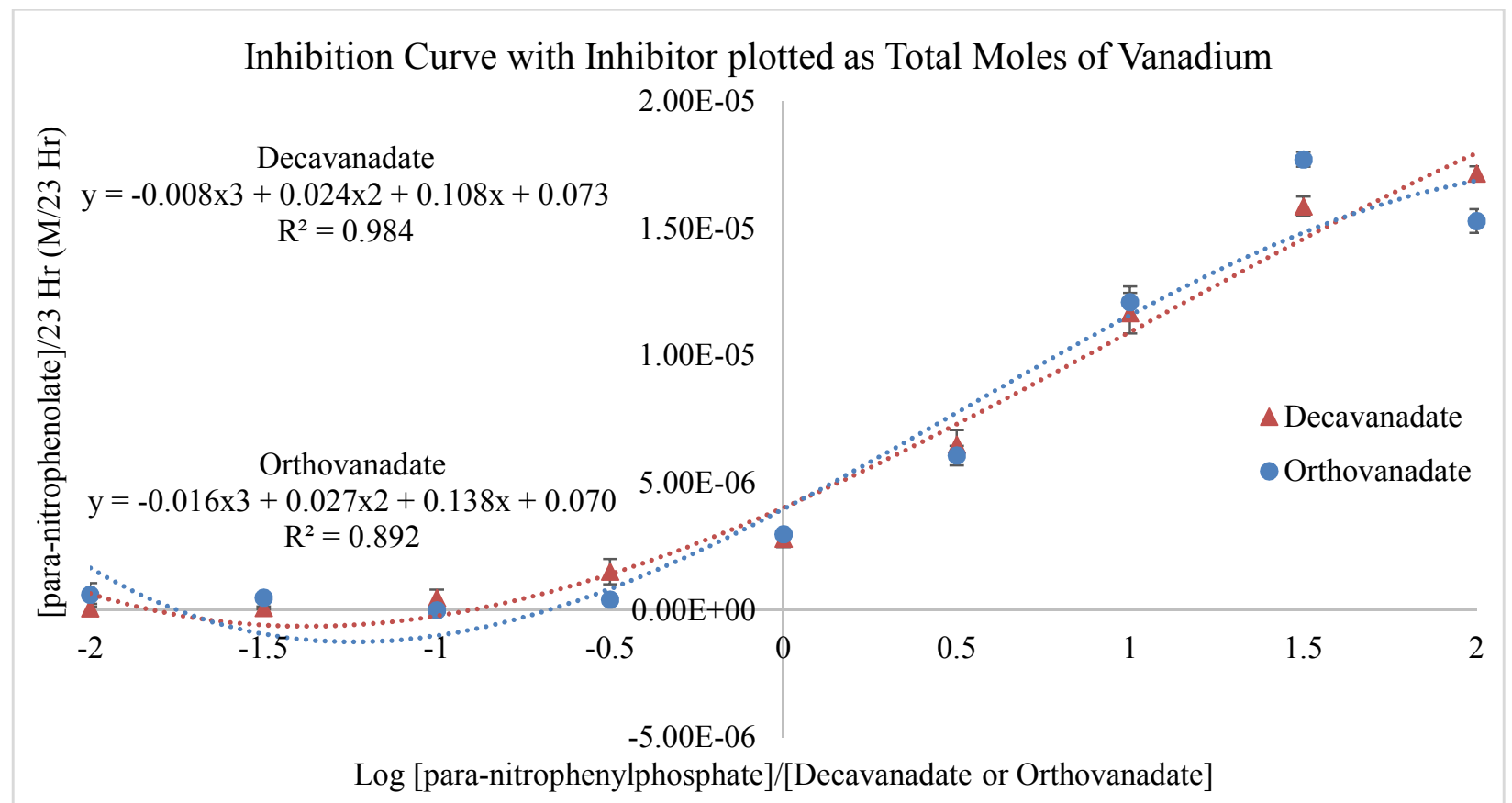

Figure 49. L. tarentolae secreted acid phosphatase enzyme activity (Y-axis) when incubated with decavanadate (red curve) or orthovanadate (blue curve) plotted as a function of $\log [\mathrm{S}] /[\mathrm{I}]$ (Xaxis). [I] is either total moles of decavanadate or orthovanadate

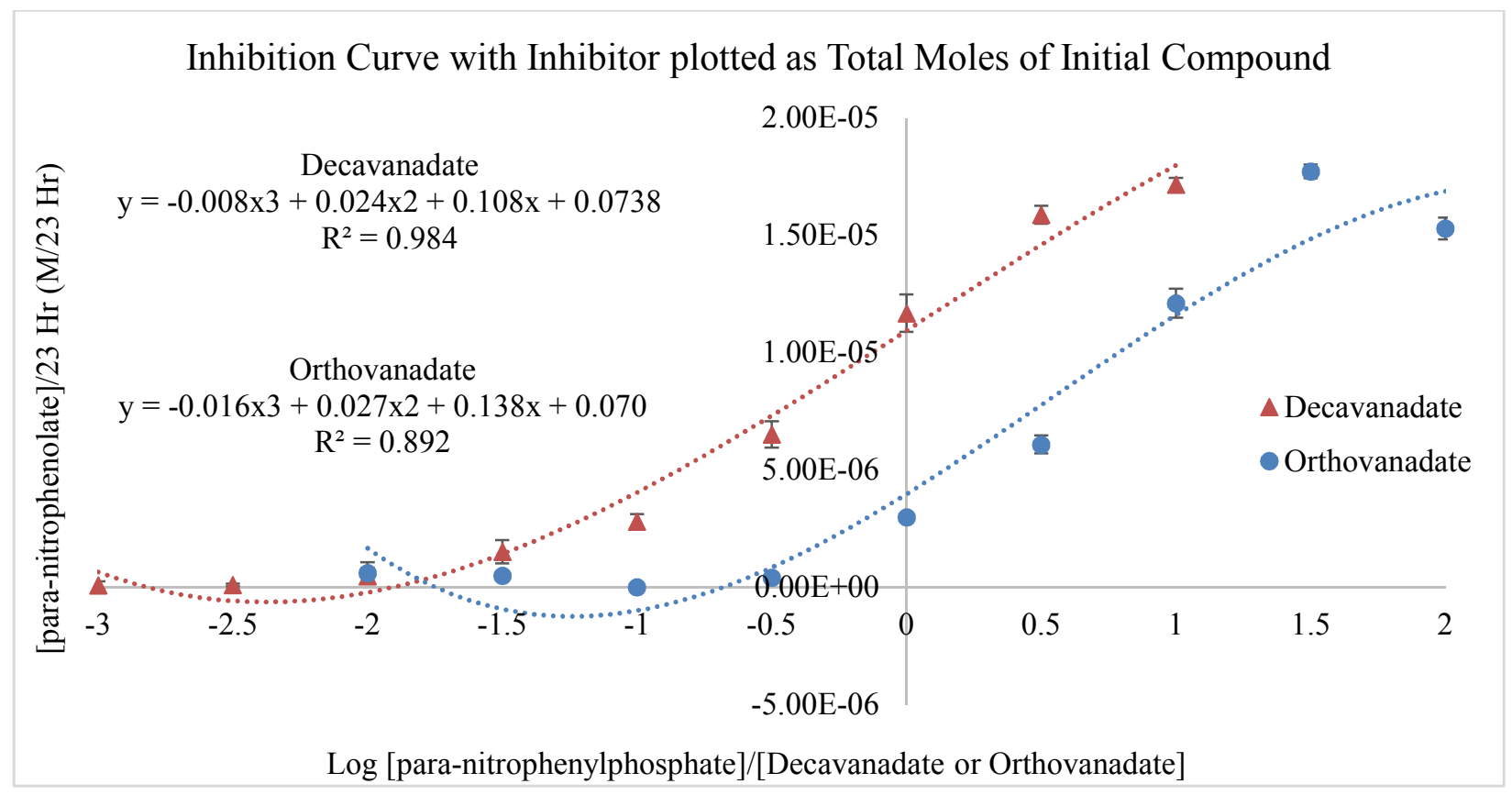

Figure 50. L. tarentolae secreted acid phosphatase enzyme activity (Y-axis) when incubated with decavanadate (red curve) or orthovanadate (blue curve) plotted as a function of $\log [\mathrm{S}] /[\mathrm{I}](\mathrm{X}$ axis). [I] is total moles of vanadium 


\section{Secreted Acid Phosphatase Enzyme Inhibition Assays with Pretreatment with Electric \\ Fields Followed by Incubation with and without Orthovanadate}

$$
(25 \mu \mathrm{M} \text { or LOG }[\mathrm{S}] /[\mathrm{I}]=1.19)
$$

The pretreatment of $L$. tarentolae $\log$ phase supernatant with a $50 \mathrm{~Hz}$, cathodic electric field at various current amplitudes resulted in three conditions $(150,200$, or $250 \mu \mathrm{A})$ that are different from control (Figure 51). These three conditions are statistically significant $(p<0.05$ for a paired, two tailed t-test). There is no consistent trend between current and secreted acid phosphatase inhibition greater than orthovanadate alone. The synergistic effect (more inhibition) of pretreatment with electric field followed by orthovanadate incubation is small.

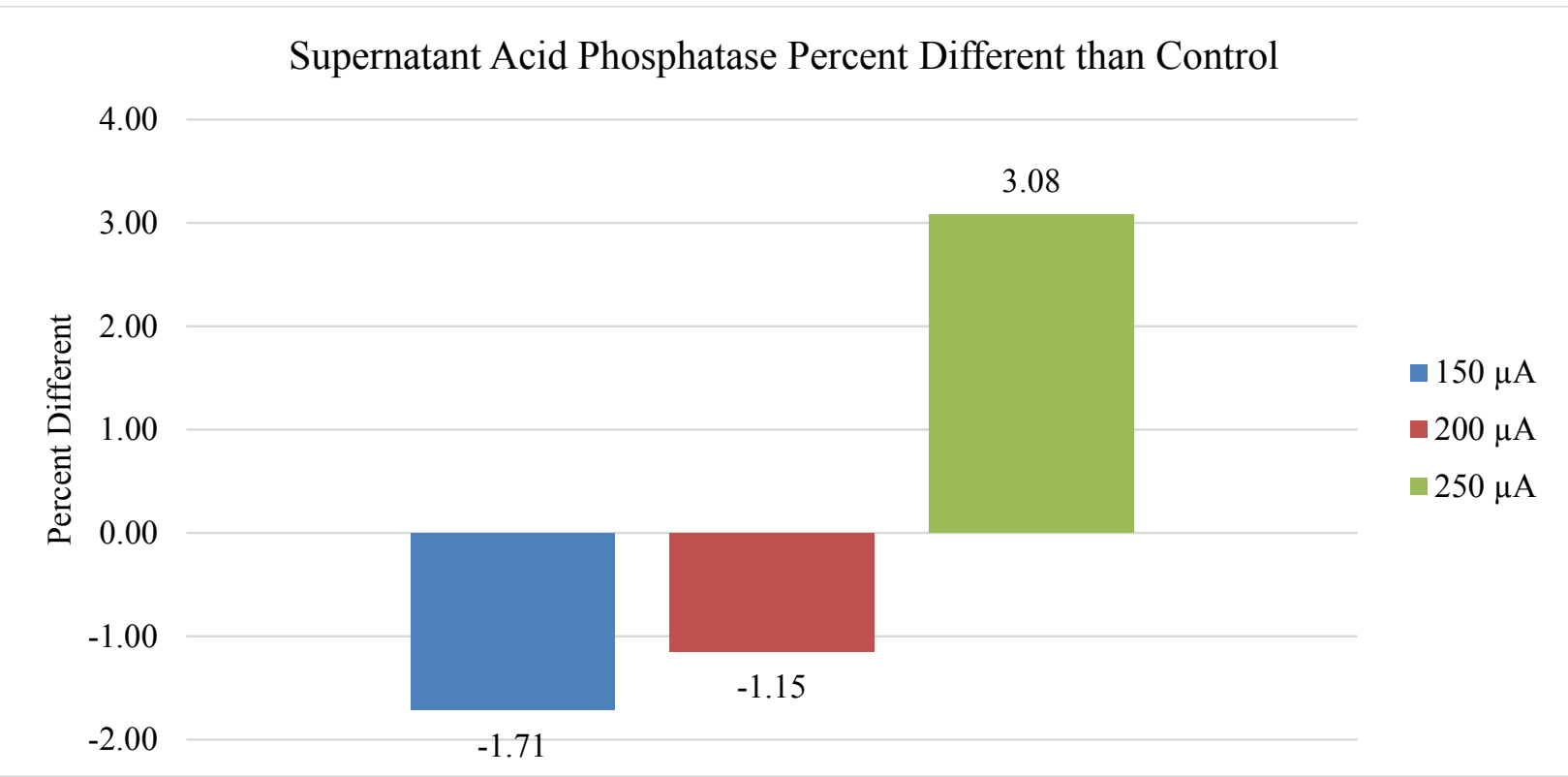

Figure 51. The effects, plotted as percent different from control, of pretreating the log phase $L$. tarentolae secreted acid phosphatase enzyme pool with $50 \mathrm{~Hz}$, cathodic electric field at various current exposures followed by orthovanadate $(25 \mu \mathrm{M})$ incubation compared to same time control ( $25 \mu \mathrm{M}$ orthovanadate exposure only) are shown

The pretreatment of $L$. tarentolae $\log$ phase supernatant with a $50 \mathrm{~Hz}$, symmetric biphasic electric field at various current amplitudes resulted in three conditions $(200,300$, or $500 \mu \mathrm{A})$ that 
are significantly different from control (Figure 52). These three conditions are statistically significant ( $\mathrm{p}<0.05$ for a paired, two tailed t-test). Under these conditions more current leads to greater inhibition compared to orthovanadate only incubation. The synergistic effect of pretreatment with electric field followed by orthovanadate incubation is, however, small.

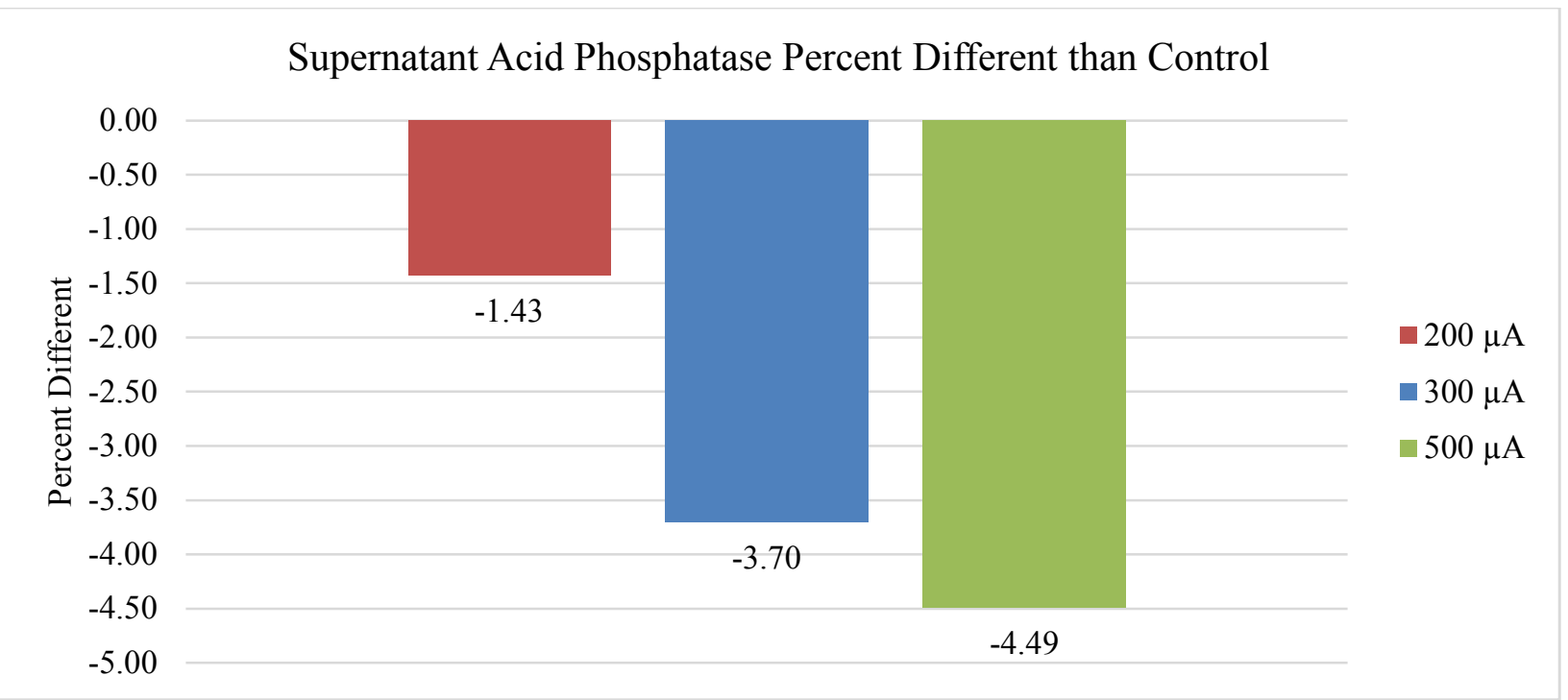

Figure 52. The effects, plotted as percent different from control, of pretreating the log phase $L$. tarentolae secreted acid phosphatase enzyme pool with $50 \mathrm{~Hz}$, symmetric biphasic electric field at various current exposures followed by orthovanadate $(25 \mu \mathrm{M})$ incubation compared to same time control ( $25 \mu \mathrm{M}$ orthovanadate exposure only) are shown

The pretreatment of $L$. tarentolae log phase supernatant with a $50 \mathrm{~Hz}$, anodic electric field at various current amplitudes resulted in three conditions $(150,200$, or $250 \mu \mathrm{A})$ that are different from control (Figure 53). These three conditions are statistically significant $(\mathrm{p}<0.05$ for a paired, two tailed t-test). There is no apparent trend between current and inhibition. The synergistic effect of pretreatment with electric field followed by orthovanadate incubation is small. 


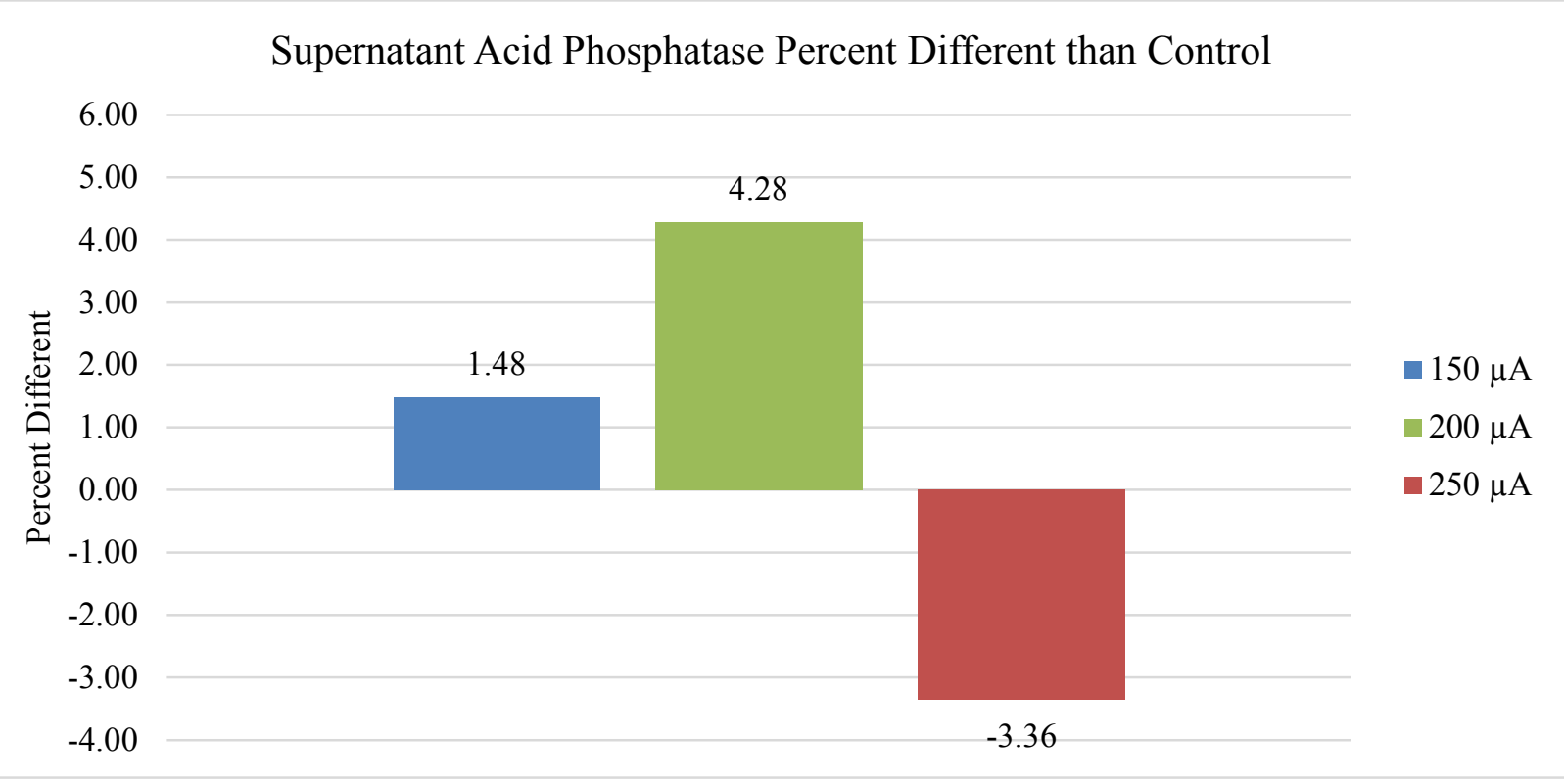

Figure 53. The effects, plotted as percent different from control, of pretreating the log phase $L$. tarentolae secreted acid phosphatase enzyme pool with $50 \mathrm{~Hz}$, anodic electric field at various current exposures followed by orthovanadate $(25 \mu \mathrm{M})$ incubation compared to same time control ( $25 \mu \mathrm{M}$ orthovanadate exposure only) are shown

The pretreatment of L. tarentolae log phase supernatant with a $10,000 \mathrm{~Hz}$, cathodic electric field at various current amplitudes resulted in five conditions $(150,250,300,400$, or 500 $\mu \mathrm{A})$ that are different from control (Figure 54). These five conditions are statistically significant $(\mathrm{p}<0.05$ for a paired, two tailed t-test). There is no apparent trend between current and inhibition. The synergistic effect of pretreatment with electric field followed by orthovanadate incubation is small, but more substantial than with $50 \mathrm{~Hz}$, cathodic treatment. 


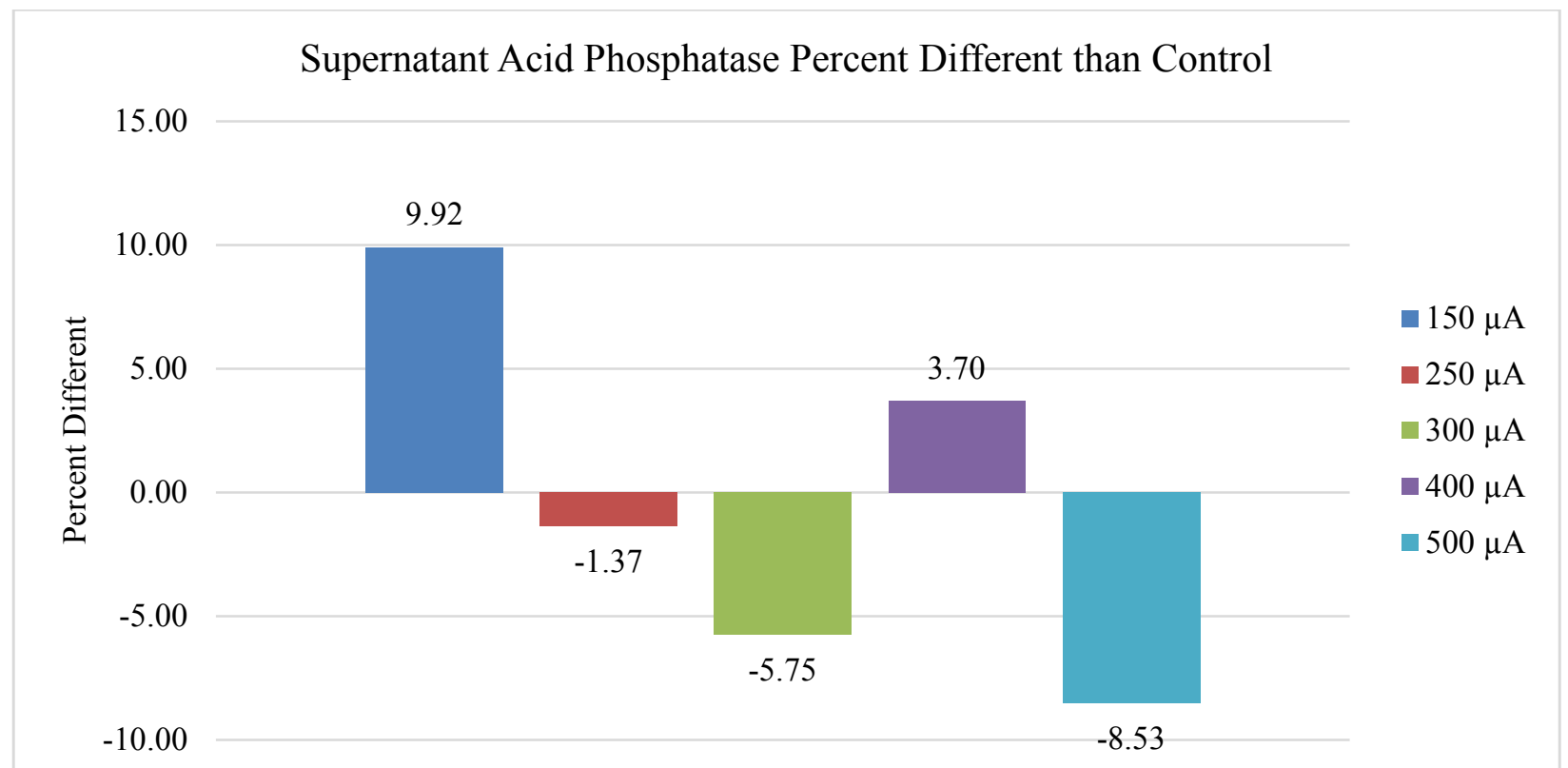

Figure 54. The effects, plotted as percent different from control, of pretreating the log phase $L$. tarentolae secreted acid phosphatase enzyme pool with $10,000 \mathrm{~Hz}$, cathodic electric field at various current exposures followed by orthovanadate $(25 \mu \mathrm{M})$ incubation compared to same time control ( $25 \mu \mathrm{M}$ orthovanadate exposure only) are shown

The pretreatment of $L$. tarentolae $\log$ phase supernatant with a $10,000 \mathrm{~Hz}$, symmetric biphasic electric field at various current amplitudes resulted in five conditions $(150,200,250$, 300 , or $400 \mu \mathrm{A}$ ) that are different from control (Figure 55). These five conditions are statistically significant ( $\mathrm{p}<0.05$ for a paired, two tailed t-test). There is no apparent trend between current and inhibition. The synergistic effect of pretreatment with electric field followed by orthovanadate incubation is small, and moderately smaller than shown by the $50 \mathrm{~Hz}$, symmetric biphasic treatment. 


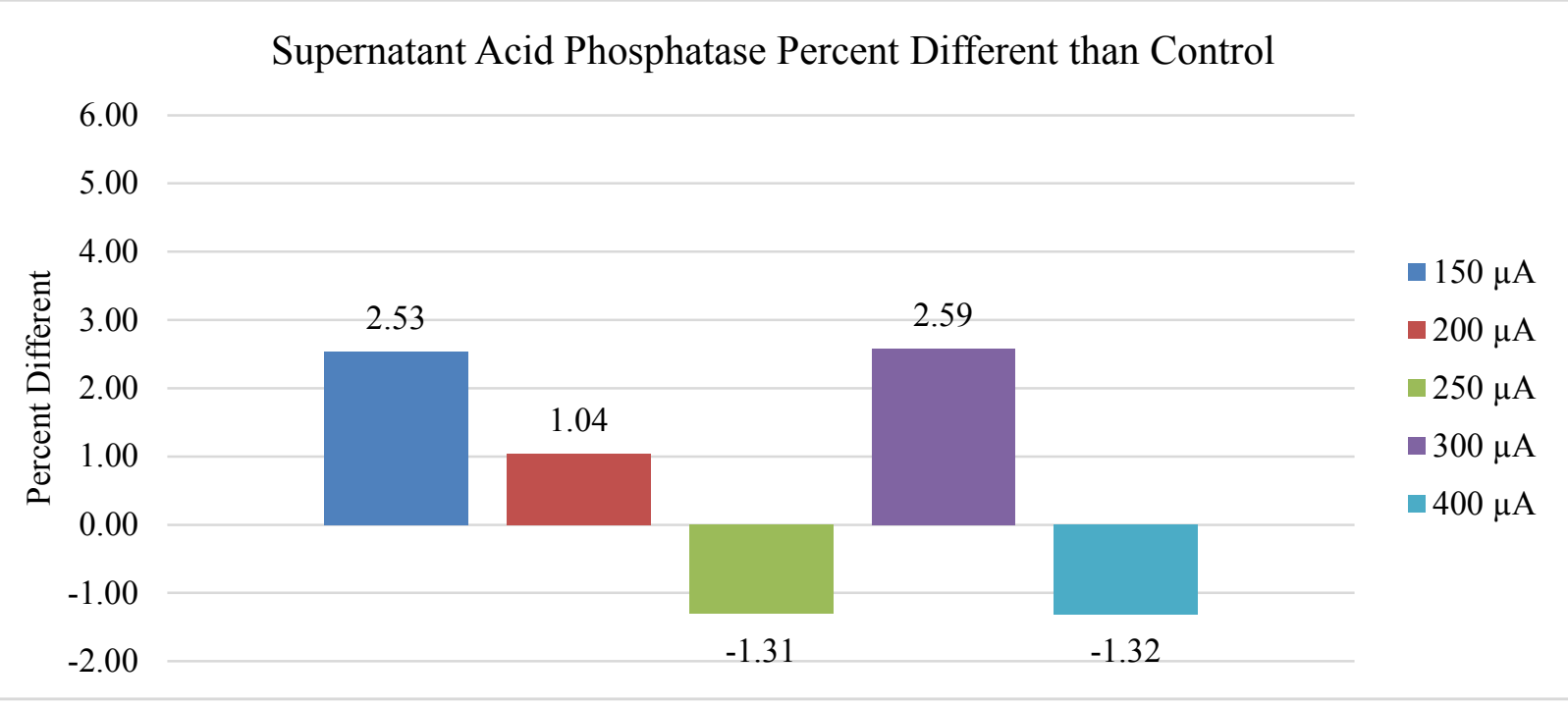

Figure 55. The effects, plotted as percent different from control, of pretreating the log phase $L$. tarentolae secreted acid phosphatase enzyme pool with $10,000 \mathrm{~Hz}$, symmetric biphasic electric field at various current exposures followed by orthovanadate $(25 \mu \mathrm{M})$ incubation compared to same time control ( $25 \mu \mathrm{M}$ orthovanadate exposure only) are shown

The pretreatment of $L$. tarentolae $\log$ phase supernatant with a $10,000 \mathrm{~Hz}$, anodic electric field at various current amplitudes resulted in six conditions $(100,150,200,250,300$, or 500 $\mu \mathrm{A})$ that are different from control (Figure 56). These six conditions are statistically significant $(\mathrm{p}<0.05$ for a paired, two tailed t-test). There is no apparent trend between current and inhibition. The synergistic effect of pretreatment with electric field followed by orthovanadate incubation is small, and in the range observed with the $50 \mathrm{~Hz}$, anodic treatment. 


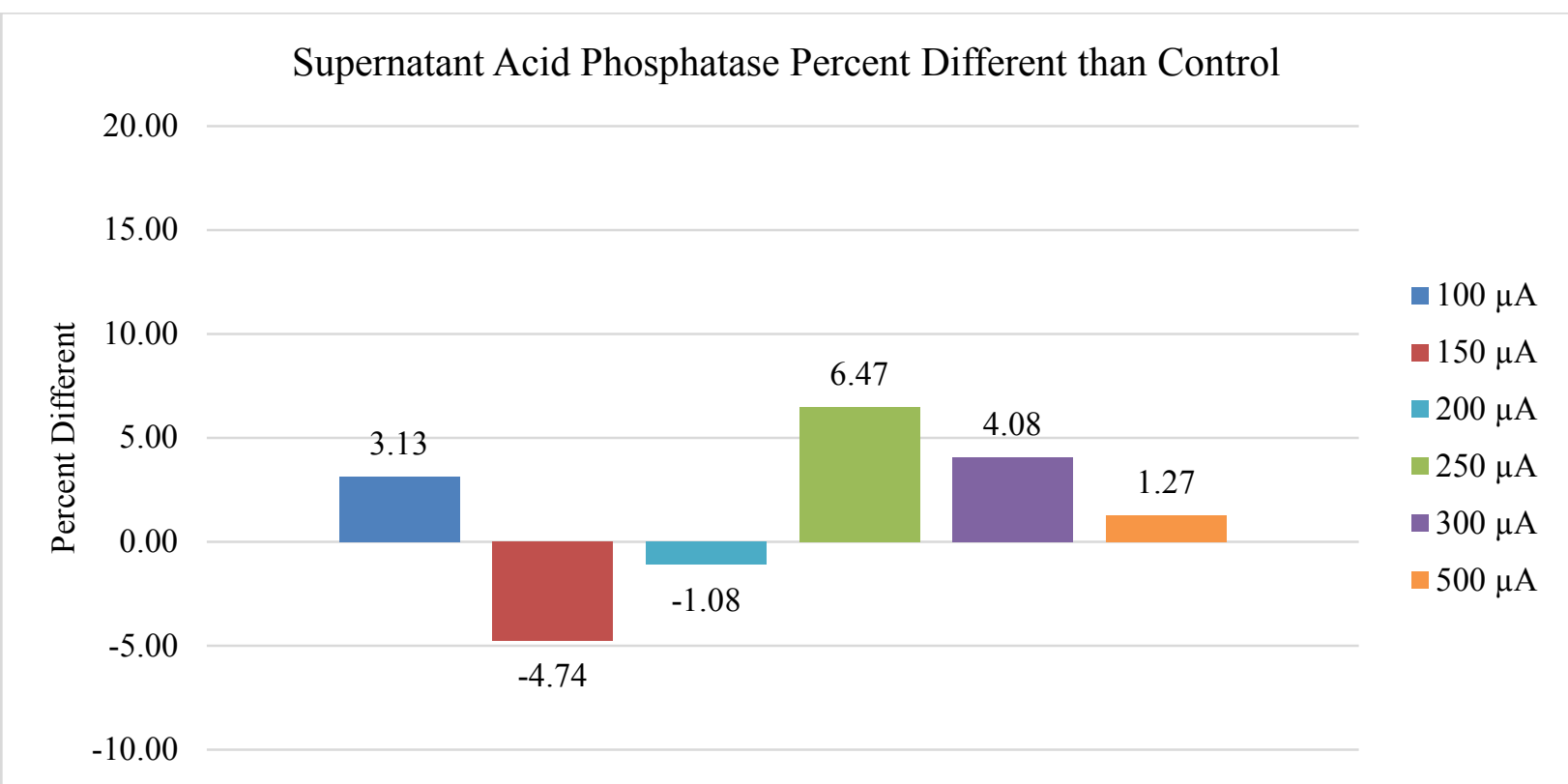

Figure 56. The effects, plotted as percent different from control, of pretreating the log phase $L$. tarentolae secreted acid phosphatase enzyme pool with $10,000 \mathrm{~Hz}$, anodic electric field at various current exposures followed by orthovanadate $(25 \mu \mathrm{M})$ incubation compared to same time control $(25 \mu \mathrm{M}$ orthovanadate exposure only) are shown

\section{Secreted Acid Phosphatase Kinetics Assay with and without the Preincubation with a}

\section{Glycosidase, Followed by Pretreatment with and without Electric Fields}

The pretreatment of log phase L. tarentolae enzyme pool with the glycosidase, PNGase F, resulted in a $5.00 \%$ decrease in the $\mathrm{k}_{\mathrm{M}}$ value of enzyme 1 compared to control, but no

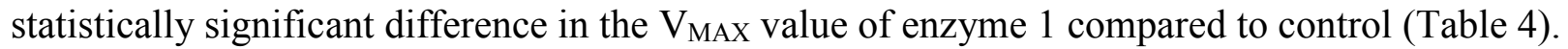
The pretreatment of $\log$ phase L. tarentolae enzyme pool with PNGase F resulted in a $36.49 \%$ decrease in the $\mathrm{k}_{\mathrm{M}}$ value of enzyme 2 compared to control, but no statistically significant difference in the $\mathrm{V}_{\text {MAX }}$ value of enzyme 2 compared to control (Table 5). The pretreatment of log phase L. tarentolae enzyme pool with PNGase F followed by the application of $10,000 \mathrm{~Hz}, 100$ $\mu \mathrm{A}$, anodic electric field resulted in an 8.33 percent decrease in $\mathrm{k}_{\mathrm{M}}$ value of enzyme 1 compared to control, and a 12.57 increase in the $\mathrm{V}_{\mathrm{MAX}}$ value of enzyme 1 compared to control. The pretreatment of log phase L. tarentolae enzyme pool with PNGase F followed by the application 
of $10,000 \mathrm{~Hz}, 100 \mu \mathrm{A}$, anodic electric field resulted in no changes in either $\mathrm{k}_{\mathrm{M}}$ or $\mathrm{V}_{\mathrm{MAX}}$ value of enzyme 2 that were statistically different compared to control.

\begin{tabular}{|c|c|c|c|c|}
\hline Conditions & $\mathrm{k}_{\mathrm{M}}(\mu \mathrm{M})$ & $\begin{array}{c}\mathrm{V}_{\mathrm{MAX}} \\
(\mu \mathrm{M} / 23 \mathrm{Hr})\end{array}$ & $\begin{array}{c}\mathrm{k}_{\mathrm{M}} \text { Percent } \\
\text { different versus } \\
\text { control }\end{array}$ & $\begin{array}{c}\text { V } \\
\text { different versus } \\
\text { control }\end{array}$ \\
\hline $\begin{array}{c}\text { 24 Hour } \\
\text { incubation with } \\
\text { PNGase F }\end{array}$ & $0.114 \pm 0.030$ & $55.866 \pm 1.616$ & -5.00 & $\begin{array}{c}\text { Not statistically } \\
\text { different from } \\
\text { control }\end{array}$ \\
\hline $\begin{array}{c}\text { 24 Hour } \\
\text { incubation with } \\
\text { PNGase F } \\
\text { followed by 30 } \\
\text { min exposure to } \\
10,000 \text { Hz, 100 } \\
\mu \text { A, anodic } \\
\text { electric field }\end{array}$ & $0.130 \pm 0.011$ & $62.500 \pm 1.937$ & -8.33 & 12.57 \\
\hline
\end{tabular}

Table 4. Enzyme 1 kinetic parameters $\mathrm{k}_{\mathrm{M}}$ and $\mathrm{V}_{\mathrm{MAX}}$ under different conditions compared to control. Negative percentages indicate a decrease in value compared to control. Positive percentages indicate an increase in value compared to control 


\begin{tabular}{|c|c|c|c|c|}
\hline Conditions & $\mathrm{k}_{\mathrm{M}}(\mu \mathrm{M})$ & $\begin{array}{c}V_{\text {MAX }} \\
(\mu \mathrm{M} / 23 \mathrm{Hr})\end{array}$ & $\begin{array}{c}\mathrm{k}_{\mathrm{M}} \text { Percent } \\
\text { different versus } \\
\text { control } \\
\end{array}$ & $\begin{array}{l}\mathrm{V}_{\text {MAX Percent }} \\
\text { different versus } \\
\text { control }\end{array}$ \\
\hline $\begin{array}{c}24 \text { Hour } \\
\text { incubation with } \\
\text { PNGase F }\end{array}$ & $\begin{array}{c}1.480 \mathrm{E}-04 \pm \\
0.033 \mathrm{E}-04\end{array}$ & $30.647 \pm 0.688$ & -34.69 & $\begin{array}{l}\text { Not statistically } \\
\text { different from } \\
\text { control }\end{array}$ \\
\hline $\begin{array}{c}24 \text { Hour } \\
\text { incubation with } \\
\text { PNGase F } \\
\text { followed by } 30 \\
\text { min exposure to } \\
10,000 \mathrm{~Hz}, 100 \\
\mu \mathrm{A}, \text { anodic } \\
\text { electric field }\end{array}$ & $\begin{array}{c}4.926 \mathrm{E}-04 \pm \\
2.440 \mathrm{E}-04\end{array}$ & $33.818 \pm 1.891$ & $\begin{array}{l}\text { Not statistically } \\
\text { different from } \\
\text { control }\end{array}$ & $\begin{array}{l}\text { Not statistically } \\
\text { different from } \\
\text { control }\end{array}$ \\
\hline
\end{tabular}

Table 5. Enzyme 2 kinetic parameters $\mathrm{k}_{\mathrm{M}}$ and $\mathrm{V}_{\mathrm{MAX}}$ under different conditions compared to control. Negative percentages indicate a decrease in value compared to control. Positive percentages indicate an increase in value compared to control 


\title{
CHAPTER IV \\ CONCLUSIONS AND FUTURE WORK
}

\section{Cell Culture and Microscopy of $L$. tarentolae and Assessment of Cell Viability by the MTT}

\begin{abstract}
Assay
Using L. tarentolae promastigotes as a model system to probe potential Leishmania therapeutics continues to prove itself useful, especially in the context of this work. The capacity for these cells to be easily grown, assessed by multiple metrics (MTT assay and microscopy), and their predictable behavior make them a valuable tool as a model system.
\end{abstract}

\section{Secreted Acid or Alkaline Phosphatase Enzyme Assay}

Secreted acid phosphatase activity for L. tarentolae supernatant is detectable on all eight days of a typical L. tarentolae growth curve. Because the log phase is likely the most relevant phase to the Leishmania infection cycle, log phase whole cells or cell supernatant should be used in all future studies for this work. Secreted alkaline phosphatase activity is not detectable on any of the eight days of the L. tarentolae growth curve. Therefore, secreted alkaline phosphatase activity should not be assayed in any future studies of this work.

\section{Kinetic Enzyme Assay}

Supernatant enzyme source collected from L. tarentolae log phase cells gives an apparent typical Michaelis-Menten type response to increasing substrate concentrations. However, the Lineweaver-Burk linear transformation of the V versus S curve of the L. tarentolae log phase supernatant produced two straight lines (Figures 15, 16, and 17). Thus, two enzymes with different $\mathrm{k}_{\mathrm{M}}$ or $\mathrm{V}_{\mathrm{MAX}}$ values are detectable in the L. tarentolae log phase cell supernatant (Figures 18 and 19, and Tables 2 and 3) using this kinetic approach. These kinetic data correlate with the gene data indicating two separate enzymes as reported by Shakariana et al., 1997. 
Enzyme 1 has a larger $\mathrm{k}_{\mathrm{M}}$ and larger $\mathrm{V}_{\mathrm{MAX}}\left(\right.$ Table 2) than enzyme 2. Enzyme 2 has a smaller $\mathrm{k}_{\mathrm{M}}$ and smaller $\mathrm{V}_{\mathrm{MAX}}$ (Table 3) than enzyme 1. Enzyme 1 binds substrate less effectively than enzyme 2, but enzyme 1 makes product at a larger velocity than enzyme 2 . The capacity of enzyme 1 to be detected on all eight days of the L. tarentolae growth curve suggests this enzyme may play a role beyond that of aiding in survival of the parasite in the sand fly or aiding in human infectivity. The inability for enzyme 2 to be detected on days one and two of the $L$. tarentolae growth curve, followed by its lower $\mathrm{V}_{\mathrm{MAX}}$ value on days three to six, then a large apparent increase in $\mathrm{V}_{\mathrm{MAX}}$ as the culture appears to enter the senescence phase (Figure 19, Day 7) suggests that enzyme 2 may be stored and released for a specific function. This interpretation assumes $V_{\text {MAX }}$ is only increasing because the concentration of enzyme 2 is increasing, and that $\mathrm{V}_{\mathrm{MAX}}$ is equal to $\mathrm{k}_{2}\left[\mathrm{E}_{\text {total }}\right]$ for a Michaelis-Menten type enzyme.

Testing the Acute Effects of Electric Fields on L. tarentolae Growth Curves and Microscopy

L. tarentolae MTT response was unaffected by treatment with any of the tested electric fields. However, the cells do appear to respond to electric fields since $L$. tarentolae cell clumping is differentially affected by electric field frequency, polarity, and current. As the electric field frequency increases, L. tarentolae cell clumping increases. Effect of polarity is such that the application of any electric field causes aggregation of $L$. tarentolae underneath the electrode, with cell population density decreasing as a function of distance away from the electrode. Furthermore, the application of anodic electric fields causes the cells not only to aggregate, but also to clump. We interpret this clumping as a stress response from L. tarentolae. As current amplitude increases, $L$. tarentolae cell clumping increases. The interpretation of a treatment causing cell clumping is that said treatment is stressing the cells. In cell clumps, L. tarentolae may exhibit a behavior identified as quorum sensing. During quorum sensing, cells restrict the 
expression of specific genes to the high cell densities at which the resulting phenotypes will be most beneficial to survival (Miller, Bassler, 2001). Therefore, the conditions of electric fields could be optimized such that maximum cell aggregation occurs in one area, thus making effective dosing of a topical therapeutic more easily accomplished.

\section{Testing the Effects of Electric Fields on L. tarentolae Acid Phosphatase Activity in}

\section{Supernatant or Pellet (Cells), Method 1}

Method 1 was used to investigate eighty-four different experimental conditions and Figure 57 is a summary. Seventy-two of the eighty-four experimental conditions were different than control and statistically significant $(\mathrm{p}<0.05$ for a paired, two tailed t-test). Thirty-eight of the forty-two conditions tested with the supernatant enzymes were statistically different from controls $(\mathrm{p}<0.05$ for a paired, two tailed t-test). Thirty-four of the forty-two conditions tested on the cell pellets were statistically different from controls ( $\mathrm{p}<0.05$ for a paired, two tailed t-test). Thirty of the eighty-four tested conditions affected both the supernatant and the cell pellet acid phosphatase activity. Twenty-one of the thirty conditions caused an increase in supernatant activity and a decrease in pellet activity. Five of the thirty conditions increased both supernatant and pellet activity. Two of the thirty conditions decreased the supernatant or pellet activity. Two of the thirty conditions decreased supernatant activity or increased pellet activity.

Thirty-four of the forty-two $50 \mathrm{~Hz}$ conditions tested were statistically significant $(\mathrm{p}<$ 0.05 for a paired, two tailed t-test). Eighteen of the thirty-four significant results were from applying electric fields to L. tarentolae log phase cell supernatant. The magnitude of the average effect from a $50 \mathrm{~Hz}$ cathodic electric field is $2.10 \%$ different from control $(2.35 \%$ activation, $0.86 \%$ inhibition). The magnitude of the average effect from a $50 \mathrm{~Hz}$ symmetric biphasic electric field is $2.59 \%$ different from control (2.00\% activation, $3.19 \%$ inhibition). The 
magnitude of the average effect from a $50 \mathrm{~Hz}$ anodic electric field is $0.56 \%$ different from control ( $0.52 \%$ activation, $0.57 \%$ inhibition). Sixteen of the thirty-four significant results were from applying electric fields to $L$. tarentolae log phase cell pellets. The magnitude of the average effect from a $50 \mathrm{~Hz}$ cathodic electric field is $1.72 \%$ different from control (1.51\% activation, $1.93 \%$ inhibition). The magnitude of the average effect from a $50 \mathrm{~Hz}$ symmetric biphasic electric field is $3.91 \%$ different from control ( $4.47 \%$ activation, $3.54 \%$ inhibition). The magnitude of the average effect from a $50 \mathrm{~Hz}$ anodic electric field is $4.38 \%$ different from control ( $5.08 \%$ activation, $3.33 \%$ inhibition). Within the $50 \mathrm{~Hz}$ frequency, the largest activation effect on average is seen from the application of $50 \mathrm{~Hz}$ anodic electric fields to L. tarentolae cell pellets. The greatest average inhibition caused by $50 \mathrm{~Hz}$ is the application of $50 \mathrm{~Hz}$ symmetric biphasic electric fields to L. tarentolae log phase cell pellets.

Thirty-eight of the forty-two $10,000 \mathrm{~Hz}$ conditions tested were statistically significant ( $\mathrm{p}$ $<0.05$ for a paired, two tailed t-test). Twenty of the thirty-eight significant results were from applying electric fields to $L$. tarentolae log phase cell supernatant. The magnitude of the average effect from a 10,000 $\mathrm{Hz}$ cathodic electric field is $12.31 \%$ different from control (12.31\% activation, $0.00 \%$ inhibition). The magnitude of the average effect from a 10,000 $\mathrm{Hz}$ symmetric biphasic electric field is $2.31 \%$ different from control (2.64\% activation, $0.35 \%$ inhibition). The magnitude of the average effect from a $10,000 \mathrm{~Hz}$ anodic electric field is $14.27 \%$ different from control ( $14.27 \%$ activation, $0.00 \%$ inhibition). Eighteen of the thirty-eight significant results were from applying electric fields to $L$. tarentolae log phase cell pellets. The magnitude of the average effect from a $10,000 \mathrm{~Hz}$ cathodic electric field is $16.56 \%$ different from control ( $0.00 \%$ activation, $16.56 \%$ inhibition). The magnitude of the average effect from a $10,000 \mathrm{~Hz}$ symmetric biphasic electric field is $7.81 \%$ different from control (7.30 \% activation, $7.90 \%$ 
inhibition). The magnitude of the average effect from a $10,000 \mathrm{~Hz}$ anodic electric field is $4.28 \%$ different from control (4.90\% activation, $4.16 \%$ inhibition). Within the $10,000 \mathrm{~Hz}$ frequency, the largest activation effect on average is seen from the application of $10,000 \mathrm{~Hz}$ cathodic electric fields to $L$. tarentolae cell pellets. The greatest average activation caused by $10,000 \mathrm{~Hz}$ is the application of $10,000 \mathrm{~Hz}$ anodic electric fields to L. tarentolae log phase cell supernatant. The greatest average inhibition caused by $10,000 \mathrm{~Hz}$ is the application of $10,000 \mathrm{~Hz}$ cathodic electric fields to L. tarentolae log phase cell pellets.

\section{Testing the Effects of Electric Fields on L. tarentolae Acid Phosphatase Activity in}

\section{Supernatant or Pellet (Cells), Method 2}

Method 2 was used to investigate eighty-four different experimental conditions and Figure 58 is a summary. Forty-five of the eighty-four experimental conditions were different than control and statistically significant $(\mathrm{p}<0.05$ for a paired, two tailed t-test). Nineteen of the forty-two conditions tested with the supernatant enzymes were statistically different from controls ( $p<0.05$ for a paired, two tailed t-test). Twenty-six of the forty-two conditions tested on the pellets were statistically different from controls $(\mathrm{p}<0.05$ for a paired, two tailed $\mathrm{t}$-test). Fourteen of the eighty-four tested conditions affected both the supernatant and the pellet acid phosphatase activity. Two of the fourteen conditions caused an increase in supernatant activity and a decrease in pellet activity. Six of the fourteen conditions increased both supernatant and pellet activity. Three of the fourteen conditions decreased both the supernatant and pellet activity. Three of the fourteen conditions decreased supernatant activity or increased pellet activity.

Twenty of the forty-two $50 \mathrm{~Hz}$ conditions tested were statistically significant $(\mathrm{p}<0.05$ for a paired, two tailed t-test). Seven of the twenty significant results were from applying electric 
fields to L. tarentolae log phase cell supernatant. The magnitude of the average effect from a 50 $\mathrm{Hz}$ cathodic electric field is $2.50 \%$ different from control (3.04 \% activation, $1.70 \%$ inhibition). The magnitude of the average effect from a $50 \mathrm{~Hz}$ symmetric biphasic electric field cannot be discussed due to these data not being statistically different from control. The magnitude of the average effect from a $50 \mathrm{~Hz}$ anodic electric field is $2.67 \%$ different from control $(2.67 \%$ activation, $0.00 \%$ inhibition). Thirteen of the twenty significant results were from applying electric fields to $L$. tarentolae $\log$ phase cell pellets. The magnitude of the average effect from a $50 \mathrm{~Hz}$ cathodic electric field is $3.11 \%$ different from control (3.38\% activation, $2.97 \%$ inhibition). The magnitude of the average effect from a $50 \mathrm{~Hz}$ symmetric biphasic electric field is $19.34 \%$ different from control (36.2\% activation, $2.43 \%$ inhibition). The magnitude of the average effect from a $50 \mathrm{~Hz}$ anodic electric field is $2.43 \%$ different from control (1.91\% activation, $3.21 \%$ inhibition). Within the $50 \mathrm{~Hz}$ frequency, the largest effect on average is seen from the application of $50 \mathrm{~Hz}$ symmetric biphasic electric fields to L. tarentolae cell pellets. The greatest average activation caused by $50 \mathrm{~Hz}$ is the application of $50 \mathrm{~Hz}$ cathodic electric fields to L. tarentolae log phase cell supernatant. The greatest average inhibition caused by $50 \mathrm{~Hz}$ is the application of $50 \mathrm{~Hz}$ symmetric biphasic electric fields to L. tarentolae log phase cell pellets.

Twenty-five of the forty-two $10,000 \mathrm{~Hz}$ conditions tested were statistically significant ( $\mathrm{p}$ $<0.05$ for a paired, two tailed t-test). Twelve of the twenty-five significant results were from applying electric fields to L. tarentolae log phase cell supernatant. The magnitude of the average effect from a 10,000 Hz cathodic electric field is $1.17 \%$ different from control $(1.49 \%$ activation, $0.71 \%$ inhibition). The magnitude of the average effect from a $10,000 \mathrm{~Hz}$ symmetric biphasic electric field is $0.88 \%$ different from control ( $0.69 \%$ activation, $1.26 \%$ inhibition). The magnitude of the average effect from a $10,000 \mathrm{~Hz}$ anodic electric field is $2.25 \%$ different 
from control (1.51\% activation, $2.98 \%$ inhibition). Thirteen of the twenty-five significant results were from applying electric fields to $L$. tarentolae log phase cell pellets. The magnitude of the average effect from a $10,000 \mathrm{~Hz}$ cathodic electric field is $4.48 \%$ different from control (7.31\% activation, $3.07 \%$ inhibition). The magnitude of the average effect from a 10,000 Hz symmetric biphasic electric field is $9.91 \%$ different from control ( $8.75 \%$ activation, $12.22 \%$ inhibition). The magnitude of the average effect from a $10,000 \mathrm{~Hz}$ anodic electric field is $5.13 \%$ different from control (6.00\% activation, $3.35 \%$ inhibition). Within the $10,000 \mathrm{~Hz}$ frequency, the largest effect on average is seen from the application of $10,000 \mathrm{~Hz}$ symmetric biphasic electric fields to $L$. tarentolae cell pellets. The greatest average activation caused by $10,000 \mathrm{~Hz}$ is the application of $10,000 \mathrm{~Hz}$ symmetric biphasic electric fields to L. tarentolae log phase cell supernatant. The greatest average inhibition caused by $10,000 \mathrm{~Hz}$ is the application of $10,000 \mathrm{~Hz}$ symmetric biphasic electric fields to L. tarentolae log phase cell pellets. This apparent discrepancy can be explained by understanding that different currents within a single frequency and polarity had different effects on acid phosphatase enzyme activity.

\section{Comparing the Effectiveness of Method 1 to Method 2}

When comparing the effectiveness of method 1 (separating supernatant from pellet then applying electric fields directly to enzyme pools) to method 2 (applying electric fields to whole cells followed by separation of supernatant from pellet), the number of total experiments that produced statistically different enzyme activity compared to control are seventy-two (method 1) compared to forty-five (method 2). As shown in Figures 57 and 58, the total number of statistically significant supernatant experiments is thirty-eight (method 1) compared to nineteen

(method 2). The total number of statistically significant pellet experiments is thirty-four (method 1) compared to twenty-six (method 2). Comparing the average effect from a $50 \mathrm{~Hz}$ waveform on 
L. tarentolae cell supernatant acid phosphatase activity, utilizing either method 1 or method 2, method 2 (2.59\% different than control) produced a larger effect, on average, than method 1 (1.75\% different than control). Comparing the activating effect from a $50 \mathrm{~Hz}$ waveform on $L$. tarentolae cell supernatant acid phosphatase activity, utilizing either method 1 or method 2, method 2 (2.86\% different than control) is more effective than method $1(1.62 \%$ different than control). Comparing the inhibition effect from a $50 \mathrm{~Hz}$ waveform on $L$. tarentolae cell supernatant acid phosphatase activity, utilizing either method 1 or method 2, method 1 (1.54\% different than control) is more effective than method $2(0.85 \%$ different than control). Thus, while the total number of statistically significant results is larger when using method 1 , the overall magnitude of the effect, or the activation effect, of the application of $50 \mathrm{~Hz}$ electric fields is larger on L. tarentolae cell supernatant when using method 2. The magnitude of the inhibition effect on L. tarentolae cell supernatant caused by the application of $50 \mathrm{~Hz}$ magnetic fields is largest when using method 1.

Comparing the average effect from a $10,000 \mathrm{~Hz}$ waveform on $L$. tarentolae cell supernatant acid phosphatase activity, utilizing either method 1 or method 2, method 1 (9.63\% different than control) is more effective than method 2 (1.43\% different than control). Comparing the activating effect from a $10,000 \mathrm{~Hz}$ waveform on $L$. tarentolae cell supernatant acid phosphatase activity, utilizing either method 1 or method 2 , method $1(9.74 \%$ different than control) is more effective than method 2 ( $1.23 \%$ different than control). Comparing the inhibition effect from a $10,000 \mathrm{~Hz}$ waveform on $L$. tarentolae cell supernatant acid phosphatase activity, utilizing either method 1 or method 2 , method 2 (1.65\% different than control) is more effective than method $1(0.12 \%$ different than control). Thus, the total number of statistically significant results is larger when using method 1 , and the overall magnitude of the effect, or the 
activation effect, of the application of $10,000 \mathrm{~Hz}$ electric fields is larger on L. tarentolae cell supernatant when using method 1 . The magnitude of the inhibition effect on L. tarentolae cell supernatant caused by the application of $10,000 \mathrm{~Hz}$ magnetic fields is largest when using method 2 .

Comparing the average effect from a $50 \mathrm{~Hz}$ waveform on L. tarentolae cell pellet acid phosphatase activity, utilizing either method 1 or method 2 , method $2(8.29 \%$ different than control) is more effective than method 1 (3.34 \% different than control). Comparing the activating effect from a $50 \mathrm{~Hz}$ waveform on $L$. tarentolae cell pellet acid phosphatase activity, utilizing either method 1 or method 2 , method $2(13.84 \%$ different than control) is more effective than method 1 (3.69 \% different than control). Comparing the inhibition effect from a $50 \mathrm{~Hz}$ waveform on $L$. tarentolae cell supernatant acid phosphatase activity, utilizing either method 1 or method 2 , method 1 (2.93\% different than control) is more effective than method 2 ( $2.87 \%$ different than control). Thus, while the total number of statistically significant results is larger when using method 1 , the overall magnitude of the effect, or the activation effect, of the application of 10,000 Hz electric fields is larger on L. tarentolae cell pellets when using method 2. The magnitude of the inhibition effect on L. tarentolae cell pellets caused by the application of $50 \mathrm{~Hz}$ magnetic fields is largest when using method 1.

Comparing the average effect from a $10,000 \mathrm{~Hz}$ waveform on $L$. tarentolae cell pellet acid phosphatase activity, utilizing either method 1 or method 2 , method 1 (9.55\% different than control) is more effective than method 2 (6.51\% different than control). Comparing the activating effect from a 10,000 $\mathrm{Hz}$ waveform on L. tarentolae cell pellet acid phosphatase activity, utilizing either method 1 or method 2 , method 2 ( $7.35 \%$ different than control) is more effective than method 1 (4.07 \% different than control). Comparing the inhibition effect from a 
$10,000 \mathrm{~Hz}$ waveform on L. tarentolae cell supernatant acid phosphatase activity, utilizing either method 1 or method 2 , method $1(9.54 \%$ different than control) is more effective than method 2 (6.21\% different than control). Thus, both the total number of statistically significant results is larger when using method 1 , and the overall magnitude, or inhibition effect, of the application of $10,000 \mathrm{~Hz}$ electric fields is larger on L. tarentolae cell pellets when using method 1 . The magnitude of the activation effect on L. tarentolae cell pellets caused by the application of $10,000 \mathrm{~Hz}$ magnetic fields is largest when using method 2.

\section{Total Experiments}

\section{Significantly \\ Different vs. Control}

\section{Conditions Affect Both}

Supernatant and Pellet

Figure 57. A summary of the results from method 1 


\section{Total Experiments}

\section{Significantly \\ Different vs. Control}

39 Not Significantly

Different vs. Control

\section{Supernatant Significantly} Different vs. Control

\section{Pellet Significantly \\ Different vs. Control}

\section{Conditions Affect Both}

Supernatant and Pellet

Figure 58. A summary of the results from method 2

\section{Secreted Acid Phosphatase Enzyme Inhibition Assay (Following the Method of Baumhardt}

$$
\text { et al., 2015) }
$$

Using Baumhardt et al., 2015 as model system, it is clear that when comparing the inhibitory effects of decavanadate to orthovanadate on L. tarentolae log phase supernatant acid phosphatase activity, orthovanadate is a better inhibitor than decavanadate on a mole of total vanadium basis (Figure 50). These data correlate with the x-ray diffraction data in the studies reviewed by McLauchlan et al. (2015). Therefore, orthovanadate was used as an inhibitor at the $\log [\mathrm{S}] /[\mathrm{I}]$ ratio $=1.19$ in most of this thesis work. This ratio is selected because it inhibits acid phosphatase activity but does not completely shut down the enzyme. Thus, any potential synergistic effect caused by electric field treatment followed by orthovanadate exposure can be observed. 


\section{Secreted Acid Phosphatase Enzyme Inhibition Assays with Pretreatment with Electric Fields Followed by Incubation with and without Orthovanadate (25 $\mu \mathrm{M})$}

Pretreatment of $L$. tarentolae log phase supernatant with $50 \mathrm{~Hz}$ electric fields followed by incubation with competitive inhibitor orthovanadate $(25 \mu \mathrm{M}, \log [\mathrm{S}] /[\mathrm{I}]=1.19)$ resulted in nine out of the twenty-one tested conditions being statistically different $(\mathrm{p}<0.05$ for a paired, two tailed t-test) than control (incubation with orthovanadate, $25 \mu \mathrm{M}$, only). The average magnitude of the $50 \mathrm{~Hz}$ cathodic electric field is $1.98 \%$ different from control (3.08 \% activation, $1.43 \%$ inhibition). The average magnitude of the $50 \mathrm{~Hz}$ symmetric biphasic electric field is $3.21 \%$ different from control ( $0.00 \%$ activation, $3.21 \%$ inhibition). The average magnitude of the 50 $\mathrm{Hz}$ anodic electric field is $3.04 \%$ different from control (2.88 \% activation, $3.36 \%$ inhibition).

Pretreatment of L. tarentolae $\log$ phase supernatant with $10,000 \mathrm{~Hz}$ electric fields followed by incubation with competitive inhibitor orthovanadate $(25 \mu \mathrm{M})$ resulted in seventeen out of the twenty-one tested conditions being statistically different $(\mathrm{p}<0.05$ for a paired, two tailed t-test) than control (incubation with orthovanadate, $25 \mu \mathrm{M}$, only). The average magnitude of the $10,000 \mathrm{~Hz}$ cathodic electric field is $5.85 \%$ different from control $(6.81 \%$ activation, 5.22 $\%$ inhibition). The average magnitude of the $10,000 \mathrm{~Hz}$ symmetric biphasic electric field is 1.76 $\%$ different from control (2.05\% activation, $1.32 \%$ inhibition). The average magnitude of the $10,000 \mathrm{~Hz}$ anodic electric field is $3.46 \%$ different from control (3.74 \% activation, $2.91 \%$ inhibition).

The total average effect from the application of electric fields to $L$. tarentolae log phase cell supernatant is larger for 10,000 Hz electric fields (3.69\%) compared to $50 \mathrm{~Hz}$ electric fields ( $2.74 \%)$. The average activation from the application of electric fields to L. tarentolae log phase cell supernatant is larger for 10,000 Hz electric fields (4.20 \%) compared to $50 \mathrm{~Hz}$ electric fields 
(1.99\%). The average deactivation from the application of electric fields to L. tarentolae log phase cell supernatant is larger for $10,000 \mathrm{~Hz}$ electric fields (3.15\%) compared to $50 \mathrm{~Hz}$ electric fields $(2.67 \%)$. Therefore, the greatest antagonistic effects that occur from pretreatment by electric fields followed by orthovanadate incubation are with $10,000 \mathrm{~Hz}$ electric fields. The largest synergistic effect between electric fields and orthovanadate incubation also comes from $10,000 \mathrm{~Hz}$ electric fields. This apparent discrepancy can be explained by the fact that different current amplitudes or electric field polarities within the $10,000 \mathrm{~Hz}$ frequency have different effects, some activate secreted acid phosphatase activity (antagonistic effect with orthovanadate inhibitor), some inhibit secreted acid phosphatase activity (synergistic effect with orthovanadate inhibitor).

\section{Secreted Acid Phosphatase Kinetic Assay with and without the Preincubation with a Glycosidase, Followed by Pretreatment with and without Electric Fields}

The importance of carbohydrate attachment to $L$. tarentolae SAP1 or SAP2 becomes apparent when the enzyme source was incubated with PNGase F. The capacity of the PNGase F incubation with $L$. tarentolae enzyme pool to alter kinetic parameters of enzyme 1 and enzyme 2 indicates that the $\mathrm{N}$-linked carbohydrates of enzyme 1 and enzyme 2 are of importance to these enzymes to bind substrate $\left(\mathrm{k}_{\mathrm{M}}\right.$ values of enzyme 1 and enzyme 2 are affected by PNGase F incubation). Furthermore, enzyme 1 is more sensitive to the application of a $10,000 \mathrm{~Hz}, 100 \mu \mathrm{A}$, anodic electric field after preincubation of the $L$. tarentolae enzyme pool with PNGase F. These data further support the idea that there are two isoforms of SAP secreted by L. tarentolae into the culture medium, and that their responses to PNGase F incubation and electric field application are different and thus may have different roles in successful infections. 


\section{Final Global Conclusions and Recommendations for Future Work}

L. tarentolae secrete two detectable acid phosphatases into the culture medium, enzyme 1 and enzyme 2. These two isoforms have different kinetic parameters, $\mathrm{k}_{\mathrm{M}}$ and $\mathrm{V}_{\mathrm{MAX}}$, such that enzyme 1 binds substrate less tightly than enzyme 2, but enzyme 1 also produces product more quickly than does enzyme 2. Furthermore, L. tarentolae has utility as a model system for assessing the effects applying electric fields have on cell viability and enzyme activity of enzyme 1 and enzyme 2. The application of electric fields does not affect cell viability of L. tarentolae, but does have a large effect on L. tarentolae cell clumping. Increasing frequency, or current, or applying anodic electric fields leads to increased L. tarentolae cell clumping compared to control. Applying electric fields to L. tarentolae cell supernatant (method 1) produced more statistically significant results than did applying electric fields to whole cells followed by separation and collection of supernatant (method 2). The application of 10,000 Hz electric fields

produced larger effects on L. tarentolae cell supernatant on average than did the application of $50 \mathrm{~Hz}$ electric fields ( $9.63 \%$ different from control vs. $1.75 \%$ different from control). The application of $10,000 \mathrm{~Hz}$ electric fields produced larger activation effects on L. tarentolae cell supernatant than did the application of $50 \mathrm{~Hz}$ electric fields $(9.74 \%$ different from control vs. $2.86 \%$ different from control). The application of $10,000 \mathrm{~Hz}$ electric fields produced larger inhibition effects on L. tarentolae cell supernatant than did the application of $50 \mathrm{~Hz}$ electric fields (1.65\% different from control vs. $1.54 \%$ different from control). Overall, electric fields had the effect of increasing SAP activity from L. tarentolae log or stationary phase enzyme pools. The method of Baumhardt et al. proved useful for determining which of the two tested inhibitors were better on a mole of vanadium basis, orthovanadate or decavanadate. By this method, orthovanadate was a better inhibitor of $L$. tarentolae SAP activity than was 
decavanadate. Following through with this result, the application of electric fields to $L$.

tarentolae followed by incubation with orthovanadate $(25 \mu \mathrm{M})$ did not lead to a consistent synergistic effect on $L$. tarentolae SAP activity. Incubation of $L$. tarentolae stationary phase SAP enzyme pool with PNGase F did lead to changes in $\mathrm{k}_{\mathrm{M}}$ values of both enzyme 1 and enzyme 2. The incubation of $L$. tarentolae stationary phase SAP enzyme pool followed by the application of $10,000 \mathrm{~Hz}, 100 \mu \mathrm{A}$, anodic electric field had an effect on $\mathrm{k}_{\mathrm{M}}$ and $\mathrm{V}_{\mathrm{MAX}}$ values of enzyme 1, but no effect on enzyme 2 .

Based on these global conclusions this author recommends the following when working under the conditions of the methods presented here. To investigate SAP activity from L. tarentolae, collection of the supernatant from the log phase or stationary phase of the L. tarentolae growth curve will result in the greatest amount of activity from enzyme 1 . To investigate enzyme 2 , collection of the L. tarentolae stationary or senescence phase supernatant will result in the greatest activity from enzyme 2 . To investigate both enzymes, collection of $L$. tarentolae log or stationary phase supernatant will suffice, as both enzymes are present and detectable during these phases of the L. tarentolae growth curve. To further investigate the effect of electric field on L. tarentolae cell aggregation and/or cell clumping, use larger frequencies $(10,000 \mathrm{~Hz})$, larger currents $(500$ $\mu \mathrm{A})$, and anodic polarities for thirty minute exposures. These conditions will result in a large clumping effect, but will also not lead to L. tarentolae cell death due to electric field exposure. To further investigate, or to begin probing the mechanism, of how the application of electric fields modulates $\log$ or stationary phase $L$. tarentolae SAP activity, the $10,000 \mathrm{~Hz}$ frequency is most useful as it has produced the greatest measurable effects thus far. To further investigate any potential synergism between the application of electric fields followed by incubation with a competitive inhibitor, the method of Baumhardt et al., with experiments performed under the same 
assay conditions as electric field experiments, proves very useful. This method allows the determination of which of any potential competitive inhibitor is most effective at enzyme inhibition on a stoichiometric basis of inhibitor to substrate $(\log [\mathrm{S}] /[\mathrm{I}])$. This work suggests that the application of electric fields followed by incubation with orthovanadate does not produce a large synergistic effect. The following method is recommended for future work on synergism between orthovanadate and electric fields for the purpose of inhibiting L. tarentolae SAP activity. A master pool of assay buffer, enzyme source and orthovanadate should be produced such that buffer occupies $55.56 \%$ of the volume of the master pool, enzyme source occupies $33.33 \%$ of the volume of the master pool, orthovanadate $(25 \mu \mathrm{M})$ is added to the master pool, and aliquots $(2.00$ $\mathrm{mL}$ ) of this master pool are then exposed to electric fields. After electric field exposure, aliquots of the master pool will be added to $1.5 \mathrm{~mL}$ polypropylene tubes, and PNPP will be added $(100 \mu \mathrm{L}$ of $1.347 \mathrm{mM}$ ) to give a final assay volume of $0.9 \mathrm{~mL}$. Assays will be stopped with the addition of $\mathrm{NaOH}(0.1 \mathrm{~mL}, 10 \mathrm{M})$, and product will be measured by spectroscopy (A405 nm). Results from this thesis do now suggest that the therapeutic response reported by Hejazi et al. (1972), using electrical treatment of mice, may involve the direct as well as indirect effects of electricity on the activity of secreted acid phosphatases. Clearly more work is needed to sort out the full mechanism of action of electric fields on Leishmania secreted acid phosphatases. 


\section{REFERENCES}

Abbott, S. J., Jones, S. R., Weinman, S. A., Bockhoff, F. M., McLafferty, F. W., Knowles, J. R. (1979). Chiral[16O, 17O, 18O]phosphate monoesters. Asymmetric synthesis and stereochemical analysis of [1(R)-16O, 17O, 18O]phosphor-(S)-propane-1,2-diol. Journal of the American Chemical Society, 101, 4323-4332.

Agency for Toxic Substances and Disease Registry, (2016). https://www.atsdr.cdc.gov/phs/phs.asp?id=274\&tid=50 (accessed 29 Dec. 2016).

Baghaei, M., BAGHAEI, M. (2003). Characterization of acid phosphatase in the promastigotes of three isolates of Leishmania major. Iranian Journal of Medical Sciences, 28(1),1-8.

Baumhardt, J. M., Dorsey, B. M., McLauchlan, C. C., Jones, M. A. (2015). An additional method for analyzing the reversible inhibition of an enzyme using acid phosphatase as a model. Current Enzyme Inhibition, (11), 140-146.

Baes, J., Charles F., Mesmer, R. E. (1976). In The Hydrolysis of Cations, Baes, J., Charles F., Mesmer, R. E., Eds., New York: John Wiley \& Sons.

Biophysics of Membrane Potential, (2017). https://www.cise.ufl.edu/ arunava/Teaching/Lectures-CN/neuroelectronics.pdf (accessed 21 June. 2017).

Box Shade Server, (2017). http://www.ch.embnet.org/software/BOX_form.html (accessed 21 June. 2017).

Chawla, B., and Madhubala, R. (2010). Drug targets in Leishmania Journal of Parasitic Diseases, Dis, 34(1),1-13.

Corigliano, F., Pasquale, S. D. (1975). Comparative IR study of solid hydrate decavanadates and polyvanadates in acidic aqueous solution. Inorganica Chimica Acta, (12), 99-101.

Enslen, H., Tokumitsu, H., Stork, P. J. S., Davis, R. J., Soderling, T. R. (1996). Regulation of mitogen-activated protein kinases by a calcium/ calmodulin-dependent protein kinase cascade. Proceedings of the National Academy of Sciences, Sci, (93), 10803-10808.

ExPASy, (2016). http://enzyme.expasy.org/EC/3.1. (accessed 8 Jan 2016).

Fernandes, A. C., Soares, D. C., Saraiva, E. M., Meyer-Fernandez, J. R., Souto-Padron, T. (2013). Different secreted phosphatase activites in Leishmania amazonensis. FEMS Microbiology Letters, 340(2),117-128.

Gani, D., Wilkie, J. (1997). Metal Sites in Proteins and Models, Structure and Bonding. (89): 133-175. In Metal Ions in The Mechanism of Enzyme-Catalyzed Phosphate Monoester Hydrolysis. Sadler, PJ., Thomson, AJ., Berlin Heidelberg: Eds, Springer. 
Gordon, J. A. (1991). Use of vanadate as Protein-Phosphotyrosine phosphatase inhibitor. Methods in Enzymology, (201), 477-482.

Gressor, M. J., Tracey, A. S., Stankiewwicz, P. J., (1987). In Advances in protein phosphatases, Merlev, W., DiSalvo, J.Eds.,Leuven University Press: Belgum.

Hejazi, H., Eslami, G., Dalimi, A. (1972). The parasiticidal effect of electricity on Leishmania major, both in vitro and in vivo. Annals of Tropical Medicine \& Parasitology, 98(1), $37-42$.

Henneberry, M. O., Engel, G., Grayhack, J. T. (1979). Acid phosphatase. Urologic Clinics of North America, 6(3), 629-641.

Holden, K. R. Biological effects of pulsed electromagnetic field (PEMF) therapy, (2017). http://www.ondamed.net/us/biological-effects-of-pulsed-electromagnetic-field-pemftherapy (Accessed 2 Feb. 2017).

Ilg, T., Stierhof,Y-D., Etges, R., Adrian, M., Harbecke, D. (1991). Secreted acid phosphatase of Leishmania Mexicana: A filamentous phosphoglycoprotein polymer. Proceedings of the National Academy of Sciences, (88), 8774-8778.

Isnard, A., Shio, M. T., Oliver, M. (2012). Impact of Leishmania metalloprotease GP63 on macrophage signaling. Frontiers in Cellular and Infection Microbiology, (2), 72.

Kalign, (2016). http://www.ebi.ac.uk/Tools/msa/kalign/ (accessed 20 Dec 2016).

King, M. W. The Medicinal Biochemistry Page. Introduction to cholesterol metabolism, (2017). http://themedicalbiochemistrypage.org/cholesterol.php (accessed 5 Feb. 2017).

Knowles, J. R. (1980). Enzyme-catalyzed phosphoryl transfer reactions. Annual Review of Biochemistry, (49), 877-919.

Leishmaniasis, (2016). https://www.cdc.gov/parasites/leishmaniasis/epi.html (accessed 20 Dec. 2016).

Leishmaniasis Professionals, (2016). https://www.cdc.gov/parasites/leishmaniasis/health_professionals/index.html\#tx (accessed 20 Dec. 2016).

Li, M., Ding, W., Baruah, B., Crans, D. C., Wang, R., (2008). Inhibition of protein tyrosine phosphatases $1 \mathrm{~B}$ and alkaline phosphatase by bis(maltolato)oxovanadium (IV). BioMetals, (102), 1846-1853.

Lippert, D. N., Dwyer, D. W., Li, F., Olafson, R. W. (1999). Phosphoglycosylation of a secreted acid phosphatase from Leishmania donovani. Glycobiology, 9(6), 627-636. 
McLauchlan, C. C., Peters, B. J., Willsky, G. R., Crans, D. C. (2015). Vanadium-phosphatse complexes: Phosphatase inhibitors favor the trigonal bipyramidal transition state geometries. Coordination Chemistry Reviews, (301-302), 163-199.

Mendez, R. S., Dorsey, B. M., McLauchlan, C. C., Beio, M., Turner, T. L., Nguyen, V. H., Su, A., Beynon, W., Friesen, J. A., Jones, M. A. (2014). Vanadium complexes are in vitro inhibitors of leishmania secreted acid phosphatases. International journal of Chemistry, $6(1), 35-49$.

Merril, D. R., Bikson, M., Jefferys, J. G. R. (2005). Electrical stimulation of excitable tissue: design of efficatious and safe protocols. Journal of Neuroscience Methods, (141), 171198.

Miller, M. B., Bassler, B. L. (2001). Quorum sensing in bacteria. Annual Review of Microbiology, (55), 165-199.

Mojtahedi Z, Clos J, Kamali-Sarvestani E. (2008). Leishmania major: identification of developmentally regulated proteins in procyclic and metacyclic promastigotes. Experimental Parasitology, 119(3), 422-429.

Morgenthaler, J. B., Peters, S. J., Cedeno, D. L., Constantino, M. H., Edwards, K. A., Kamowski, E. M., Jones, M. A. (2008). Carbaporphyrin ketals as potential agents for a new photodynamic therapy treatment of leishmaniasis. Bioorganic and Medicinal Chemistry, 16(4), 7033-7038.

Mosmann, T. (1983). Rapid colorimetric assay for cellular growth and survival: Application to proliferation and cytotoxicity assays. Journal of Immunological Methods, 65(1-2), 55-63.

Navabi, A., Soleimanifard, S. (2015) Enzymatic characterization of acid phosphatase in the logarithmic and stationary phase of Ieishmania major promastagotes. Shiraz E-Medical Journal, 16(1), e26246-.

PNGase F, (2017). http://www.sigmaaldrich.com/life-science/proteomics/post-translationalanalysis/phosphorylation/pngase-f.html (accessed 18 October. 2017).

Rehder, D. (2013). Vanadium. Its role for humans. Metal Ion in Life Sciences, (13), 139-169.

Rigden, D. J., Littlejohn, J. E., Henderson, K., Jedrzejas, M. J. (2003). Structures of phosphate and trivanadate of Bacillus stearothermophilus phosphatase PhoE: structural and functional analysis in the cofactor-dependent phosphoglycerate mutase superfamily. Journal of Molecular Biology, (325), 411-420.

Rossotti, F. J. C., Rossotti, H. (1956). Equilibrium studies of polyanions. Acta Chemica Scandinavica, (10), 957-984. 
Shakariana, A. M., Ellisa, S. L., Mallinsonac, D. J., Olafsonb, R. W., Dwyera, D. M. (1997). Two tandemly arrayed genes encode the (histidine) secretory acid phosphatases of Leishmania donovani. Gene, 196 (1-2), 127-137.

Taylor, V. M., Munoz, D. L., Cedeno, D. L., Velez, I. V., Jones, M. A., Robledo, S. M. (2010). Leishmania tarentolae: Utility as an in vitro model for screening of antileishmanial agents. Experimental Parasitology, (126), 471-475.

VanEtten, R. L., Waymack, P. P., Rehkop, D. M. (1974). Inhibition of myosin ATPase by vanadate ion. Journal of the American Chemical Society, (96), 6782-6785.

Vannier-Stantos, M.A., Martiny, A., \& de Souza W. (2002). Cell biology of Leishmania spp.: Invading and evading. Current Pharmaceutical Design, 8(4), 297-318. http://dx.doi.org/10.2174/138161202339623

Vincent, JB., Crowder, MW., Averill, BA. (1992). Hydrolysis of phosphate monoesters: a biological problemwith multiple chemical solutions. Trends in Biochemical. Sciences, 17(3), 105-110.

World Health Organization Leishmaniasis Treatment Cost, (2017). http://www.who.int/leishmaniasis/research/978_92_4_12_949_6_Annex6.pdf (accessed 21 June. 2017). 


\section{APPENDIX A}

\section{THE INDIVIDUAL LINEWEAVER-BURK PLOTS AND DATA POINTS CORRESPONDING TO THE TEXT (TABLE 2, FIGURE 18,}

TABLE 3, AND FIGURE 19).

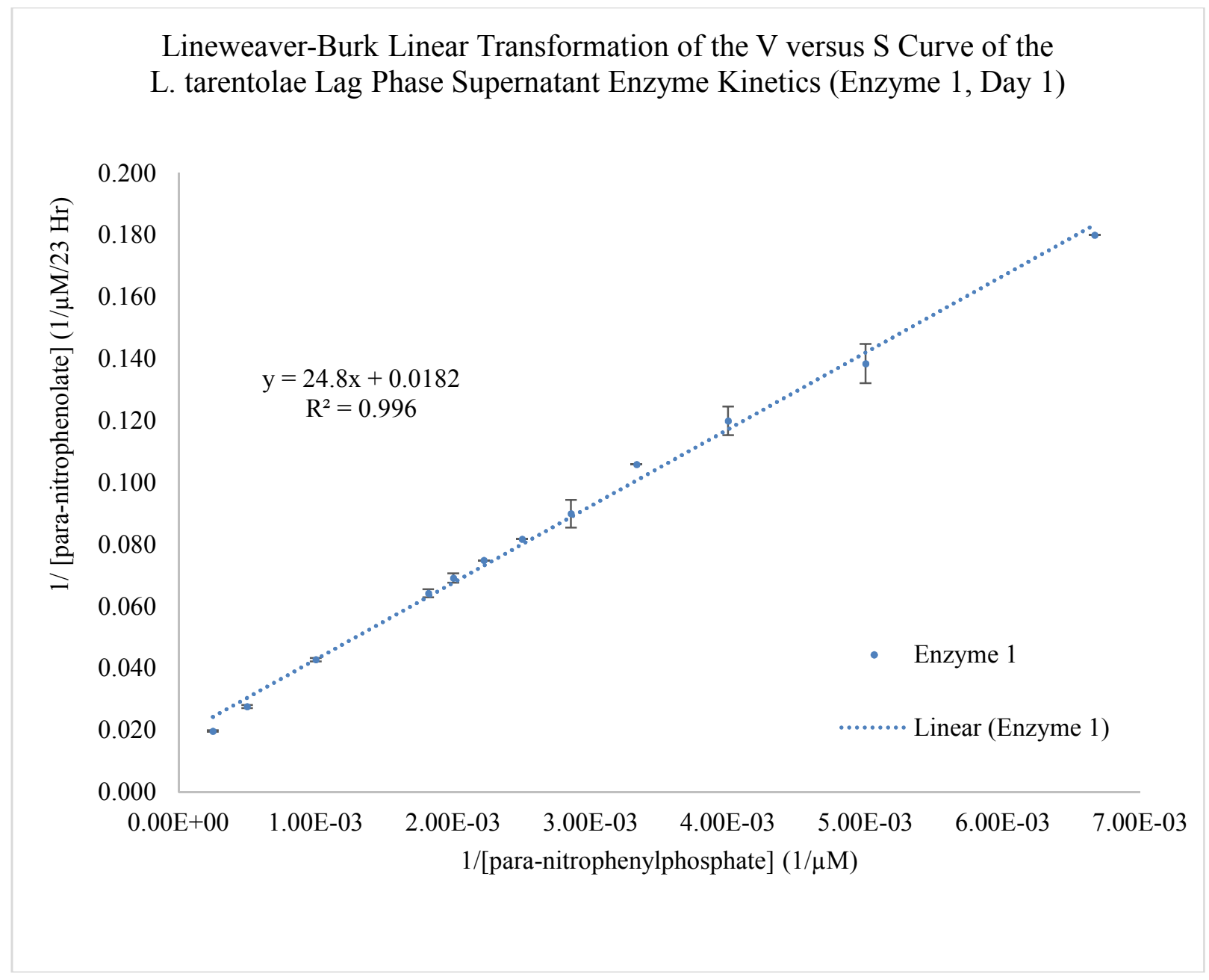




\begin{tabular}{|c|c|c|c|c|}
\hline $\begin{array}{c}\text { Day 1 } \\
\text { Enzyme 1 } \\
\text { KM }(\mu \mathrm{M}): \\
\text { 1.36E03 } \pm 1.3 E 02 \\
\text { VMX }(\boldsymbol{\mu M} / 23 \mathrm{Hr}): \\
54.9 \pm 1.1 \mathrm{E}-01 \\
\end{array}$ & & & & \\
\hline $\begin{array}{c}\text { [para-nitrophenylphosphate] } \\
\qquad(\mu \mathrm{M})\end{array}$ & $\begin{array}{c}\text { Average } \\
\text { [para-nitrophenolate] } \\
(\mu \mathrm{M} / 23 \mathrm{Hr})\end{array}$ & $\begin{array}{c}1 /[\text { para-nitrophenolate }] \\
(1 / \mu \mathrm{M} / 23 \mathrm{Hr})\end{array}$ & $\begin{array}{c}1 /[\text { para-nitrophenyl } \\
\text { phosphate] } \\
(1 / \mu \mathrm{M})\end{array}$ & $\begin{array}{c}\text { standard deviation } \\
\text { [para-nitrophenol] } \\
(1 / \mu \mathrm{M} / 23 \mathrm{Hr}) \\
\end{array}$ \\
\hline 150 & 5.56 & 0.180 & $6.67 \mathrm{E}-03$ & $0.00 \mathrm{E}+00$ \\
\hline 200 & 7.22 & 0.138 & $5.00 \mathrm{E}-03$ & $6.31 \mathrm{E}-03$ \\
\hline 250 & 8.33 & 0.120 & $4.00 \mathrm{E}-03$ & $4.62 \mathrm{E}-03$ \\
\hline 300 & 9.44 & 0.106 & $3.33 \mathrm{E}-03$ & $0.00 \mathrm{E}+00$ \\
\hline 350 & 11.1 & $9.00 \mathrm{E}-02$ & $2.86 \mathrm{E}-03$ & $4.50 \mathrm{E}-03$ \\
\hline 400 & 12.2 & $8.18 \mathrm{E}-02$ & $2.50 \mathrm{E}-03$ & $1.26 \mathrm{E}-17$ \\
\hline 450 & 13.3 & $7.50 \mathrm{E}-02$ & $2.22 \mathrm{E}-03$ & $0.00 \mathrm{E}+00$ \\
\hline 500 & 14.4 & $6.92 \mathrm{E}-02$ & $2.00 \mathrm{E}-03$ & $1.52 \mathrm{E}-03$ \\
\hline 550 & 15.6 & $6.43 \mathrm{E}-02$ & $1.82 \mathrm{E}-03$ & $1.31 \mathrm{E}-03$ \\
\hline $1.00 \mathrm{E}+03$ & 23.3 & $4.29 \mathrm{E}-02$ & $1.00 \mathrm{E}-03$ & $5.84 \mathrm{E}-04$ \\
\hline $2.00 \mathrm{E}+03$ & 36.1 & $2.77 \mathrm{E}-02$ & $5.00 \mathrm{E}-04$ & $4.89 \mathrm{E}-04$ \\
\hline $4.00 \mathrm{E}+03$ & 50.6 & $1.98 \mathrm{E}-02$ & $2.50 \mathrm{E}-04$ & $2.51 \mathrm{E}-04$ \\
\hline
\end{tabular}


Lineweaver-Burk Linear Transformation of the $\mathrm{V}$ versus $\mathrm{S}$ Curve of the

L. tarentolae Lag Phase Supernatant Enzyme Kinetics (Enzyme 1, Day 2)

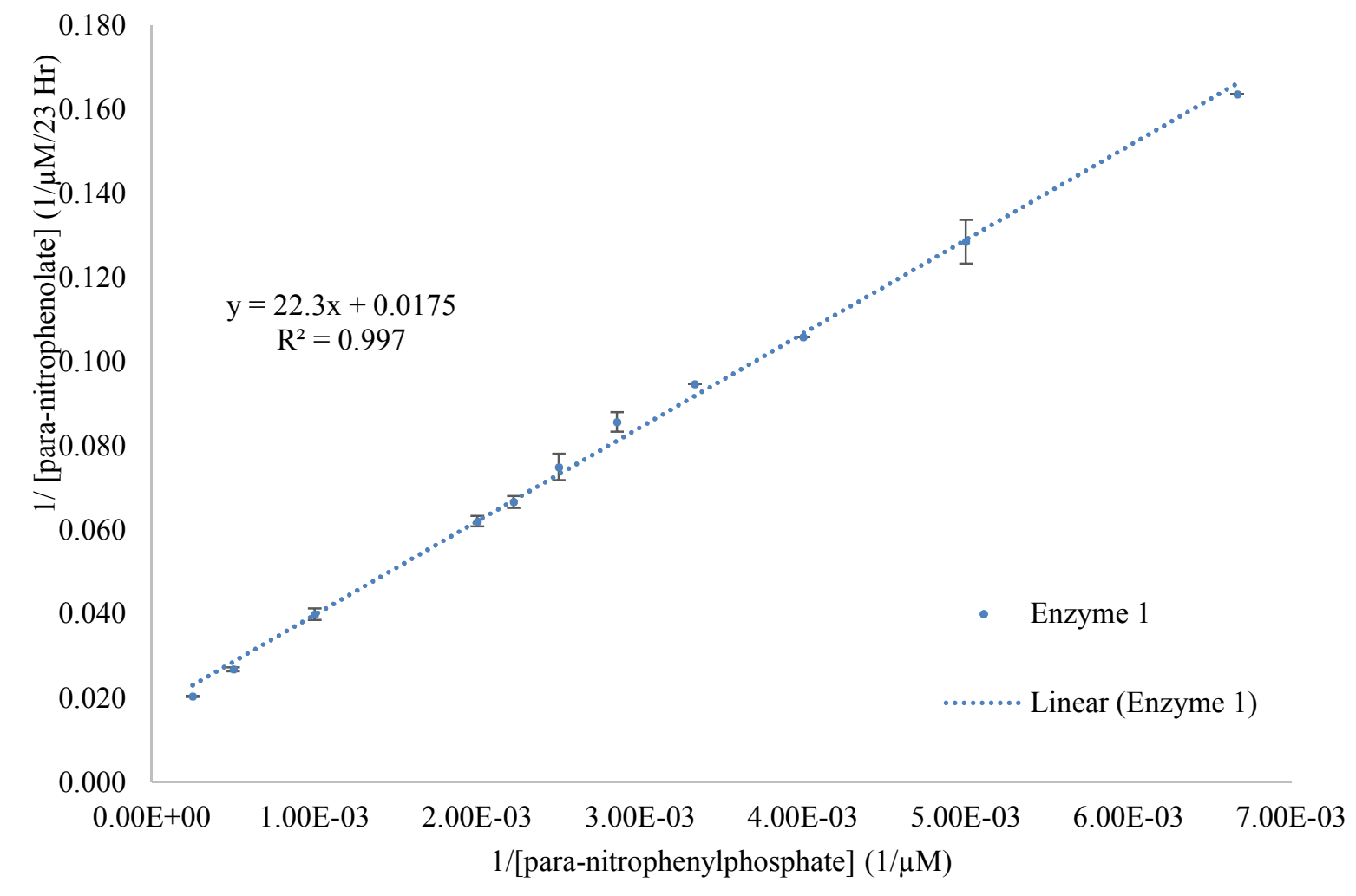




\begin{tabular}{|c|c|c|c|c|}
\hline $\begin{array}{c}\text { Day 2 } \\
\text { Enzyme 1 } \\
\text { KM }_{M}(\mu M): \\
1.27 E 03 \pm 1.0 E 02 \\
\text { VMAX }(\mu M / 23 \text { Hr }): \\
57.1 \pm 1.0 E-01 \\
\end{array}$ & & & & \\
\hline [para-nitrophenylphosphate] $(\mu \mathrm{M})$ & $\begin{array}{c}\text { Average } \\
\text { [para-nitrophenolate] } \\
(\mu \mathrm{M} / 23 \mathrm{Hr})\end{array}$ & $\begin{array}{c}\text { 1/[para-nitrophenolate] } \\
(1 / \mu \mathrm{M} / 23 \mathrm{Hr})\end{array}$ & $\begin{array}{c}1 /[\text { para- } \\
\text { nitrophenyl } \\
\text { phosphate] } \\
(1 / \mu \mathrm{M})\end{array}$ & $\begin{array}{c}\text { standard } \\
\text { deviation } \\
\text { [para- } \\
\text { nitrophenol] } \\
(1 / \mu \mathrm{M} / 23 \mathrm{Hr}) \\
\end{array}$ \\
\hline 150 & 6.11 & 0.164 & $6.67 \mathrm{E}-03$ & $0.00 \mathrm{E}+00$ \\
\hline 200 & 7.78 & 0.129 & $5.00 \mathrm{E}-03$ & $5.18 \mathrm{E}-03$ \\
\hline 250 & 9.44 & 0.106 & $4.00 \mathrm{E}-03$ & $0.00 \mathrm{E}+00$ \\
\hline 300 & 10.6 & $9.47 \mathrm{E}-02$ & $3.33 \mathrm{E}-03$ & $1.69 \mathrm{E}-17$ \\
\hline 350 & 11.7 & $8.57 \mathrm{E}-02$ & $2.86 \mathrm{E}-03$ & $2.32 \mathrm{E}-03$ \\
\hline 400 & 13.3 & $7.50 \mathrm{E}-02$ & $2.50 \mathrm{E}-03$ & $3.13 \mathrm{E}-03$ \\
\hline 450 & 15.0 & $6.67 \mathrm{E}-02$ & $2.22 \mathrm{E}-03$ & $1.44 \mathrm{E}-03$ \\
\hline 500 & 16.1 & $6.21 \mathrm{E}-02$ & $2.00 \mathrm{E}-03$ & $1.25 \mathrm{E}-03$ \\
\hline $1.00 \mathrm{E}+03$ & 25.0 & $4.00 \mathrm{E}-02$ & $1.00 \mathrm{E}-03$ & $1.39 \mathrm{E}-03$ \\
\hline $2.00 \mathrm{E}+03$ & 37.2 & $2.69 \mathrm{E}-02$ & $5.00 \mathrm{E}-04$ & 4.61E-04 \\
\hline $4.00 \mathrm{E}+03$ & 48.9 & $2.05 \mathrm{E}-02$ & $2.50 \mathrm{E}-04$ & $1.34 \mathrm{E}-04$ \\
\hline
\end{tabular}




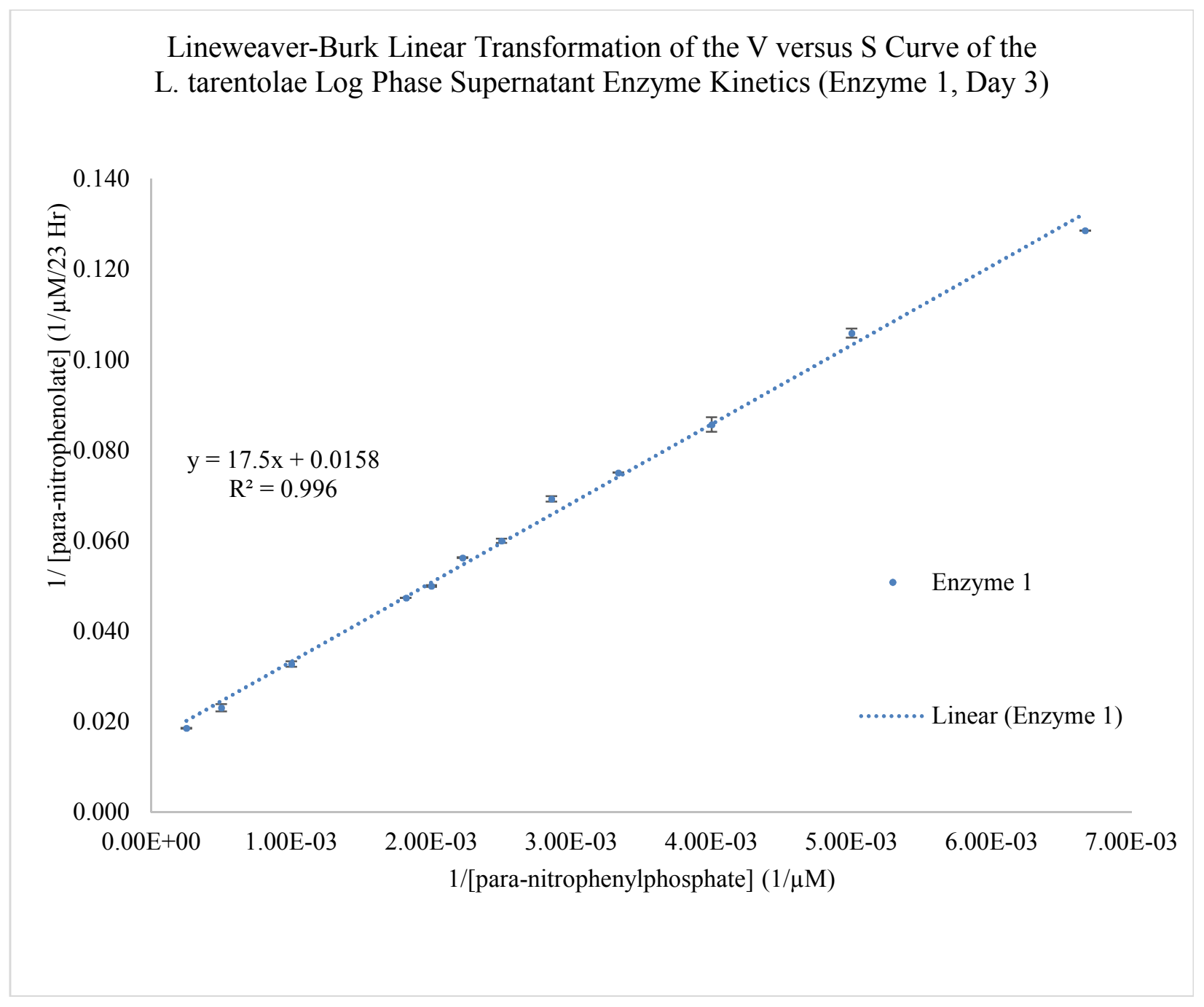




\begin{tabular}{|c|c|c|c|c|}
\hline $\begin{array}{c}\text { Day 3 } \\
\text { Enzyme 1 } \\
\text { KM }(\mu M): \\
\text { 1.11E03 } \pm 9.1 \mathrm{E} 01 \\
\text { VMAX }(\mu \mathrm{M} / 23 \text { Hr }): \\
63.3 \pm 9.0 \mathrm{E}-01 \\
\end{array}$ & & & & \\
\hline [para-nitrophenylphosphate] $(\mu \mathrm{M})$ & $\begin{array}{c}\text { Average } \\
\begin{array}{c}\text { [para-nitrophenolate] } \\
(\mu \mathrm{M} / 23 \mathrm{Hr})\end{array}\end{array}$ & $\begin{array}{c}\text { 1/[para-nitrophenolate] } \\
(1 / \mu \mathrm{M} / 23 \mathrm{Hr})\end{array}$ & $\begin{array}{c}1 /[\text { para- } \\
\text { nitrophenyl } \\
\text { phosphate] } \\
(1 / \mu \mathrm{M})\end{array}$ & $\begin{array}{c}\begin{array}{c}\text { standard } \\
\text { deviation } \\
\text { [para- } \\
\text { nitrophenol] }\end{array} \\
(1 / \mu \mathrm{M} / 23 \mathrm{Hr}) \\
\end{array}$ \\
\hline 150 & 7.78 & 0.129 & $6.67 \mathrm{E}-03$ & $0.00 \mathrm{E}+00$ \\
\hline 200 & 9.44 & 0.106 & $5.00 \mathrm{E}-03$ & $1.00 \mathrm{E}-03$ \\
\hline 250 & 11.7 & $8.57 \mathrm{E}-02$ & $4.00 \mathrm{E}-03$ & $1.62 \mathrm{E}-03$ \\
\hline 300 & 13.3 & $7.50 \mathrm{E}-02$ & $3.33 \mathrm{E}-03$ & $8.47 \mathrm{E}-18$ \\
\hline 350 & 14.4 & $6.92 \mathrm{E}-02$ & $2.86 \mathrm{E}-03$ & $5.95 \mathrm{E}-04$ \\
\hline 400 & 16.7 & $6.00 \mathrm{E}-02$ & $2.50 \mathrm{E}-03$ & 4.54E-04 \\
\hline 450 & 17.8 & $5.63 \mathrm{E}-02$ & 2.22E-03 & $1.11 \mathrm{E}-04$ \\
\hline 500 & 20.0 & $5.00 \mathrm{E}-02$ & $2.00 \mathrm{E}-03$ & $2.00 \mathrm{E}-04$ \\
\hline 550 & 21.1 & $4.74 \mathrm{E}-02$ & $1.82 \mathrm{E}-03$ & $0.00 \mathrm{E}+00$ \\
\hline $1.00 \mathrm{E}+03$ & 30.6 & $3.27 \mathrm{E}-02$ & $1.00 \mathrm{E}-03$ & $6.00 \mathrm{E}-04$ \\
\hline $2.00 \mathrm{E}+03$ & 43.3 & $2.31 \mathrm{E}-02$ & $5.00 \mathrm{E}-04$ & $8.00 \mathrm{E}-04$ \\
\hline $4.00 \mathrm{E}+03$ & 53.9 & $1.86 \mathrm{E}-02$ & $2.50 \mathrm{E}-04$ & $1.00 \mathrm{E}-04$ \\
\hline
\end{tabular}


Lineweaver-Burk Linear Transformation of the V versus $\mathrm{S}$ Curve of the

L. tarentolae Log Phase Supernatant Enzyme Kinetics (Enzyme 2, Day 3)

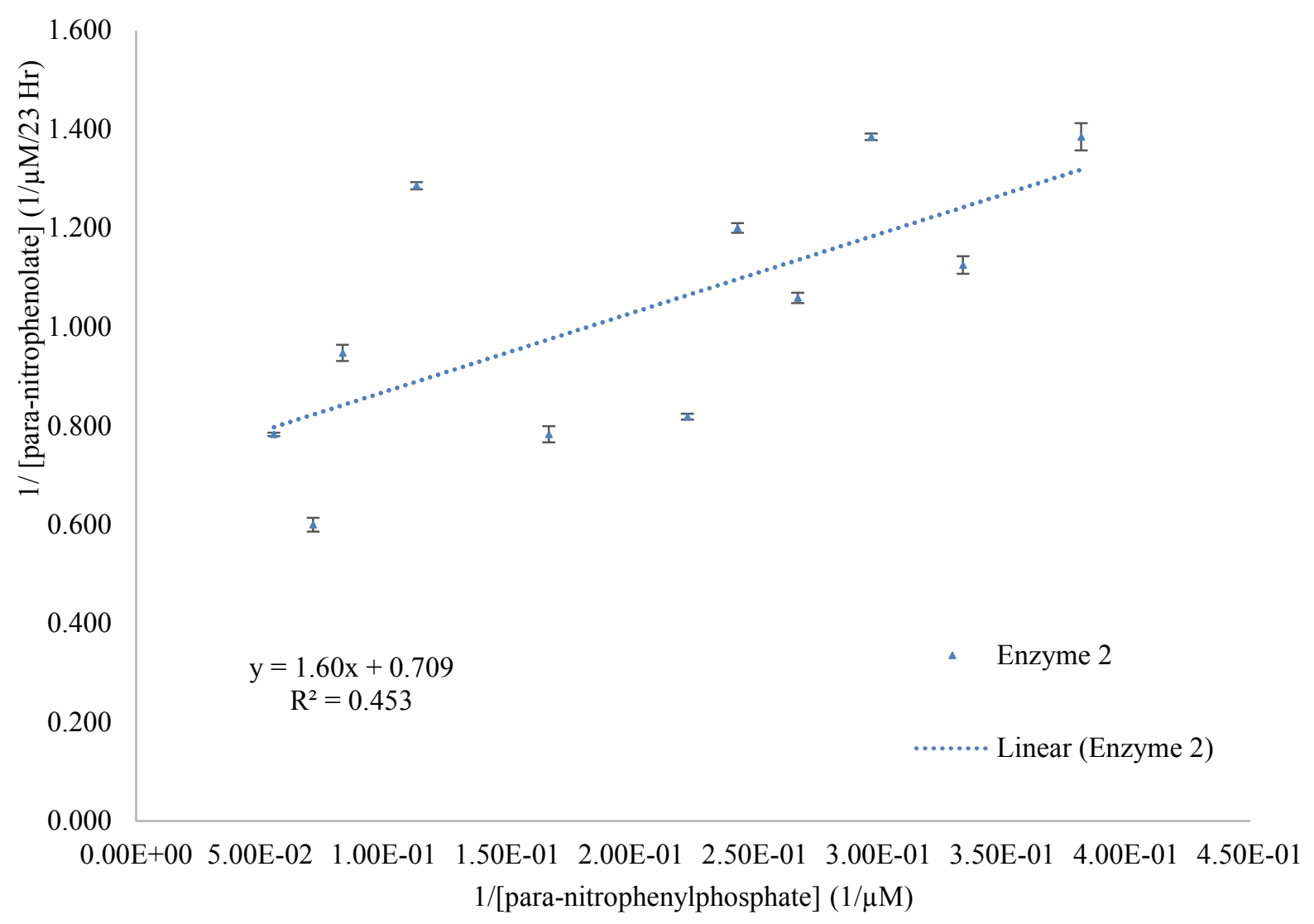




\begin{tabular}{|c|c|c|c|c|}
\hline $\begin{array}{c}\text { Day 3 } \\
\text { Enzyme } 2 \\
\text { KM }(\mu \mathrm{M}): \\
2.26 \pm 7.20 \mathrm{E}-02 \\
\text { VMAX }(\mu \mathrm{M} / 23 \mathrm{Hr}): \\
1.40 \pm 2.00 \mathrm{E}-01\end{array}$ & & & & \\
\hline [para-nitrophenylphosphate] $(\mu \mathrm{M})$ & $\begin{array}{c}\text { Average } \\
\underset{(\boldsymbol{\mu} \text { ara-nitrophenolate] }}{(\mu \mathrm{M})}\end{array}$ & $\begin{array}{c}1 /[\text { para-nitrophenolate }] \\
(1 / \mu \mathrm{M} / 23 \mathrm{Hr})\end{array}$ & $\begin{array}{c}1 / \text { para- } \\
\text { nitrophenyl } \\
\text { phosphate] } \\
(1 / \mu \mathrm{M})\end{array}$ & $\begin{array}{c}\text { standard } \\
\text { deviation } \\
\text { [para- } \\
\text { nitrophenol] } \\
(1 / \mu \mathrm{M} / 23 \mathrm{Hr})\end{array}$ \\
\hline 2.62 & 0.722 & 1.38 & $3.82 \mathrm{E}-01$ & $2.73 \mathrm{E}-02$ \\
\hline 2.99 & 0.889 & 1.13 & $3.34 \mathrm{E}-01$ & $1.78 \mathrm{E}-02$ \\
\hline 3.37 & 0.722 & 1.38 & $2.97 \mathrm{E}-01$ & $6.84 \mathrm{E}-03$ \\
\hline 3.74 & 0.944 & 1.06 & $2.67 \mathrm{E}-01$ & $1.03 \mathrm{E}-02$ \\
\hline 4.12 & 0.833 & 1.20 & $2.43 \mathrm{E}-01$ & $9.72 \mathrm{E}-03$ \\
\hline 4.49 & 1.22 & 0.818 & $2.23 \mathrm{E}-01$ & $5.95 \mathrm{E}-03$ \\
\hline 6.00 & 1.28 & 0.783 & $1.67 \mathrm{E}-01$ & $1.64 \mathrm{E}-02$ \\
\hline 8.83 & 0.778 & 1.29 & $1.13 \mathrm{E}-01$ & $7.18 \mathrm{E}-03$ \\
\hline $1.20 \mathrm{E}+01$ & 1.06 & 0.947 & $8.33 \mathrm{E}-02$ & $1.65 \mathrm{E}-02$ \\
\hline $1.40 \mathrm{E}+01$ & 1.67 & 0.600 & $7.14 \mathrm{E}-02$ & $1.39 \mathrm{E}-02$ \\
\hline $1.80 \mathrm{E}+01$ & 1.28 & 0.783 & $5.56 \mathrm{E}-02$ & $3.74 \mathrm{E}-03$ \\
\hline
\end{tabular}


Lineweaver-Burk Linear Transformation of the V versus $\mathrm{S}$ Curve of the

L. tarentolae Log Phase Supernatant Enzyme Kinetics (Enzyme 1, Day 4)

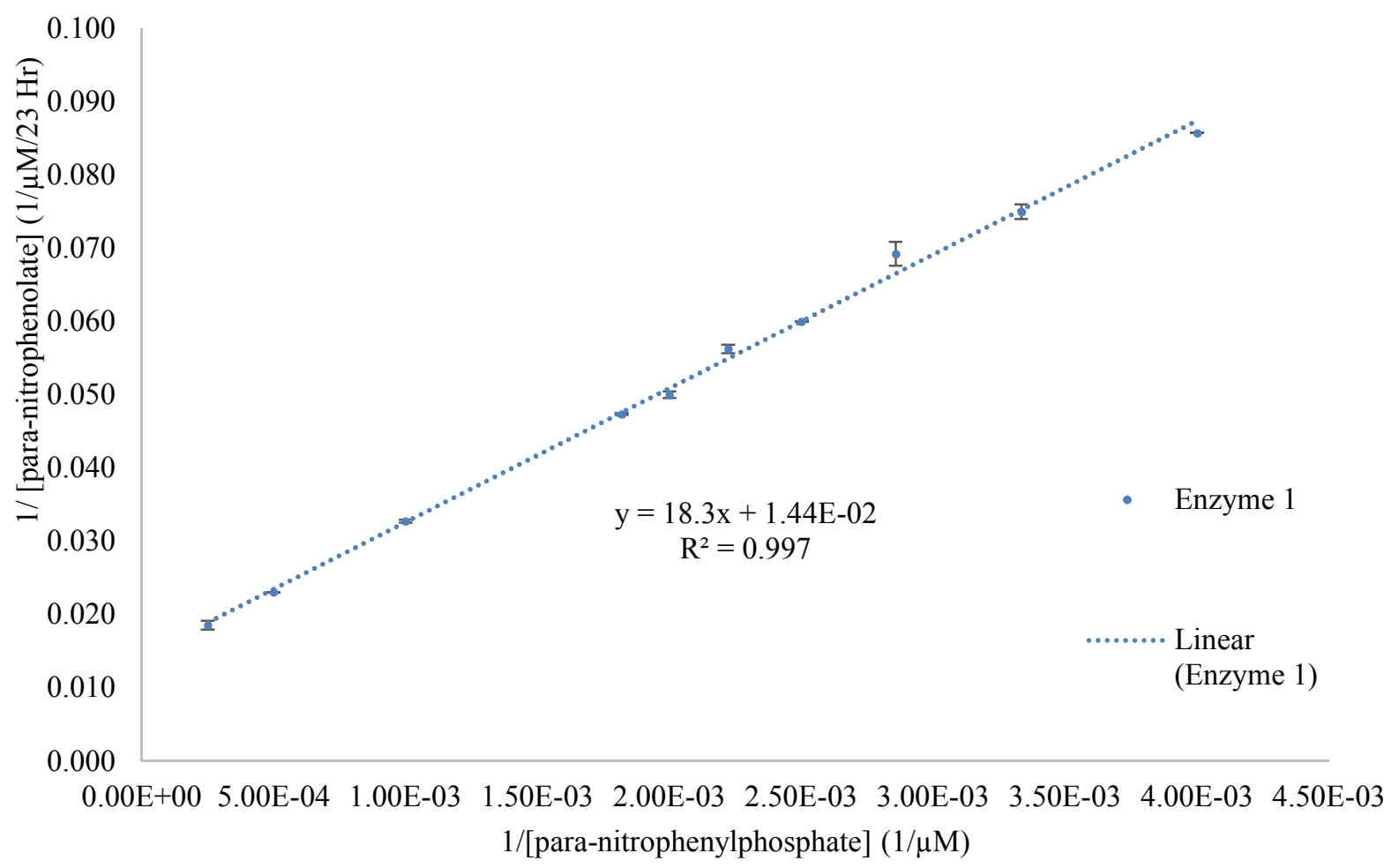




\begin{tabular}{|c|c|c|c|c|}
\hline $\begin{array}{c}\text { Day 4 } \\
\text { Enzyme 1 } \\
\text { KM }(\mu \mathrm{M}): \\
1.27 \mathrm{E03} \pm 9.0 \mathrm{E01} \\
\text { VMA }(\boldsymbol{\mu M} / 23 \mathrm{Hr}): \\
69.4 \pm 6.1 \mathrm{E}-01\end{array}$ & & & & \\
\hline [para-nitrophenylphosphate] $(\mu \mathrm{M})$ & $\begin{array}{c}\text { Average } \\
\begin{array}{c}\text { [para-nitrophenolate] } \\
(\mu \mathrm{M} / 23 \mathrm{Hr})\end{array}\end{array}$ & $\begin{array}{c}1 /[\text { para-nitrophenolate }] \\
(1 / \mu \mathrm{M} / 23 \mathrm{Hr})\end{array}$ & $\begin{array}{c}1 /[\text { para- } \\
\text { nitrophenyl } \\
\text { phosphate] } \\
(1 / \mu \mathrm{M})\end{array}$ & $\begin{array}{c}\text { standard } \\
\text { deviation } \\
\text { [para- } \\
\text { nitrophenol] } \\
(1 / \mu \mathrm{M} / 23 \mathrm{Hr})\end{array}$ \\
\hline 250 & 11.7 & $8.57 \mathrm{E}-02$ & $4.00 \mathrm{E}-03$ & $4.60 \mathrm{E}-03$ \\
\hline 300 & 13.3 & $7.50 \mathrm{E}-02$ & $3.33 \mathrm{E}-03$ & $7.36 \mathrm{E}-03$ \\
\hline 350 & 14.4 & $6.92 \mathrm{E}-02$ & $2.86 \mathrm{E}-03$ & $2.81 \mathrm{E}-03$ \\
\hline 400 & 16.7 & $6.00 \mathrm{E}-02$ & $2.50 \mathrm{E}-03$ & $2.71 \mathrm{E}-03$ \\
\hline 450 & 17.8 & $5.62 \mathrm{E}-02$ & $2.22 \mathrm{E}-03$ & $1.19 \mathrm{E}-03$ \\
\hline 500 & 20.0 & $5.00 \mathrm{E}-02$ & $2.00 \mathrm{E}-03$ & $9.56 \mathrm{E}-04$ \\
\hline 550 & 21.1 & $4.74 \mathrm{E}-02$ & $1.82 \mathrm{E}-03$ & $0.00 \mathrm{E}+00$ \\
\hline $1.00 \mathrm{E}+03$ & 30.6 & $3.27 \mathrm{E}-02$ & $1.00 \mathrm{E}-03$ & $0.00 \mathrm{E}+00$ \\
\hline $2.00 \mathrm{E}+03$ & 43.3 & $2.31 \mathrm{E}-02$ & $5.00 \mathrm{E}-04$ & $4.86 \mathrm{E}-04$ \\
\hline $4.00 \mathrm{E}+03$ & 53.9 & $1.86 \mathrm{E}-02$ & $2.50 \mathrm{E}-04$ & $0.00 \mathrm{E}+00$ \\
\hline
\end{tabular}


Lineweaver-Burk Linear Transformation of the $\mathrm{V}$ versus $\mathrm{S}$ Curve of the

L. tarentolae Log Phase Supernatant Enzyme Kinetics (Enzyme 2, Day 4)

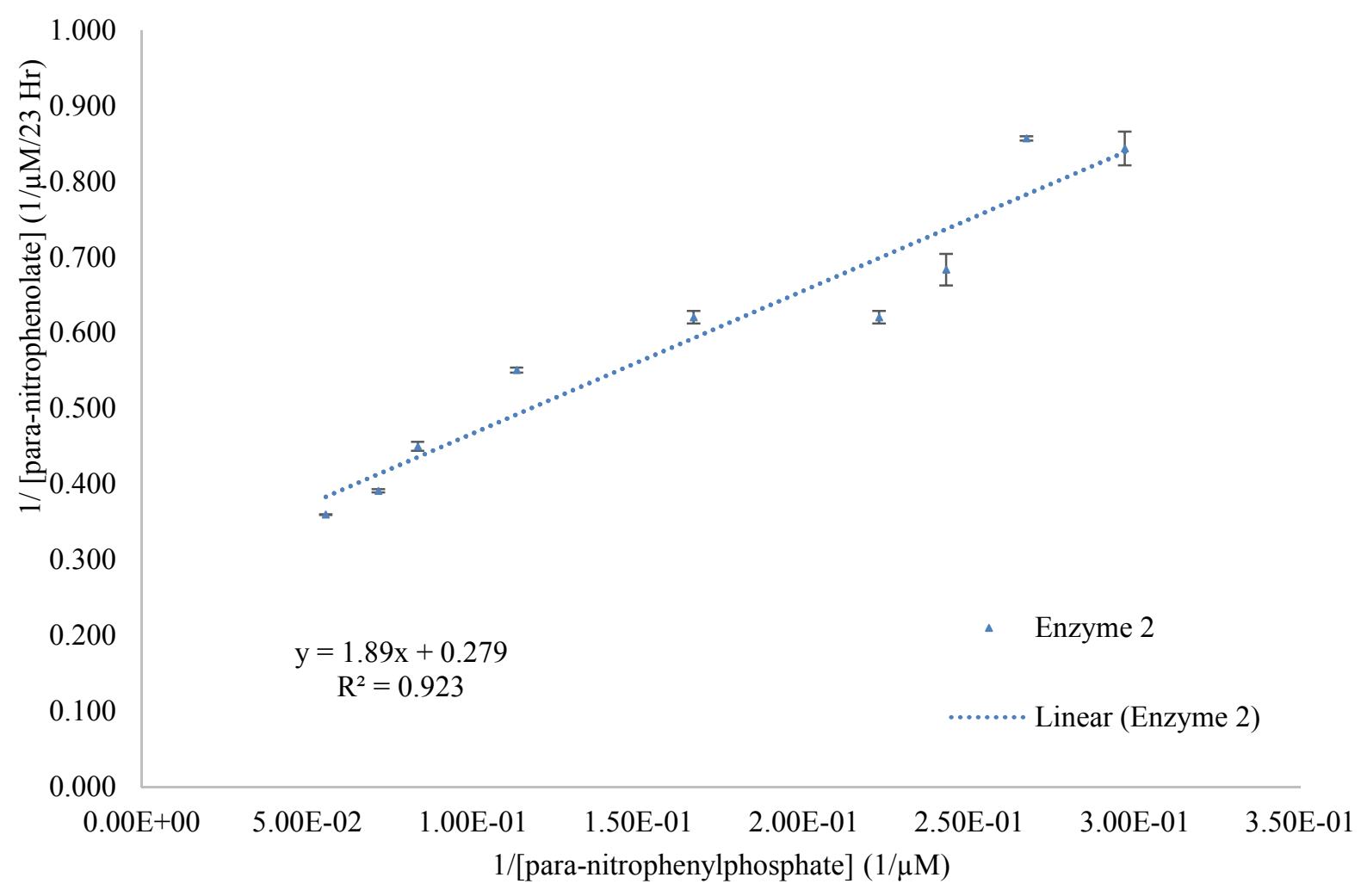




\begin{tabular}{|c|c|c|c|c|}
\hline $\begin{array}{c}\text { Day 4 } \\
\text { Enzyme } 2 \\
\text { KM }(\mu \mathrm{M}): 6.93 \pm 0.42 \\
\text { VMAX }(\mu \mathrm{M} / 23 \mathrm{Hr}): \\
3.58 \pm 0.12\end{array}$ & & & & \\
\hline $\begin{array}{l}\text { [para-nitrophenylphosphate] } \\
\qquad(\mu \mathrm{M})\end{array}$ & $\begin{array}{c}\text { Average } \\
{\left[\begin{array}{c}\text { [para-nitrophenolate] } \\
(\mu \mathrm{M} / 23 \mathrm{Hr})\end{array}\right.}\end{array}$ & $\begin{array}{c}1 /[\text { para-nitrophenolate }] \\
(1 / \mu \mathrm{M} / 23 \mathrm{Hr})\end{array}$ & $\begin{array}{c}1 /[\text { para- } \\
\text { nitrophenyl } \\
\text { phosphate] } \\
(1 / \mu \mathrm{M})\end{array}$ & 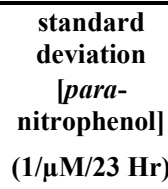 \\
\hline 3.37 & 1.19 & 0.844 & 2.97E-01 & $2.23 \mathrm{E}-02$ \\
\hline 3.74 & 1.17 & 0.857 & $2.67 \mathrm{E}-01$ & $2.94 \mathrm{E}-03$ \\
\hline 4.12 & 1.46 & 0.684 & $2.43 \mathrm{E}-01$ & 2.09E-02 \\
\hline 4.49 & 1.61 & 0.621 & $2.23 \mathrm{E}-01$ & 8.32E-03 \\
\hline 6.00 & 1.61 & 0.621 & $1.67 \mathrm{E}-01$ & $8.32 \mathrm{E}-03$ \\
\hline 8.83 & 1.81 & 0.551 & $1.13 \mathrm{E}-01$ & $3.29 \mathrm{E}-03$ \\
\hline $1.20 \mathrm{E}+01$ & 2.22 & 0.450 & 8.33E-02 & $5.98 \mathrm{E}-03$ \\
\hline $1.40 \mathrm{E}+01$ & 2.56 & 0.391 & 7.14E-02 & $2.25 \mathrm{E}-03$ \\
\hline $1.80 \mathrm{E}+01$ & 2.78 & 0.360 & $5.56 \mathrm{E}-02$ & $5.68 \mathrm{E}-04$ \\
\hline
\end{tabular}




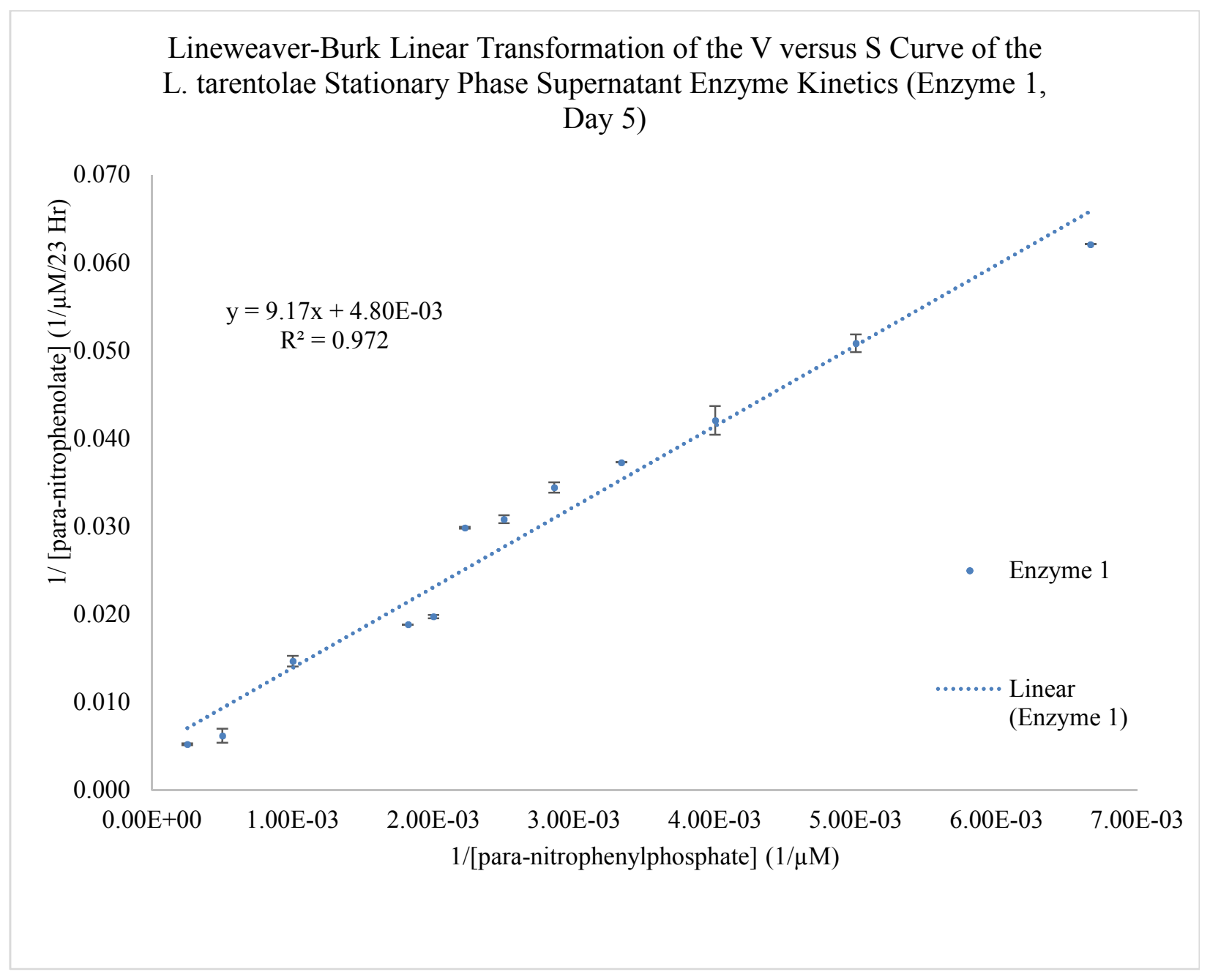




\begin{tabular}{|c|c|c|c|c|}
\hline 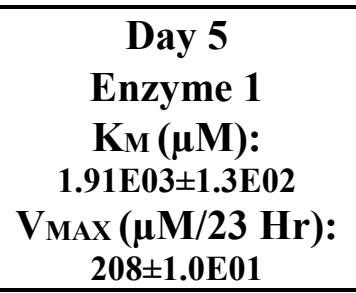 & & & & \\
\hline $\begin{array}{c}\text { [para-nitrophenylphosphate] } \\
\qquad(\mu \mathrm{M})\end{array}$ & $\begin{array}{c}\text { Average } \\
\begin{array}{c}\text { [para-nitrophenolate] } \\
(\mu \mathrm{M} / 23 \mathrm{hr})\end{array}\end{array}$ & $\begin{array}{c}1 /[\text { para-nitrophenolate }] \\
(1 / \mu \mathrm{M} / 23 \mathrm{Hr})\end{array}$ & $\begin{array}{c}1 /[\text { para- } \\
\text { nitrophenyl } \\
\text { phosphate] } \\
(1 / \mu \mathrm{M})\end{array}$ & 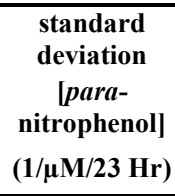 \\
\hline 150 & 16.1 & $6.21 \mathrm{E}-02$ & $6.67 \mathrm{E}-03$ & $1.93 \mathrm{E}-03$ \\
\hline 200 & 19.7 & $5.08 \mathrm{E}-02$ & $5.00 \mathrm{E}-03$ & $8.30 \mathrm{E}-04$ \\
\hline 250 & 23.8 & $4.21 \mathrm{E}-02$ & $4.00 \mathrm{E}-03$ & $4.11 \mathrm{E}-04$ \\
\hline 300 & 26.8 & $3.73 \mathrm{E}-02$ & $3.33 \mathrm{E}-03$ & $4.90 \mathrm{E}-04$ \\
\hline 350 & 29.1 & $3.44 \mathrm{E}-02$ & $2.86 \mathrm{E}-03$ & $5.32 \mathrm{E}-04$ \\
\hline 400 & 32.4 & $3.08 \mathrm{E}-02$ & $2.50 \mathrm{E}-03$ & $1.58 \mathrm{E}-04$ \\
\hline 450 & 33.5 & $2.99 \mathrm{E}-02$ & $2.22 \mathrm{E}-03$ & $5.58 \mathrm{E}-04$ \\
\hline 500 & 50.7 & $1.97 \mathrm{E}-02$ & $2.00 \mathrm{E}-03$ & $2.83 \mathrm{E}-04$ \\
\hline 550 & 53.0 & $1.89 \mathrm{E}-02$ & $1.82 \mathrm{E}-03$ & $8.62 \mathrm{E}-05$ \\
\hline $1.00 \mathrm{E}+03$ & 68.1 & $1.47 \mathrm{E}-02$ & $1.00 \mathrm{E}-03$ & $6.72 \mathrm{E}-05$ \\
\hline $2.00 \mathrm{E}+03$ & 162 & $6.18 \mathrm{E}-03$ & $5.00 \mathrm{E}-04$ & $1.07 \mathrm{E}-04$ \\
\hline $4.00 \mathrm{E}+03$ & 192 & $5.22 \mathrm{E}-03$ & $2.50 \mathrm{E}-04$ & $7.34 \mathrm{E}-05$ \\
\hline
\end{tabular}


Lineweaver-Burk Linear Transformation of the V versus S Curve of the

L. tarentolae Stationary Phase Supernatant Enzyme Kinetics (Enzyme 2,

Day 5)

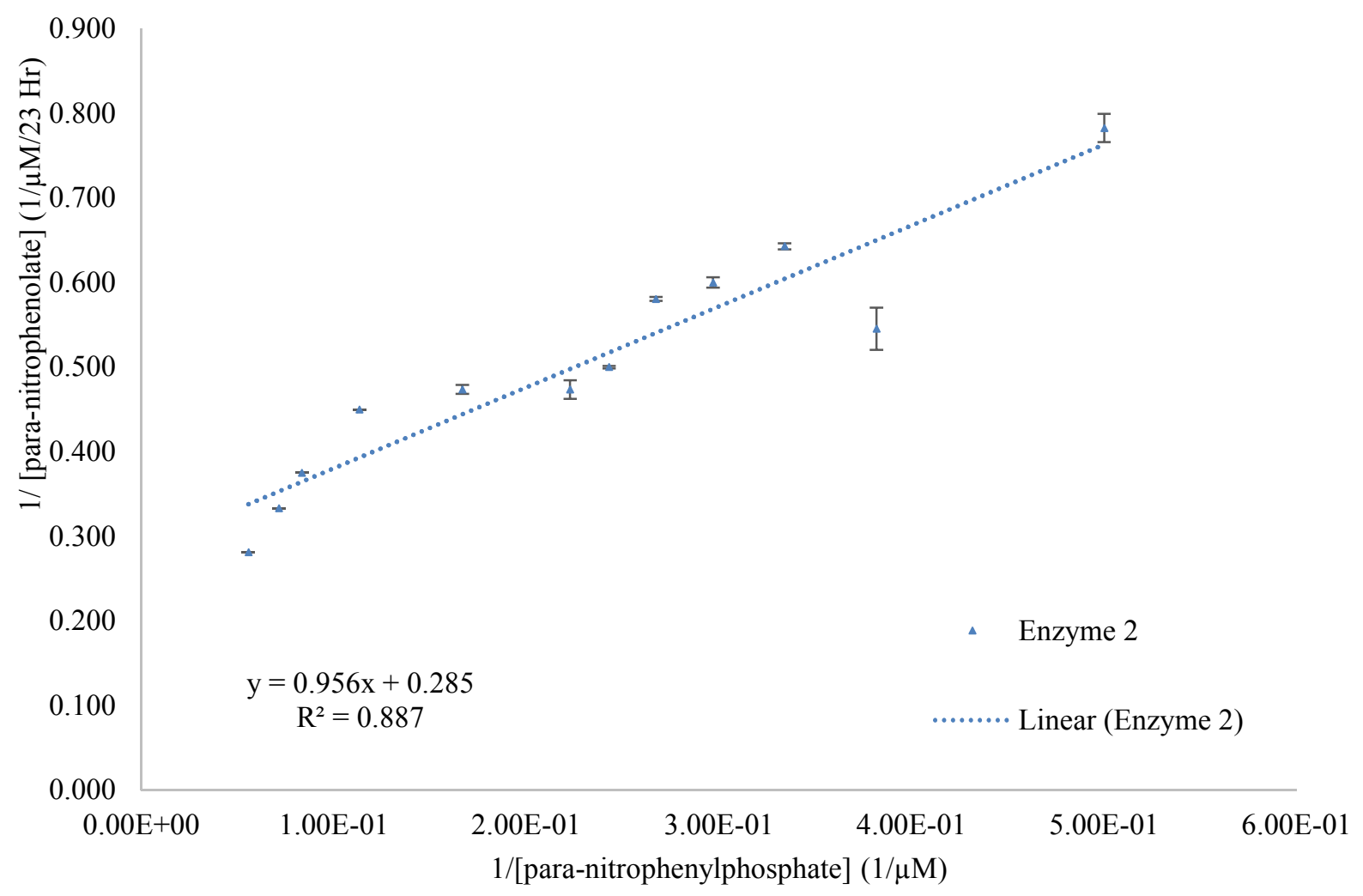




\begin{tabular}{|c|c|c|c|c|}
\hline $\begin{array}{c}\text { Day 5 } \\
\text { Enzyme 2 } \\
\text { KM }_{M}(\boldsymbol{\mu M}): \\
3.35 \pm 7.7 E-02 \\
\text { VMAX }(\boldsymbol{\mu M} / 23 \mathrm{Hr}): \\
3.51 \pm 2.9 E-01\end{array}$ & & & & \\
\hline [para-nitrophenylphosphate] $(\mu \mathrm{M})$ & $\begin{array}{c}\text { Average } \\
\begin{array}{c}\text { [para-nitrophenolate] } \\
(\mu \mathrm{M} / 23 \mathrm{hr})\end{array}\end{array}$ & $\begin{array}{c}1 /[\text { para-nitrophenolate] } \\
(1 / \mu \mathrm{M} / 23 \mathrm{Hr})\end{array}$ & $\begin{array}{c}1 /[\text { para- } \\
\text { nitrophenyl } \\
\\
\text { phosphate] } \\
(1 / \mu \mathrm{M})\end{array}$ & 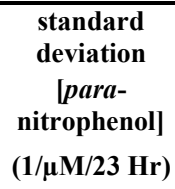 \\
\hline 2.00 & 1.28 & 0.783 & $5.00 \mathrm{E}-01$ & $1.66 \mathrm{E}-02$ \\
\hline 2.62 & 1.83 & 0.545 & $3.82 \mathrm{E}-01$ & $2.49 \mathrm{E}-02$ \\
\hline 2.99 & 1.56 & 0.643 & $3.34 \mathrm{E}-01$ & $3.56 \mathrm{E}-03$ \\
\hline 3.37 & 1.67 & 0.600 & $2.97 \mathrm{E}-01$ & $6.18 \mathrm{E}-03$ \\
\hline 3.74 & 1.72 & 0.581 & $2.67 \mathrm{E}-01$ & $2.25 \mathrm{E}-03$ \\
\hline 4.12 & 2.00 & 0.500 & $2.43 \mathrm{E}-01$ & $1.59 \mathrm{E}-03$ \\
\hline 4.49 & 2.11 & 0.474 & $2.23 \mathrm{E}-01$ & $1.10 \mathrm{E}-02$ \\
\hline 6.00 & 2.11 & 0.474 & $1.67 \mathrm{E}-01$ & $5.40 \mathrm{E}-03$ \\
\hline 8.83 & 2.22 & 0.450 & $1.13 \mathrm{E}-01$ & $0.00 \mathrm{E}+00$ \\
\hline $1.20 \mathrm{E}+01$ & 2.67 & 0.375 & $8.33 \mathrm{E}-02$ & $0.00 \mathrm{E}+00$ \\
\hline $1.40 \mathrm{E}+01$ & 3.00 & 0.333 & $7.14 \mathrm{E}-02$ & $0.00 \mathrm{E}+00$ \\
\hline $1.80 \mathrm{E}+01$ & 3.56 & 0.281 & $5.56 \mathrm{E}-02$ & $0.00 \mathrm{E}+00$ \\
\hline
\end{tabular}




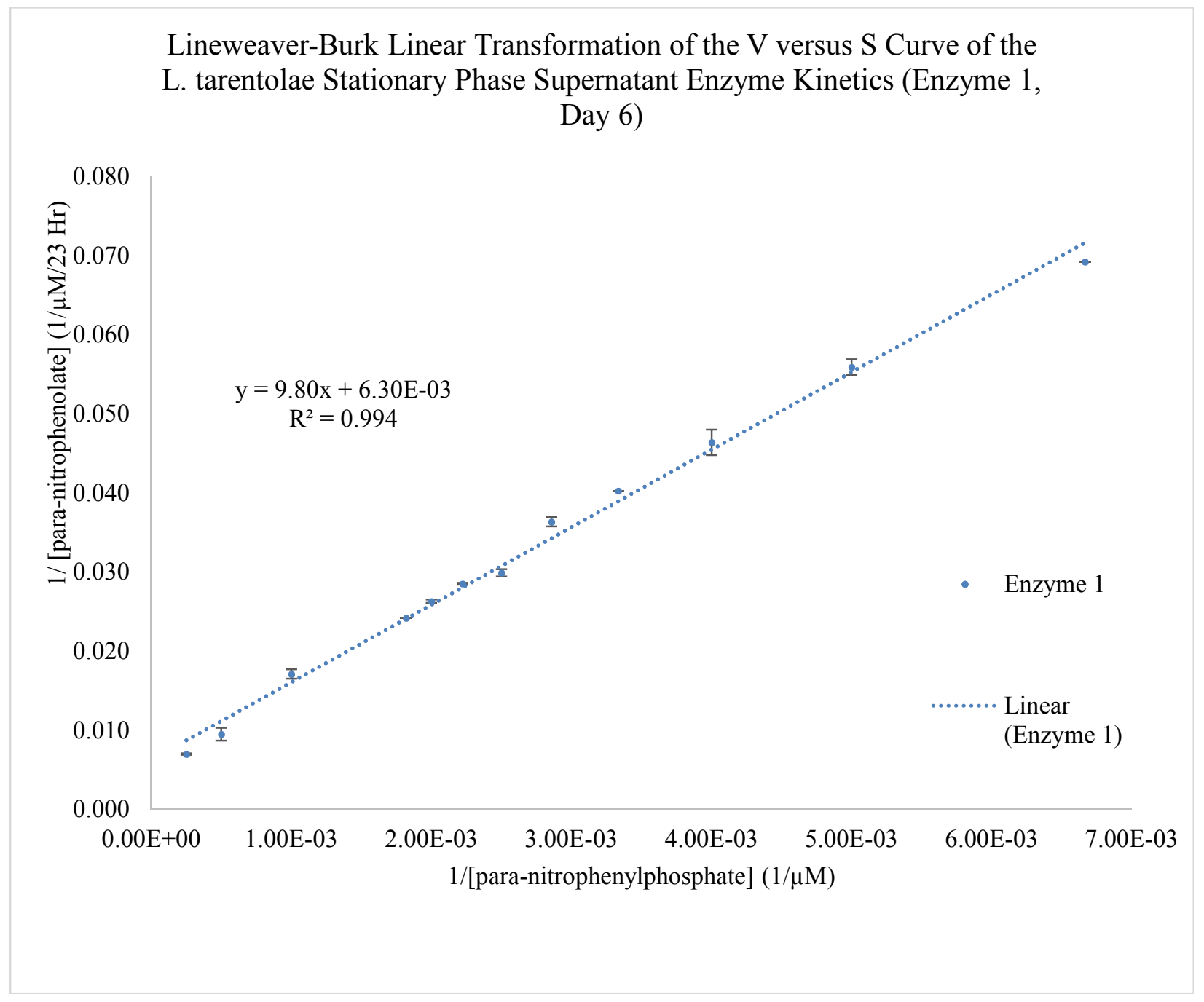




\begin{tabular}{|c|c|c|c|c|}
\hline $\begin{array}{c}\text { Day 6 } \\
\text { Enzyme 1 } \\
\text { KM }_{M}(\mu \mathrm{M}): \\
1.56 \mathrm{E03} \pm 6.0 \mathrm{E} 01 \\
\text { VMAX }(\mu \mathrm{M} / 23 \mathrm{Hr}):_{159 \pm 7.0} \\
\end{array}$ & & & & \\
\hline $\begin{array}{c}\text { [para-nitrophenylphosphate] } \\
\qquad(\mu \mathrm{M})\end{array}$ & $\begin{array}{c}\text { Average } \\
\text { [para-nitrophenolate] } \\
(\mu \mathrm{M} / 23 \mathrm{Hr})\end{array}$ & $\begin{array}{c}1 /[\text { para-nitrophenolate] } \\
(1 / \mu \mathrm{M} / 23 \mathrm{Hr})\end{array}$ & $\begin{array}{c}1 /[\text { para- } \\
\text { nitrophenyl } \\
\text { phosphate] } \\
(1 / \mu \mathrm{M})\end{array}$ & $\begin{array}{c}\text { standard } \\
\text { deviation } \\
\text { [para- } \\
\text { nitrophenol] } \\
(1 / \mu \mathrm{M} / 23 \mathrm{Hr})\end{array}$ \\
\hline 150 & 14.4 & $6.92 \mathrm{E}-02$ & $6.67 \mathrm{E}-03$ & $1.93 \mathrm{E}-03$ \\
\hline 200 & 17.9 & $5.59 \mathrm{E}-02$ & $5.00 \mathrm{E}-03$ & $8.30 \mathrm{E}-04$ \\
\hline 250 & 21.6 & $4.64 \mathrm{E}-02$ & $4.00 \mathrm{E}-03$ & $4.11 \mathrm{E}-04$ \\
\hline 300 & 24.8 & $4.03 \mathrm{E}-02$ & $3.33 \mathrm{E}-03$ & $4.90 \mathrm{E}-04$ \\
\hline 350 & 27.5 & $3.64 \mathrm{E}-02$ & $2.86 \mathrm{E}-03$ & $5.32 \mathrm{E}-04$ \\
\hline 400 & 33.4 & $2.99 \mathrm{E}-02$ & $2.50 \mathrm{E}-03$ & $1.58 \mathrm{E}-04$ \\
\hline 450 & 35.1 & $2.85 \mathrm{E}-02$ & $2.22 \mathrm{E}-03$ & $5.58 \mathrm{E}-04$ \\
\hline 500 & 38.0 & $2.63 \mathrm{E}-02$ & $2.00 \mathrm{E}-03$ & $2.83 \mathrm{E}-04$ \\
\hline 550 & 41.3 & $2.42 \mathrm{E}-02$ & $1.82 \mathrm{E}-03$ & $8.62 \mathrm{E}-05$ \\
\hline $1.00 \mathrm{E}+03$ & 58.4 & $1.71 \mathrm{E}-02$ & $1.00 \mathrm{E}-03$ & $6.72 \mathrm{E}-05$ \\
\hline $2.00 \mathrm{E}+03$ & 105 & $9.51 \mathrm{E}-03$ & $5.00 \mathrm{E}-04$ & $1.07 \mathrm{E}-04$ \\
\hline $4.00 \mathrm{E}+03$ & 143 & $6.98 \mathrm{E}-03$ & $2.50 \mathrm{E}-04$ & 7.34E-05 \\
\hline
\end{tabular}




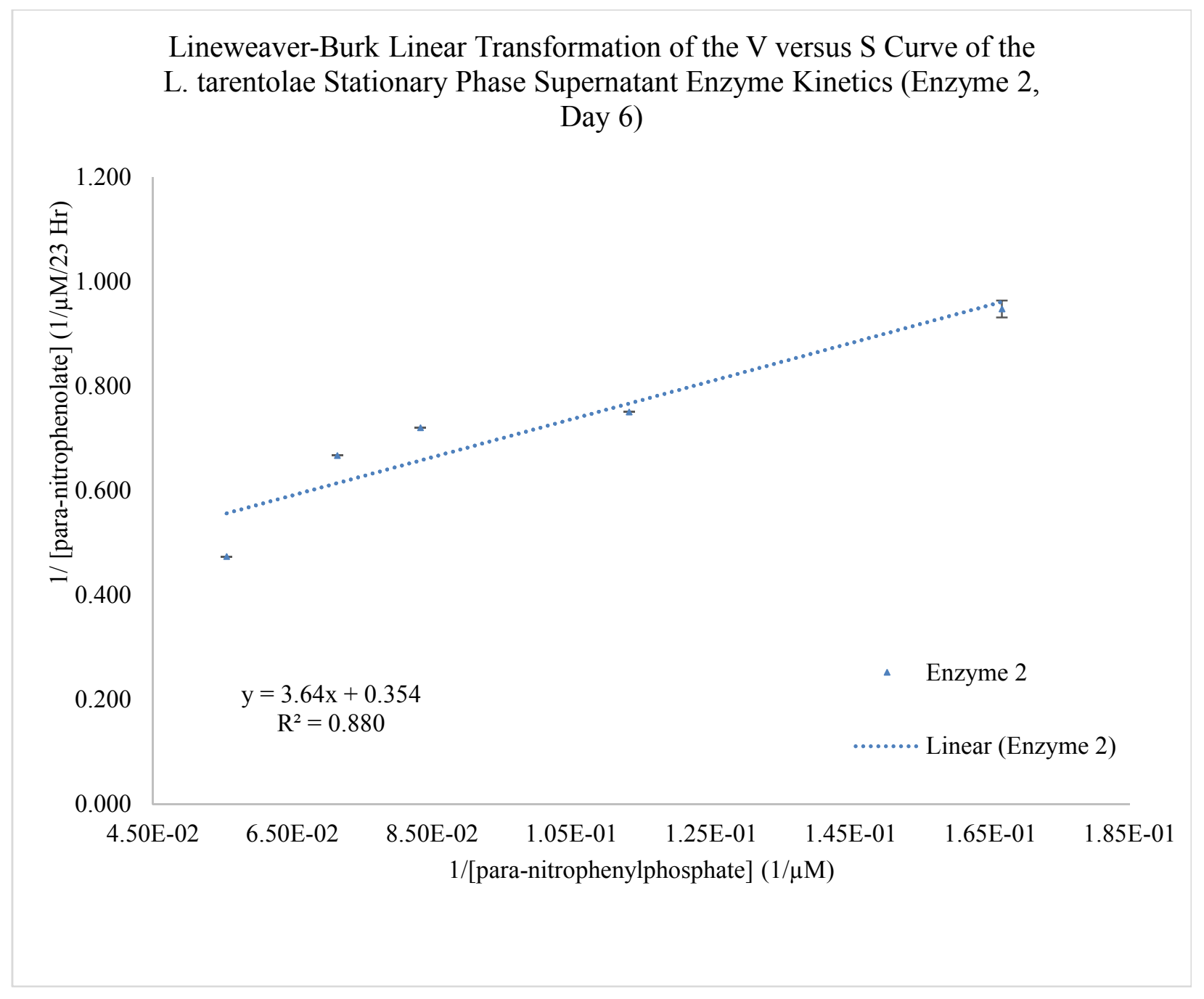




\begin{tabular}{|c|c|c|c|c|}
\hline $\begin{array}{c}\text { Day 6 } \\
\text { Enzyme } 2 \\
\mathrm{~K}_{\mathrm{M}}(\mu \mathrm{M}): 10.3 \pm 8.1 \mathrm{E01} \\
\mathrm{V}_{\mathrm{MAX}}(\boldsymbol{\mu M} / 23 \mathrm{Hr}): \\
2.82 \pm 1.9 \mathrm{E}-01 \\
\end{array}$ & & & & \\
\hline [para-nitrophenylphosphate] $(\mu \mathrm{M})$ & $\begin{array}{c}\text { Average } \\
\text { [para-nitrophenolate] } \\
(\mu \mathrm{M}) / 23 \mathrm{Hr}\end{array}$ & $\begin{array}{c}1 /[\text { para-nitrophenolate }] \\
1 /(\mu \mathrm{M} / 23 \mathrm{Hr})\end{array}$ & $\begin{array}{c}1 /[\text { para- } \\
\text { nitrophenyl } \\
\text { phosphate] } \\
(1 / \mu \mathrm{M})\end{array}$ & 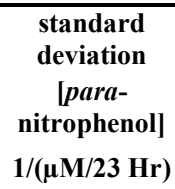 \\
\hline 6.00 & 1.06 & 0.947 & $1.67 \mathrm{E}-01$ & $1.61 \mathrm{E}-02$ \\
\hline 8.83 & 1.33 & 0.750 & $1.13 \mathrm{E}-01$ & $0.00 \mathrm{E}+00$ \\
\hline 12.0 & 1.39 & 0.720 & $8.33 \mathrm{E}-02$ & $0.00 \mathrm{E}+00$ \\
\hline 14.0 & 1.50 & 0.667 & $7.14 \mathrm{E}-02$ & $0.00 \mathrm{E}+00$ \\
\hline 18.0 & 2.11 & 0.474 & $5.56 \mathrm{E}-02$ & $0.00 \mathrm{E}+00$ \\
\hline
\end{tabular}


Lineweaver-Burk Linear Transformation of the V versus S Curve of the L. tarentolae Senescence Phase Supernatant Enzyme Kinetics (Enzyme 1, Day 7)

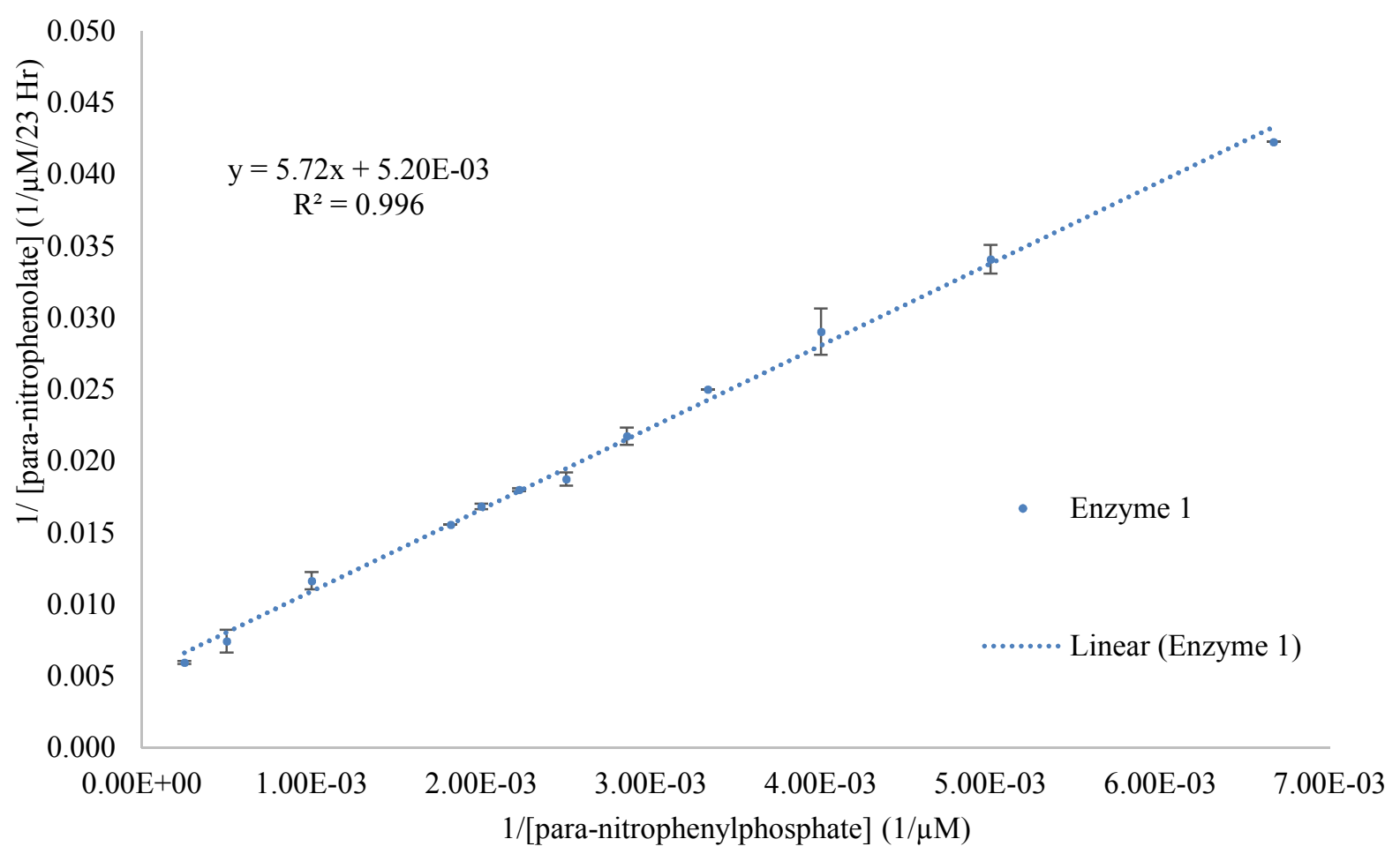




\begin{tabular}{|c|c|c|c|c|}
\hline $\begin{array}{c}\text { Day } 7 \\
\text { Enzyme } 1 \\
\text { KM }(\boldsymbol{\mu M}): \\
1.10 \mathrm{E03} \pm 3.0 \mathrm{E01} \\
\text { VMAX }(\boldsymbol{\mu M} / 23 \text { Hr }): \\
192 \pm 9.0 \\
\end{array}$ & & & & \\
\hline $\begin{array}{l}\text { [para-nitrophenylphosphate] } \\
\qquad(\mu \mathrm{M})\end{array}$ & $\begin{array}{c}\text { Average } \\
\begin{array}{l}\text { [para-nitrophenolate] } \\
(\mu \mathrm{M} / 23 \mathrm{Hr})\end{array}\end{array}$ & $\begin{array}{c}1 /[\text { para-nitrophenolate] } \\
(1 / \mu \mathrm{M} / 23 \mathrm{Hr})\end{array}$ & $\begin{array}{c}1 /[\text { para- } \\
\text { nitrophenyl } \\
\text { phosphate] } \\
(1 / \mu \mathrm{M})\end{array}$ & 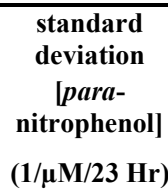 \\
\hline 150 & 23.7 & $4.23 \mathrm{E}-02$ & $6.67 \mathrm{E}-03$ & $4.36 \mathrm{E}-04$ \\
\hline 200 & 29.3 & $3.41 \mathrm{E}-02$ & $5.00 \mathrm{E}-03$ & $1.79 \mathrm{E}-04$ \\
\hline 250 & 34.4 & $2.90 \mathrm{E}-02$ & $4.00 \mathrm{E}-03$ & $2.45 \mathrm{E}-04$ \\
\hline 300 & 40.0 & $2.50 \mathrm{E}-02$ & $3.33 \mathrm{E}-03$ & 4.89E-05 \\
\hline 350 & 46.0 & $2.17 \mathrm{E}-02$ & $2.86 \mathrm{E}-03$ & $2.50 \mathrm{E}-04$ \\
\hline 400 & 53.3 & $1.88 \mathrm{E}-02$ & $2.50 \mathrm{E}-03$ & $2.70 \mathrm{E}-04$ \\
\hline 450 & 55.6 & $1.80 \mathrm{E}-02$ & $2.22 \mathrm{E}-03$ & $2.53 \mathrm{E}-04$ \\
\hline 500 & 59.4 & $1.68 \mathrm{E}-02$ & $2.00 \mathrm{E}-03$ & $1.13 \mathrm{E}-04$ \\
\hline 550 & 64.3 & $1.56 \mathrm{E}-02$ & $1.82 \mathrm{E}-03$ & $1.07 \mathrm{E}-04$ \\
\hline $1.00 \mathrm{E}+03$ & 85.8 & $1.17 \mathrm{E}-02$ & $1.00 \mathrm{E}-03$ & $1.65 \mathrm{E}-04$ \\
\hline $2.00 \mathrm{E}+03$ & 134 & 7.44E-03 & $5.00 \mathrm{E}-04$ & $2.90 \mathrm{E}-04$ \\
\hline $4.00 \mathrm{E}+03$ & 168 & $5.95 \mathrm{E}-03$ & $2.50 \mathrm{E}-04$ & $4.50 \mathrm{E}-05$ \\
\hline
\end{tabular}




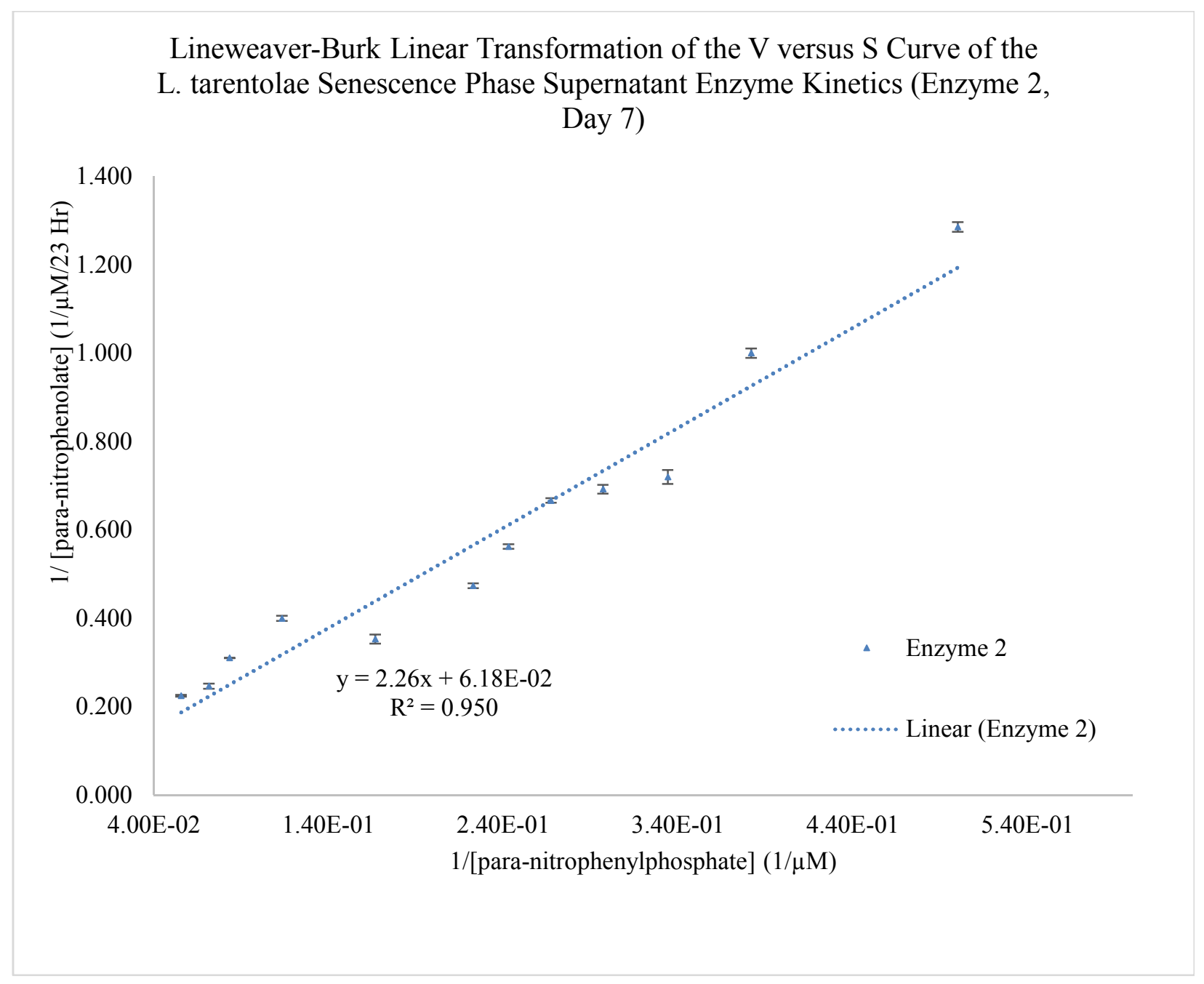




\begin{tabular}{|c|c|c|c|c|}
\hline $\begin{array}{c}\text { Day } 7 \\
\text { Enzyme } 2 \\
\mathrm{KM}_{\mathrm{M}}(\boldsymbol{\mu M}): 36.6 \pm 1.8 \\
\mathrm{~V}_{\mathrm{MAX}}(\boldsymbol{\mu M} / \mathbf{2 3} \mathrm{Hr}): \\
16.2 \pm 7.0 \mathrm{E}-01 \\
\end{array}$ & & & & \\
\hline [para-nitrophenylphosphate] $(\mu \mathrm{M})$ & $\begin{array}{c}\text { Average } \\
\begin{array}{c}\text { [para-nitrophenolate] } \\
(\mu \mathrm{M} / 23 \mathrm{Hr})\end{array}\end{array}$ & $\begin{array}{c}\text { 1/[para-nitrophenolate] } \\
(1 / \mu \mathrm{M} / 23 \mathrm{Hr})\end{array}$ & $\begin{array}{c}\text { 1/[para- } \\
\text { nitrophenyl } \\
\text { phosphate] } \\
(1 / \mu \mathrm{M})\end{array}$ & $\begin{array}{c}\text { standard } \\
\text { deviation } \\
\text { [para- } \\
\text { nitrophenol] } \\
(1 / \mu \mathrm{M} / 23 \mathrm{Hr})\end{array}$ \\
\hline 2.00 & 0.778 & 1.29 & $5.00 \mathrm{E}-01$ & $1.08 \mathrm{E}-02$ \\
\hline 2.62 & 1.00 & 1.00 & $3.82 \mathrm{E}-01$ & $1.09 \mathrm{E}-02$ \\
\hline 2.99 & 1.39 & 0.720 & $3.34 \mathrm{E}-01$ & $1.59 \mathrm{E}-02$ \\
\hline 3.37 & 1.44 & 0.692 & $2.97 \mathrm{E}-01$ & $9.98 \mathrm{E}-03$ \\
\hline 3.74 & 1.50 & 0.667 & $2.67 \mathrm{E}-01$ & $5.38 \mathrm{E}-03$ \\
\hline 4.12 & 1.78 & 0.563 & $2.43 \mathrm{E}-01$ & $5.16 \mathrm{E}-03$ \\
\hline 4.49 & 2.11 & 0.474 & $2.23 \mathrm{E}-01$ & $5.64 \mathrm{E}-03$ \\
\hline 6.00 & 2.83 & 0.353 & $1.67 \mathrm{E}-01$ & $1.01 \mathrm{E}-02$ \\
\hline 8.83 & 2.50 & 0.400 & $1.13 \mathrm{E}-01$ & $5.92 \mathrm{E}-03$ \\
\hline $1.20 \mathrm{E}+01$ & 3.22 & 0.310 & $8.33 \mathrm{E}-02$ & 4.99E-04 \\
\hline $1.40 \mathrm{E}+01$ & 4.06 & 0.247 & 7.14E-02 & $5.94 \mathrm{E}-03$ \\
\hline $1.80 \mathrm{E}+01$ & 4.44 & 0.225 & $5.56 \mathrm{E}-02$ & $1.90 \mathrm{E}-03$ \\
\hline
\end{tabular}




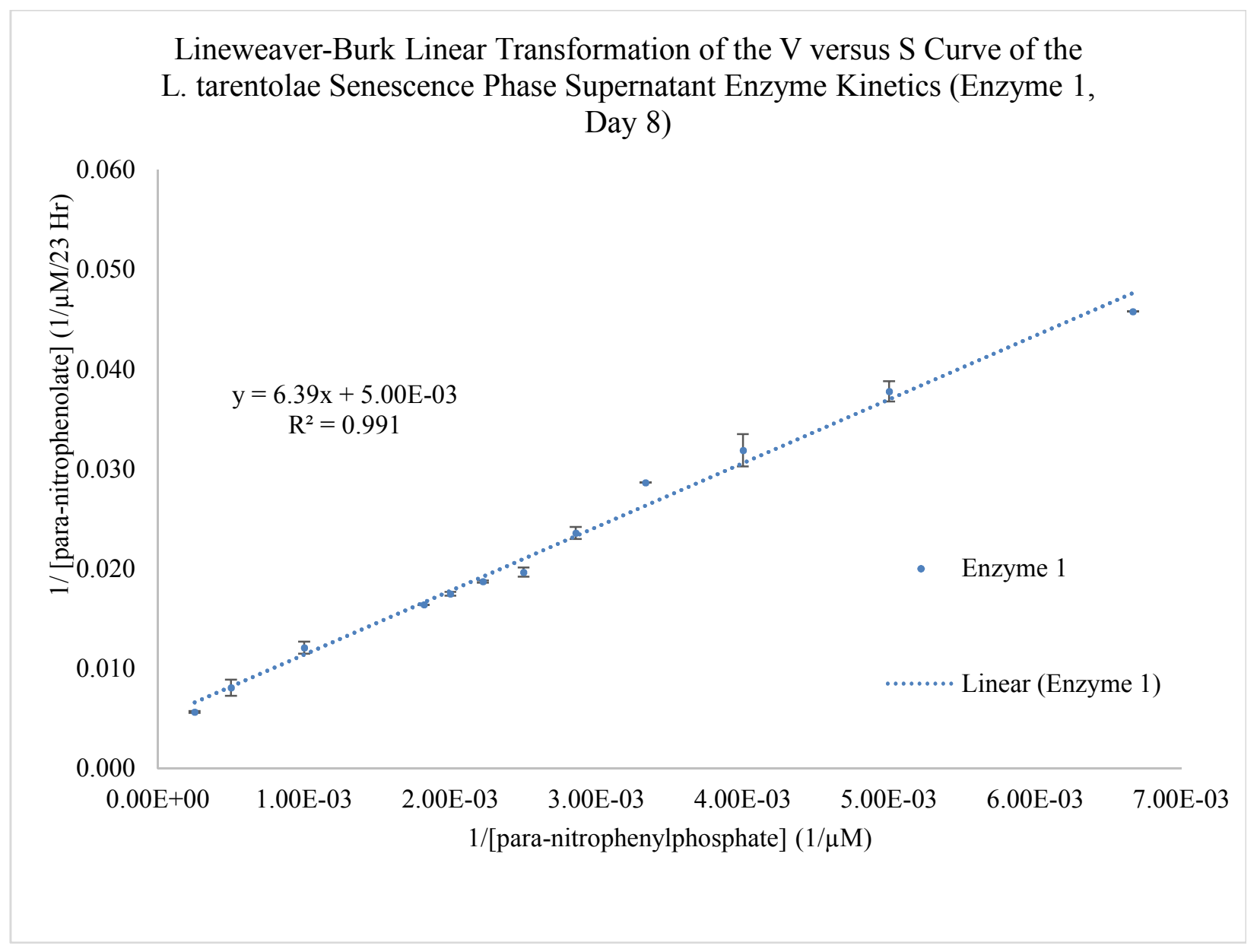




\begin{tabular}{|c|c|c|c|c|}
\hline $\begin{array}{c}\text { Day 8 } \\
\text { Enzyme 1 } \\
\text { KM }(\boldsymbol{\mu M}): \\
1.28 E 03 \pm 5.0 \mathrm{E01} \\
\text { VMAX }(\boldsymbol{\mu M} / 23 \mathrm{Hr}): \\
200 \pm 8.0\end{array}$ & & & & \\
\hline $\begin{array}{l}\text { [para-nitrophenylphosphate] } \\
\qquad(\mu \mathrm{M})\end{array}$ & $\begin{array}{c}\text { Average } \\
\begin{array}{l}\text { [para-nitrophenolate] } \\
(\mu \mathrm{M} / 23 \mathrm{Hr})\end{array}\end{array}$ & $\begin{array}{c}1 /[\text { para-nitrophenolate }] \\
(1 / \mu \mathrm{M} / 23 \mathrm{Hr})\end{array}$ & $\begin{array}{c}1 /[\text { para- } \\
\text { nitrophenyl } \\
\\
\text { phosphate] } \\
(1 / \mu \mathrm{M})\end{array}$ & 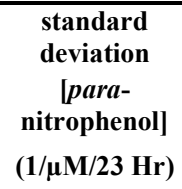 \\
\hline 150 & 21.8 & $4.58 \mathrm{E}-02$ & $6.67 \mathrm{E}-03$ & $2.61 \mathrm{E}-02$ \\
\hline 200 & 26.4 & $3.78 \mathrm{E}-02$ & $5.00 \mathrm{E}-03$ & $1.02 \mathrm{E}-02$ \\
\hline 250 & 31.3 & $3.19 \mathrm{E}-02$ & $4.00 \mathrm{E}-03$ & $1.04 \mathrm{E}-02$ \\
\hline 300 & 34.9 & $2.87 \mathrm{E}-02$ & $3.33 \mathrm{E}-03$ & $8.04 \mathrm{E}-03$ \\
\hline 350 & 42.3 & $2.36 \mathrm{E}-02$ & $2.86 \mathrm{E}-03$ & $2.89 \mathrm{E}-03$ \\
\hline 400 & 50.8 & $1.97 \mathrm{E}-02$ & $2.50 \mathrm{E}-03$ & $1.69 \mathrm{E}-03$ \\
\hline 450 & 53.3 & $1.88 \mathrm{E}-02$ & $2.22 \mathrm{E}-03$ & $1.09 \mathrm{E}-03$ \\
\hline 500 & 57.1 & $1.75 \mathrm{E}-02$ & $2.00 \mathrm{E}-03$ & $2.89 \mathrm{E}-03$ \\
\hline 550 & 60.8 & $1.64 \mathrm{E}-02$ & $1.82 \mathrm{E}-03$ & $3.39 \mathrm{E}-04$ \\
\hline $1.00 \mathrm{E}+03$ & 82.4 & $1.21 \mathrm{E}-02$ & $1.00 \mathrm{E}-03$ & $2.10 \mathrm{E}-03$ \\
\hline $2.00 \mathrm{E}+03$ & 123 & $8.11 \mathrm{E}-03$ & $5.00 \mathrm{E}-04$ & $6.53 \mathrm{E}-04$ \\
\hline $4.00 \mathrm{E}+03$ & 176 & $5.68 \mathrm{E}-03$ & $2.50 \mathrm{E}-04$ & $0.00 \mathrm{E}+00$ \\
\hline
\end{tabular}




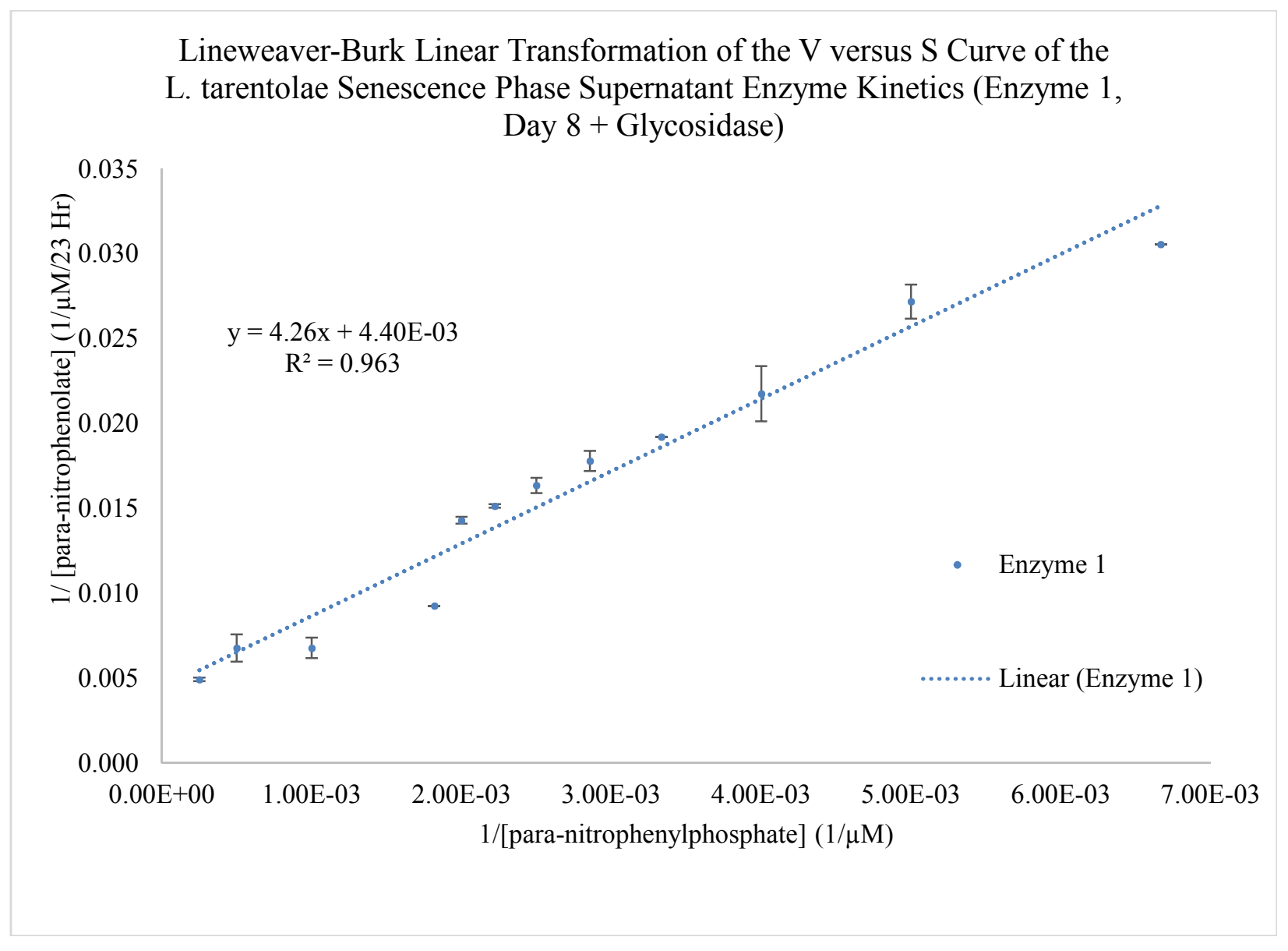




\begin{tabular}{|c|c|c|c|c|}
\hline \multicolumn{5}{|l|}{$\begin{array}{c}\text { Day } 8+\text { Glycosidase } \\
\text { Enzyme } 1 \\
\text { KM }(\mu M): 968 \pm 1.3 \mathrm{E} 02 \\
\text { VMAX }(\mu M / 23 \mathrm{Hr}): \\
227 \pm 50 \\
\end{array}$} \\
\hline $\begin{array}{c}\text { [para-nitrophenylphosphate] } \\
\qquad(\mu \mathrm{M})\end{array}$ & $\begin{array}{c}\text { Average } \\
\text { [para-nitrophenolate }] \\
(\mu \mathrm{M} / 23 \mathrm{Hr})\end{array}$ & $\begin{array}{c}\text { 1/[para-nitrophenolate }] \\
(1 / \mu \mathrm{M} / 23 \mathrm{Hr})\end{array}$ & $\begin{array}{c}\text { 1/[para- } \\
\text { nitrophenyl } \\
\text { phosphate] } \\
(1 / \mu \mathrm{M})\end{array}$ & $\begin{array}{c}\text { standard } \\
\text { deviation } \\
\text { [para- } \\
\text { nitrophenol] } \\
(1 / \mu \mathrm{M} / 23 \mathrm{Hr})\end{array}$ \\
\hline 150 & 32.7 & $3.06 \mathrm{E}-02$ & $6.67 \mathrm{E}-03$ & $9.53 \mathrm{E}-03$ \\
\hline 200 & 36.8 & $2.72 \mathrm{E}-02$ & $5.00 \mathrm{E}-03$ & $1.26 \mathrm{E}-02$ \\
\hline 250 & 45.9 & $2.18 \mathrm{E}-02$ & $4.00 \mathrm{E}-03$ & $6.42 \mathrm{E}-03$ \\
\hline 300 & 52.1 & $1.92 \mathrm{E}-02$ & $3.33 \mathrm{E}-03$ & $1.33 \mathrm{E}-03$ \\
\hline 350 & 56.2 & $1.78 \mathrm{E}-02$ & $2.86 \mathrm{E}-03$ & $1.39 \mathrm{E}-03$ \\
\hline 400 & 61.1 & $1.64 \mathrm{E}-02$ & $2.50 \mathrm{E}-03$ & $5.06 \mathrm{E}-03$ \\
\hline 450 & 66.0 & $1.52 \mathrm{E}-02$ & $2.22 \mathrm{E}-03$ & $3.00 \mathrm{E}-03$ \\
\hline 500 & 69.9 & $1.43 \mathrm{E}-02$ & $2.00 \mathrm{E}-03$ & $2.69 \mathrm{E}-03$ \\
\hline 550 & 108 & $9.28 \mathrm{E}-03$ & $1.82 \mathrm{E}-03$ & $1.32 \mathrm{E}-03$ \\
\hline $1.00 \mathrm{E}+03$ & 147 & $6.78 \mathrm{E}-03$ & $1.00 \mathrm{E}-03$ & $0.00 \mathrm{E}+00$ \\
\hline $2.00 \mathrm{E}+03$ & 147 & $6.78 \mathrm{E}-03$ & $5.00 \mathrm{E}-04$ & $0.00 \mathrm{E}+00$ \\
\hline $4.00 \mathrm{E}+03$ & 203 & $4.93 \mathrm{E}-03$ & $2.50 \mathrm{E}-04$ & $0.00 \mathrm{E}+00$ \\
\hline
\end{tabular}




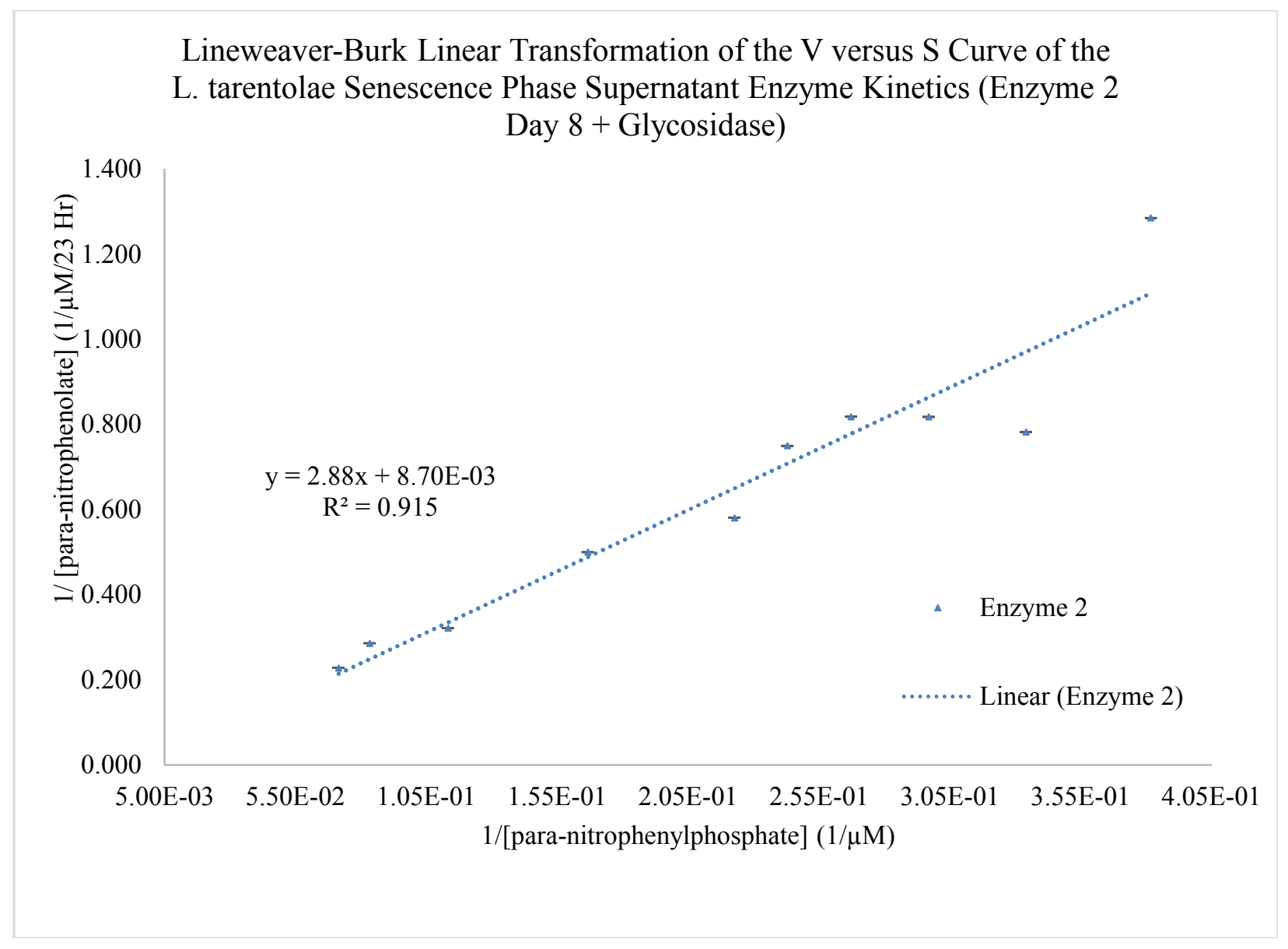




\begin{tabular}{|c|c|c|c|c|}
\hline \multicolumn{5}{|l|}{$\begin{array}{c}\text { Day } 8+\text { Glycosidase } \\
\text { Enzyme } 2 \\
\text { KM }(\boldsymbol{\mu M}): 33 \pm 14 \\
\text { VMAX }(\mu \mathrm{M} / 23 \mathrm{Hr}): \\
115 \pm 17\end{array}$} \\
\hline $\begin{array}{c}\text { [para-nitrophenylphosphate] } \\
(\mu \mathrm{M})\end{array}$ & $\begin{array}{c}\text { Average } \\
\text { [para-nitrophenolate }] \\
(\mu \mathrm{M} / 23 \mathrm{Hr})\end{array}$ & $\begin{array}{c}\text { 1/[para-nitrophenolate] } \\
(1 / \mu \mathrm{M} / 23 \mathrm{Hr})\end{array}$ & $\begin{array}{c}1 /[\text { para- } \\
\text { nitrophenyl } \\
\text { phosphate] } \\
(1 / \mu \mathrm{M})\end{array}$ & $\begin{array}{c}\text { standard } \\
\text { deviation } \\
\text { [para- } \\
\text { nitrophenol] } \\
(1 / \mu \mathrm{M} / 23 \mathrm{Hr})\end{array}$ \\
\hline 2.00 & 0.278 & 3.600 & $5.00 \mathrm{E}-01$ & $4.99 \mathrm{E}-04$ \\
\hline 2.62 & 0.778 & 1.286 & $3.82 \mathrm{E}-01$ & $5.44 \mathrm{E}-04$ \\
\hline 2.99 & 1.28 & 0.783 & $3.34 \mathrm{E}-01$ & $6.06 \mathrm{E}-04$ \\
\hline 3.37 & 1.22 & 0.818 & $2.97 \mathrm{E}-01$ & $4.42 \mathrm{E}-04$ \\
\hline 3.74 & 1.22 & 0.818 & $2.67 \mathrm{E}-01$ & $4.25 \mathrm{E}-04$ \\
\hline 4.12 & 1.33 & 0.750 & $2.43 \mathrm{E}-01$ & $2.90 \mathrm{E}-05$ \\
\hline 4.49 & 1.72 & 0.581 & $2.23 \mathrm{E}-01$ & $1.75 \mathrm{E}-04$ \\
\hline 6.00 & 2.00 & 0.500 & $1.67 \mathrm{E}-01$ & $1.37 \mathrm{E}-04$ \\
\hline 8.83 & 3.11 & 0.321 & $1.13 \mathrm{E}-01$ & $3.07 \mathrm{E}-04$ \\
\hline 12.0 & 3.50 & 0.286 & $8.33 \mathrm{E}-02$ & $5.76 \mathrm{E}-05$ \\
\hline 14.0 & 4.39 & 0.228 & 7.14E-02 & $6.42 \mathrm{E}-05$ \\
\hline 18.0 & 26.5 & $3.77 \mathrm{E}-02$ & $5.56 \mathrm{E}-02$ & $8.58 \mathrm{E}-05$ \\
\hline
\end{tabular}

